\title{
ANÁLISE DE TENSÕES EM EQUIPAMENTOS DE MOAGEM DA CANA-DE-AÇÚCAR USANDO O METÓDO DOS ELEMENTOS FINITOS
}

\section{Fábio Caltarosso}

Dissertação apresentada à Escola de Engenharia de São Carlos da Universidade de São Paulo, como parte dos requisitos para a obtenção do título de Mestre em Engenharia Mecânica.

ORIENTADOR: Prof. PhD Reginaldo Teixeira Coelho

São Carlos 
FOLHA DE JULGAMENTO

Candidato: Engenheiro FÁBIO CALTAROSSO

Dissertação defendida e julgada em 04/09/2008 perante a Comissão Julgadora:

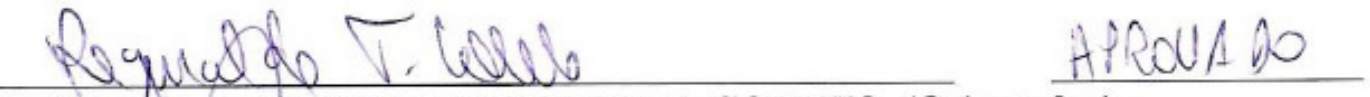

Prof. Associado REGINALDO TEIXEIRA COELHO (Orientador)

(Escola de Engenharia de São Carlos/USP)

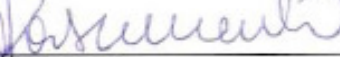

Prof ${ }^{a}$. Assoeiada DAISY APARECIDA DO NASCIMENTO REBELATTO

(Escola de Engenharia de São Carlos/USP)

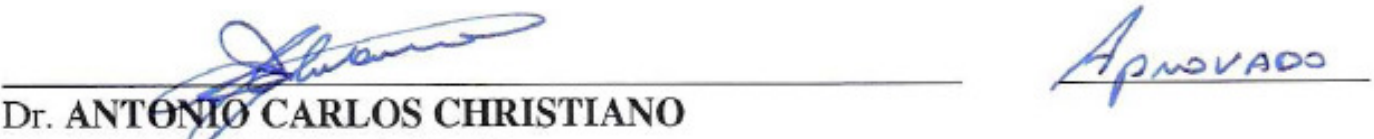

(Dedini S/A Indústrias de Base)

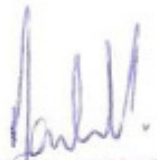

Prof. Associado JONAS DE CARVALHO

Coordenador do Programa de Pós-Graduação em

Engenharia Mecânica

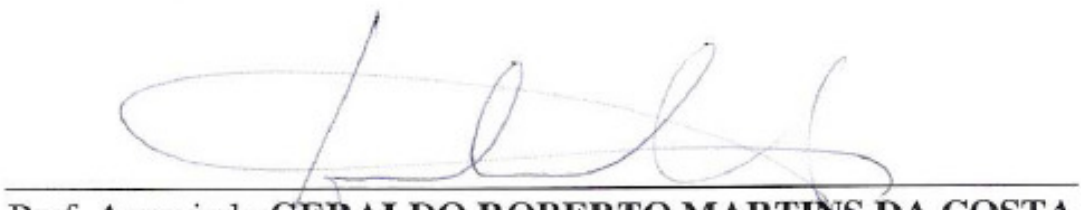

Prof. Associado GERALDO ROBERTO MARTINS DA COSTA

Presidente da Comissão da Pós-Graduação da EESC 


\section{Dedicatória}

Dedico este trabalho a todos que depositaram confiança e respeito a mim, em especial a minha mulher. 


\section{Agradecimentos}

A realização deste trabalho não é uma ação individual, há o envolvimento de outras pessoas que, indiretamente ou diretamente contribuíram para a realização e conclusão deste trabalho. Agradeço a todos os colaboradores, em especial:

- A DEUS, por me proporcionar a vida, me guinado sempre pelo caminho correto e justo.

- Aos meus pais, pela educação que me proporcionaram e ainda proporcionam, ensinando-me o certo e o errado.

- À minha querida mulher, por estar sempre ao meu lado, nos momentos de dificuldade e alegria, me incentivando e apoiando em todas as ocasiões.

- Ao professor Reginaldo Teixeira Coelho da Escola de Engenharia de São Carlos, pela coordenação e orientação deste trabalho.

- A Universidade de São Paulo - Escola de Engenharia de São Carlos, por me proporcionar o crescimento científico.

- Aos meus amigos de trabalho que sempre estavam à disposição para ajudar.

- Aos meus companheiros de mestrado, João e Orlando, pelo apoio a realização e conclusão deste trabalho.

- A empresa Dedini Indústrias de Base, por me proporcionar a oportunidade de freqüentar as aulas e a colaboração para a realização deste trabalho, em especial ao Dr. Antonio Carlos Christiano, diretor de operações. 


\section{RESUMO}

CAlTAROSSO, F. (2008). Análise de Tensões em Equipamentos de Moagem da Cana-de-Açúcar usando o Método dos Elementos Finitos. São Carlos, 2008. Dissertação - Escola de Engenharia de São Carlos, Universidade de São Paulo.

O álcool produzido no Brasil por meio da cana-de-açúcar é um combustível alternativo que obteve seu espaço no mercado mundial junto com o interesse dos países industrializados em contribuir para a diminuição da poluição no planeta. Para o processo de produção do álcool, há varias etapas e, uma delas é a extração do caldo da cana-de-açúcar realizada, em sua grande maioria, por equipamentos denominados "ternos de moenda". Conhecer o comportamento destes equipamentos sob os esforços atuantes em sua estrutura é de suma importância para a realização de novos projetos destes e uma otimização dos já existentes. Para o conhecimento de tais tensões, tecnologias na área da engenharia auxiliada por computador (CAE) trazem programas de computador (softwares) capazes de cumprir tal finalidade. Muitos destes softwares são responsáveis por uma otimização no processo de concepção de um produto, pois os mesmos são capazes de detectar falhas em projetos com extrema facilidade, coisa que seria muito difícil por cálculos realizados manualmente. Assim, o objetivo deste trabalho é estudar as tensões atuantes num castelo de moenda 53"x90", peça de maior expressão no conjunto do terno de moenda de mesma bitola, para auxilio em futuros projetos e otimização dos já existentes. Para o conhecimento das tensões atuantes no castelo a utilização do Cosmosworks, software de elementos finitos que apresenta resultados com grande precisão, será utilizado. Depois de analisadas, as tensões atuantes no castelo foram apresentadas com ênfase aos pontos de maior concentração de tensão. A verificação de coeficientes de segurança elevados nas mais diversas regiões do castelo também foi explorada. Com base nos resultados apresentados pôde-se otimizar o castelo de moenda reduzindo seu peso próprio em 15\%, que corresponde aproximadamente a $3.000 \mathrm{Kg}$. O conhecimento das tensões atuantes em componentes para o setor sucroalcooleiro oferece condições de se projetar novos equipamentos otimizados para um mercado cada vez mais globalizado e conseqüentemente mais competitivo.

Palavras-chave: Moagem da cana-de-açúcar. Terno de moenda. Castelo de moenda. Análise de tensões. Elementos finitos. 


\section{ABSTRACT}

Caltarosso, F. (2008). Análise de Tensões em Equipamentos de Moagem da Cana-de-Açúcar usando o Método dos Elementos Finitos. São Carlos, 2008. Dissertação - Escola de Engenharia de São Carlos, Universidade de São Paulo.

The alcohol produced in Brazil through the sugar cane is an alternative fuel that acquire her space on the world market with the interest of industrialized countries to contribute to reducing the planet pollution. In the process of ethanol production, there are several steps and one is the extraction of juice from sugar cane held, in majority, of the equipment called "milling housing". Knowing the behavior of this equipment efforts engaged in its structure is of paramount importance for the realization of these new projects and an optimization of existing ones. To the knowledge of these stress, technologies in the field of computer-aided engineering (CAE) bring computer programs (software) capable of fulfilling this purpose. Many of these software are responsible for an optimization in the process of product design, due to the fact that they are capable of detecting projects flaws with great ease, when something would be very difficult handling calculation. The objective of this work is to study the stresses working in the milling housing, the greatest expression throughout the suit of milling, to help in future projects and optimization of existing ones. To the knowledge of the stress working in the housing Cosmosworks, software for finite element that gives results with great accuracy, had been used. After the analysis, stresses working in the housing were presented with emphasis on the points of greatest stress concentration. The proof of factor of safety in the most diverse regions of the housing had been also explored. Based on the results presented, it is possible to optimize the milling housing reducing its own weight by $15 \%$, which is approximately $3,000 \mathrm{Kg}$. Knowledge of stresses in active components for the sector offers conditions to design new equipment optimized for an increasingly globalised market and thereafter more competitive.

Keywords: Extraction of sugar cane. Milling housing. Housing. Analysis of stress. Finite element. 


\section{LISTA DE FIGURAS}

Figura 1: Esquema dos passos a serem seguidos na resoluções de problemas estruturais.

Figura 2: Composição da cana madura........................................................................ 27

Figura 3: Inversão da sacarose em glicose e frutose. Fonte: (Moendas..., 2002) ........... 29

Figura 4: Esquema do processo de recepção, preparo e extração. ................................ 31

Figura 5: Exemplo de colheita manual de cana, mostrando o trabalhador e a maneira de

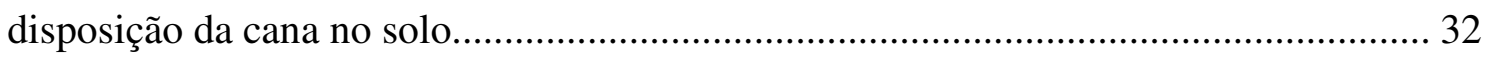

Figura 6: Colhedeira mecânica em atividade. .......................................................... 33

Figura 7: Exemplo de caminhão trucado para transporte de cana em uma usina........... 34

Figura 8: Tomador de amostra oblíquo em uma usina............................................... 35

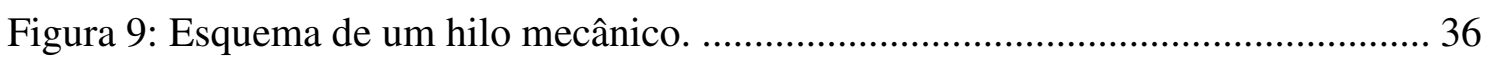

Figura 10: Esquema de uma mesa alimentadora inclinada a $45^{\circ}$................................ 37

Figura 11: Esquema de uma esteira metálica utilizada para a condução de cana. Fonte:

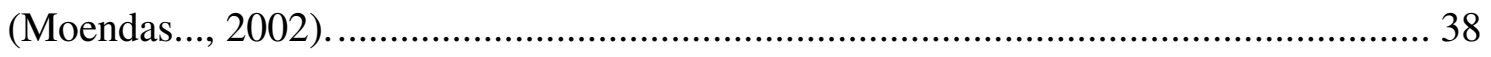

Figura 12: Esquema de um nivelador/picador de lâminas oscilantes (DEDINI, 2007). 39

Figura 13: Esquema de um desfibrador, tambor alimentador e placa desfibradora

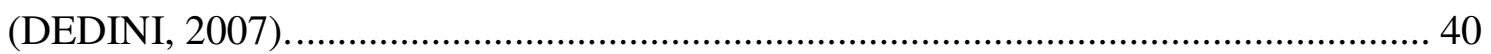

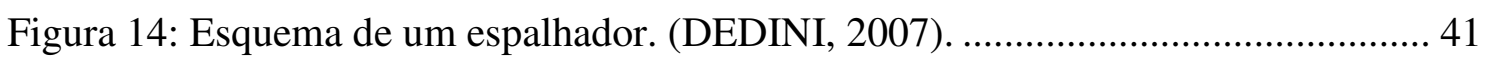

Figura 15: Esquema de um terno de moenda (DEDINI, 2007) .................................... 42

Figura 16: Esquema de embebição composta (MOENDAS, 2002) .............................. 43

Figura 17: Esquema de geração e utilização do vapor a partir da queima do bagaço da

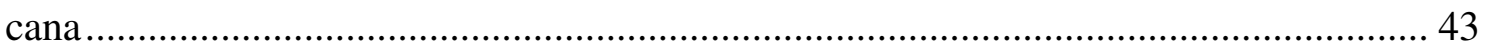

Figura 18: Esquemas das etapas do tratamento do caldo de cana. ................................ 45

Figura 19: Esquema das etapas para a fabricação do açúcar......................................... 46

Figura 20: Esquema da etapas da fabricação do álcool................................................ 48

Figura 21: Esquema da disposição dos cilindros e seus sentidos de giro (MOENDAS,

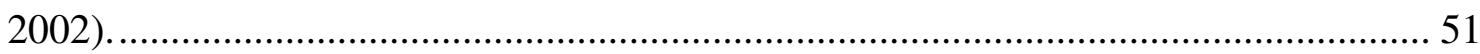

Figura 22: Esquema de um terno de moenda (DEDINI, 2007) .................................... 52

Figura 23: Subconjuntos de um terno de moenda (DEDINI, 2007) ….......................... 53

Figura 24: Exemplo de um castelo de moenda (DEDINI, 2007)................................. 54

Figura 25: Localização dos castelos no terno de moenda (DEDINI, 2007).................. 55

Figura 26: Componentes do sistema de regulagem da bagaceira (DEDINI, 2007). ...... 56 
Figura 27: Localização do sistema de regulagem da bagaceira no terno de moenda (DEDINI, 2007)

Figura 28: Cabeçotes laterais de entrada e saída (DEDINI, 2007).

Figura 29: Localização dos cabeçotes laterais de entrada e saída no terno de moenda

(DEDINI, 2007) 58

Figura 30: Componentes do rolo inferior (DEDINI, 2007)........................................ 59

Figura 31: Componentes de um mancal inferior.

Figura 32: Localização dos rolos inferiores de entrada e saída do terno de moenda (DEDINI, 2007) 60

Figura 33: Componentes do rolo de pressão (DEDINI, 2007). 61

Figura 34: Localização do rolo de pressão no terno de moenda (DEDINI, 2007). 62

Figura 35: Componentes do rolo superior (DEDINI, 2007). 63

Figura 36: Localização do rolo superior no terno de moenda (DEDINI, 2007). 63

Figura 37: Componentes do cabeçote hidráulico (DEDINI, 2007). 64

Figura 38: Localização dos cabeçotes hidráulicos no terno de moenda (DEDINI, 2007).

Figura 39: Pente superior e pente inferior do terno de moenda (DEDINI, 2007)......... 66

Figura 40: Classificação dos materiais. 68

Figura 41: Tensão de tração, tensão de compressão e tensão de cisalhamento respectivamente. As linhas tracejadas representam o material sem aplicação de cargas e as linhas cheias representam o material deformado após a aplicação das cargas (CALLISTER, 1991). 70

Figura 42: Curva típica da tensão- deformação (GARCIA e SANTOS, 2000) 72

Figura 43: Curva tensão- deformação para alguns materiais (GARCIA e SANTOS, 2000)

Figura 44: Diagrama Esquemático tensão-deformação mostrando deformação elástica linear para ciclos de carregamento e descarregamento (CALLISTER, 1991). 74 Figura 45: Efeito do coeficiente de Poisson. As linhas tracejadas representam o material com a carga aplicada e as linhas cheias representam o material sem carga aplicada.

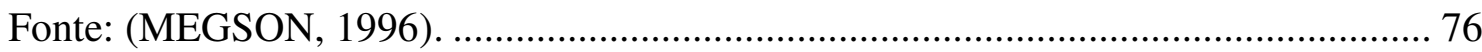

Figura 46: Designação do aço conforme o sistema ABNT. ........................................ 79

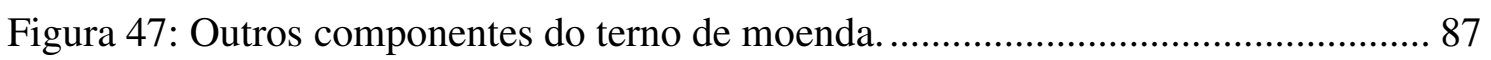

Figura 48: Esquema de uma placa de apoio do pistão................................................. 88

Figura 49: Esquema da pressão hidráulica atuando no pistão........................................ 94 
Figura 50: Carga distribuida sobre a superficie projeta do casquilho. 96

Figura 51: Direçao das forças de reação sobre o rolo superior (RAIN, 2007). 97

Figura 52: Esquema das aberturas entre os rolos de moenda com o terno em atividade. 105

Figura 53: Esquema da triangulação do terno de moenda (OPERAÇÂA, 1991)......... 109

Figura 54: Esquema para a localização da bagaceira (HUGOT, 1969)........................ 111

Figura 55: Esquema para traçado da bagaceira (HUGOT, 1969)................................ 112

Figura 56: Seções onde ocorrem as fraturas nos eixos dos rolos do terno de moenda. 113

Figura 57: Rodete de acionamento para rolos de moenda........................................ 120

Figura 58: Montagem de 3 rodetes de um único lado do terno de moenda................... 121

Figura 59: Curva evolvente (ADAPTAÇÃO - FINZI, 1963). ..................................... 122

Figura 60: Construção da curva evolvente (OLIVEIRA, 1980).................................. 122

Figura 61: Esquema construtivo de um rodete (pinhão) para acionamento dos rolos de

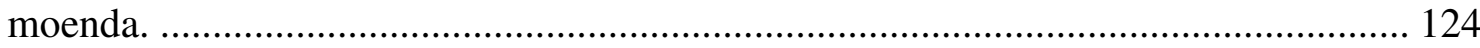

Figura 62: Força normal a superfície do dente do rodete.......................................... 124

Figura 63: Critério de Mohr-Coulomb para materiais pulverulentos (LAIER, 2003).. 129

Figura 64: Critério de Mohr-Coulomb para materiais coesivos (LAIER, 2003).......... 131

Figura 65: Critério de Mohr-Coulomb para estado plano (LAIER, 2003)................... 131

Figura 66: Esquema de um componente divido em pequenas regiões (ALVES

FILHO,2006)

Figura 67: Divisão de um componente em elementos tetraédrico linear (ALVES

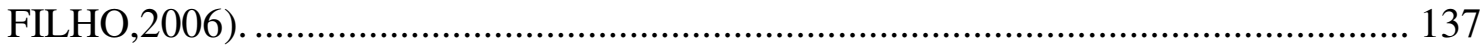

Figura 68: Elemento finito tetraédrico linear (ALVES FILHO,2006)......................... 138

Figura 69: Divisão de um componente em elementos tetraédrico parabólicos (ALVES

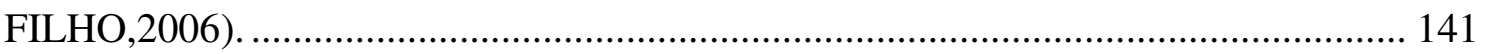

Figura 70: Elemento finito tetraédrico parabólico (ALVES FILHO,2006). ................ 142

Figura 71: Procedimento padrão para formulação dos elementos finitos (ADAPTAÇÂO

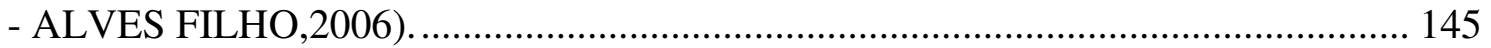

Figura 72: Esquema de uma moenda convencional de bitola 53"x90" (DEDINI, 2007).

Figura 73: Conjunto do rolo inferior adequado para análise em elementos finitos...... 147

Figura 74: Conjunto do rolo superior adequado para análise em elementos finitos..... 147

Figura 75: Conjunto do rolo de pressão adequado para análise em elementos finitos. 147 
Figura 76: Sistema de regulagem da bagaceira adequado para análise em elementos finitos

Figura 77: Cabeçote lateral de entrada (à esquerda) e cabeçote lateral de saída (à direita) adequados para análise em elementos finitos.......................................................... 148

Figura 78: Cabeçote hidráulico adequado para análise em elementos finitos.

Figura 79: Peso dos principais componentes a serem considerados na simulação do terno de moenda convencional.

Figura 80: Decomposição da CHT.

Figura 81: Forças de engrenamento nos rodetes dos rolos inferiores e rolo superior do lado do acionamento

Figura 82: Força de engrenamento entre o rolo de pressão e o rolo superior do lado oposto do acionamento.

Figura 83: Elemento tetraédrico de primeira ordem.................................................... 160

Figura 84: Elemento tetraédrico de segunda ordem.................................................. 160

Figura 85: Elementos triangulares de primeira ordem.............................................. 161

Figura 86: Elemento triangular de segunda ordem...................................................... 161

Figura 87: Graus de liberdades do nó numa malha de elementos finitos...................... 162

Figura 88: Processo para análises através do Cosmosworks....................................... 163

Figura 89: Criação de um novo estudo no Cosmosworks.......................................... 164

Figura 90: Campos para preenchimento das propriedades mecânicas dos materiais no

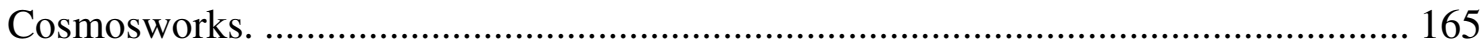

Figura 91: Locais (circulados em vermelho) onde serão criados os pin. ..................... 166

Figura 92: Locais (circulados em vermelho) onde serão aplicadas restrições. ............. 166

Figura 93: Locais (circulados em vermelho) onde será aplicada restrição de translação em apenas uma direção.

Figura 94: Locais (circulados em vermelho) onde serão aplicadas as forças

correspondente a CHT.

Figura 95: Locais (circulados em vermelho) onde serão aplicadas as forças obtidas em

[2] e [3] correspondente ao esmagamento da cana pelos rolos.

Figura 96: Locais (circulados em vermelho) onde serão aplicadas as forças correspondentes a pressão da cana na entrada do terno.

Figura 97: Face superior da bagaceira (circulados em vermelho) onde serão aplicadas as forças. 
Figura 98: Faces horizontais e verticais das caixas dos mancais dos rolos inferiores com suas respectivas forças e direções a serem aplicadas.

Figura 99: Faces inclinada a $15^{\circ}$ das caixas dos mancais do rolo superior com suas respectivas forças e direções a serem aplicadas.

Figura 100: Faces horizontais e verticais das caixas dos mancais do rolo de pressão com suas respectivas forças e direções a serem aplicadas.

Figura 101: Faces (circuladas em vermelho) onde serão aplicadas as forças correspondentes ao peso do sistema de regulagem da bagaceira assim como sua direção.

Figura 102: Faces (em verde) do castelo e do cabeçote hidráulico que se tocam. 173

Figura 103: Faces (em verde) do castelo e do pino excêntrico que se tocam.....

Figura 104: Faces (em verde) do castelo e do suporte da balança que se tocam. 174

Figura 105: Faces (em verde) do castelo e do cabeçote lateral de saída que se tocam. 175 Figura 106: Faces (em verde) do castelo e do cabeçote lateral de entrada que se tocam.

Figura 107: Faces (em verde) do castelo e do mancal do rolo de pressão que se tocam.

Figura 108: Faces (em verde) do cabeçote lateral de entrada e do mancal do rolo de pressão que se tocam.

Figura 109: Faces (em verde) do mancal do rolo inferior de entrada e do castelo que se tocam.

Figura 110: Faces (em verde) do mancal do rolo inferior de entrada e do cabeçote lateral de entrada que se tocam.

Figura 111: Faces (em verde) do mancal do rolo inferior de entrada e do castelo que se tocam.

Figura 112: Faces (em verde) do mancal do rolo inferior de saída e do cabeçote lateral de saída que se tocam.

Figura 113: Faces (em verde) do "garfo" do castelo e do mancal do rolo superior que se tocam.

Figura 114: Faces (em verde) do cabeçote hidráulico (encaixe superior) e do castelo que se tocam.

Figura 115: Configuração das opções para a execução da malha.

Figura 116: Terno de moenda após a execução da malha.

Figura 117: Configuração das opções para a "rodar" o programa. 
Figura 118: Tensões de Von Misses (MPa) no terno de moenda limitadas a 70 MPa. 184

Figura 119: Deslocamentos (mm) no terno de moenda limitado a $1 \mathrm{~mm}$. 185

Figura 120: Tensões de Von Misses (MPa) no castelo do lado do acionamento limitadas a $70 \mathrm{MPa}$.

Figura 121: Tensões de Von Misses (MPa) no castelo do lado do acionamento limitadas a $70 \mathrm{MPa}$. 186

Figura 122: Tensões de Von Misses (MPa) no castelo em corte do lado do acionamento limitadas a $70 \mathrm{MPa}$. 187

Figura 123: Efeito das tensões no castelo. A parte cinza corresponde ao castelo sem deformação enquanto o modelo está deformado com uma escala de 500 vezes. 188 Figura 124: Deslocamentos (mm) no castelo do lado do acionamento limitado a $1 \mathrm{~mm}$.

Figura 125: Tensões (MPa) em alguns pontos de maior solicitação. 190

Figura 126: Tensões (MPa) em alguns pontos de maior solicitação. 190

Figura 127: Tensões (MPa) em alguns pontos de maior solicitação.

Figura 128: Distribuição do fator de segurança no castelo do lado do acionamento limitado a $20 \mathrm{MPa}$.

Figura 129: Castelo em corte com sua geometria original.

Figura 130: Castelo em corte com sua geometria modificada.

Figura 131: Distribuição do fator de segurança no castelo do lado do acionamento

limitado a $20 \mathrm{MPa}$ depois das modificações propostas.

Figura 132: Distribuição do fator de segurança no castelo original (a esquerda) e no castelo com as modificações propostas (a direita). 


\section{LISTA DE TABELAS}

Tabela 1: Estágios da maturação da cana através do IM.......................................................28

Tabela 2: Estimativa da produção e destino da cana para safra 2007/2008 ............................30

Tabela 3: Capacidade de carga dos caminhões para transporte da cana. .................................34

Tabela 4: Capacidade de moagem dos ternos de moenda.................................................52

Tabela 5: Módulo de elasticidade (E) dos materiais utilizado na engenharia........................75

Tabela 6: Módulo de elasticidade transversal $(\mathrm{G})$ dos materiais utilizado na engenharia. ..... 76

Tabela 7: Coeficiente de Poisson $(v)$ dos materiais utilizado na engenharia. ........................77

Tabela 8: Coeficientes de segurança para materiais dúcteis baseados nas informações

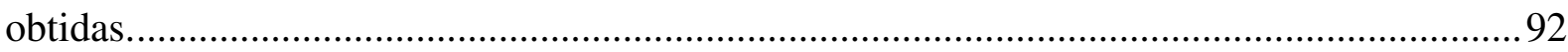

Tabela 9: Coeficiente relativo aos equipamentos de preparação da cana.. ............................99

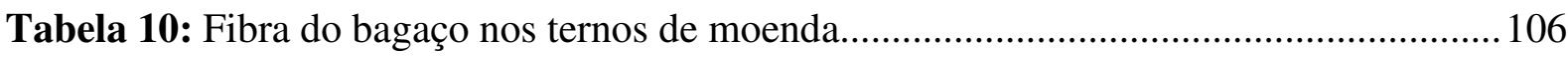

Tabela 11: Relação entre as abertura de entrada e saída com o terno em atividade............... 107

Tabela 12: Valores do coeficiente de endurecimento superficial...................................... 114

Tabela 13: Valores do fator de concentração $K \sigma_{\text {Rug }}$ devido à rugosidade superficial e o

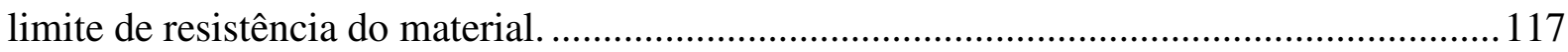

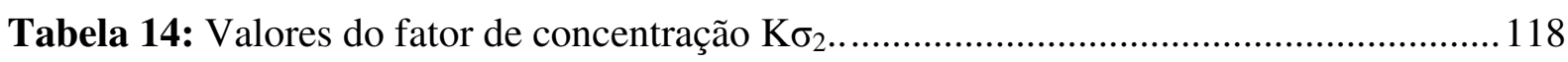

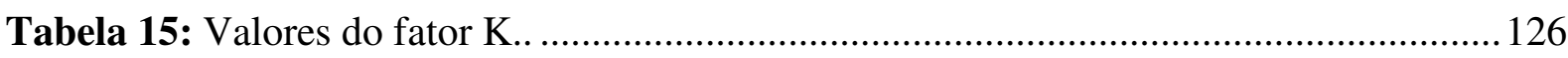

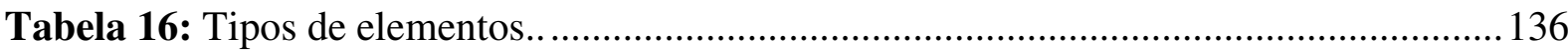

\section{LISTA DE GRÁFICOS}

Gráfico 1: Coeficiente de escala.

Gráfico 2: Fator de concentração de tensão $K_{t}$ para eixo com rebaixo arredondado em flexão.

Gráfico 3: Fator de sensibilidade do material 


\section{LISTA DAS NOTAÇÕES E SÍMBOLOS}

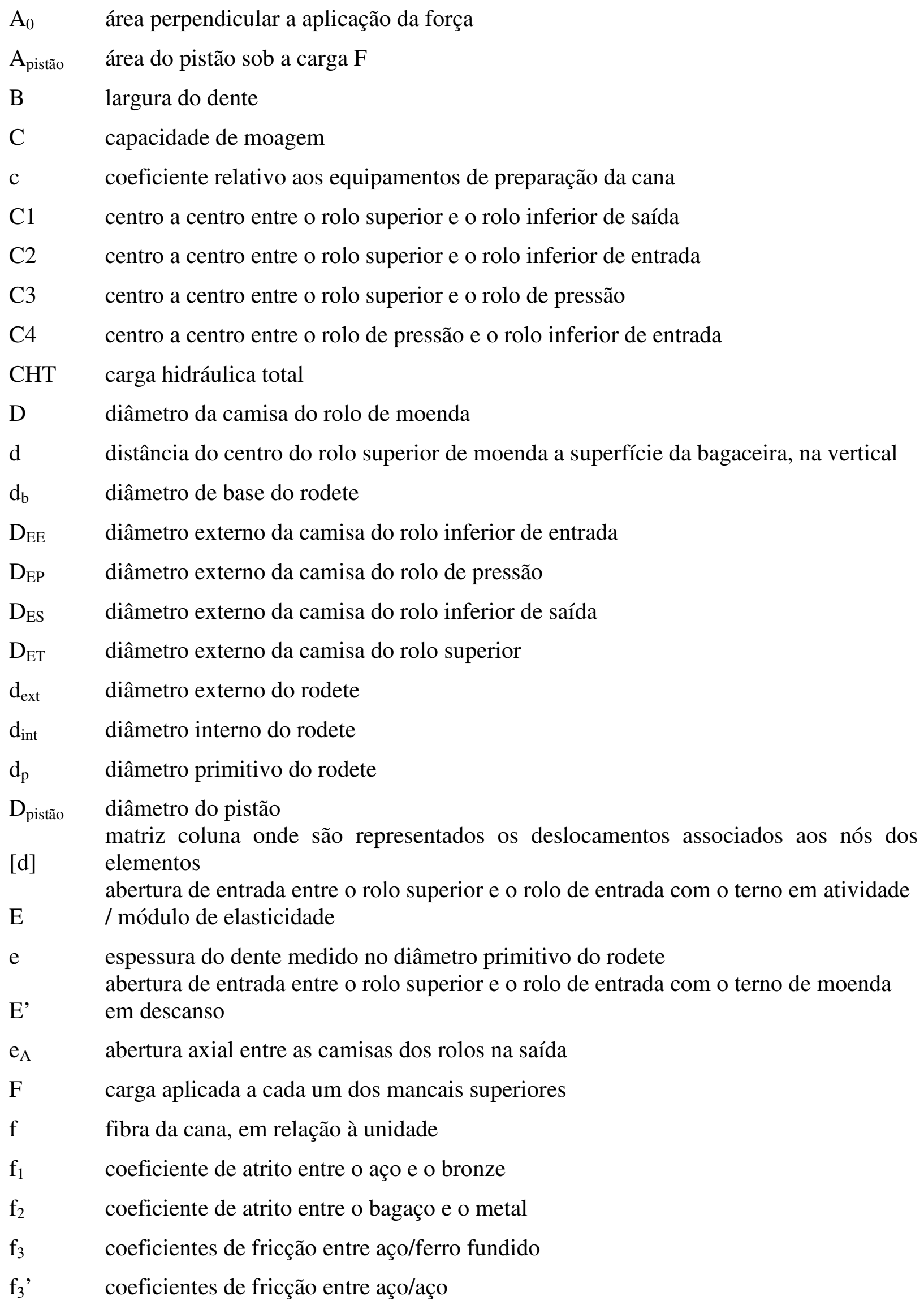


$\mathrm{F}_{\text {rec }} \quad$ fator de segurança a fadiga recomendado

Fs fator de segurança

$\mathrm{F}_{\mathrm{S}} \quad$ fator de segurança a fadiga

\{f\} matriz coluna onde são representadas as forças que atuam nos nós dos elementos

G módulo de elasticidade transversal

IM índice de maturação

$\mathrm{H}_{\mathrm{E}} \quad$ altura do friso da camisa do rolo inferior de entrada

$\mathrm{H}_{\mathrm{P}} \quad$ altura do friso da camisa do rolo de pressão

$\mathrm{H}_{\mathrm{S}} \quad$ altura do friso da camisa do rolo inferior de saída

$\mathrm{H}_{\mathrm{T}} \quad$ altura do friso da camisa do rolo superior

$\mathrm{K}$ e K' fatores que definem a altura do dente

$\mathrm{K}_{\mathrm{c}} \quad$ coeficiente relativo a distribuição de carga não uniforme na largura do dente

$\mathrm{K}_{\mathrm{D}} \quad$ coeficiente relativo ao aparecimento de forças dinâmicas adicionais

$\mathrm{K}_{\mathrm{t}}$ fator teórico de concentração em função da mudança de dimensão do eixo

$\mathrm{K}_{\sigma} \quad$ fator de concentração de tensão

K $\sigma_{1} \quad$ fator de concentração de tensão

$K \sigma_{\text {Loc }}$ fator de concentração de tensão devido à geometria local

$K \sigma_{\text {Rug }}$ fator de concentração de tensão devido à rugosidade superficial matriz quadrada contento os coeficientes de rigidez, também conhecida como matriz

[k] de rigidez do elemento

L comprimento da camisa do rolo de moenda

1 comprimento após a aplicação da força

$1_{0} \quad$ comprimento inicial de referência sem aplicação da força

$\mathrm{L}_{1} \quad$ distância da carga $\mathrm{F}$ a seção 1

$\mathrm{L}_{2} \quad$ distância da carga $\mathrm{F}$ a seção 2

M moagem horária de trabalho do terno de moenda

$\mathrm{m}$ relação entre as abertura de entrada e saída com o terno em atividade / módulo

$\mathrm{M}_{1} \quad$ momento fletor na seção 1

$\mathrm{M}_{2} \quad$ momento fletor na seção 2

Mt torque a ser transmitido pelo rodete

n velocidade de rotação dos rolos

$\mathrm{N} \quad$ número de rolos constituindo o tandem

p pressão para o desprendimento do bagaço por centímetro de comprimento

Pt potência total consumida em um terno de moenda

P abertura de entrada entre o rolo superior e o rolo de pressão

p' pressão para o desprendimento do bagaço entre o rolo de entrada e a bagaceira 


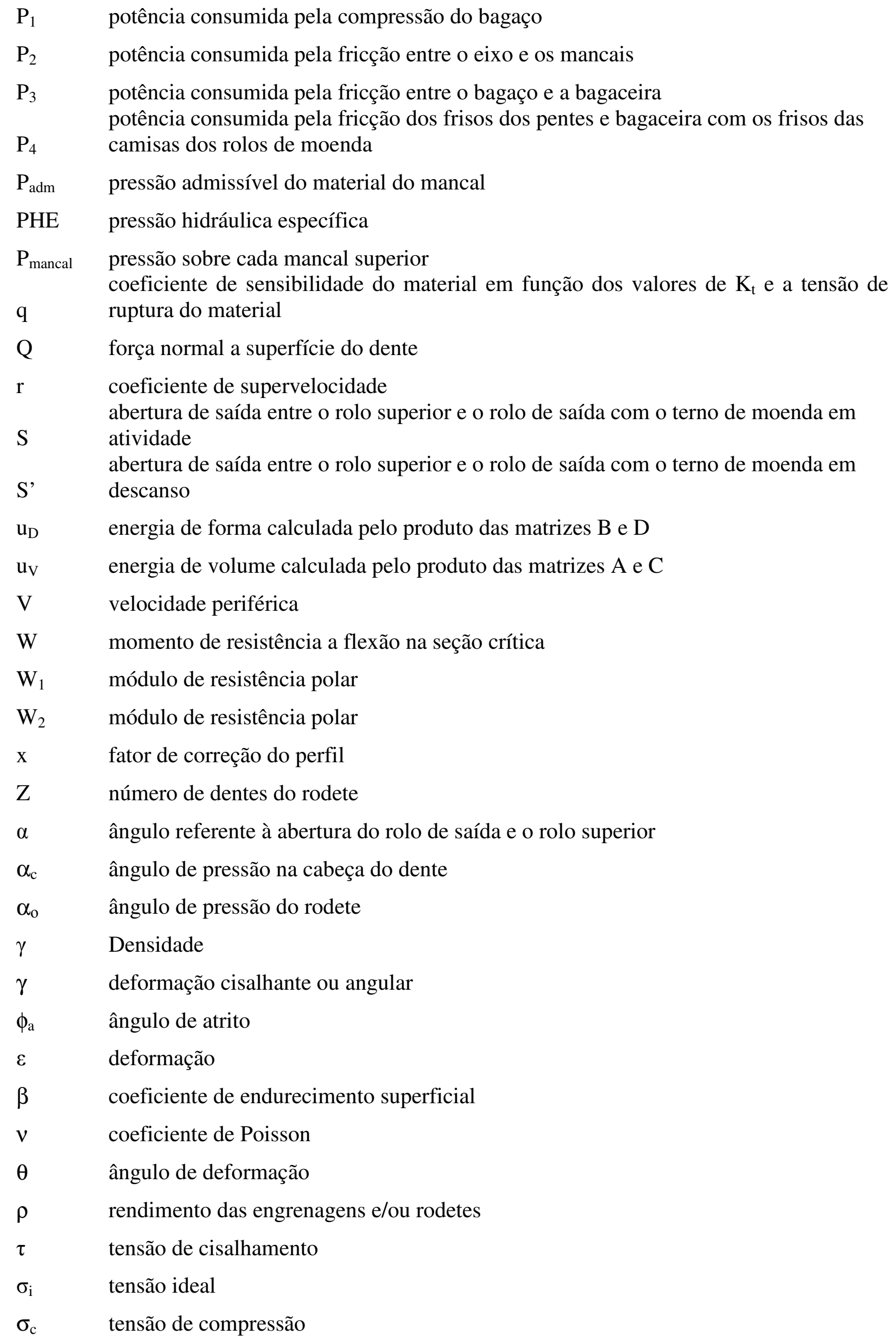




$\begin{array}{ll}\sigma_{\mathrm{e}} & \text { limite de escoamento } \\ \sigma_{\mathrm{flex}} & \text { tensão de flexão } \\ \sigma_{\mathrm{t}} & \text { limite de resitencia } \\ \sigma & \text { tensão tração ou compressão } \\ \sigma_{\mathrm{a}} & \text { tensão causada pelo momento fletor no eixo } \\ \sigma_{\mathrm{a} 1} & \text { tensão causada pelo momento fletor na seção 1 } \\ \sigma_{\mathrm{a} 2} & \text { tensão causada pelo momento fletor na seção 2 } \\ \sigma_{\mathrm{F}} & \text { limite de resistência a fadiga } \\ \xi & \text { coeficiente de escala }\end{array}$

\section{LISTA DE ABREVIATURAS E SIGLAS}

$\begin{array}{ll}\text { ABNT } & \text { Associação Brasileira de Normas Técnicas } \\ \text { AISC } & \text { American Institute of Steel Construction } \\ \text { AISI } & \text { American Iron Steel Institute } \\ \text { ATR } & \text { Açucares Totais Recuperáveis } \\ \text { CONAB } & \text { Companhia Nacional de Abastecimento } \\ \text { DIN } & \text { Deutsche Industrie Normen } \\ \text { FEM } & \text { Finite Element Method } \\ \text { RPE } & \text { Recepção, Preparo e Extração } \\ \text { SAE } & \text { Society of Automotive Engineers } \\ \text { TCD } & \text { Tonelada de Cana por Dia } \\ \text { TCH } & \text { Tonelada de Cana por Hora } \\ \text { VHP } & \text { Very Hight Polarization }\end{array}$




\section{Sumário}

\section{RESUMO}

\section{ABSTRACT}

INTRODUÇÃ

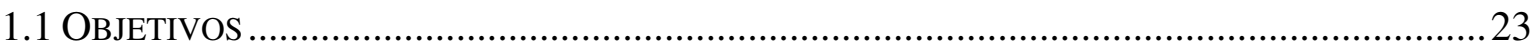

1.2 DESCRIÇÃO DOS CAPÍTULOS DA DiSSERTAÇÃo ………………………………………....24

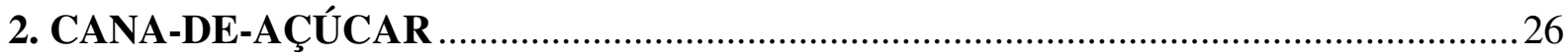

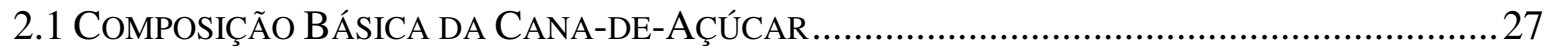

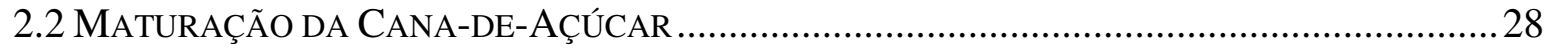

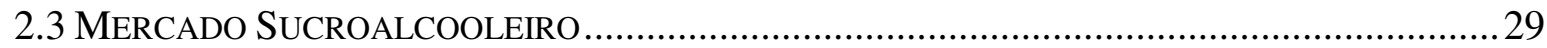

3. PROCESSO INDUSTRIAL DA CANA-DE-AÇÚCAR …………………………..........

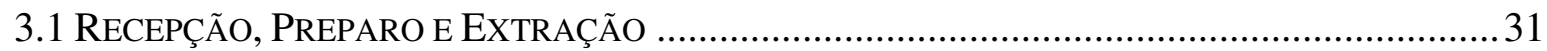

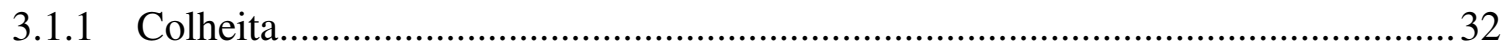

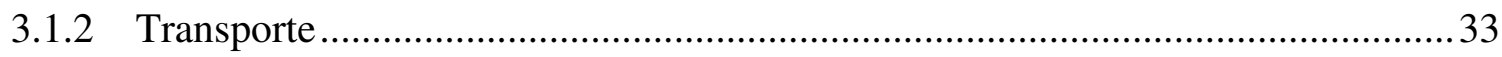

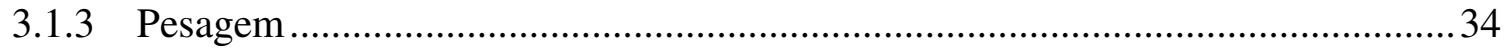

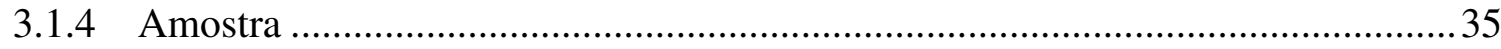

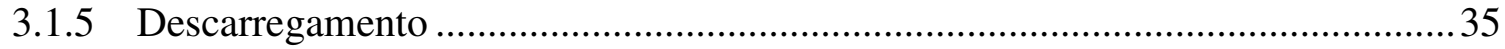

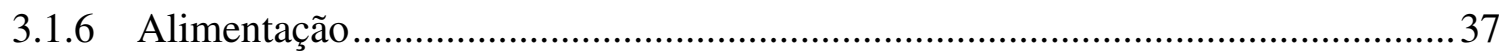

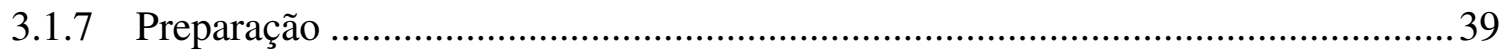

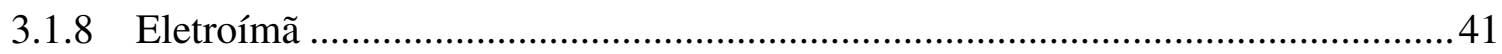

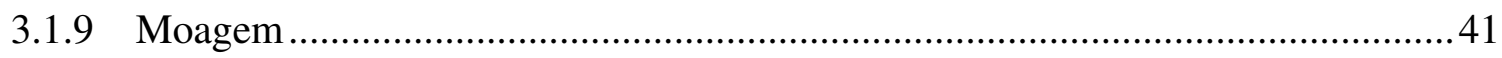

3.2 GERAÇÃO DE ENERGIA .....................................................................................4

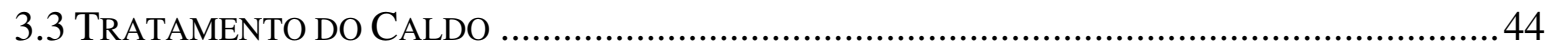

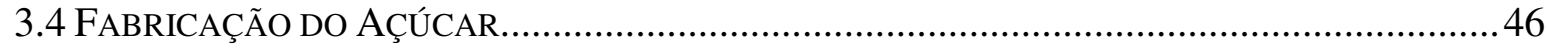

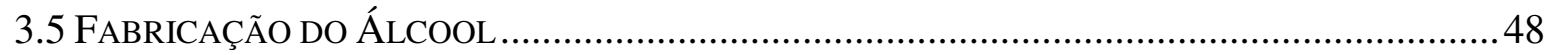

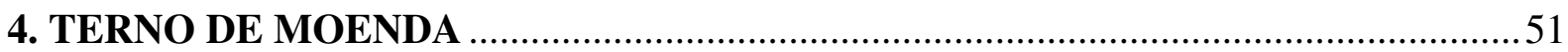

4.1 Componentes do TERno DE MoEnda e SUAS FunÇÕES .................................................53

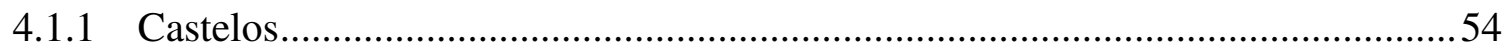

4.1.2 Sistema de Regulagem da Bagaceira.............................................................55

4.1.3 Cabeçotes Laterais ......................................................................................... 


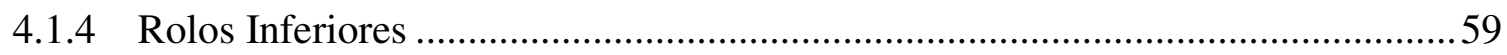

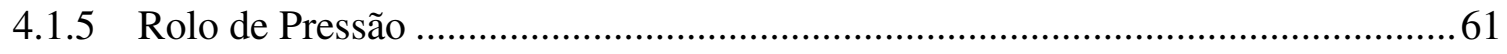

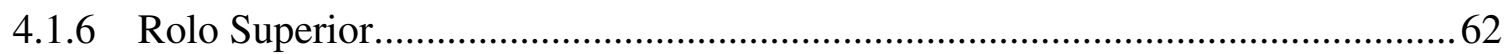

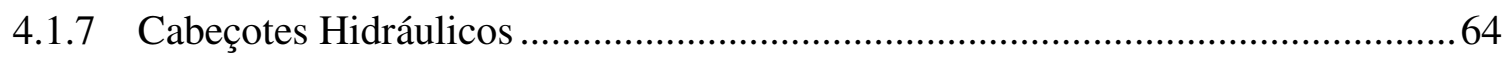

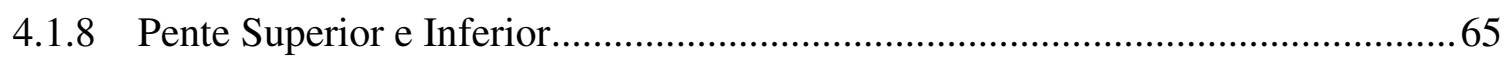

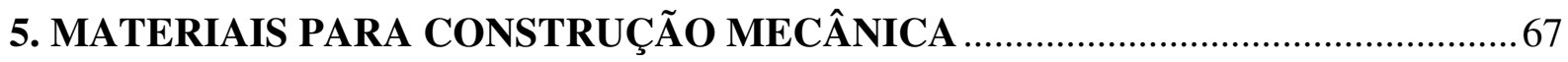

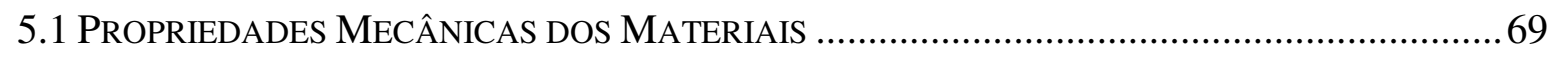

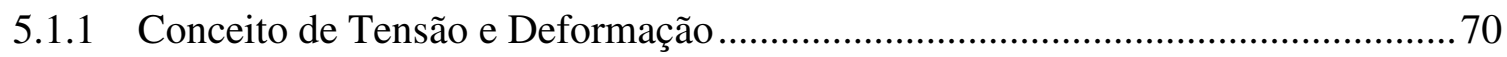

5.1.2 Materiais Elásticos e Materiais Plásticos .................................................................... 71

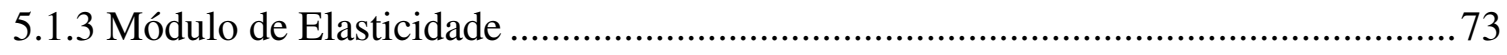

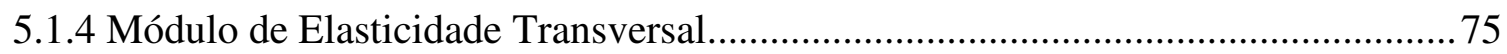

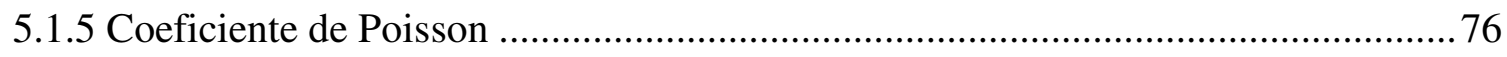

5.2 PrinciPais Materiais UtiliZados na ConstruÇÃo MECÂNICA .................................78

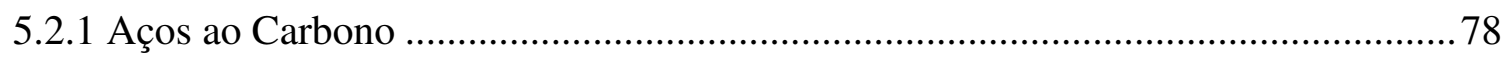

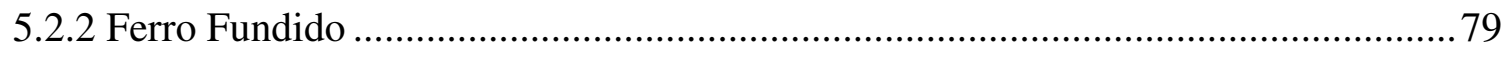

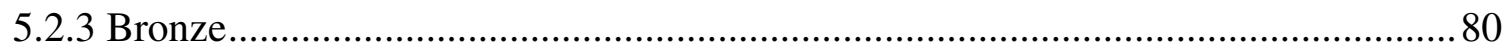

5.3 Materiais dos Componentes do Terno de MoEnda e SuAs PropriedAdes .............80

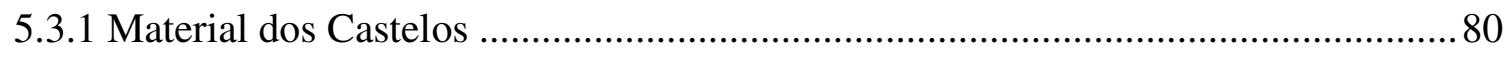

5.3.2 Materiais do Sistema de Regulagem da Bagaceira.............................................. 81

5.3.3 Material dos Cabeçotes Laterais ....................................................................... 82

5.3.4 Materiais dos Rolos do Terno de Moeda........................................................... 82

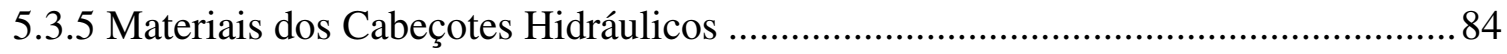

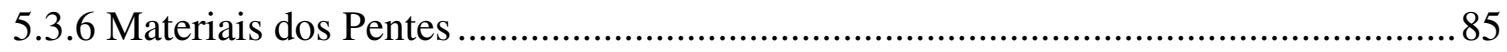

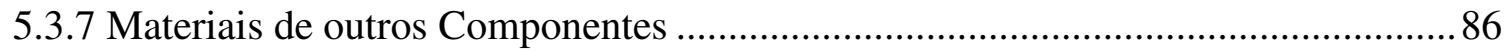

6. PROJETO DE MÁQUINAS - TERNO DE MOENDA ............................................ 90

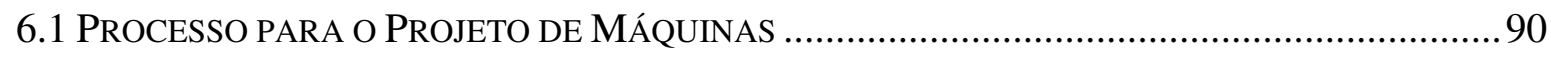

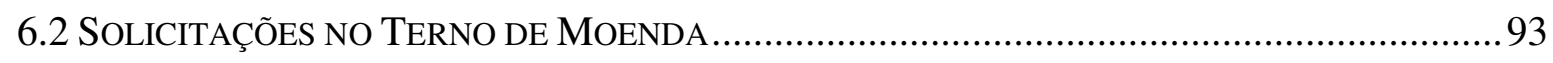

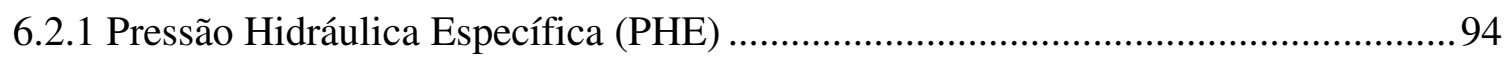

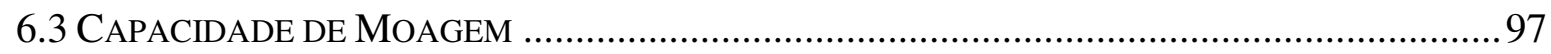

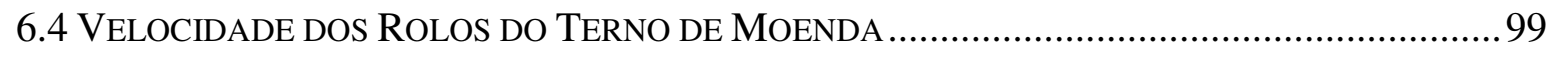

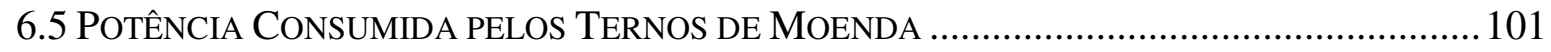

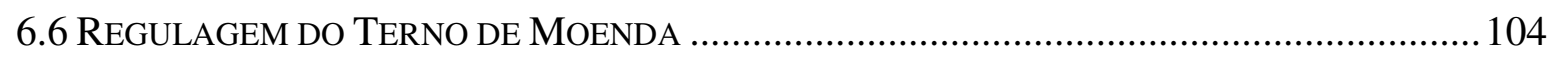

6.6.1 Regulagem das Aberturas entre os Rolos do Terno de Moenda............................ 104 


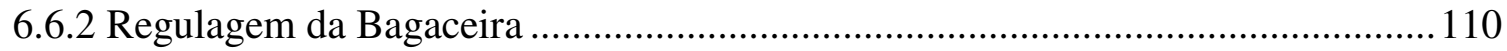

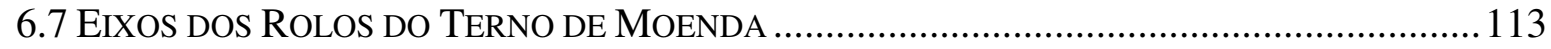

6.8 Projeto de Pinhões PARA Acionamento dos Rolos do Terno de MoEnda ........... 119

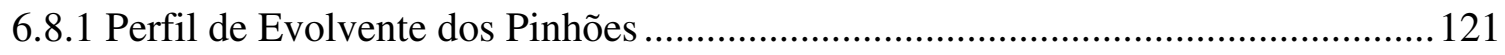

6.8.2 Relações de Engrenamento........................................................................... 123

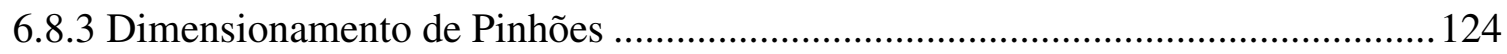

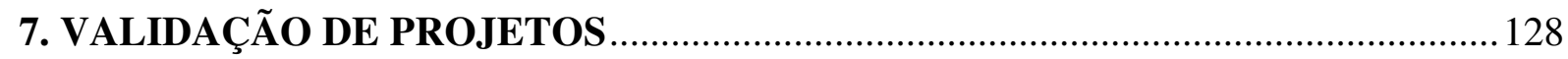

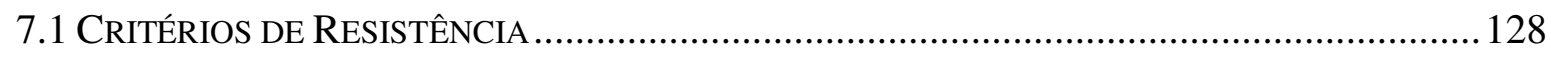

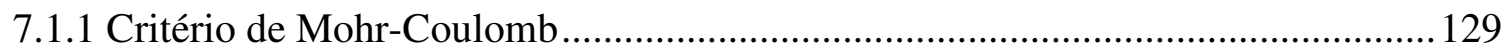

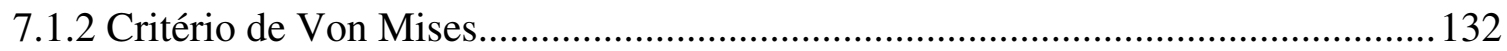

7.2 O MÉtodo dos Elementos Finitos em Projetos....................................................... 135

7.2.1 Formulação do Elemento Tetraédrico Linear...................................................... 137

7.2.2 Formulação do Elemento Tetraédrico Parabólico ................................................. 141

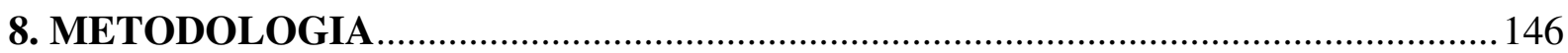

8.1 ESFORÇOS EXTERNO NO TERNO DE MOENDA ........................................................... 149

8.2 Software Utilizado PARA A ANÁliSE EM ElEMENTOS Finitos ............................... 158

8.2.1 Construção do Modelo Matemático ....................................................................... 159

8.2.2 Construção do Modelo de Elementos Finitos............................................................ 159

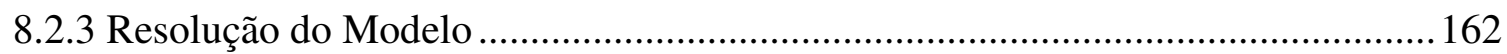

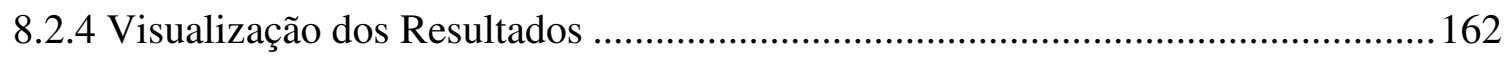

8.3 Procedimento PARA A ANÁlise EM ElEMENTOS Finitos .......................................... 164

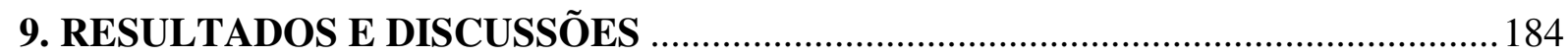

9.1 Proposta de Melhoria Para o CAStelo de Moenda .............................................. 192

CONCLUSÕES E SUGESTÕES PARA FUTUROS TRABALHOS ............................. 196

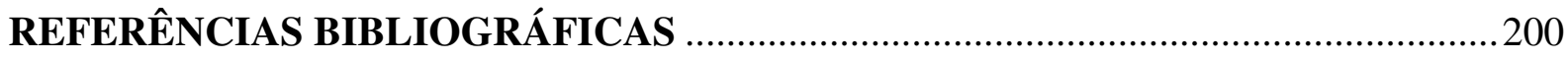




\section{Introdução}

Nas atividades diárias da engenharia, engenheiros são colocados diante dos mais variados tipos de problemas tendo que resolvê-los de forma satisfatória. Para tal tarefa, são utilizados conceitos, fórmulas, tabelas entre outros, os quais são apresentados nos cursos de engenharia. Em particular, na área de resistência dos materiais, o engenheiro deve garantir que o componente em estudo não sofra falhas sob os mais diversos tipos de esforços que o mesmo sofra em condições de operação. Para o sucesso do desenvolvimento dos cálculos, não necessita apenas o conhecimento de um aparato de fórmulas matemáticas, mas o conhecimento e a capacidade do engenheiro de entender os fenômenos físicos atuantes no problema a ser resolvido. A Figura 1 mostra um esquema dos principais passos a serem seguidos para a resolução de um problema de resistência dos materiais. (ALVES FILHO, A., 2006).

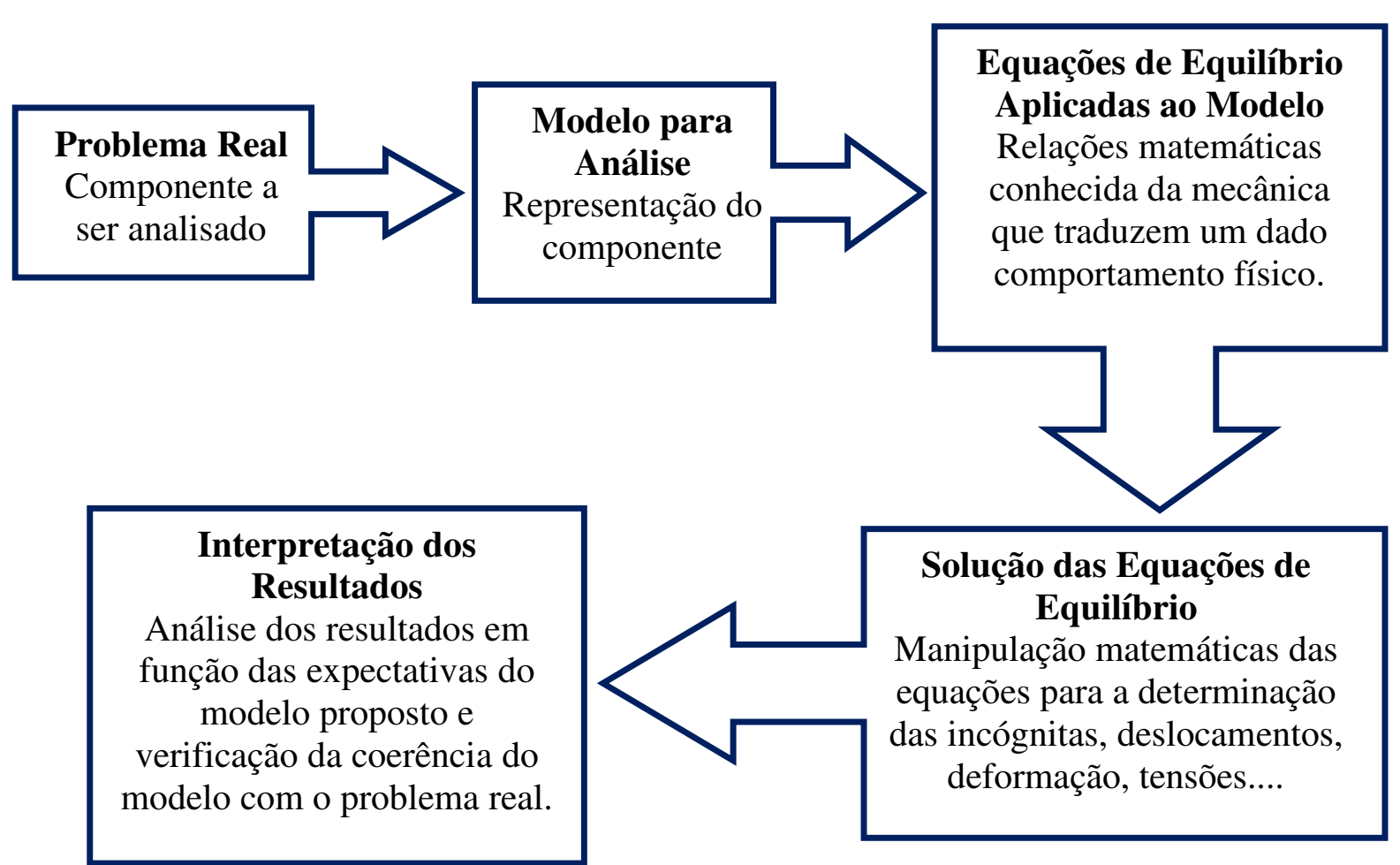

Figura 1: Esquema dos passos a serem seguidos na resoluções de problemas estruturais. 
Entendidos os fenômenos fisicos que envolvem o problema, o engenheiro, na maioria dos casos reais, se depara com problemas de dificil solução devido á compexidade da geometria. Para tais problemas, é utilizado o método dos elementos finitos (FEM - Finite Element Method). Este, transforma o meio contínuo em um meio discreto escrevendo as equações de compatibilidade e equilibrio entre eles, admitindo funções contínuas que podem respresentar, por exemplo, os deslocamentos em um elemento e obter as deformações correspondentes que, associadas as propriedades do material, definem o estado de tensão em todo o meio (ASSAN, 2003).

Grandes desenvolvimentos na área computacional, aliados ao crescente progresso na formulação de problemas utilizando o método dos elementos finitos, tem possibilitado o desenvolvimento de programas computacionais capazes de simular corretamente e com grande precisão o comportamento dos materias sob as mais diversas condições de trabalho impostas (OWEN, et al, 1997).

O método dos elementos finitos, segundo Assan (2003), está totalmente agregado às atividades diárias do engenheiro, auxiliando-o nos cálculos para o conhecimento do comportamento de um componente em atividade. Como consequência, as empresas diminuem o número de revisões de um dado projeto e realizam as modificações necessárias nos componentes antes do produto final ser lançado no mercado, otimizando tempo e custos (CLARKE, 2003).

Hà vários programas de computador (softwares) no mercado capazes de realizar os mais diversos tipos de análises lineares e não lineares, incluindo deformações, deslocamentos, tensões térmicas, concentração de tensão, pressões hidrostáticas entre outros. As análises podem ser realizadas em componentes individuais, ou em montagens utilizando contatos entre os componentes. Na maioria dos softwares destinados a tal propósito, os seguintes passos são seguidos: criação ou configuração do tipo de estudo a ser realizado, criação e aplicação de materiais para os componentes, aplicação das restrições, aplicações das forças/pressões, criação das malha, "rodar" o estudo e por fim a visualização dos resultados (ROWE, 2003).

Ao mesmo tempo em que a tecnologia avança na área da engenharia, proporcionando grandes benefícios, o setor sucroalcooleiro brasileiro desperta grande interesse mundial, principalmente para a produção de álcool, o qual surge como uma fonte alternativa de combustível menos poluente para o planeta. Diante da crescente demanda pelo álcool brasileiro, surge a necessidade de aumentar a produção do mesmo 
e, um equipamento que está diretamente ligado a produção de álcool é chamado de "terno de moenda".

De acordo com Luca (2006), o terno de moenda é responsável pela extração do caldo contido na cana-de-açúca, por meio do esmagamento da mesma entre rolos com determinada pressão e rotação. O terno de moenda é constituido por duas peças laterais, chamados castelos, que sustentam os componentes como os rolos inferiores, rolo superior, rolo de pressão, sistema de regulagem da bagaceira, cabeçotes hidráulicos e cabeçotes laterias. O castelo de moenda é considerado a peça de maior expressão no conjunto do terno de moenda.

Para um aumento da produção, há a necessidade de se projetar ternos de moendas que possuam a capacidade de produção equivalente à demanda nacional e mundial.

Assim, é importante o conhecimento das tensões, deformações entre outros parâmetros, provenientes dos esforços externos nesse equipamento para a realização de novos projetos otimizados. Com o auxílio dos softwares que trabalham com o método os elementos finitos, são realizadas análises para tal propósito em peças de geometria complexa. Os resultados, no entanto devem ser cuidadosamente avaliados à luz dos conhecimentos acumulados ao longo do tempo por engenheiros de projeto.

\subsection{Objetivo}

Este trabalho objetiva conhecer as tensões atuantes em componentes de moagem da cana-de-açúcar, em especial o terno de moenda, por meio do método dos elementos finitos. Para a realização do trabalho, o software de elemento finitos CosmosWorks foi utilizado para a análise e apresentação dos resultados. O castelo de moenda, componente de maior expressão do conjunto do terno de moeda, foi o objeto principal de estudo. Como segundo objetivo está o teste de soluções propostas para otimização do projeto inicial. 


\subsection{Descrição dos Capítulos da Dissertação}

Esta dissertação foi estruturada e formatada segundo as normas para trabalho científico da Escola de Engenharia de São Carlos - EESC/USP, e é dividida em onze capítulos sendo que desse total seis (do capítulo 2 ao capítulo 7) abordam conceitos necessários ao desenvolvimento do trabalho.

Capítulo 1: Introdução, contendo a contextualização e a motivação para o estudo, assim como o objetivo da pesquisa.

Capítulo 2: Neste capítulo é apresentada a matéria prima para a produção de açúcar e álcool no Brasil, a cana-de-açúcar. Discorre-se no mesmo por uma breve história da cana-de-açúcar no Brasil e uma apresentação de sua composição, aspecto relevante no setor industrial. Como desfecho são apresentadas informações sobre a ascensão do mercado sucroalcooleiro, onde a cana-de-açúcar tem um papel fundamental.

Capítulo 3: O processo industrial da cana-de-açúcar nas usinas é apresentado neste capítulo dividido em cincos itens (reposição, preparo e extração; geração de energia; tratamento do caldo; fabricação do açúcar e fabricação do álcool) para um melhor entendimento. É descrito o processo desde o corte da cana-de-açúcar até o produto final, apresentando ao leitor alguns equipamentos de vital importância ao processo.

Capítulo 4: Objeto de estudo deste trabalho, o terno de moenda, é apresentado neste capítulo. Uma breve descrição de como funciona o terno de moenda é apresentada para que o leitor tome conhecimento deste equipamento. São apresentados, também, os principais subconjuntos do terno de moenda com descrições de suas funções assim como algumas particularidades de cada componente. Ilustrações dos subconjuntos e suas respectivas posições no terno de moenda também fazem parte deste capítulo.

Capítulo 5: No presente capítulo discorre-se sobre materiais utilizados para construção de componentes na mecânica, apresentando alguns conceitos, coeficientes e variáveis aplicáveis a esses materiais. São apresentados ainda, com mais detalhes, os principais materiais utilizados no dia-a-dia. Como desfecho deste capítulo, são descritos os 
materiais utilizados na construção dos principais componentes do terno de moenda, assim como suas propriedades mecânicas de interesse para o presente trabalho.

Capítulo 6: Neste capítulo são apresentados ao leitor conceitos sobre projetos mecânicos. Uma abordagem especial ao projeto do terno de moenda é apresentada com os cálculos de variáveis que influenciam o projeto, assim como todas as forças externas atuantes nesse equipamento. São apresentados, também, cálculos referentes a alguns equipamentos do terno de moenda que, com equações conhecidas da mecânica levam a resultados satisfatórios.

Capítulo 7: Alguns critérios de resistência, como o de Von Misses, são apresentados neste capítulo como base para a validação de projetos mecânicos. Como conseqüência do processo de validação de projetos é apresentado ao leitor o método dos elementos finitos, o qual será utilizado para o presente trabalho. Alguns conceitos e, principalmente os tipos de elementos utilizados nesse método são ilustrados.

Capítulo 8: A metodologia é apresentada neste capítulo, com todos os cálculos necessários para o conhecimento das forças externas atuantes no terno de moenda, para a realização da análise em elementos finitos. É também apresentado o software utilizado para tal tarefa com descrições de seu funcionamento. Por fim a metodologia utilizada para a análise é descrita.

Capítulo 9: Neste capítulo são apresentados os resultados obtidos da análise em elementos finitos do terno de moenda, em especial do castelo de moenda, componente objeto principal de estudo deste trabalho. Os resultados são discutidos neste capítulo assim como uma proposta de otimização do castelo. Os resultados de uma re-análise são apresentados como desfecho.

Capítulo 10: O presente capítulo traz as conclusões obtidas com o desenvolvimento do trabalho assim como uma série de sugestões para futuros trabalhos.

Capítulo 11: Referências bibliográficas 


\section{Cana-de-Açúcar}

A cana-de-açúcar é uma planta originária do sudeste da Ásia pertencente ao gênero Saccharum e, inicialmente, classificada dentro da espécie S.officinarum. Com o surgimento de doenças e o avanço tecnológico, foram criadas novas variedades a partir do cruzamento da $S$. officinarum com outras espécies do mesmo gênero como: $S$. spontaneum, S. robustum, S. sinense, S. barberi e S. edule. As novas espécies não só ficaram mais resistentes às doenças, como houve também uma melhoria na adaptação da planta a solos mais secos e menos férteis, e também ficaram mais tolerantes às variações climáticas havendo um aumento do teor de fibra. Foi a base da economia do nordeste brasileiro no século XVII, época dos engenhos, e ganha maior importância econômica a cada dia. Essa importância é resultado da sua múltipla utilização, podendo ser empregada in natura ou como matéria-prima para a fabricação de rapadura, melado, aguardente, açúcar sob as mais diversas formas, álcool (etanol) e mais recentemente de biodiesel (A CANA..., 2007)

A cana-de-açúcar é considerada a planta que possui os melhores mecanismos fisiológicos para a produção de sacarose pelo fato de suas vias fotossintetizantes serem mecanismos muito eficientes, os quais, por meio de pesquisas, têm sido melhorados pelo homem, alcançando assim o alto teor de sacarose (TAUPIER, 1990).

Certamente, a cana-de-açúcar é uma das culturas agrícolas mais importantes para os países tropicais gerando milhares de empregos diretos neste setor. Contribui também para o desenvolvimento da região onde se localiza, destacando-se, por exemplo, o interior do estado de São Paulo, principal produtor mundial de cana-de-açúcar com elevados índices de desenvolvimento urbano e renda per capita muito acima da média nacional brasileira.

Devido à grandeza dos números atuais do setor sucroalcooleiro no Brasil, a cana-de-açúcar deixa de ser tratada como mais um produto agrícola, para ser o principal produto, base de todo o agronegócio representado por centenas de usinas de açúcar e álcool. Esse setor brasileiro tem despertado o interesse de vários países, principalmente pelo baixo custo de produção de açúcar e álcool, esse último cada vez mais adquirido pelos países desenvolvidos visando reduzir a emissão de poluentes na atmosfera e a dependência de combustíveis fósseis. 


\subsection{Composição Básica da Cana-de-Açúcar}

Das substâncias contidas no conjunto colmo, folhas e flores, partes estas da cana-de-açúcar, o que mais interessa para uso industrial é a sacarose, um dissacarídeo da fórmula bruta $\mathrm{C}_{12} \mathrm{H}_{22} \mathrm{O}_{11}$. Mostram-se, na Figura 2 as porcentagens contidas, em média, na cana-de-açúcar apresentadas de forma adaptada ao interesse industrial.

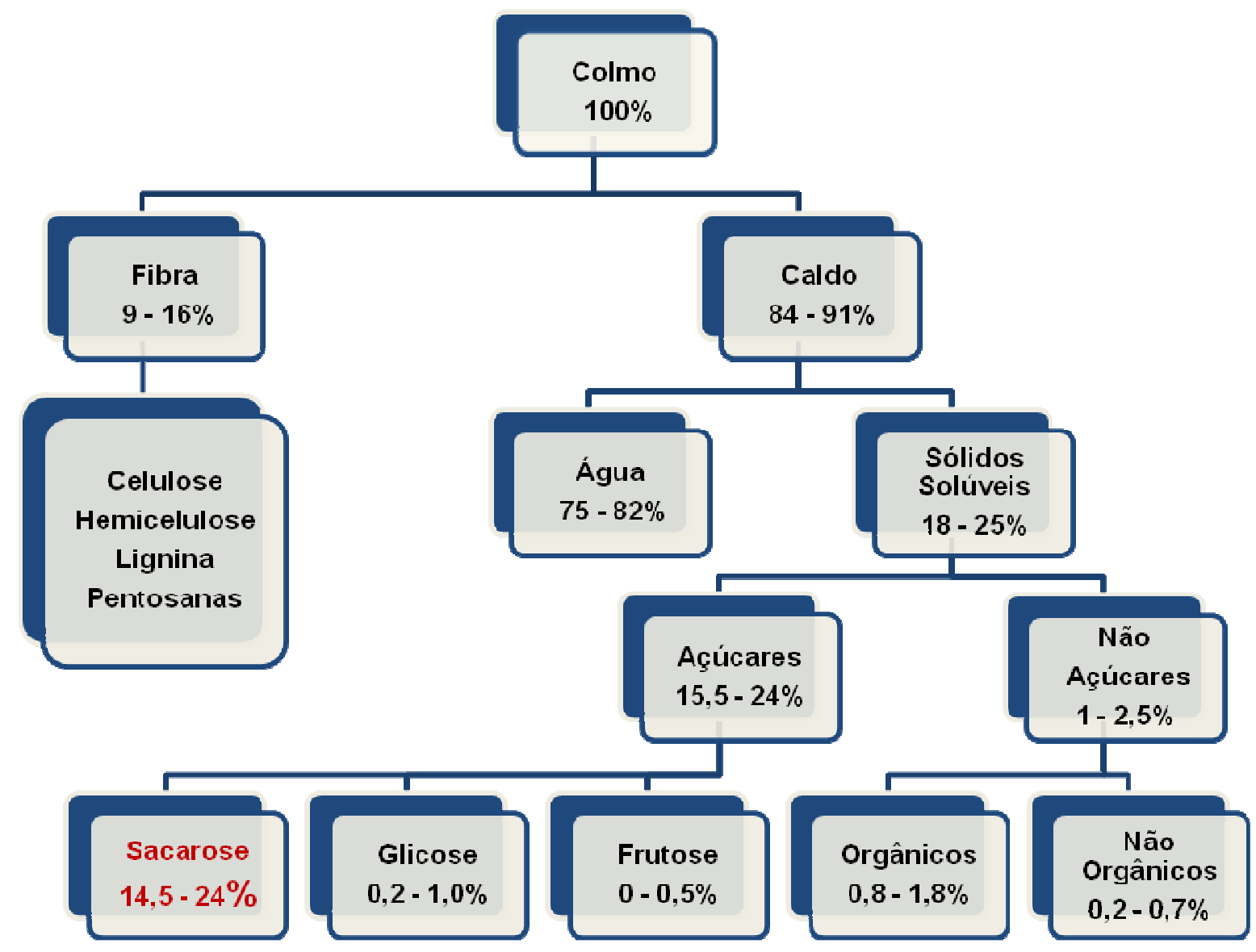

Figura 2: Composição da cana madura.

Os sólidos solúveis são os que, após serem industrializados, irão gerar os açucares sob as mais diversas formas, como por exemplo o VHP (Very Hight Polarization), cristal branco, açúcar líquido, açúcar invertido, etc. Geram também os álcoois cormercializados, como por exemplo o hidratado, anidro, industrial, neutro, etc (HORRI, 2002). 


\subsection{Maturação da Cana-de-Açúcar}

Como já mencionado, de todos os componentes da cana o que mais tem interesse industrial como elemento positivo é a sacarose. Os demais, incluindo os não açúcares, são negativos no interesse industrial. Assim é interessante para fins industriais que a cana-de-açúcar apresente um elevado teor de sacarose. Com isso, o início da colheita é realizado quando a cana entra no seu estado de maturação, ou seja, quando atinge seu máximo teor de sacarose. A cana verde é pobre em sacarose e rica em glicose e frutose e, com o amadurecimento seu teor de sacarose vai aumentando. Ao mesmo tempo os teores de glicose e frutose vão diminuindo. Daí conclui-se que é de máxima importância industrial que o corte se efetue em plena maturação.

O estado de maturação pode ser determinado no campo pelo refratômetro, instrumento que fornece a porcentagem de matéria seca nos caldos e, como a sacarose cresce com a matéria seca durante o amadurecimento, determina-se assim a maturidade com boa precisão. Como a maturação da cana ocorre da base para o ápice do colmo, o critério utilizado para estimar a maturação é o IM (Índice de Maturação), que fornece o quociente da relação:

$$
I M=\frac{\text { Sacarose_ponta_colmo }}{\text { Sacarose_base_colmo }}
$$

Admitem-se para a maturação da cana os estágios apresentados na tabela abaixo:

Tabela 1: Estágios da maturação da cana através do IM.

\begin{tabular}{|c|c|}
\hline IM & Estágio de Maturação \\
\hline \hline$<0,60$ & Cana verde \\
\hline $0,60-0,85$ & Cana em maturação \\
\hline $0,85-1,00$ & Cana madura \\
\hline$>1,00$ & Cana em declínio de maturação \\
\hline
\end{tabular}

A determinação do estágio de maturação da cana, realizado por meio de análises químicas em laboratório, fornece dados mais precisos da maturação, sendo, a rigor, uma confirmação do refratômetro (A CANA..., 2007). 
Após o corte da cana, é de vital importância que ela seja processada o mais breve possível, pois ocorre com o passar do tempo a inversão da sacarose, ou seja, num prazo aproximado de 48 horas, a sacarose contida na cana, por meio da ação de fungos e bactérias, transforma-se em glicose e frutose, havendo assim perdas consideráveis na produção.

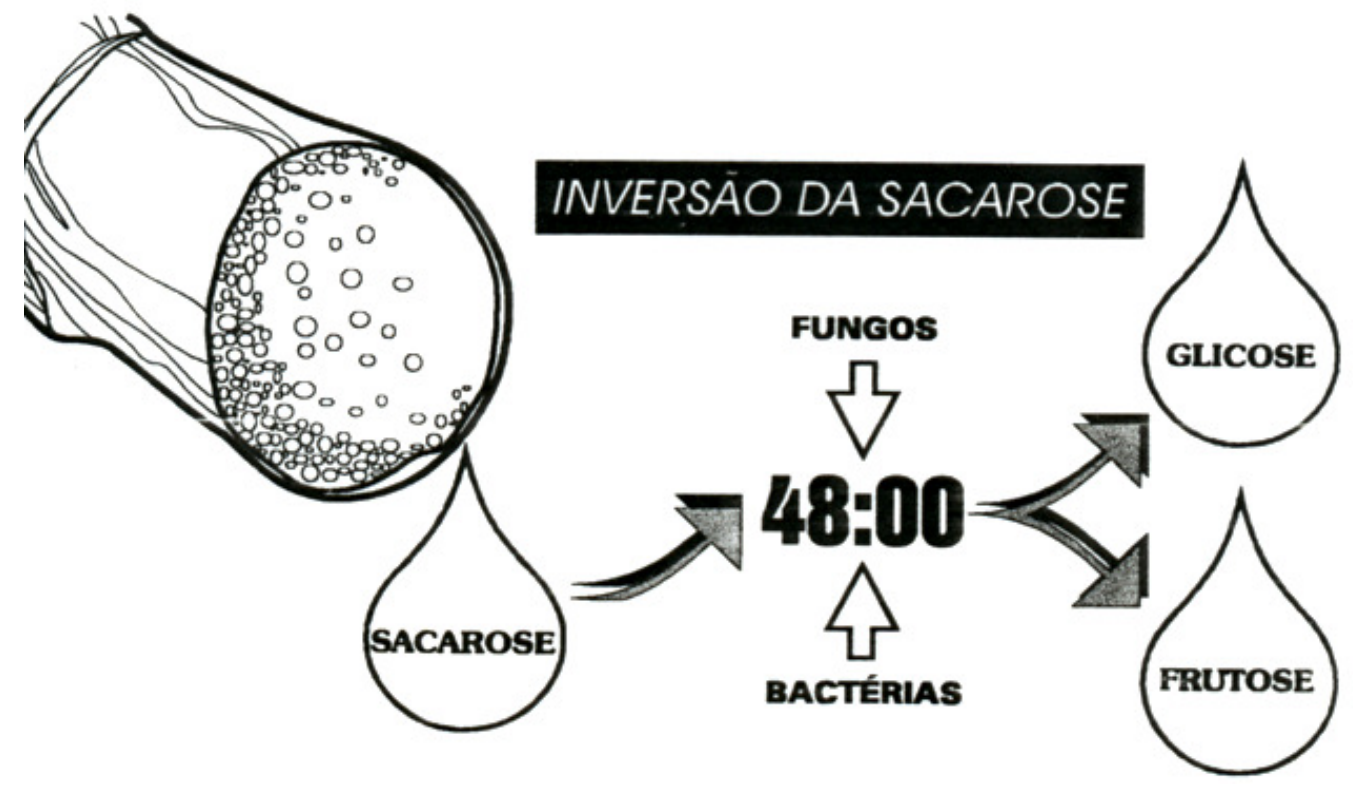

Figura 3: Inversão da sacarose em glicose e frutose. Fonte: (Moendas..., 2002)

\subsection{Mercado Sucroalcooleiro}

A estimativa da produção de cana para a safra 2007/2008, período da realização desta dissertação, é de aproximadamente 528 milhões de toneladas, superando em $11,20 \%$ a safra 2006/2007. A área de plantio da cana nesta safra alcançou os 6,6 milhões de hectares, obtendo um acréscimo de 7,40\% em relação à safra anterior (CONAB 2007/2008). Do total de produção de cana, 87,43\% são produzidas na região Centro-Sul e 12,57\% nas regiões de Norte e Nordeste. Em totais de hectares, $82,49 \%$ estão localizados na região Centro-Sul e, o restante nas regiões Norte e Nordeste (CONAB 2007/2008). Estima-se, para a atual safra, uma produtividade de $80 \mathrm{Kg} / \mathrm{ha} \mathrm{em}$ média e, do total produzido, $88,67 \%$ serão destinados à indústria sucroalcooleira.

Das 468,15 milhões de toneladas de cana que estão sendo processadas nas indústrias, 49,47\% serão destinados a produção de açúcar, totalizando uma produção de 31,31 milhões toneladas. Para a fabricação de álcool, com uma porcentagem de 50,53\%, 
serão produzidos 20,01 bilhões de litros. Tanto na produção de açúcar como na produção de álcool, os valores apresentados são superiores aos da safra anterior, com o açúcar alcançando um acréscimo de 3,60\% que corresponde a 1,09 milhões de toneladas e o álcool um acréscimo de 14,54\% que corresponde a 2,54 bilhões de litros a mais.

O setor sucroalcooleiro está em plena ascensão em função da forte demanda interna e externa, o que é justificado pela expansão da capacidade produtiva existente e pela implantação de novas unidades, bem como, melhoria tecnológica no processo de produção de cana-de-açúcar, tais como: introdução de novas variedades adaptadas ao clima, tipo de solo e sistema de corte (manual e mecânico) e maior uso de irrigação (CONAB..., 2007).

Os dados apresentados acima, e alguns complementos podem, ser visto na tabela 02:

Tabela 2: Estimativa da produção e destino da cana para safra 2007/2008 - Fonte: CONAB.

Estimativa de Produção e Destinação da Cana-de-açúcar para safra 2007/2008 (Ton)

\begin{tabular}{|l|c|c|c|c|}
\hline \multirow{2}{*}{ Região } & \multicolumn{2}{|c|}{ Indústria Sucroalcooleira } & \multirow{2}{*}{ Outros } & \multirow{2}{*}{ Total } \\
\cline { 2 - 3 } & Açúcar & Álcool & & \\
\hline Norte & $197.400,0$ & $939.900,0$ & $193.400,0$ & $1.330 .700,0$ \\
\hline Nordeste & $33.675 .000,0$ & $21.252 .500,0$ & $10.083 .900,0$ & $65.011 .400,0$ \\
\hline Centro-Oeste & $17.241 .800,0$ & $31.269 .700,0$ & $5.032 .700,0$ & $53.544 .200,0$ \\
\hline Sudeste & $159.241 .300,0$ & $162.228 .700,0$ & $39.478 .200,0$ & $360.948 .200,0$ \\
\hline Sul & $21.266 .300,0$ & $20.879 .500,0$ & $5.036 .300,0$ & $47.182 .100,0$ \\
\hline BRASIL & $\mathbf{2 3 1 . 6 2 1 . 8 0 0 , 0}$ & $\mathbf{2 3 6 . 5 7 0 . 3 0 0 , 0}$ & $\mathbf{5 9 . 8 2 4 . 5 0 0 , 0}$ & $\mathbf{5 2 8 . 0 1 6 . 6 0 0 , 0}$ \\
\hline
\end{tabular}




\section{Processo Industrial da Cana-de-Açúcar}

A cana, ao ser colhida, passa por diversas etapas até que se obtenha o produto final desejado, como o açúcar e o álcool. A indústria, a qual utiliza a cana como matéria-prima para obtenção dos produtos citados acima, tratada como Usina de Açúcar e/ou Álcool, é dividida por setores para melhor compreensão do(s) processo(s). Os setores mencionados são: Recepção, preparo e extração (RPE); Geração de energia; Tratamento do caldo; Fabricação do açúcar; Fabricação do álcool.

\subsection{Recepção, Preparo e Extração}

Setor responsável pelo controle da entrada da cana na usina até o final da moagem da cana, gerando o caldo e o bagaço. O esquema deste setor pode ser visto na Figura 4.

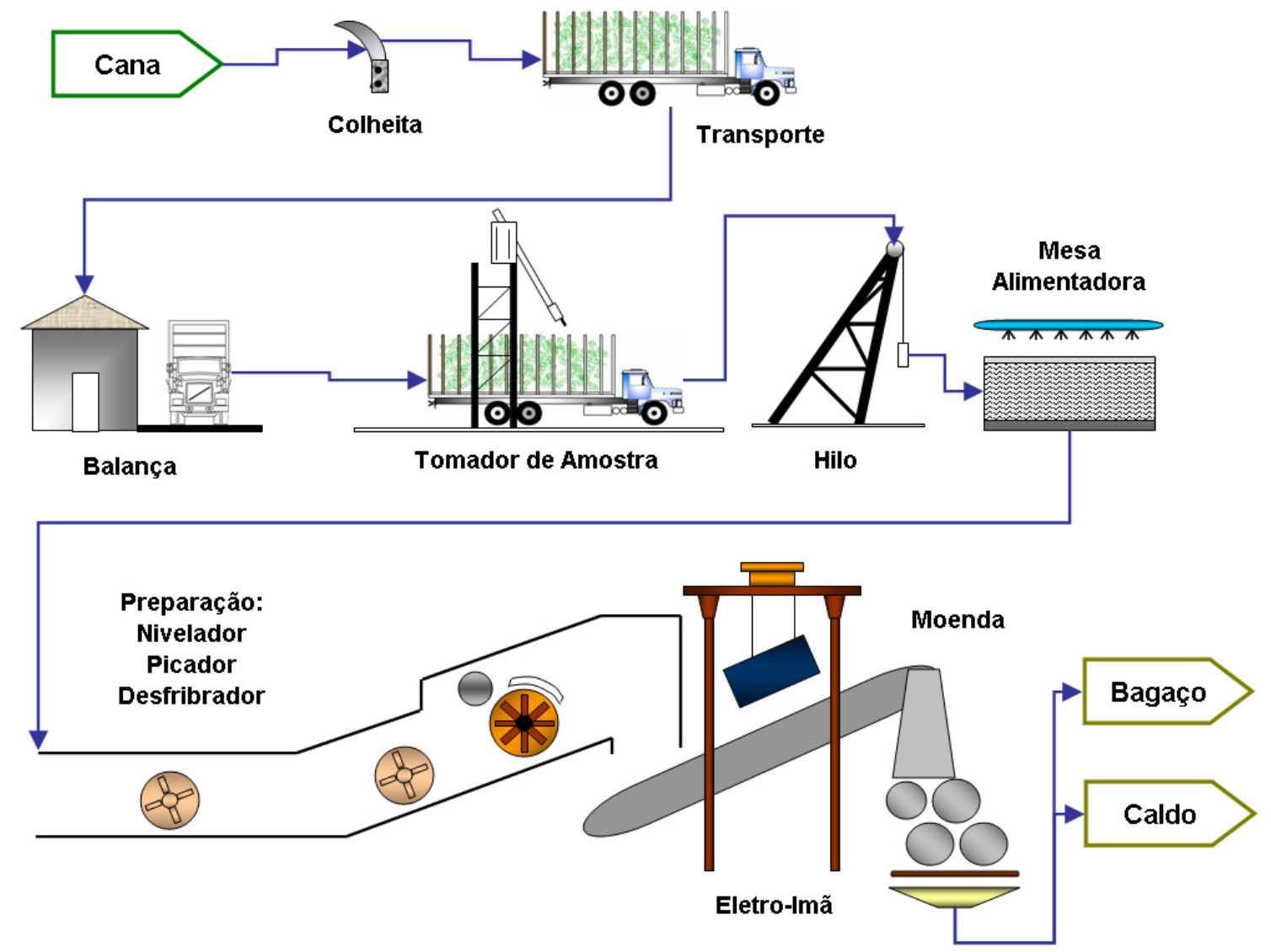

Figura 4: Esquema do processo de recepção, preparo e extração. 


\subsubsection{Colheita}

O corte da cana deve ser rente ao solo, desprezando as raízes. No Brasil o corte predominante ainda é o manual, onde se obtém um rendimento aproximado de 5 a 6 Ton/Homem/Dia.

O corte manual é executado com o auxílio de um facão com formato especial, que permite a rápida retirada da palha. $\mathrm{O}$ corte pode ser executado individualmente ou em turmas e, seu pagamento é executado na grande maioria dos casos por tonelada de cana cortada (JÚNIOR; BORGES, 1965). O fato de o corte de cana ser, ainda, predominantemente manual está atrelado, além do fator sócio-econômico, ao fato de que a grande maioria da área de plantio de cana possui inclinação aquém do permitido pela colhedeira mecânica. Com novas tecnologias das colhedeiras, permitindo o corte em locais com inclinação maior do que as atuais e a preparação das áreas de plantio para esse tipo de colheita o corte mecanizado alcançará porcentagens bem maiores das atuais, que hoje está em torno de $20-30 \%$. A Figura 5 mostra um exemplo de colheita manual de cana.

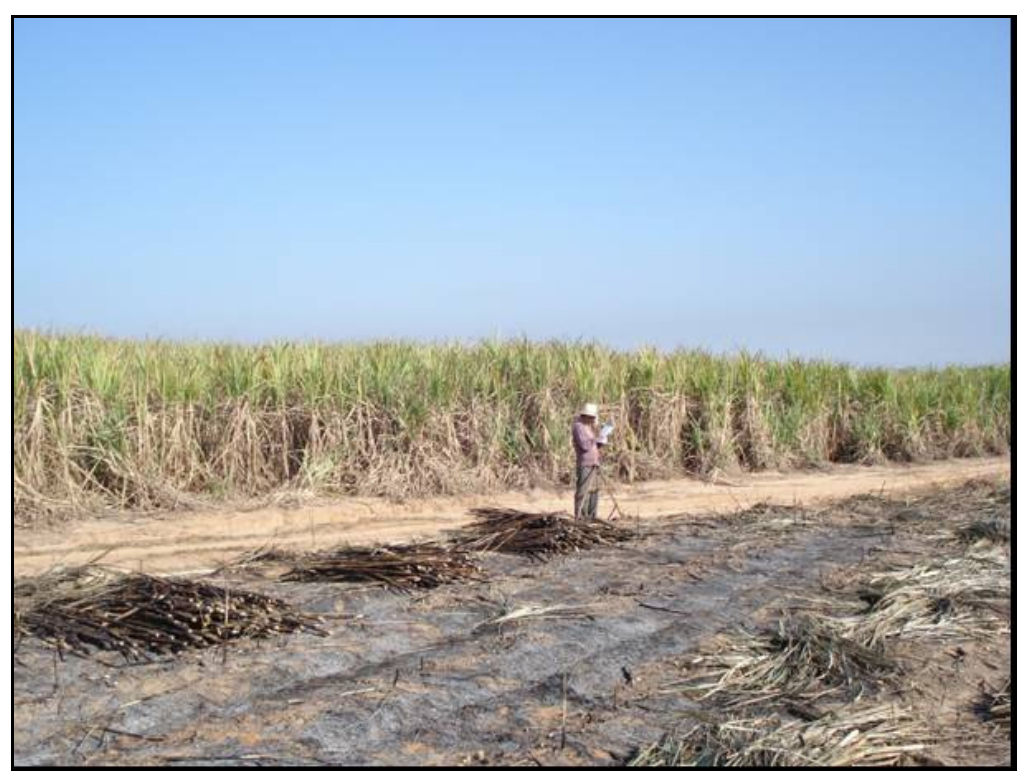

Figura 5: Exemplo de colheita manual de cana, mostrando o trabalhador e a maneira de disposição da cana no solo.

A colheita mecanizada, como citada anteriormente, é executada por máquinas próprias para tal função, as colhedeiras, sendo que as mais recentes possuem uma capacidade em torno de 1500 - 2000 Ton/cana/dia. A colhedeira possui um sistema com dois eixos cônicos com a função de levantar as canas para que possam ser cortadas, logo 
em seguida, por um sistema de discos dotados de facas localizados na parte inferior da máquina. Após o corte da cana, a mesma é transportada por meio de rolos a um cesto no centro da máquina. Nesse caminho a cana é picada com tamanhos de aproximadamente $20 \mathrm{~cm}$ de comprimento. Acima do cesto há um sistema de exaustão para as palhas. A cana é levada por uma esteira para um segundo sistema de exaustão localizado na parte superior e, logo após é descarregada no transbordo que irá alimentar os caminhões de cana. A Figura 6 mostra um exemplo da colhedeira de cana em atividade no campo.

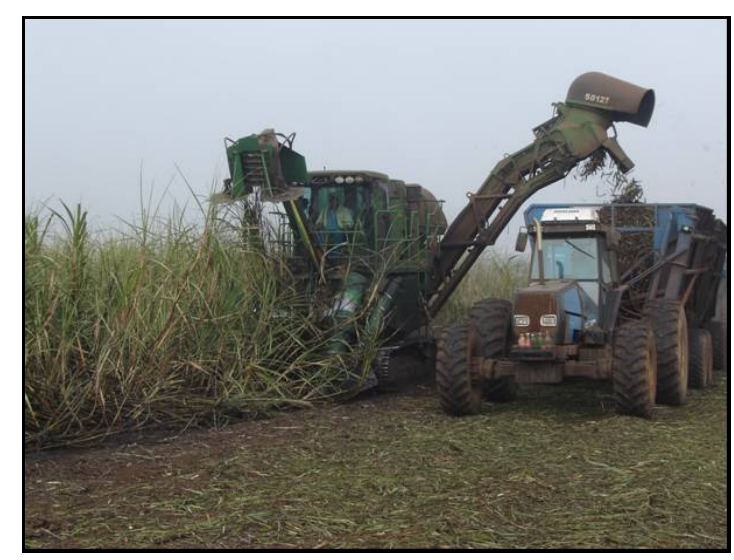

(a) Em ação colhendo e descarregando

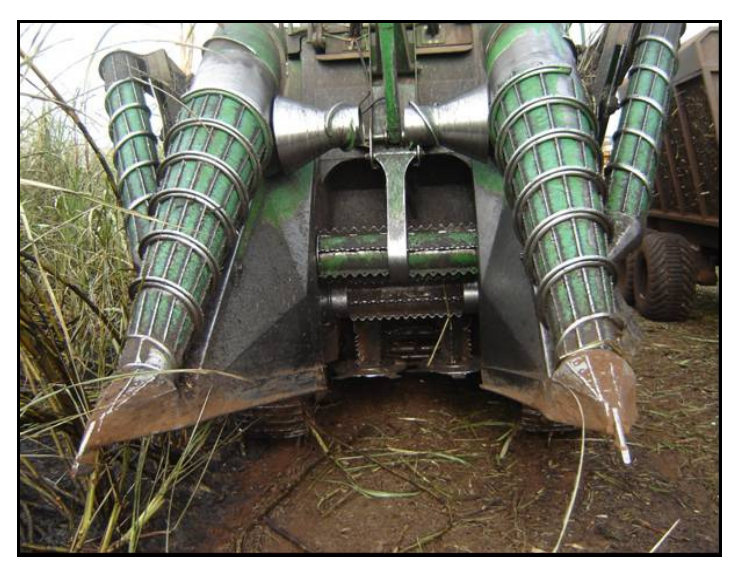

(b) Detalhe da frente à máquina

Figura 6: Colhedeira mecânica em atividade.

\subsubsection{Transporte}

Após seu corte, a cana deve ser imediatamente transportada para a moagem para que não ocorra a inversão de sacarose já citada anteriormente. Assim, a rapidez no transporte da cana é de grande importância, tanto quanto outros, no processo de fabricação de açúcar e/ou de álcool. Em Operação...(1991), destaca-se que o sistema de transporte adotado deve ser eficiente, sem que haja ociosidade de equipamentos e parada da indústria por falta de matéria-prima, uma vez que qualquer interrupção no fornecimento acarretará em transtornos no processo de obtenção do açúcar e ou do álcool e perdas de eficiência da indústria.

O fornecimento de cana para o processo deve ser ininterrupto, contudo seu transporte poderá ocorrer somente em um período, necessitando assim de um maior número de equipamentos para tal função. Já o transporte realizado continuadamente por 24 horas não necessitará do mesmo número de equipamentos. Para tal função, em contrapartida, seus equipamentos estão sujeitos a um maior de desgaste e quebras. 
O transporte da cana no Brasil é executado em sua maioria pelo sistema rodoviário, com emprego de caminhões de cana inteira ou picada com diferentes configurações: caminhão simples, "trucado" (caminhão com o cavalo e a carroceria juntos), caminhão trucado com um reboque (Romeu e Julieta), caminhão trucado com dois reboques (treminhões), cavalo mecânico com dois reboques (rodotrem) e outros. A Figura 7 mostra um exemplo de caminhão trucado para transporte de cana.

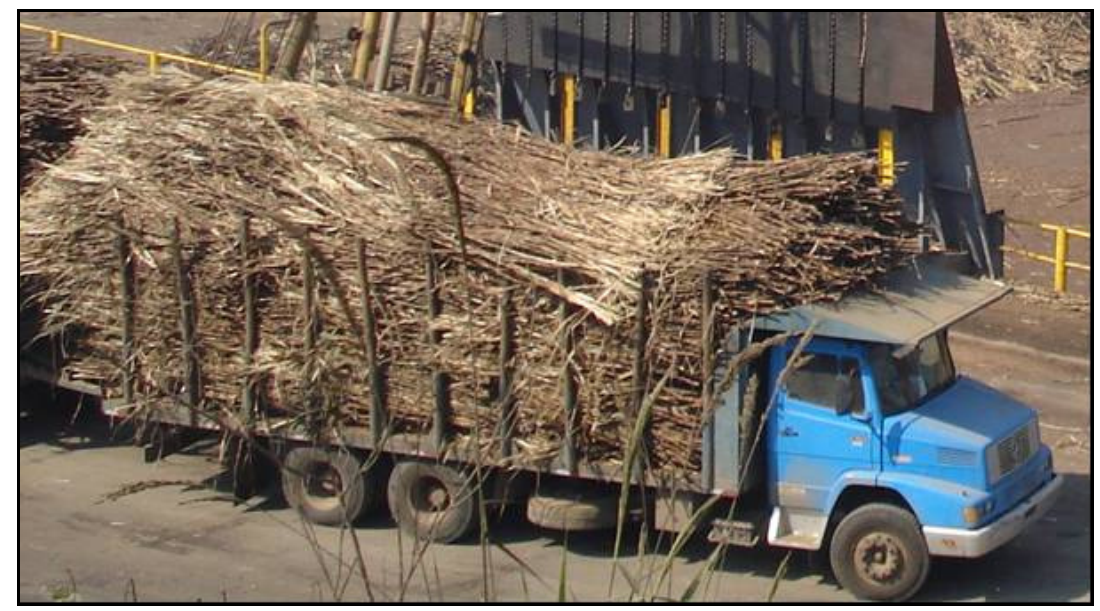

Figura 7: Exemplo de caminhão trucado para transporte de cana em uma usina.

A capacidade aproximada de carga dos caminhões é apresentada na Tabela 03, sendo que a mesma dependente do tipo de carregamento, estado, variedade e arranjo da cana.

Tabela 3: Capacidade de carga dos caminhões para transporte da cana.

\begin{tabular}{|l|c|}
\hline \multicolumn{1}{|c|}{ Tipo de Veículo } & Capacidade (TON) \\
\hline \hline Caminhão Simples & $10-13$ \\
\hline Caminhão Trucado & $13-20$ \\
\hline Romeu e Julieta & $30-40$ \\
\hline Treminhão & $40-50$ \\
\hline
\end{tabular}

\subsubsection{Pesagem}

Os caminhões que transportam a cana colhida são, antes de entrarem na usina e ao saírem, pesados com o propósito de quantificar a matéria-prima recebida para, assim, 
efetuar o pagamento da cana, calcular o rendimento global dos equipamentos da usina e quantificar as perdas, entre outros.

\subsubsection{Amostra}

Em alguns caminhões são retiradas, dentro de um sistema preestabelecido pela indústria, amostras da matéria-prima. Essas amostras são retiradas por equipamentos chamados "Tomadores de Amostras", que pode ser do tipo horizontal ou oblíquo, sendo estes os mais utilizados atualmente. Toda amostra retirada pelo tomador de amostra é encaminhado para o laboratório de recepção de cana que fica, geralmente, localizado ao lado do tomador de amostra. É nesse laboratório que são feitas as análises para o pagamento da cana de acordo com o cálculo do ATR (Açucares Totais Recuperáveis), segundo normas da Consecana (BURNQUIST, 1999). A Figura 8 mostra um exemplo de tomador de amostra em uma usina.

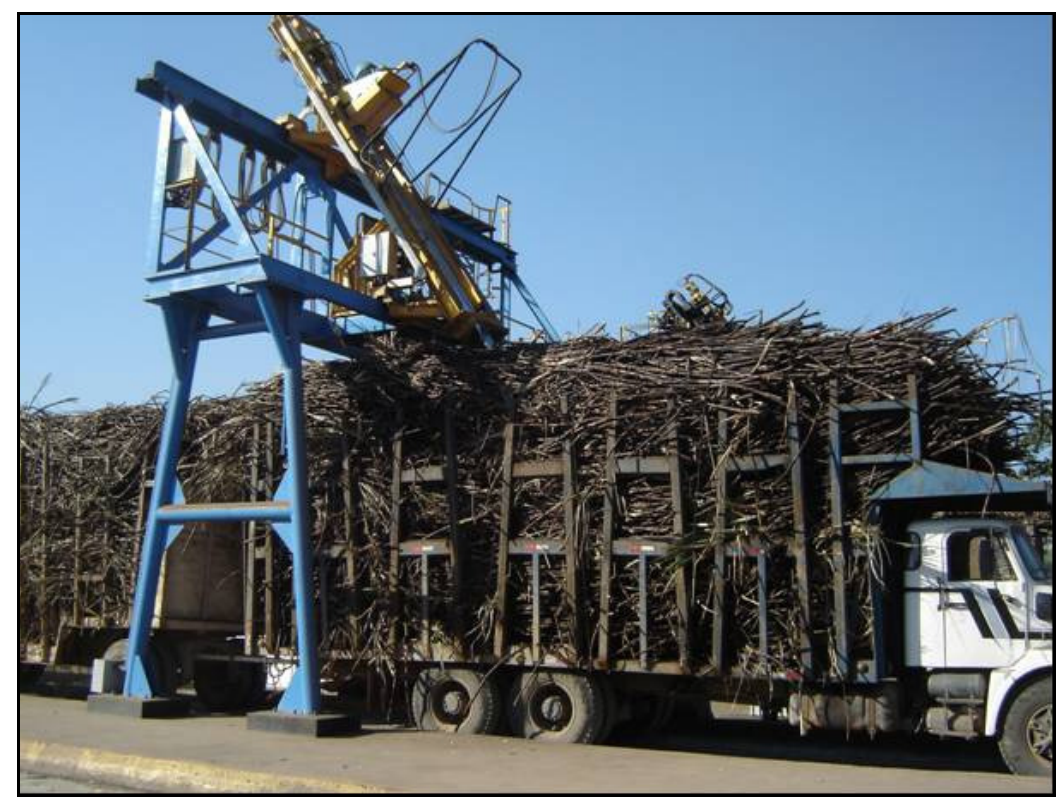

Figura 8: Tomador de amostra oblíquo em uma usina.

\subsubsection{Descarregamento}

A cana, após passar pelo tomador de amostra, pode ser descarrega no sistema de alimentação, para dar continuidade ao processo ou, pode ser estocada em pátios ou barracões. 
Quando estocadas, a cana requer um espaço relativamente grande, pois é uma matéria de densidade baixa. Os pátios são áreas a céu aberto e os barracões são construídos de alvenarias ou estruturas metálicas, providos de telhados e pontes rolantes para o descarregamento da cana. Para o descarregamento da cana, o sistema predominante nas usinas é um hilo mecânico, simples e fácil de operar. O hilo possui uma estrutura tubular ou de perfis laminados, que sustenta um sistema de cabos com polias. Estas movimentam uma viga horizontal dotada de ganchos, num movimento ascendente e descendente. $\mathrm{O}$ hilo pode ser utilizado para descarga de cana picada ou cana inteira, em pátios ou diretamente no sistema de alimentação. Possui altura entre $13-16 \mathrm{~m}$ e capacidade de carga que varia de 20 - 50 Ton. A Figura 9 mostra um esquema de um hilo mecânico.

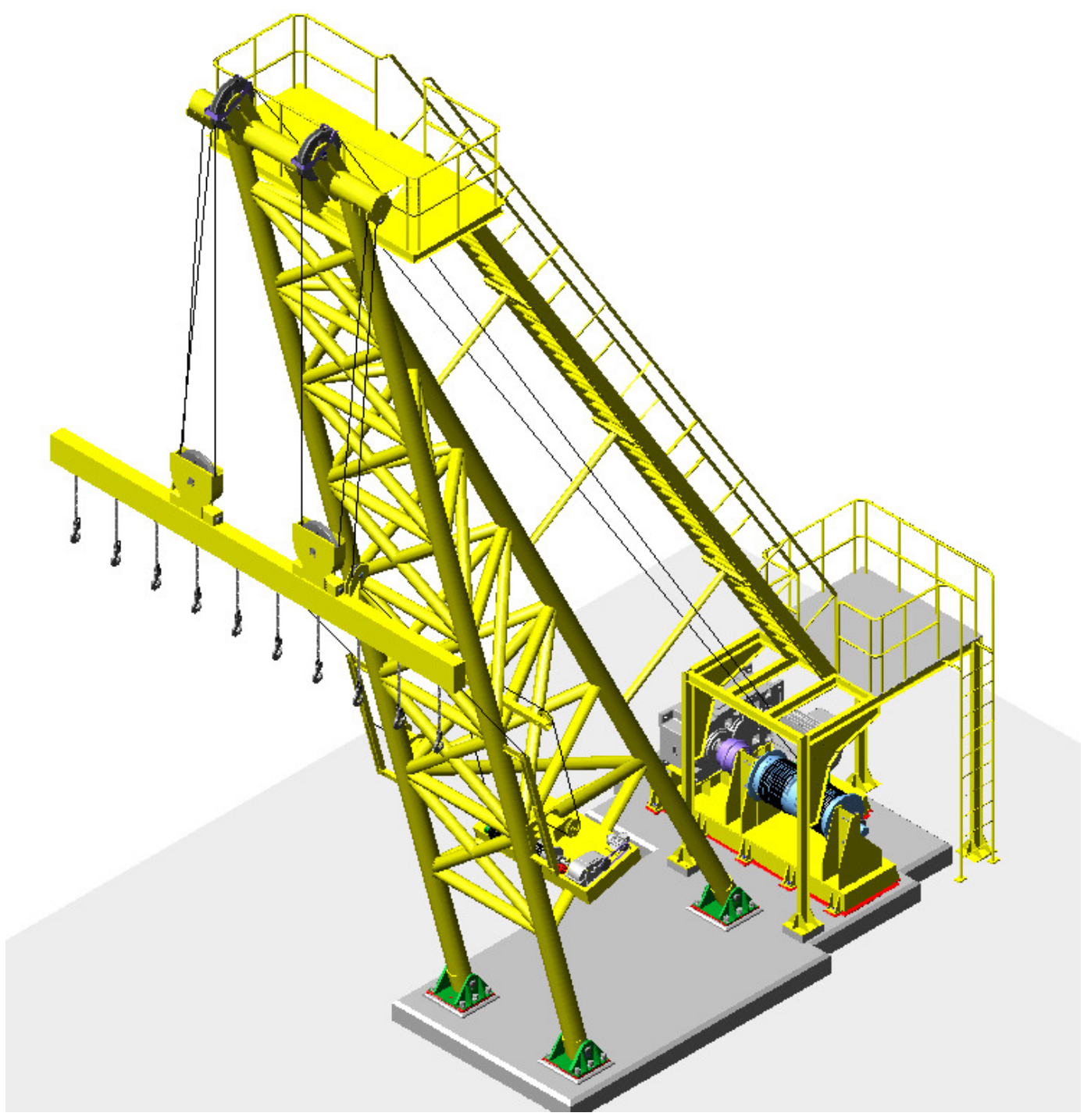

Figura 9: Esquema de um hilo mecânico. 


\subsubsection{Alimentação}

A cana recebida pela usina deve ser conduzida às moendas, passando pelo setor de preparação. A alimentação de cana deve conter um sistema confiável, que propicie uma alimentação continua e uniforme, sem interrupções, pois estes são fatores preponderantes para um bom desempenho e elevado nível de extração das moendas. A interligação da cana até as moendas é feita pelo descarregamento da mesma nas mesas alimentadoras e posterior condução da cana pela esteira.

A mesa alimentadora é um equipamento que tem a função de receber a cana dos caminhões, ou das áreas de estocagem, e fazer uma alimentação uniforme das esteiras de cana. A Figura 10 mostra um esquema de uma mesa alimentadora.

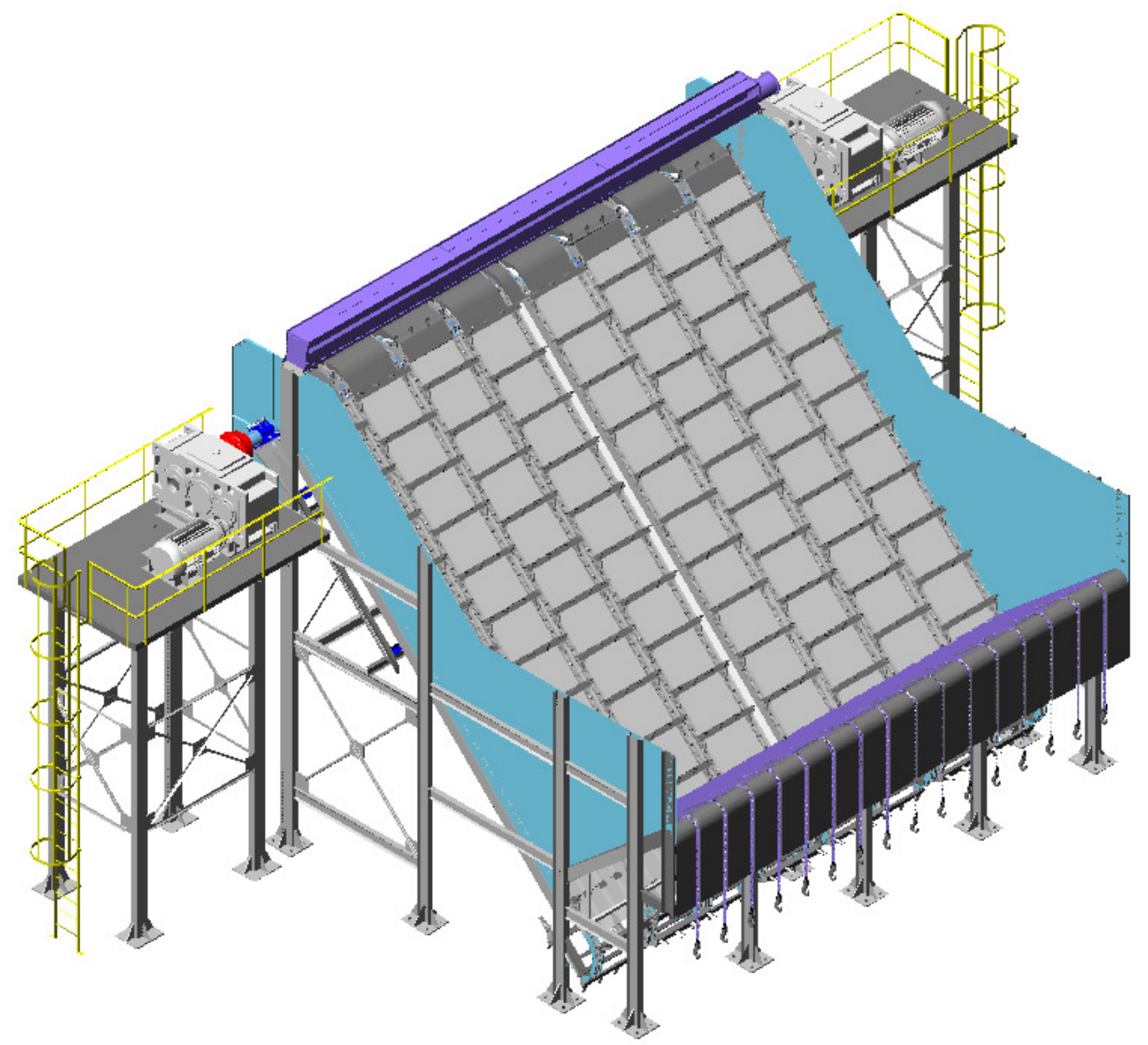

Figura 10: Esquema de uma mesa alimentadora inclinada a $45^{\circ}$.

Outra função importante da mesa alimentadora é propiciar a lavagem da cana usando um tubo perfurado, posicionado transversalmente a mesa, em sua parte superior. 
Essa lavagem tem como finalidade retirar a terra e a areia, para obter um caldo de melhor qualidade e evitar desgastes excessivos nos equipamentos (PRODUÇÃO..., 2002, p.02). As mesas alimentadoras podem ser classificadas como mesas convencionais, que possuem uma inclinação de até $18^{\circ}$, e mesas de $45^{\circ}$, cuja inclinação é correspondente ao seu nome. Atualmente são utilizadas apenas as mesas alimentadoras com inclinação de $45^{\circ}$, pois propiciam uma alimentação mais uniforme, eficiente e de fácil controle. A lavagem da cana nessa mesa é efetuada com mais eficiência do que nas mesas alimentadoras convencionais (OPERAÇÃO..., 1999, p.25).

Após a descarga nas mesas alimentadoras, a cana é conduzida pela "esteira de cana" para o setor de preparação e extração. A esteira de cana é um transportador metálico, fechado lateralmente com chapas de aço, sendo o fundo constituído de taliscas presas a correntes que se movem juntas. A velocidade da esteira de cana deve ser variável, pois deve se observar variações no processo de produção, assim como irregularidades na alimentação da cana (MOENDAS..., 2002, p.26). Como detalhado em Hugot (1969), a esteira possui uma parte plana onde está localizada a mesa alimentadora e outra parte inclinada. A inclinação da esteira varia entre $15^{\circ}$ e $22^{\circ}$. A Figura 11 mostra um esquema de uma esteira metálica.

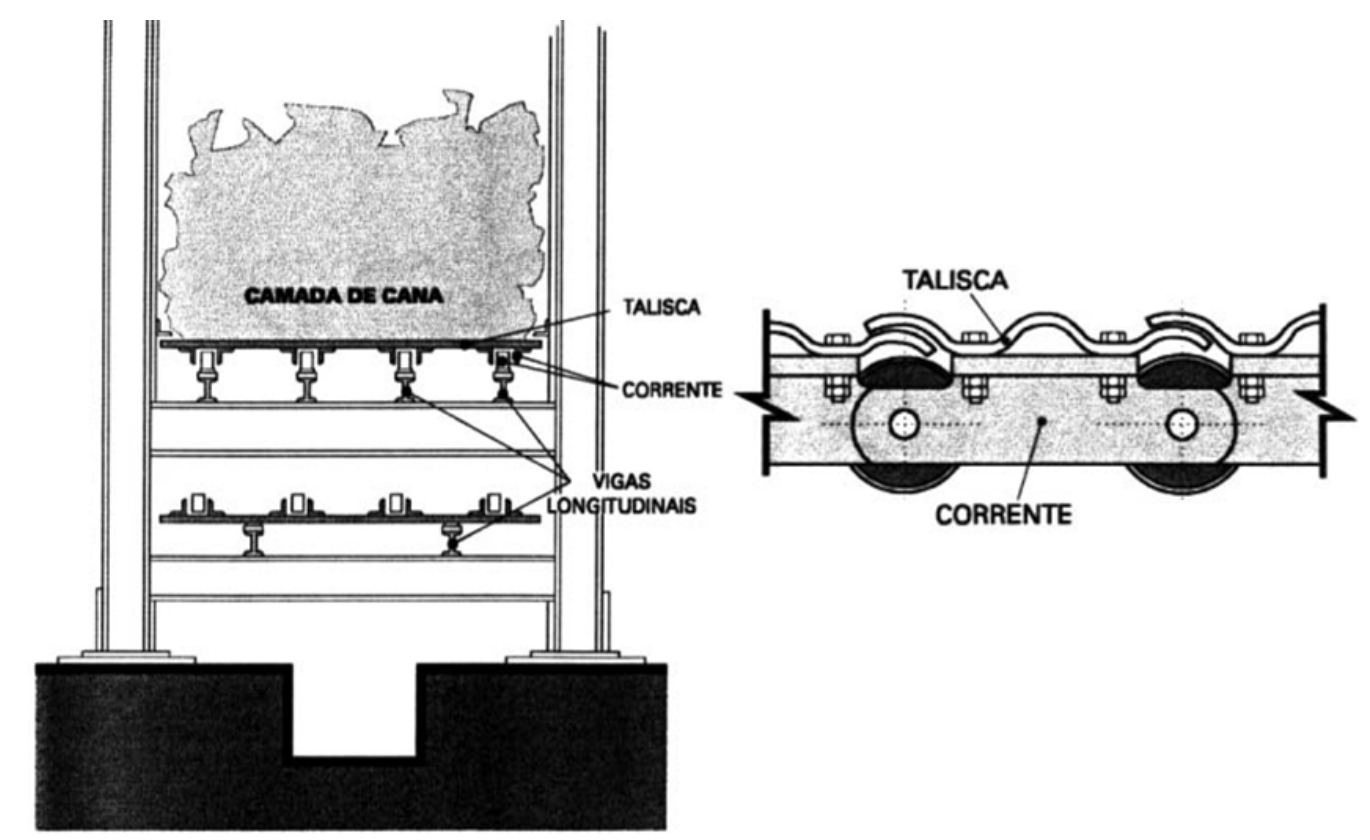

Figura 11: Esquema de uma esteira metálica utilizada para a condução de cana. Fonte: (Moendas..., 2002). 


\subsubsection{Preparação}

O processo de reduzir a cana em pedaços menores e posteriormente desfibrar estes pequenos pedaços para a operação de moagem recebe o nome de "Preparação". A preparação da cana é geralmente efetuada por picadores e desfibradores, entretanto, podem haver outros equipamentos para o auxílio do processo de preparação como os niveladores e espalhadores. A eficiência da operação de extração depende fundamentalmente de uma boa preparação da cana (REIN, 2007). A preparação tem como objetivo aumentar o poder de empacotamento da cana e realizar o máximo de rompimento das células para facilitar a extração do caldo. A densidade do empacotamento da cana desfibrada assume valores da ordem de $550 \mathrm{Kg} / \mathrm{m}^{3}$ contra 175 $\mathrm{Kg} / \mathrm{m}^{3}$ da cana inteira.

Os principais equipamentos de preparo são: niveladores, picadores, desfibradores e espalhadores. Os niveladores são usados para altas moagens (acima de $500 \mathrm{TCH}$ ) e tem a finalidade de produzir uma altura constante do colchão de cana na esteira metálica para o picador e o desfibrador. O nivelador consiste em um eixo robusto colocado transversalmente (ao movimento da) à esteira metálica, no qual são montados os suportes que sustentam as lâminas oscilantes ou fixas. Esse conjunto recebe o nome de rotor e gira sobre mancais de rolamento com uma velocidade periférica entre 50 e 60 $\mathrm{m} / \mathrm{s}$. A Figura 12 mostra um esquema de um nivelador/picador.

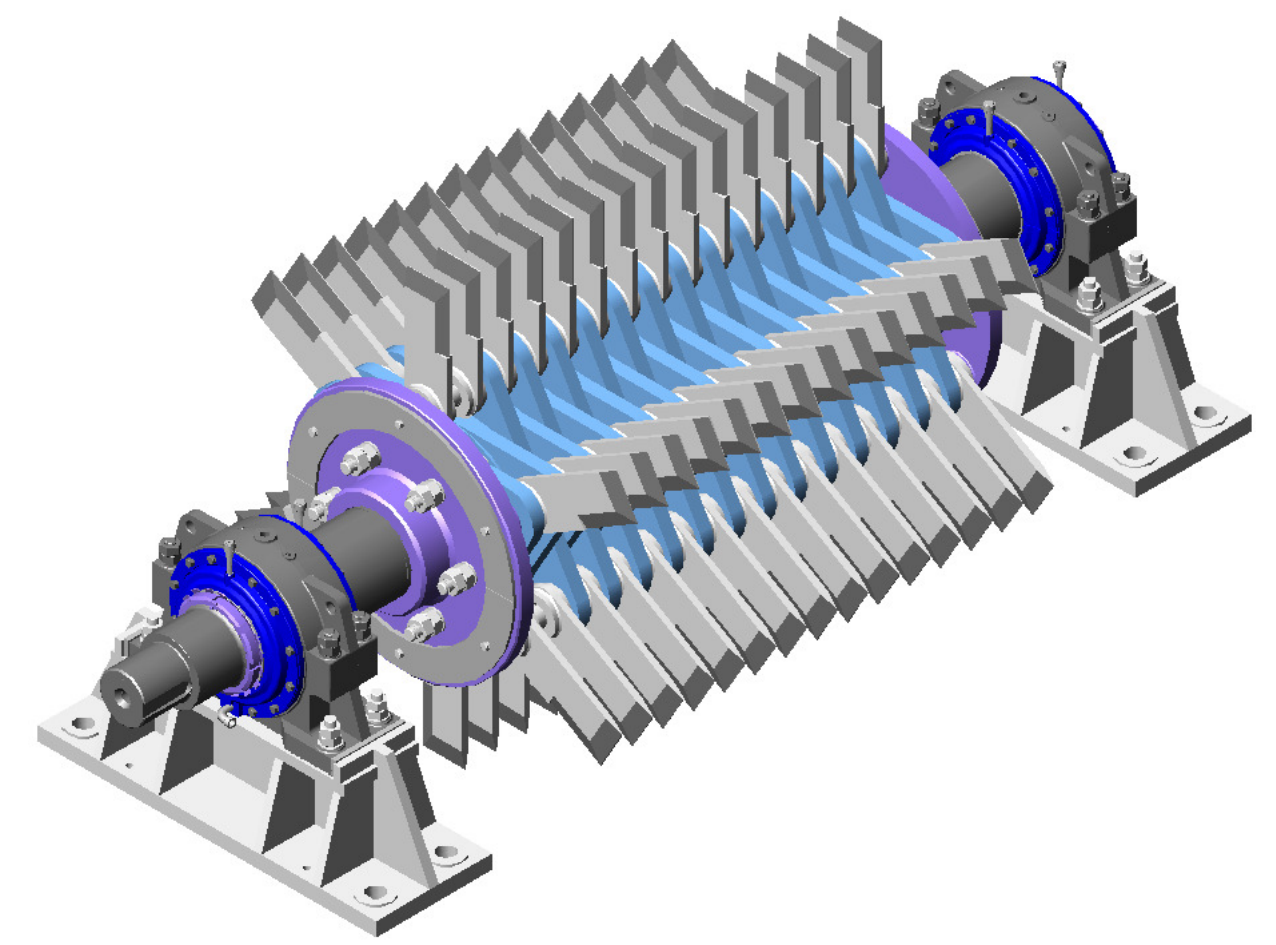

Figura 12: Esquema de um nivelador/picador de lâminas oscilantes (DEDINI, 2007). 
O picador tem a função de fragmentar a cana sem extrair o caldo, executando assim um semi-preparo para a alimentação dos desfibradores (JÚNIOR; BORGES, 1965). Sua construção é igual ao do nivelador diferenciando apenas a altura de trabalho em relação à esteira metálica; o picador trabalha mais próximo à superfície da esteira de cana.

O desfibrador é um equipamento utilizado no preparo da cana, cujo objetivo é desintegrar por completo a estrutura do colmo da cana (LOPES, 1986). Assim como os niveladores e picadores, os desfibradores são constituídos de um eixo robusto onde são montados os suportes, ao qual são fixados os martelos. Realiza o desfibramento da cana ao esfregá-la contra uma placa de aço denominada placa desfibradora que é fixada logo acima do rotor, de formato curvo acompanhando o giro do diâmetro dos martelos. Possui ainda em sua configuração o tambor alimentador que força a passagem de cana entre os martelos e a placa desfibradora. A Figura 13 mostra um esquema de um desfibrador.

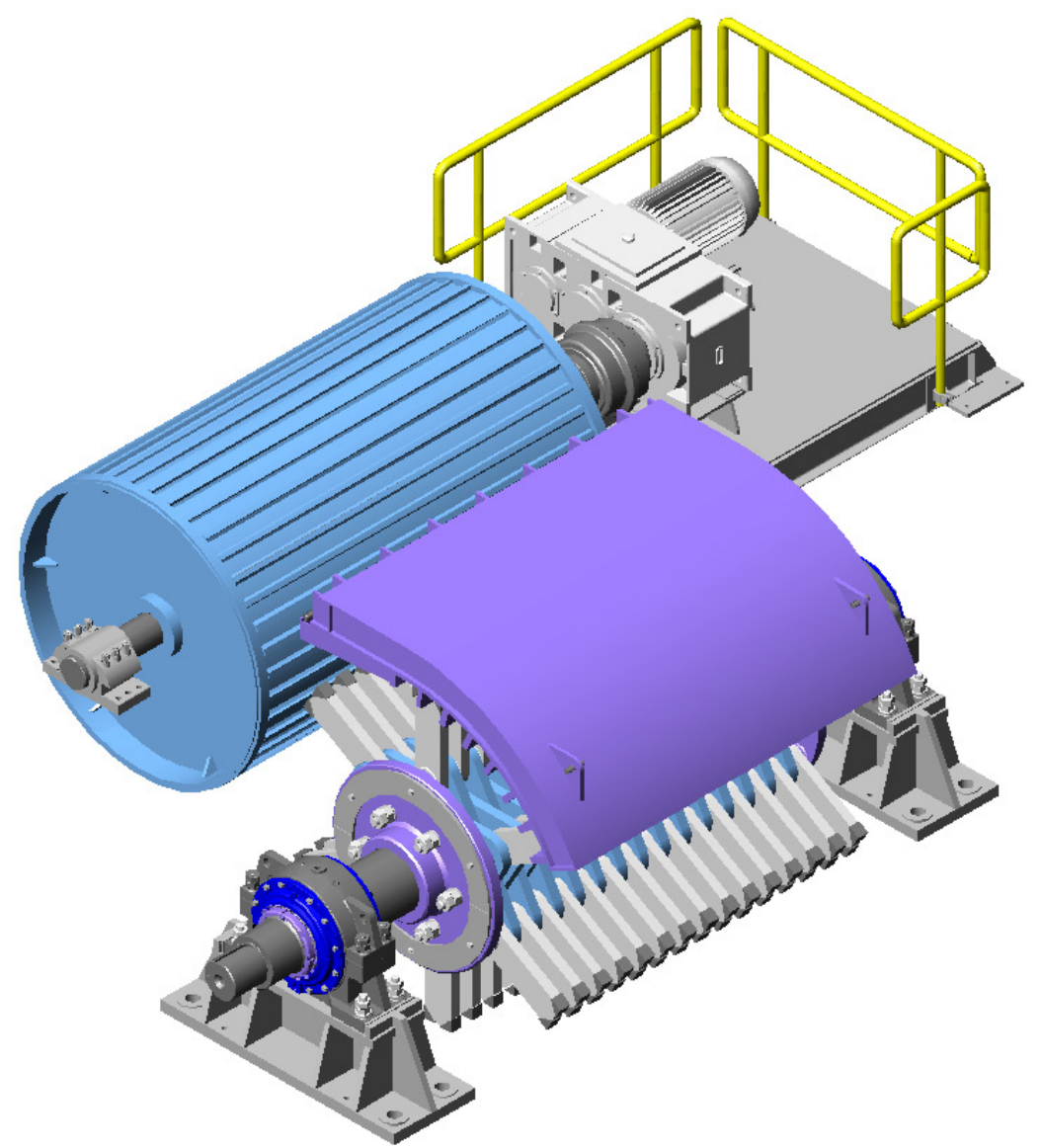

Figura 13: Esquema de um desfibrador, tambor alimentador e placa desfibradora (DEDINI, 2007). 
O espalhador tem a função de descompactar a cana desfibrada que sai do desfibrador na forma de "pacotes". Está descompactação é necessária para obter uma camada mais fina e uniforme para a correia transportadora de cana desfibrada, facilitando assim o trabalho do eletroímã e a alimentação para a moagem (D'AVILA, 2003). A Figura 14 mostra um esquema de um espalhador.

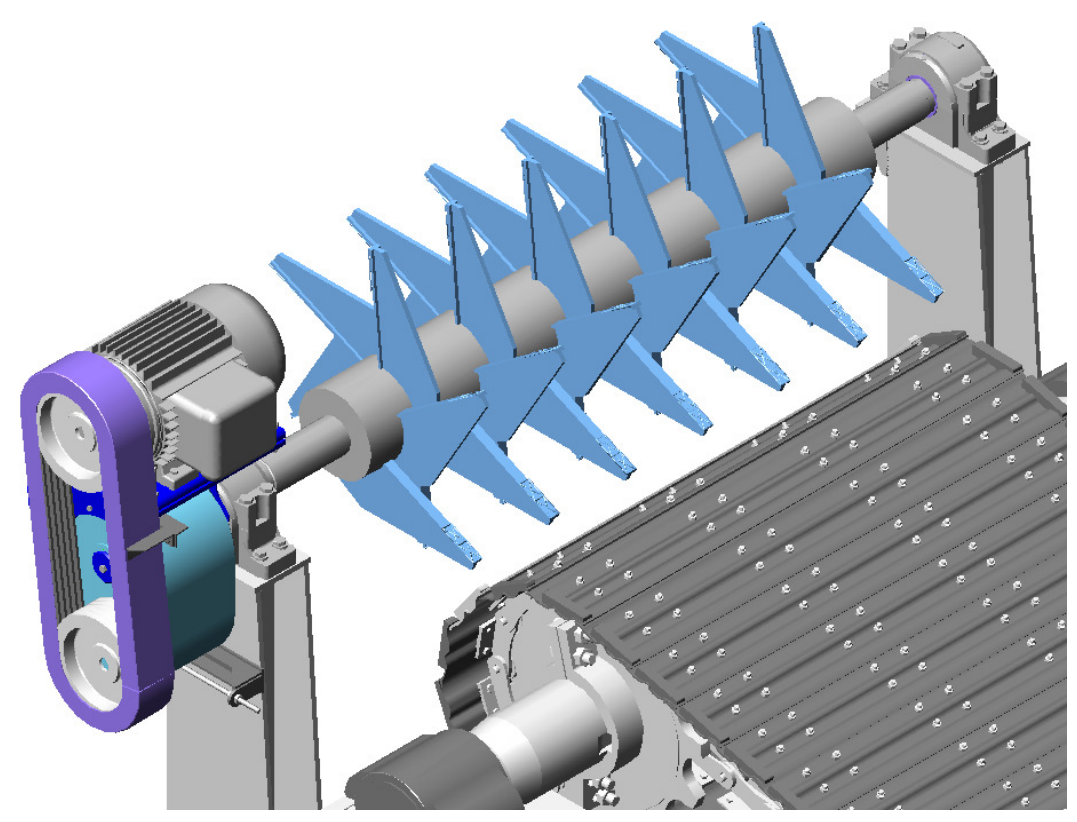

Figura 14: Esquema de um espalhador. (DEDINI, 2007).

\subsubsection{Eletroímã}

Este equipamento é utilizado para remoção de materiais ferrosos que eventualmente estejam presente na cana desfibrada. É localizado sobre a correia transportadora de cana e sua largura deve ser maior que a correia transportadora para garantir a ação do campo magnético (I SEMINÀRIO..., 1983, pg 88).

\subsubsection{Moagem}

A operação de moagem tem o objetivo principal de extrair o máximo de caldo contido na cana por meio de sucessivos esmagamentos da camada de cana preparada. $\mathrm{O}$ esmagamento dessa camada se dá pelos "ternos de moendas", equipamento que possui três principais rolos esmagadores dispostos de forma a permitir tal esmagamento. Outro 
objetivo da moagem é a produção de um bagaço final em condições favoráveis a uma queima eficiente nas caldeiras. Além do esmagamento, é necessário também que haja um sistema de embebição eficiente. A Figura 15 mostra um esquema de um terno de moenda.

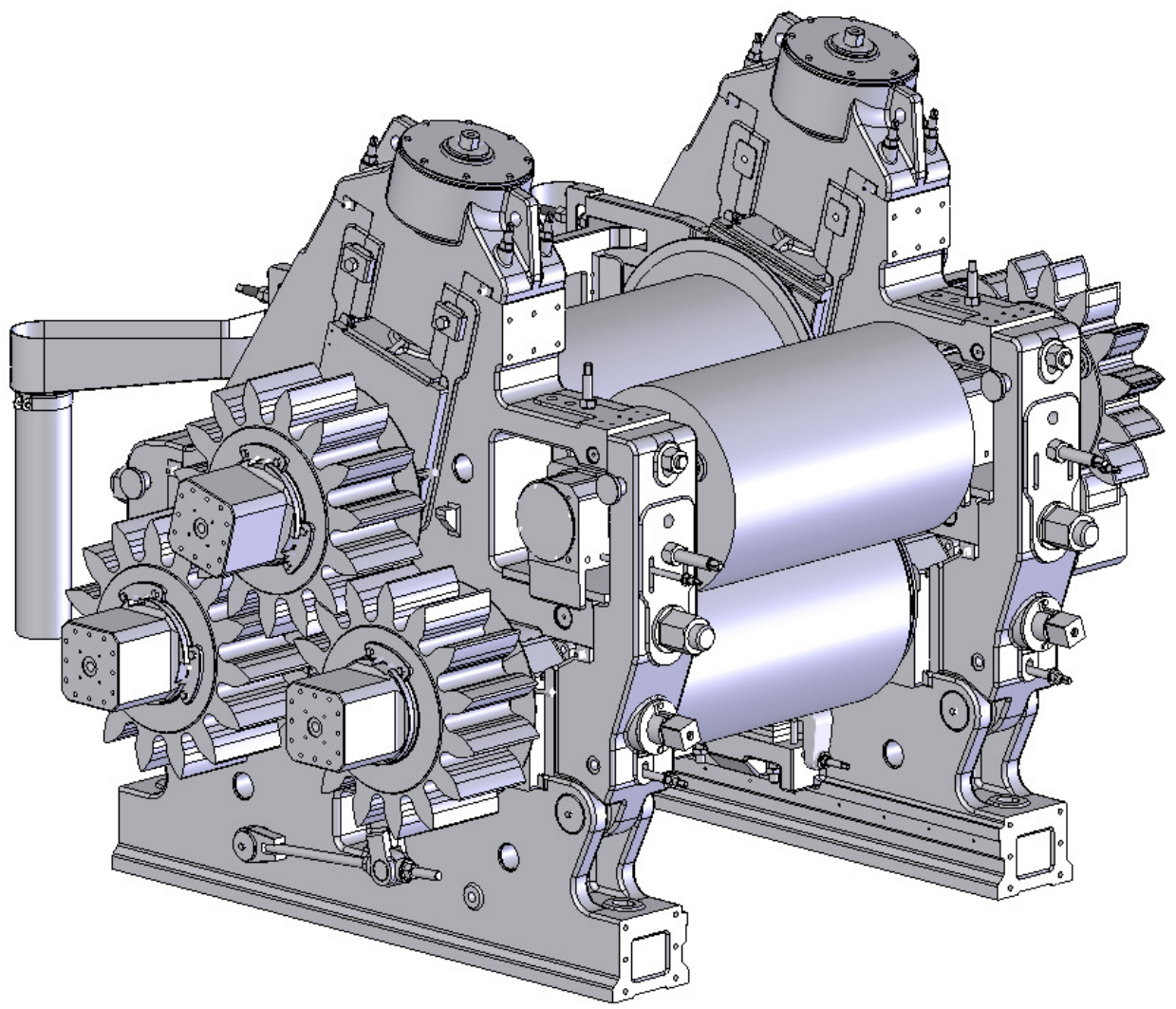

Figura 15: Esquema de um terno de moenda (DEDINI, 2007)

A chamada Embebição é um artifício de adição de água ou caldo diluído ao bagaço sob a forma de aspersão, jatos fortes ou lençol de água, com a finalidade de diluir o caldo remanescente no bagaço, aumentando a extração de sacarose. A embebição pode ser simples devido à utilização apenas de água como agente de diluição, ou embebição composta. O processo mais utilizado é a composta. Neste tipo de embebição, a água é adicionada entre os dois últimos ternos e o caldo extraído destes é enviado para o terno anterior e assim sucessivamente até o segundo terno. O caldo do segundo terno é misturado ao caldo do primeiro terno (caldo primário), constituindo o caldo misto. Utilizando a embebição é possível obter uma extração de 94 a 97\%, com uma umidade final do bagaço de aproximadamente 50\% (LOPES, 1986). A Figura 16 mostra um esquema de um sistema de embebição composta. 


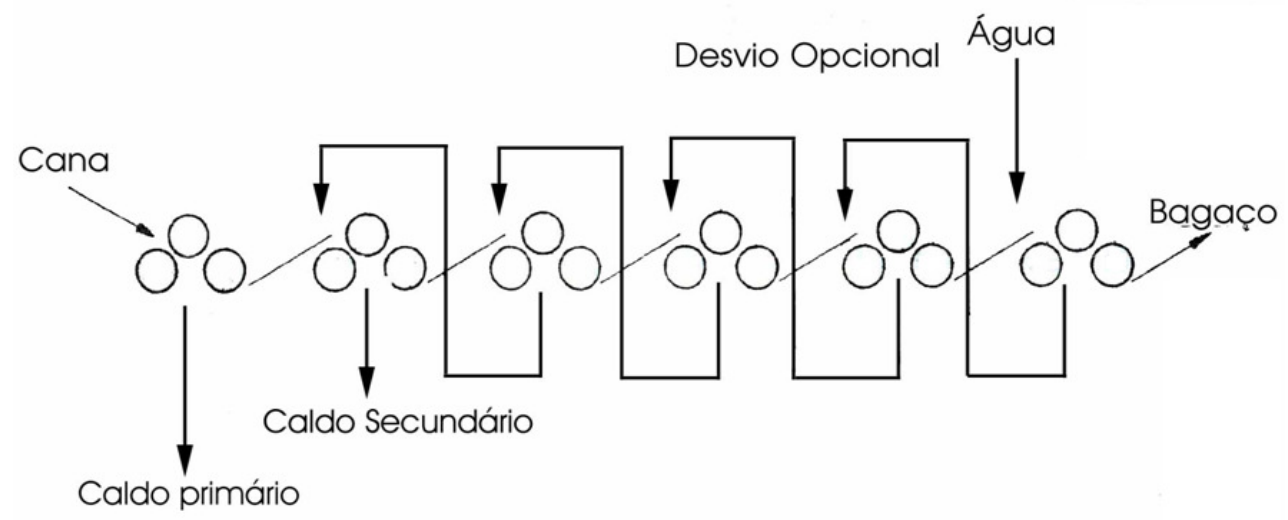

Figura 16: Esquema de embebição composta (MOENDAS, 2002).

\subsection{Geração de Energia}

Setor responsável por transformar o resíduo da operação de moagem em energia para o consumo dos equipamentos do processo de fabricação do açúcar e álcool. A Figura 17 mostra o esquema da geração de energia.

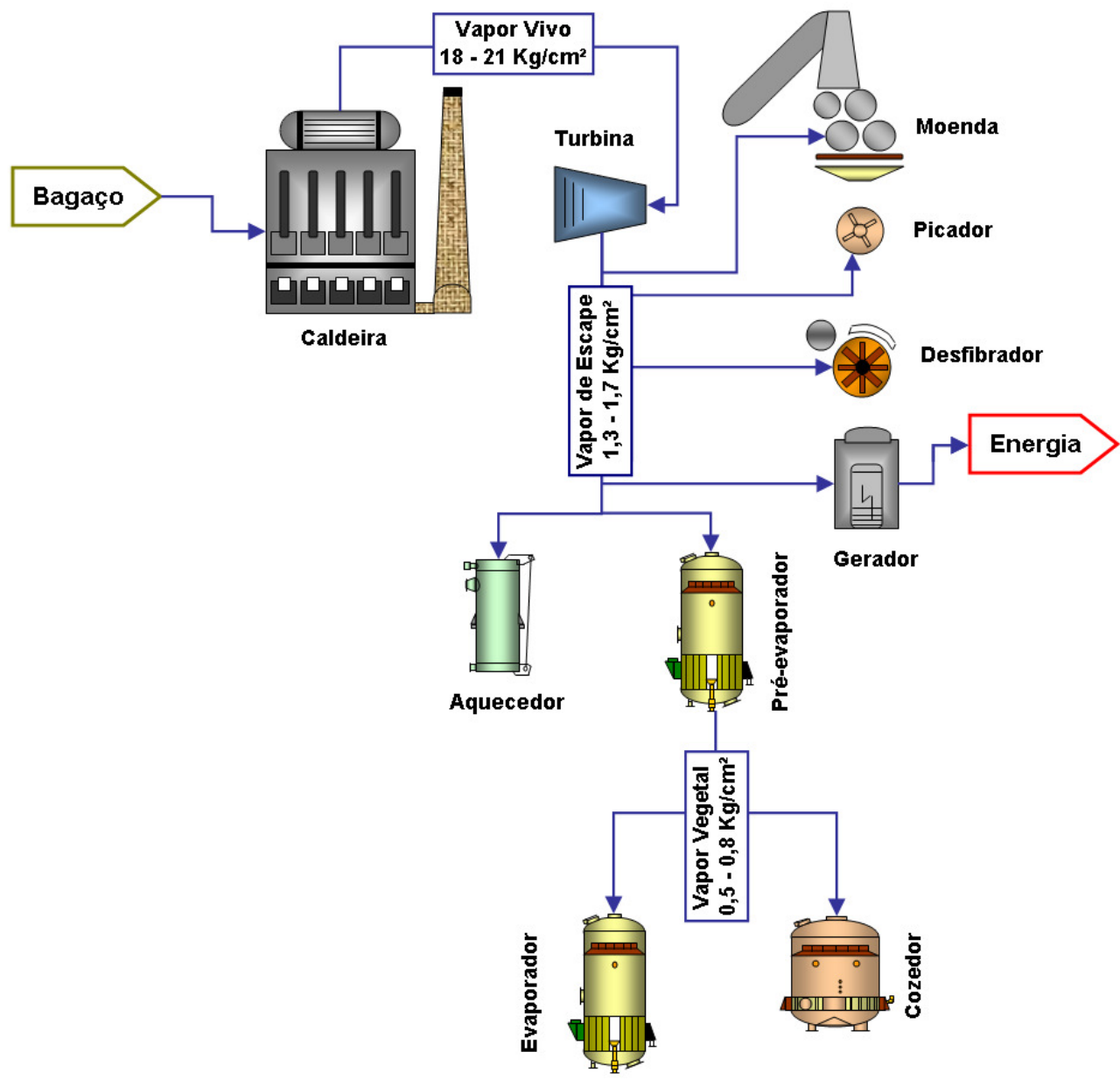

Figura 17: Esquema de geração e utilização do vapor a partir da queima do bagaço da cana 
O bagaço resultante da operação de moagem que é constituído de, aproximadamente, $46 \%$ de fibra, $50 \%$ de água e $4 \%$ de sólidos solúveis; é encaminhado para as caldeiras onde é queimado. Para cada tonelada de cana que entra na operação de moagem é gerado em média entre 240 - $280 \mathrm{~kg}$ de bagaço e, o açúcar contido neste é considerado como perdas do processo, assim é conveniente que a quantidade de açúcar restante no bagaço, o qual será encaminhado para as caldeiras, seja o mínimo possível.

A queima do bagaço nas caldeiras libera energia que vaporiza a água. Esse vapor, denominado vapor vivo, gerado nas caldeiras apresenta uma pressão média de 18 - $21 \mathrm{~kg} / \mathrm{cm}^{2}$ e é utilizado para a alimentação das turbinas a vapor, onde ocorre a transformação da energia térmica em energia mecânica. A turbina a vapor tem a função de acionar alguns componentes da usina como: os picadores, os desfibradores, as moendas e geradores de energia. Os geradores irão assim, gerar energia elétrica para o funcionamento dos demais componentes da usina que necessitam. Assim, quase que na sua totalidade, a usina gera a energia consumida através da queima do bagaço nas caldeiras. Em certas usinas, é gerada toda a energia consumida e o bagaço restante é vendido.

As turbinas a vapor ao serem alimentadas com o vapor resultante das caldeiras, liberam vapor de baixa pressão, aproximadamente $1,3-1,7 \mathrm{~kg} / \mathrm{cm}^{2}$ denominados vapor de escape. Este vapor é utilizado para a alimentação dos equipamentos contidos no processo de fabricação de açúcar e álcool como os aquecedores e os pré-evaporadores, este último alimentado com o vapor de escape $\left(1,3-1,7 \mathrm{~kg} / \mathrm{cm}^{2}\right)$ e libera vapor com uma pressão aproximada de $0,5-0,8 \mathrm{~kg} / \mathrm{cm}^{2}$ denominado vapor vegetal. Este vapor é utilizado para a alimentação de outros equipamentos do mesmo processo como os cozedores, evaporadores (FUNDAMENTOS..., 1988, p.04).

\subsection{Tratamento do Caldo}

O caldo resultante do processo de moagem passa por um tratamento antes de ser encaminhado para a produção de açúcar e/ou álcool. Esse caldo passa por alguns equipamentos como peneiras, separadores de areia e hidrociclones para a remoção de impurezas mais grosseiras. No entanto impurezas menores (solúveis, insolúveis ou coloidais) não são removidas apenas com esses aparelhos. Assim, uma seqüência de procedimentos é realizada com o intuito de coagular as impurezas, para que 
posteriormente a decantação possa separá-las. A Figura 18 mostra um esquema do tratamento de caldo.

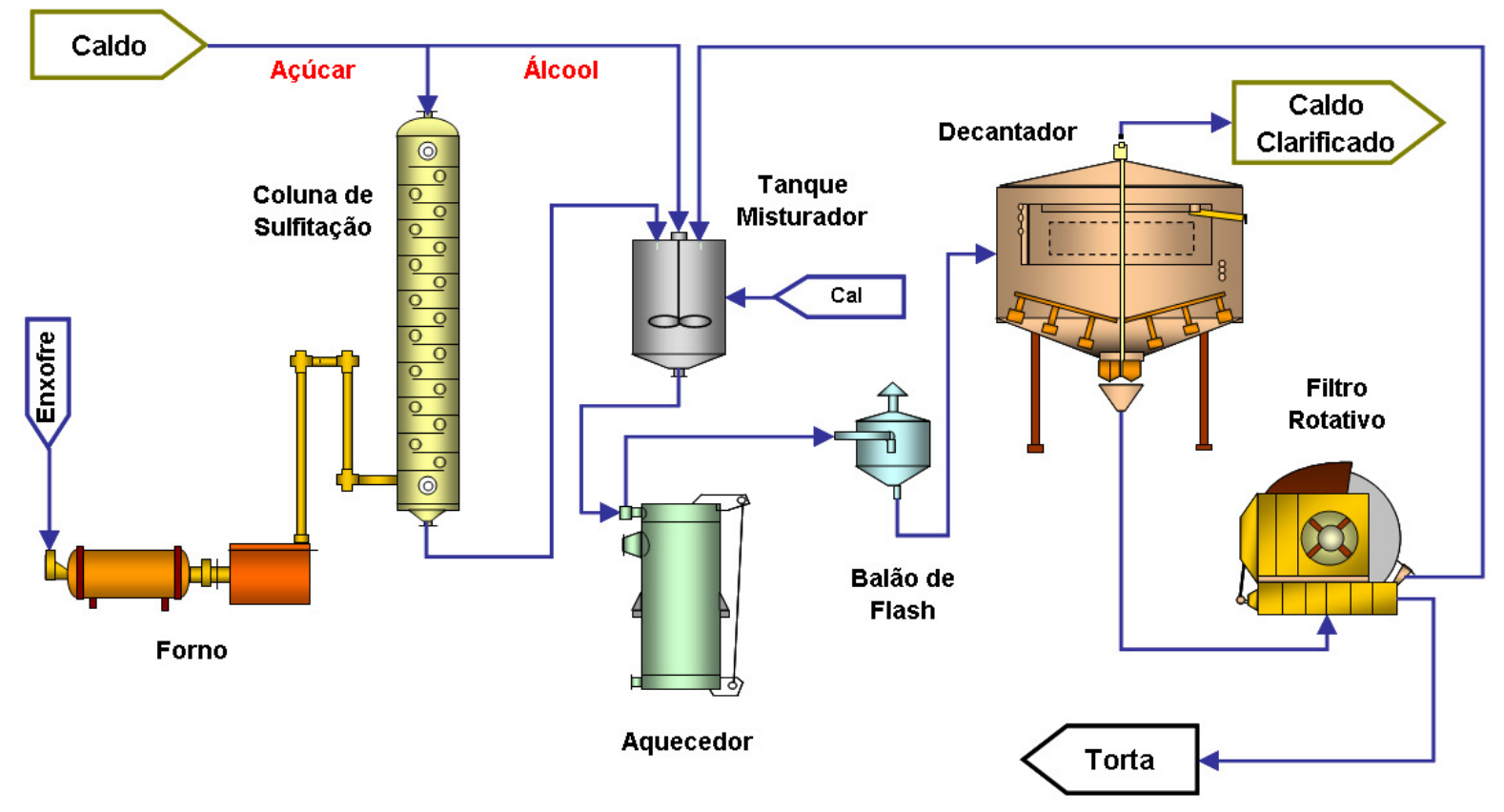

Figura 18: Esquemas das etapas do tratamento do caldo de cana.

A princípio o caldo passa pela operação de sulfitação, que consiste na absorção de $\mathrm{SO}_{2}$ pelo caldo. Essa operação tem o objetivo de coagular matérias coloidais, inibir a formação de cor e auxiliar a formação de precipitados. É realizada usualmente em uma coluna de absorção. O caldo entra na parte superior e desce por gravidade em contrapartida com o $\mathrm{SO}_{2}$ resultante da queima do enxofre num forno. A operação de sulfitação não é necessária quando o produto final é o álcool. O caldo proveniente da coluna de sulfitação é encaminhado para tanques misturadores onde é executada a "caleagem", assim denominada pelo fato de receber o "leite de cal" $\left(\mathrm{Ca}(\mathrm{OH})_{2}\right)$, o qual também tem a finalidade de coagular materiais coloidais entre outros. Nesse processo o pH do caldo é elevado para valores próximos do neutro (entre 6,8 a 7,2).

Depois da operação de caleagem o caldo é aquecido para valores próximos de $105^{\circ} \mathrm{C}$ com o objetivo de acelerar as reações de coagulação e floculação dos coloidais e não açúcares. O aquecimento do caldo aumenta a eficiência do processo de decantação e é realizado em trocadores de calor.

Para a eliminação do ar no caldo resultante da operação de aquecimento, o mesmo é submetido à operação de "flasheamento", executado no balão de flash, onde o caldo é submetido a uma queda brusca da pressão provocando sua ebulição espontânea e eliminando assim o ar nele dissolvido. 
$\mathrm{Na}$ decantação, próxima operação do tratamento, o caldo é purificado pela remoção das impurezas floculadas nas operações anteriores. O caldo resultante da operação é chamado de caldo clarificado e é encaminhado para o processo de fabricação de açúcar e/ou álcool e as impurezas resultantes são chamadas de lodo. O lodo é encaminhado à operação de filtragem com o objetivo de recuperar o açúcar nele contido. Após a filtragem o caldo filtrado volta ao processo de tratamento e o que é retido no filtro é utilizado na lavoura, agora com o nome de "torta" (OPERAÇÂO..., 2002, p. 04).

\subsection{Fabricação do Açúcar}

Em Lopes (1986) detalha-se que o açúcar é o produto final de uma usina de açúcar, constituído por grânulos de sacarose cristalizada, obtido a partir do caldo resultante da extração da cana-de-açúcar. Compõe-se de glicose e frutose, tem sabor doce e elevado valor nutritivo. Depois do tratamento do caldo e obtendo o que se convenciona chamar de caldo clarificado, o mesmo é submetido a algumas operações até que se obtenha o açúcar comercial como produto final. A Figura 19 mostra um esquema da fabricação do açúcar.

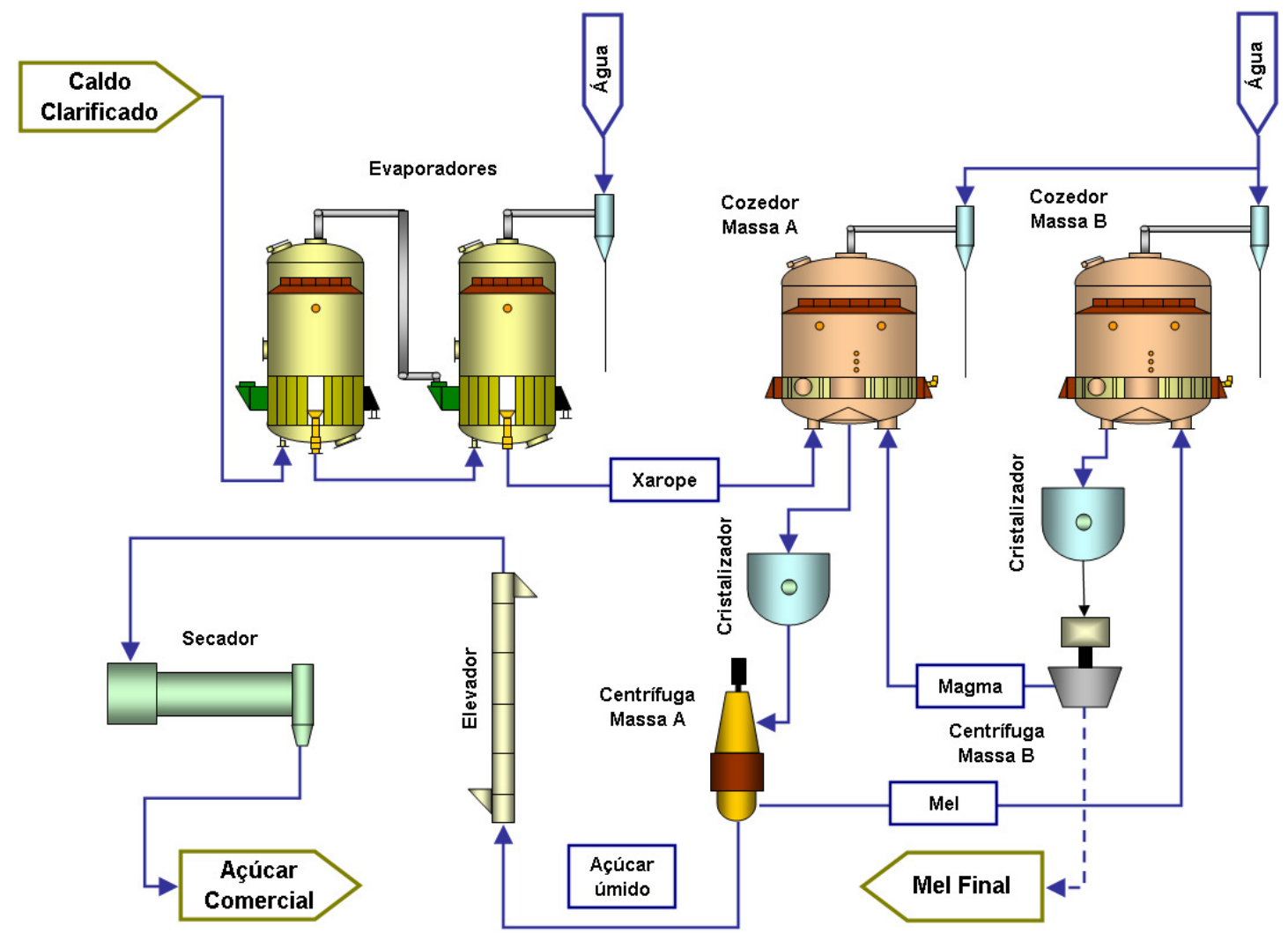

Figura 19: Esquema das etapas para a fabricação do açúcar. 
A primeira operação para a obtenção do açúcar é a evaporação, que tem o objetivo de eliminar a água existente no caldo a fim de que o açúcar se concentre até a formação de cristais. $\mathrm{O}$ caldo apresenta inicialmente uma concentração de $14-16^{\circ}$ Brix $^{1}$ e ao final da operação de evaporação alcance valores entre $55-65^{\circ}$ Brix onde passa a ser chamado de xarope (CHINTAKU, 2005).

Após a operação de evaporação, o xarope é submetido à outra operação de concentração, agora denominada cozimento. Nessa operação, executada em cozedores, ocorre a formação de cristais em virtude da precipitação da sacarose dissolvida na água. Com a evaporação da água, consegue-se uma mistura de cristais envolvida em mel que recebe o nome de massa cozida (massa A) e possui concentração entre $93-95^{\circ}$ Brix. Essa massa é lançada aos cristalizadores onde ocorre o resfriamento lento com o auxilio de água ou ar. O objetivo dessa operação é recuperar parte da sacarose ainda existente dissolvida no mel. É adicionado sacarose sobre os cristais já formados, aumentando o tamanho dos mesmos.

A massa cozida (massa A) é levada as centrifugas (de massa A), as quais são constituídas por um cesto perfurado fixado a um eixo que gira em alta velocidade, e a ação da força centrifuga faz com que o mel atravesse o cesto perfurado ficando retidos apenas os cristais de sacarose. O mel é enviado aos cozedores, agora chamado de massa $\mathrm{B}$, onde é submetidos ao mesmo processo descrito para os cozedores de massa A. O produto final das centrifugas de massa B é o magma e o mel final. O magma retorna ao processo pelo cozedor de massa A e o mel final é enviado à destilaria para a produção de álcool. Os cristais de sacarose ao saírem das centrifugas de massa A possuem um alto grau de umidade. Essa umidade é controlada pela operação de secagem, executada em um secador e, ao final desta operação obtém o açúcar comercial (SHREVE \& BRINK, 1997).

\footnotetext{
${ }^{1}$ Brix representa a medida da concentração de sólidos dissolvidos em uma solução, sendo estes sólidos basicamente representados por açúcares - sacarose, glicose e frutose.

${ }^{2}$ Magma é o açúcar retirado das centrifugas onde se trabalha com mais de uma massa (não sendo a de massa A). Este magma é reciclado no processo.
} 


\subsection{Fabricação do Álcool}

Segundo Jacques (1999) álcool é hidrocarboneto oxigenado, limpo, incolor e inflamável. Seu ponto de ebulição está aos $78.5^{\circ} \mathrm{C}$ no seu estado anidro. A sua fórmula química é $\mathrm{C}_{2} \mathrm{H}_{5} \mathrm{OH}$. Depois do tratamento do caldo e obtendo o que chamamos de caldo clarificado, o mesmo é submetido a algumas operações até que se obtenha o álcool como produto final. A primeira delas é o resfriamento desse caldo clarificado em trocadores de calor antes que seja enviado para a destilaria ${ }^{3}$. A Figura 20 mostra o um esquema da fabricação do álcool.

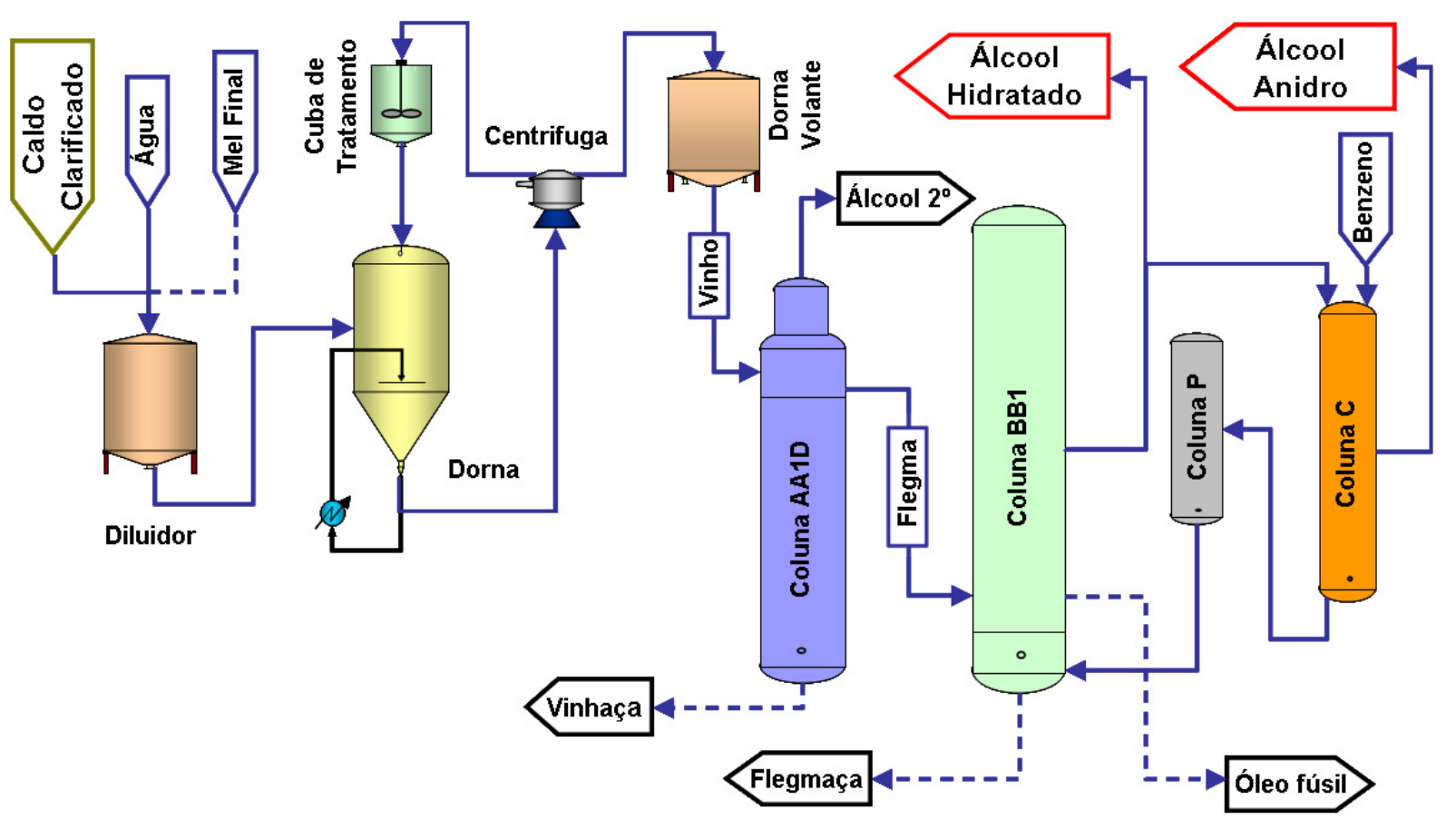

Figura 20: Esquema da etapas da fabricação do álcool.

O álcool é obtido por um processo bioquímico denominado fermentação e este processo possui três etapas, a saber: preparação do mosto, preparação do fermento e a fermentação. Após o processo de fermentação ocorre o processo de destilação, o qual possui duas etapas: a destilação e a desidratação.

\footnotetext{
${ }^{3}$ Destilaria é uma unidade industrial onde se realiza a operação de destilação, processo que se utiliza dos diferentes pontos de ebulição das diversas substância presentes, separando-as.
} 
3.5.1 - Mosto: O mosto é constituído pela mistura do caldo clarificado proveniente da operação de tratamento do mesmo e do mel final que é o resíduo das centrifugas de massa B da operação de fabricação do açúcar. Sua concentração é definida conforme a produção pretendida e a capacidade da fermentação, contudo sua variação deve estar entre $15-25^{\circ}$ Brix. Quando preciso é adicionada água para o ajuste do Brix. Esta operação é executada em tanques denominados diluidores (FABRICAÇÃO..., 2002).

3.5.2 - Fermentação: O processo de fermentação mais difundido no Brasil é o de Melle-Boinot, que tem como característica a recuperação de leveduras ${ }^{4}$ por centrifugação.

A solução produto das dornas de fermentação é enviada às centrífugas para a recuperação do fermento. $\mathrm{O}$ concentrado de fermento recuperado na centrifuga chamado de leite de levedura sofre um tratamento antes de retornar as dornas. Esse tratamento consiste em adicionar água para baixar o teor alcoólico, e ácido sulfúrico para alcançar uma solução com valores entre 2-2,5 pH, solução essa conhecida popularmente como "pé-de-cuba". Essa operação é executada em cubas de tratamento. É na fermentação que os açúcares são transformados em álcool. A reação ocorre nas dornas, onde é misturado o mosto e o pé-de-cuba na proporção 2:1. A transformação é realizada segundo a reação simplificada de Gay Lussac e dura entre 4 a 12 horas, obtendo ao final da fermentação o que se chama de "vinho" com ter alcoólico entre 7-10\%. Após a obtenção do vinho que sai das dornas e passa pela centrifuga, obtém-se o "vinho delevedurado", sendo esse o que irá continuar no processo. Após a fermentação, o vinho obtido é constituído variavelmente de substâncias gasosas, sólidas e líquidas, sendo a primeira constituída principalmente de dióxido de carbono. As substâncias sólidas são bactérias, sais minerais, açúcares infermentados e impurezas mecânicas em suspensão. As substâncias líquidas mais importantes são a água e o álcool. Dessa substância impura é separado apenas o etanol pelo processo de destilação. Nessa operação, transformam-se as substâncias mais voláteis em vapor, para em seguida condensá-lo e resfriá-lo de tal forma que se separe dos outros que se encontravam misturados (LIMA \& AQUARONE \& BORZANI, 1986).

\footnotetext{
${ }^{4}$ Leveduras são microrganismos responsáveis pelo processo de fermentação dos açúcares (transformação em álcool).
} 
A destilação é processada em três colunas superpostas denominadas coluna A, coluna A1, coluna D e também em duas colunas também superpostas denominadas coluna B e coluna B1 (vide Figura 20).

O vinho é alimentado no topo da coluna A1 descendo pela a mesma, sendo a flegma ${ }^{5}$ retirado na base desta e enviada à coluna $\mathrm{B}$. Na base da coluna $\mathrm{A}$ é retirada a vinhaça onde será utilizada como adubo para o solo. No topo da coluna D é retirado o álcool de segunda com graduação aproximada de $92^{\circ} \mathrm{GL}$.

As colunas B e B1 têm a finalidade de concentrar a flegma a uma graduação de aproximadamente $96^{\circ} \mathrm{GL}$ e proceder sua purificação com a retirada das impurezas. Assim a coluna B é alimentada pela flegma sendo retirada sob a forma de álcool hidratado.

3.5.3 - Desidrataçao: Na operação de desidratação, é adicionado no topo da coluna C, responsável por esta operação, o benzol. Este produto tem a capacidade de formar uma mistura azeotrópica ternária (benzeno-agua-álcool) com ponto de ebulição inferior ao do álcool anidro, assim álcool é retirado da coluna com graduação aproximadamente de 99,7 GL sendo denominado de álcool anidro. Da mistura azeotrópica formam-se duas fases, uma rica em benzeno que retorna à coluna e outra rica em água que é enviada à coluna de recuperação de benzeno denominada coluna $P$. Essa mistura de água-álcool é retirada da coluna $\mathrm{P}$ e enviada à coluna B1, dando fim ao processo de fabricação do álcool hidratado e do álcool anidro.

\footnotetext{
${ }^{5}$ Flegma são vapores alcoólicos com 40 a $50^{\circ}$ GL resultantes do processo de destilação. A flegma resulta da separação do etanol em relação ao vinho.
} 


\section{Terno de Moenda}

O terno de moenda é uma máquina que, trabalha na transformação de um volume de cana preparada para um volume de caldo extraído, assim sua capacidade de moagem depende muito da qualidade de preparação da cana para a moagem, com a finalidade de extrair o caldo da cana-de-açúcar por sucessivos esmagamentos por meio da passagem da cana, devidamente preparada, pelos vãos entre cilindros com ranhuras. Possui quatro cilindros, sendo 3 responsáveis pela extração, dispostos de maneira a propiciar aberturas entre eles conforme Figura 21. Possui também um sistema de condução do bagaço, proveniente do primeiro esmagamento, localizado entre os cilindros inferiores. Três desses cilindros giram no sentido horário e apenas um gira no sentido anti-horário.

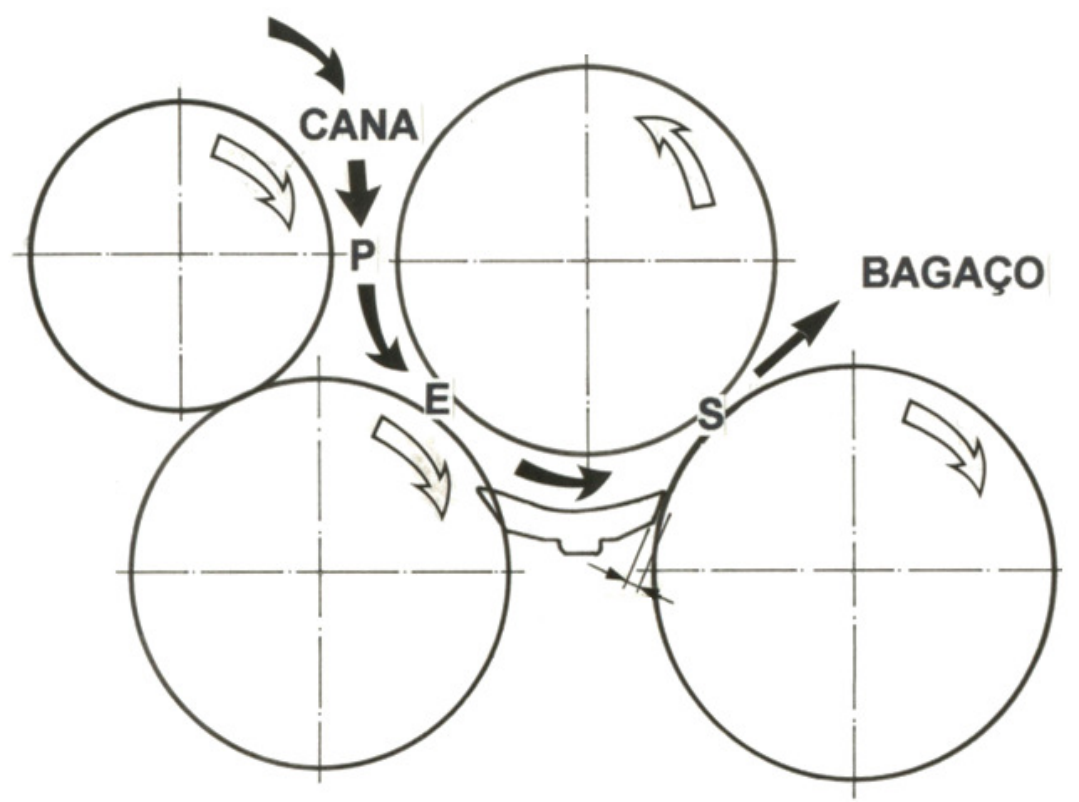

Figura 21: Esquema da disposição dos cilindros e seus sentidos de giro (MOENDAS, 2002).

Os ternos são classificados por bitola sendo as mais comuns:

- 26" x 48 "

- $30 " x$ x 5 "

- 34" x 66"

- 37" x 78"

- $42 " x ~ 84 "$ 
- 46" x 90"

- $56 " x 100 "$

Os primeiro valor corresponde ao diâmetro nominal dos cilindros e os segundo valor ao seu comprimento. Sua capacidade de moagem está relacionada a essa bitola, assim como ao número de ternos dispostos em linha. A moagem geralmente é expressa em tonelada de cana por hora (TCH).

Tabela 4: Capacidade de moagem dos ternos de moenda.

\begin{tabular}{|c|c|c|c|}
\hline \multicolumn{4}{|c|}{ Capacidade de Moagem (TCH) } \\
\hline \hline Bitola & 4 Ternos & 5 Ternos & 6 Ternos \\
\hline $30 "$ x 54" & 230 & 250 & 270 \\
\hline $34 "$ x 66" & 340 & 370 & 400 \\
\hline $37 " \times 78 "$ & 400 & 440 & 475 \\
\hline $42 " \times 84 "$ & 525 & 575 & 620 \\
\hline $46 " \times 90 "$ & 615 & 670 & 725 \\
\hline $56 " \times 100 "$ & 1020 & 1100 & 1200 \\
\hline
\end{tabular}

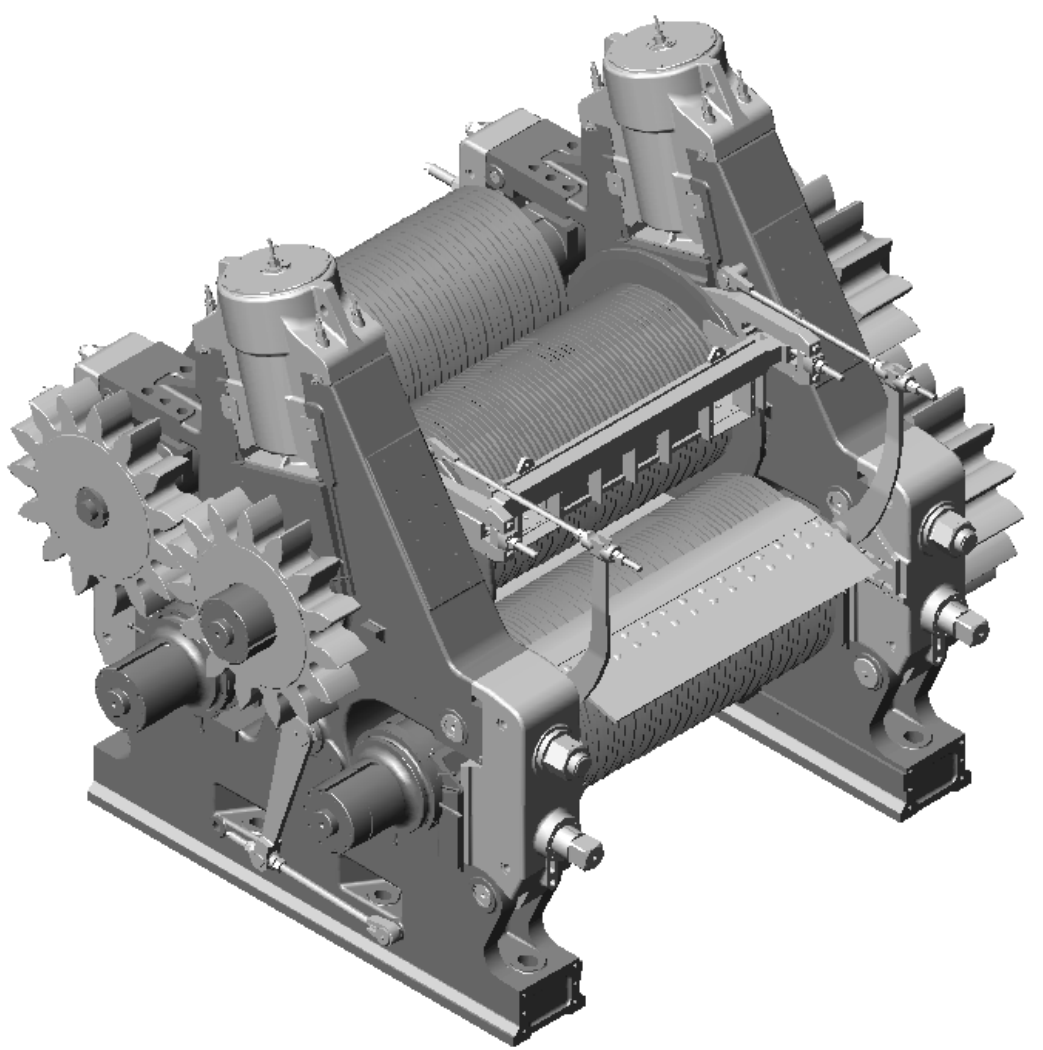

Figura 22: Esquema de um terno de moenda (DEDINI, 2007) 


\subsection{Componentes do Terno de Moenda e suas Funções}

O terno de moenda é dividido em subconjuntos, cada qual com sua importância no processo de moagem. Os subconjuntos do terno de moenda, conforme figura 23, são:

1. Castelo;

2. Sistema de regulagem da bagaceira;

3. Cabeçotes laterais de entrada;

4. Cabeçotes laterais de saída;

5. Rolos Inferiores;

6. Rolo de pressão;

7. Rolo superior;

8. Cabeçotes hidráulicos;

9. Pente superior;

10. Pente inferior.

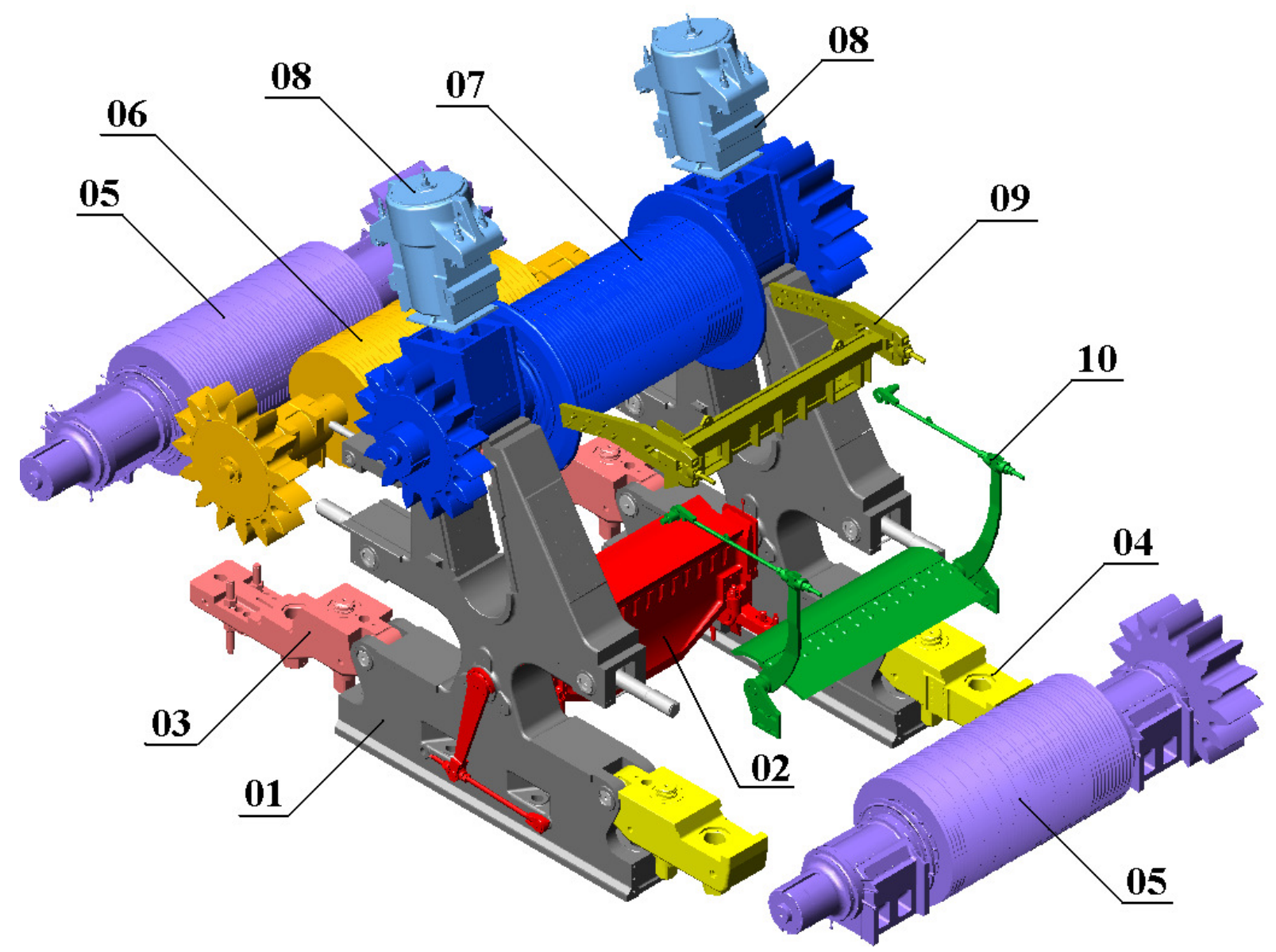

Figura 23: Subconjuntos de um terno de moenda (DEDINI, 2007) 
O modelo apresentado na Figura 22 utilizado para as ilustrações é um terno MCD-01 56”x 100” fabricado pela Dedini Indústrias de Base.

\subsubsection{Castelos}

Construídos em aço fundido, são eles que sustentam a grande maioria dos componentes do terno. Suas dimensões são definidas de modo a propiciar a abertura entre os rolos para a moagem desejável e suportar as cargas resultantes do processo de moagem. As principais superfícies sujeitas à corrosão pelo constante contato com o caldo de cana são, geralmente, revestidas em aço inoxidável. Em sua geometria possui alojamentos para os dois rolos de moenda inferiores e o rolo de pressão. Na sua parte superior possui uma abertura inclinada em $15^{\circ}$ chamada de garfo, revestida com placas de bronze, por onde o rolo superior é montado. Essa inclinação tem como finalidade diminuir os esforços do rolo superior em relação ao castelo. Também na parte superior são executados canais para a fixação do cabeçote hidráulico por meio de chavetas. A Figura 24 mostra um exemplo de castelo.

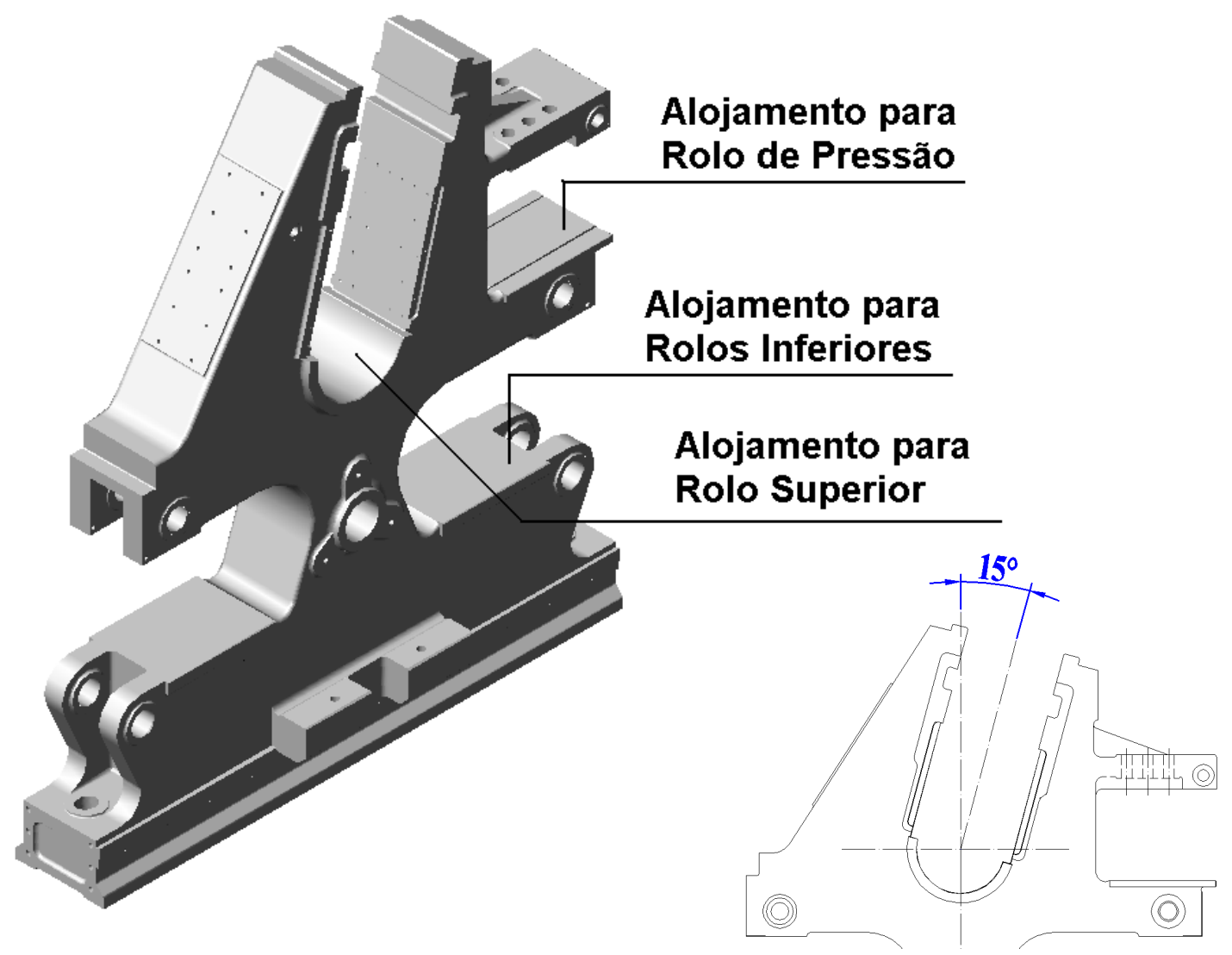

Figura 24: Exemplo de um castelo de moenda (DEDINI, 2007). 
Os castelos são montados aos pares (direito e esquerdo) em bases de concretos e fixados por parafusos chumbadores. A Figura 25 mostra os castelos (em azul) no conjunto do terno de moenda e um detalhe da fixação dos mesmos por chumbadores.

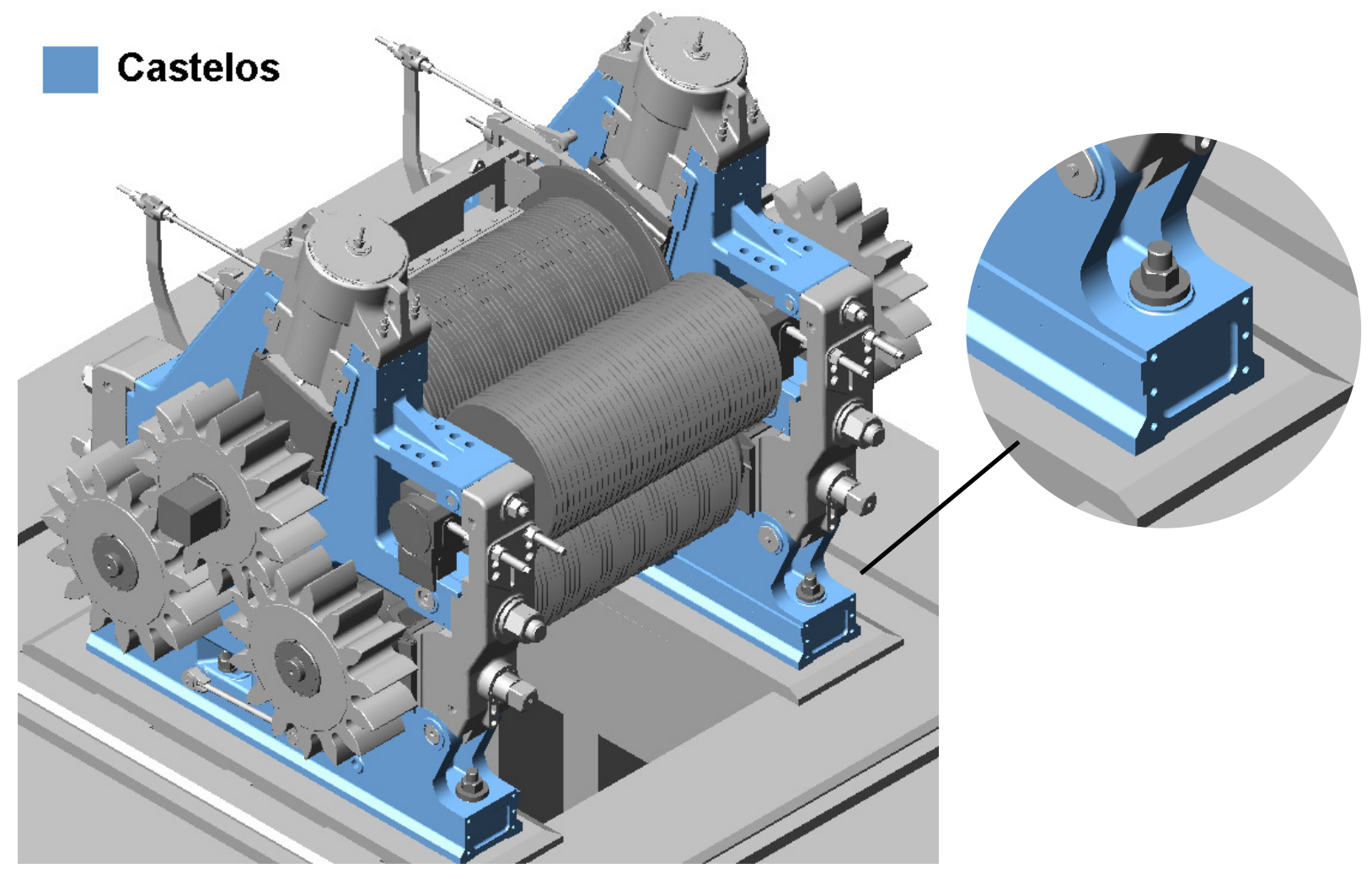

Figura 25: Localização dos castelos no terno de moenda (DEDINI, 2007).

\subsubsection{Sistema de Regulagem da Bagaceira}

O sistema de regulagem da bagaceira é um subconjunto do terno, cujos principais componentes são: bagaceira, balança, suporte da balança e o pino excêntrico conforme ilustra a Figura 26. Este está localizado sob o rolo superior e entre os rolos inferiores como ilustrado na Figura 23. 


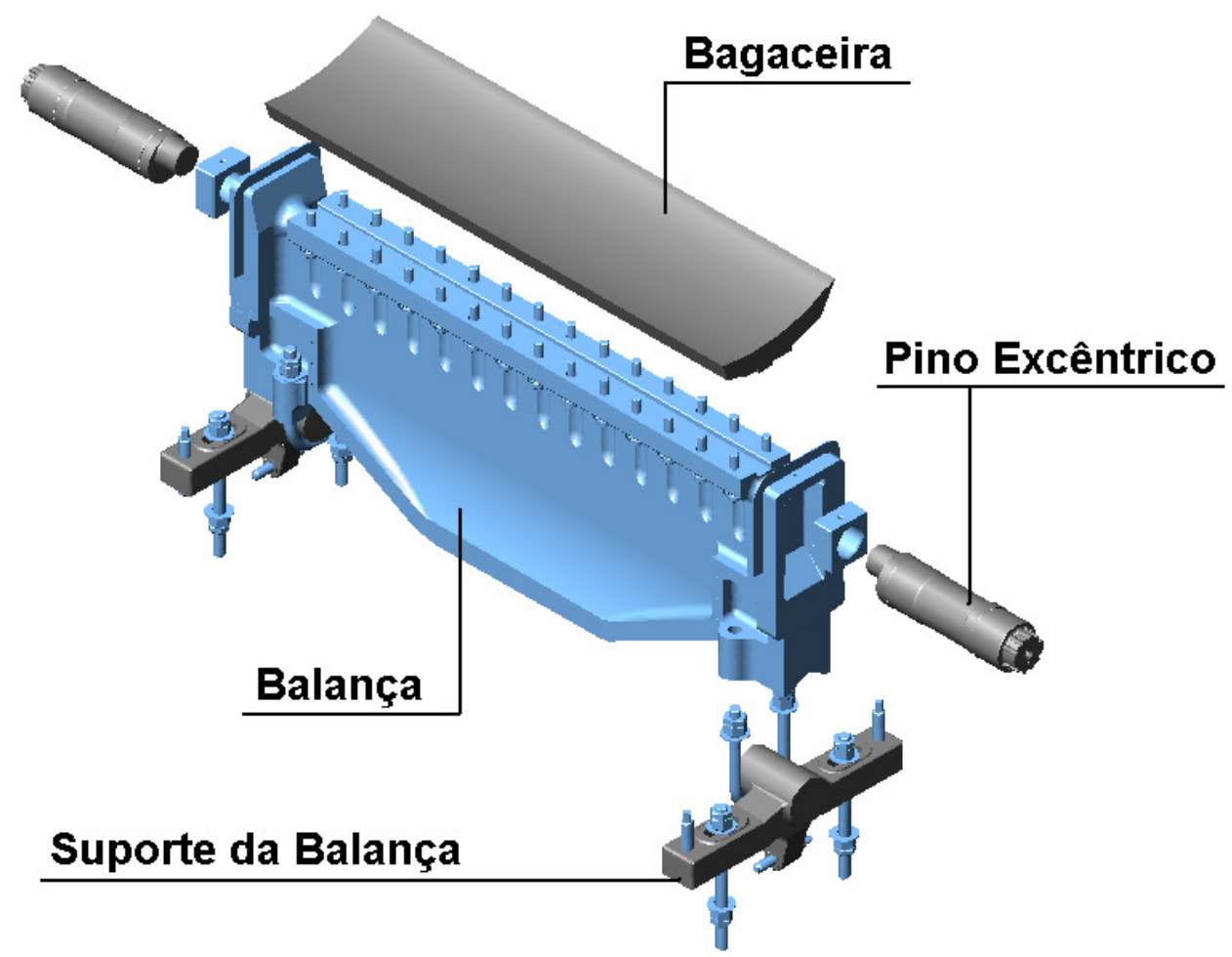

Figura 26: Componentes do sistema de regulagem da bagaceira (DEDINI, 2007).

A bagaceira possui uma geometria especial para cada terno, resultante da regulagem do terno para moagens específicas. Construída em aço fundido, a bagaceira é um equipamento fundamental no trabalho da moenda, pois tem a finalidade de conduzir o bagaço da entrada para a saída. O sistema de regulagem da bagaceira, usando pino excêntrico, garante o posicionamento correto e um perfeito ajuste com o rolo de entrada durante a safra. A bagaceira é fixada na balança, um componente que dá estabilidade para o sistema que por sua vez é fixada ao castelo pelo suporte da balança. A Figura 27 mostra o sistema de regulagem da bagaceira (em azul) no conjunto do terno de moenda 


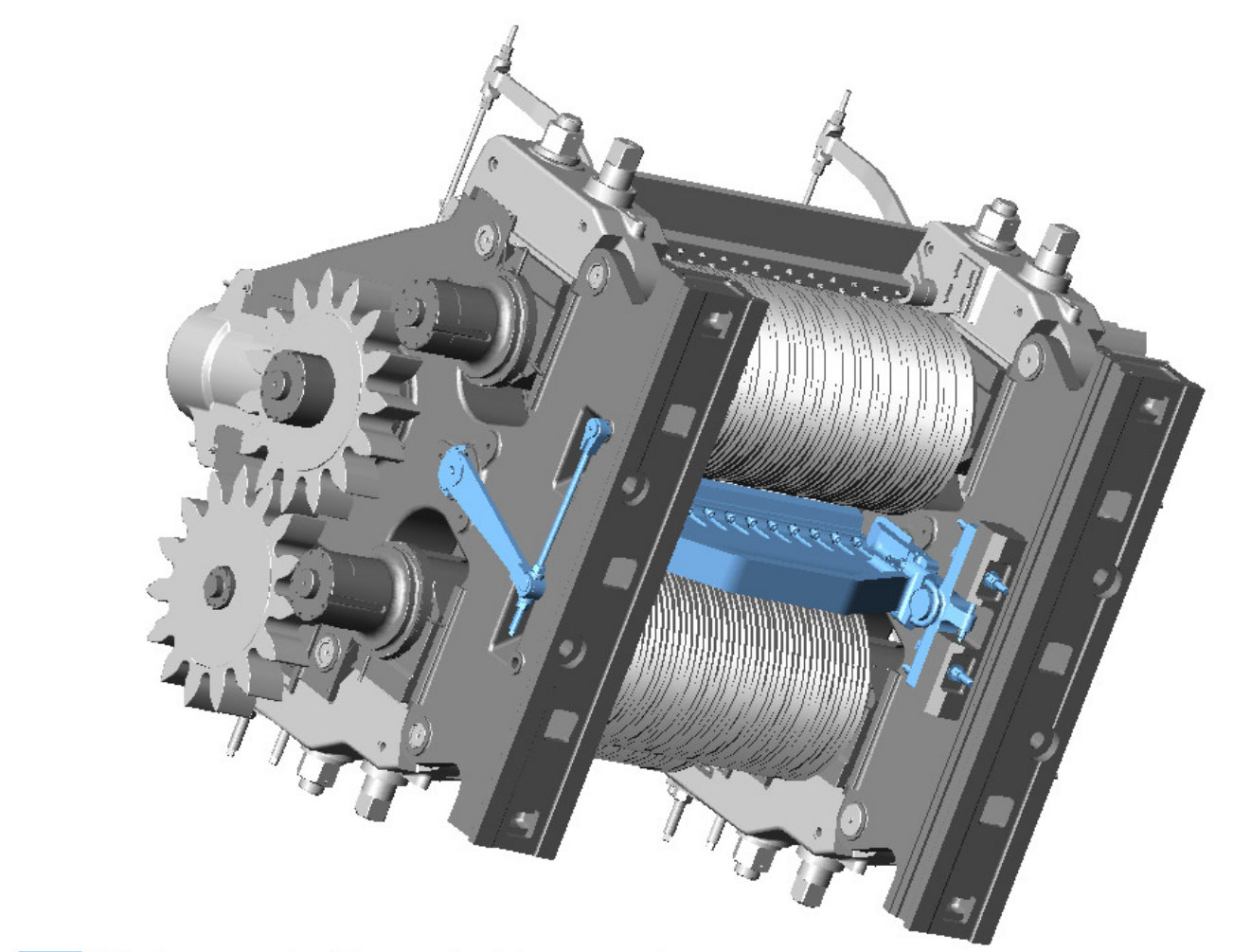

Sistema de Reg. da Bagaceira

Figura 27: Localização do sistema de regulagem da bagaceira no terno de moenda (DEDINI, 2007).

\subsubsection{Cabeçotes Laterais}

São fabricados em aço fundido e fixados aos castelos por encaixes e parafusos articulados, sendo que quando fixados, podem articular, como ilustra a Figura 28, para facilitar a montagem dos rolos inferiores. Possuem dispositivos para regulagem das aberturas, no sentido horizontal, dos rolos inferiores. Suas principais funções são: dar estabilidade necessária aos castelos e possibilitar a regulagem dos rolos inferiores. Geralmente são caracterizados pela posição de montagem no castelo. Assim, os cabeçotes laterais de entrada são montados no castelo do lado de entrada da cana e, os cabeçotes laterais de saída são montados no castelo do lado de saída da cana. A Figura 29 mostra os cabeçotes laterais de entrada (em azul) e os cabeçotes laterais de saída (em roxo) no conjunto do terno de moenda. 


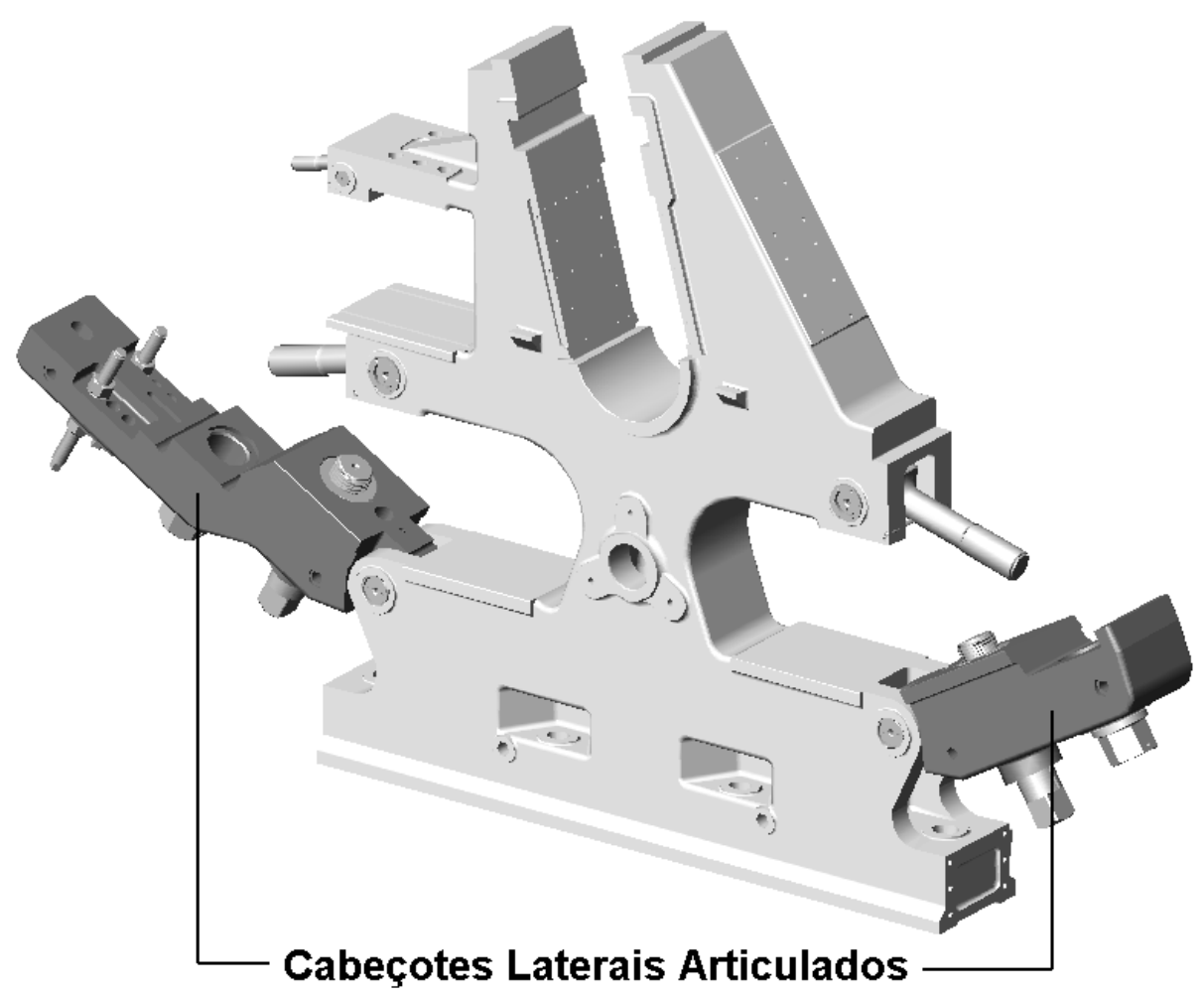

Figura 28: Cabeçotes laterais de entrada e saída (DEDINI, 2007).

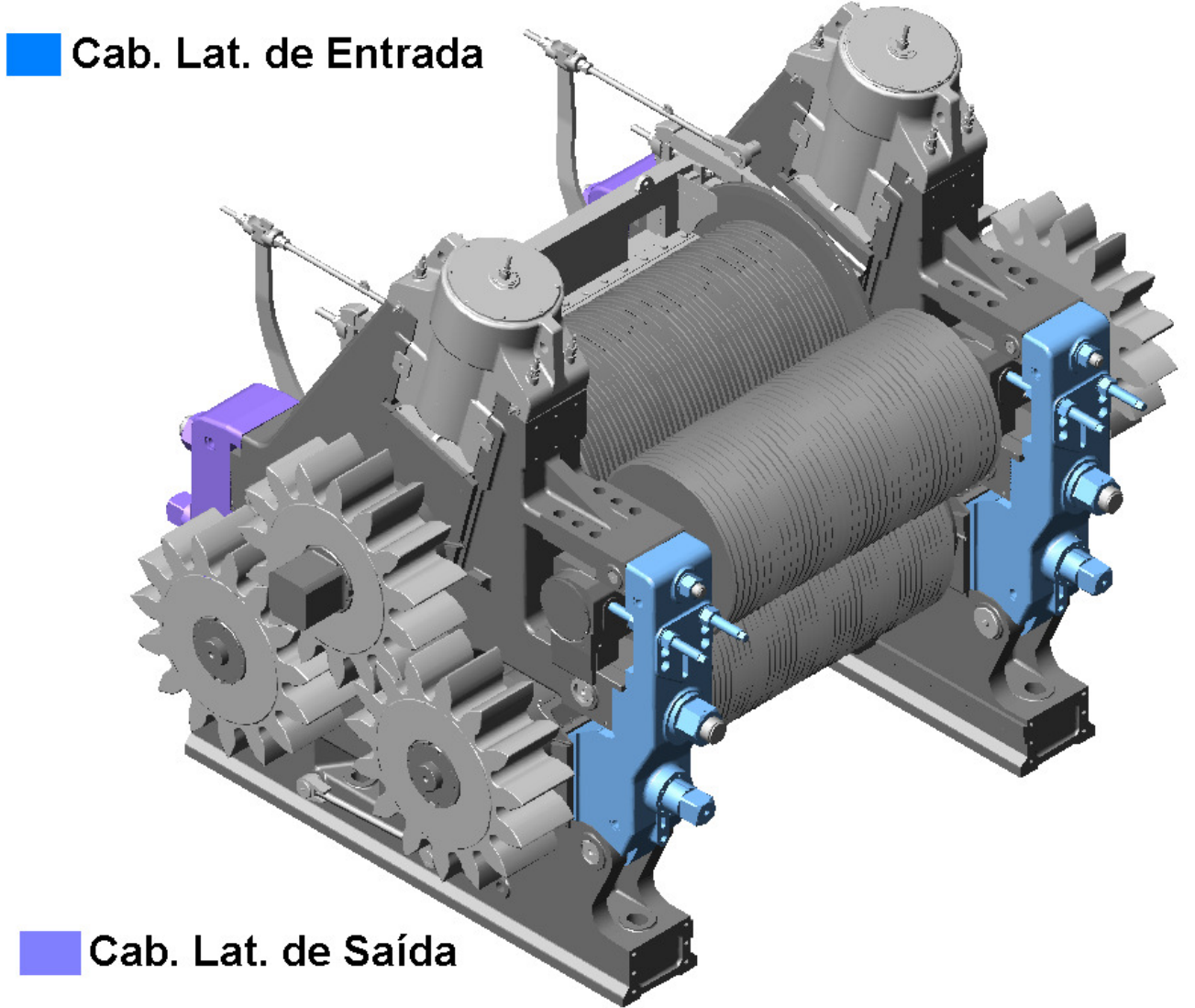

Figura 29: Localização dos cabeçotes laterais de entrada e saída no terno de moenda (DEDINI, 2007). 


\subsubsection{Rolos Inferiores}

Os rolos inferiores formam um subconjunto do terno de moenda composto por um eixo fabricado em aço forjado, uma camisa, geralmente em ferro fundido montada a quente no eixo, dois mancais de deslizamento com seus respectivos sistema de vedação, calhas montadas nas camisas para auxilio da vedação dos rolos e, quando o acionamento das moendas não se dá por motores independentes, rodetes também fazem parte dos rolos inferiores com a função de transmitirem o torque proveniente do rolo superior. A figura 30 mostra os componentes de um rolo inferior.

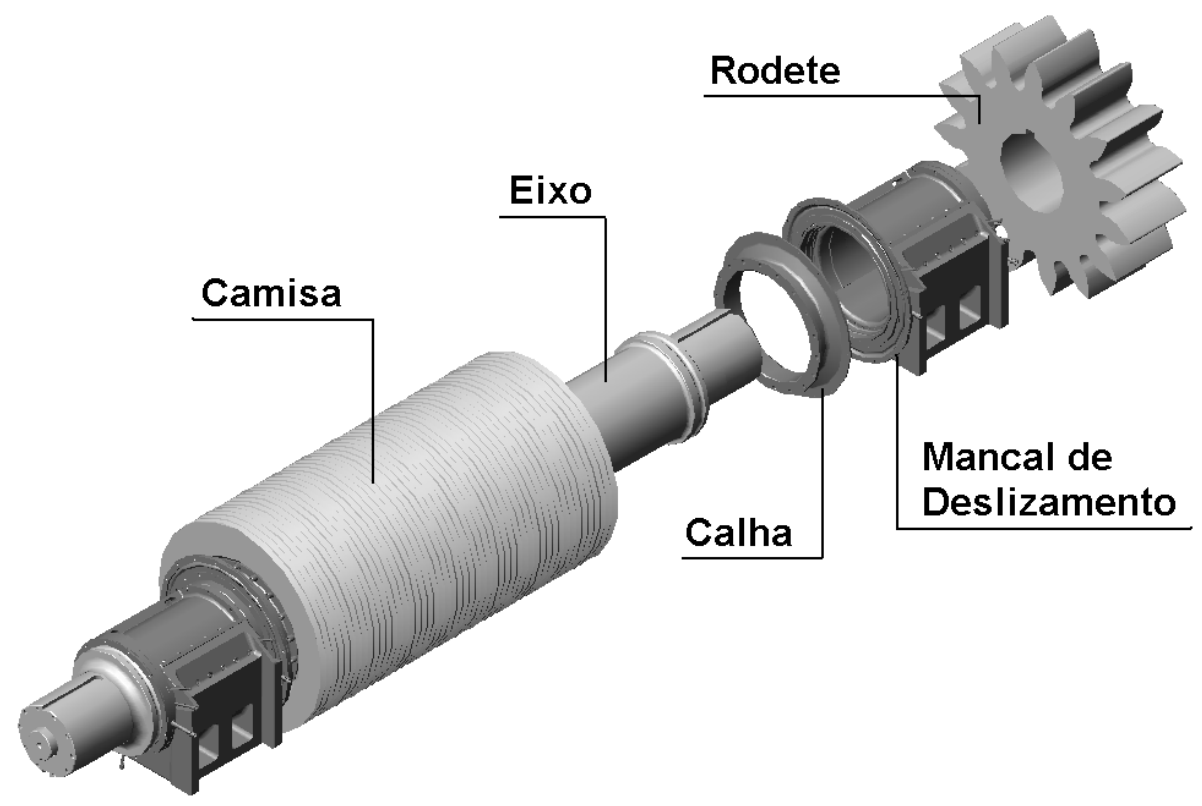

Figura 30: Componentes do rolo inferior (DEDINI, 2007).

Os rodetes são fabricados em uma liga de aço fundida e são montados a frio nos eixos com chavetas. Na região dos dentes dos rodetes é executado um tratamento superficial para aumentar a dureza do mesmo. As camisas dos rolos inferiores são dotadas de ranhuras chamadas frisos, os quais têm a finalidade de aumentar a tração ("pega") da cana por meio de atrito (adesão), ou no bagaço, evitando assim escorregamento.

Os mancais inferiores, assim designados por fazerem parte do rolo inferior, são constituídos de uma caixa fabricada em aço fundido, uma tampa fabricada em ferro fundido e um semi-casquilho de bronze conforme ilustra a Figura 31. As caixas são dotadas de guias em sua base para auxilio da movimentação dos mesmos nos castelo. 


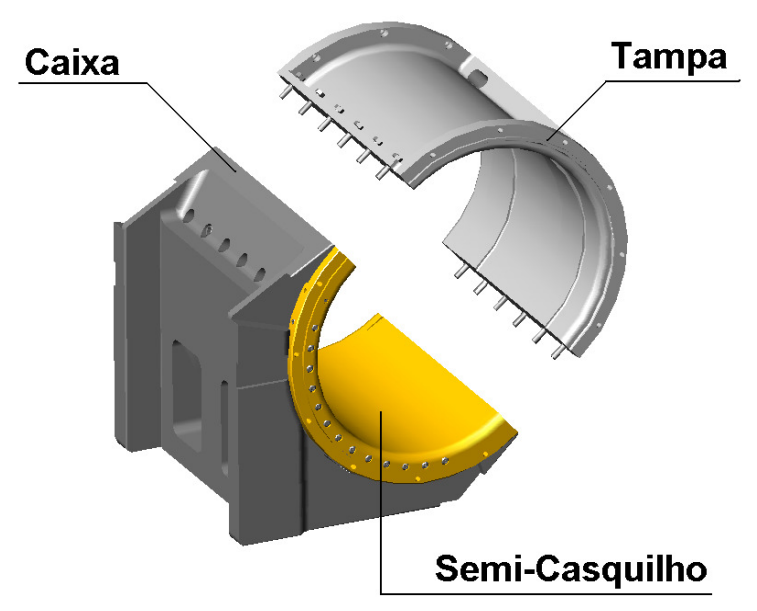

Figura 31: Componentes de um mancal inferior.

Em cada terno de moenda há dois rolos inferiores, um de entrada montado no lado de entrada da cana e um de saída, montado no lado de saída da cana. A função dos rolos inferiores é: propiciar o início do esmagamento da cana e auxiliar bagaço resultante para a abertura de saída. A figura 32 mostra o rolo inferior de entrada (em azul) e o rolo inferior de saída (em roxo) no conjunto do terno de moenda.

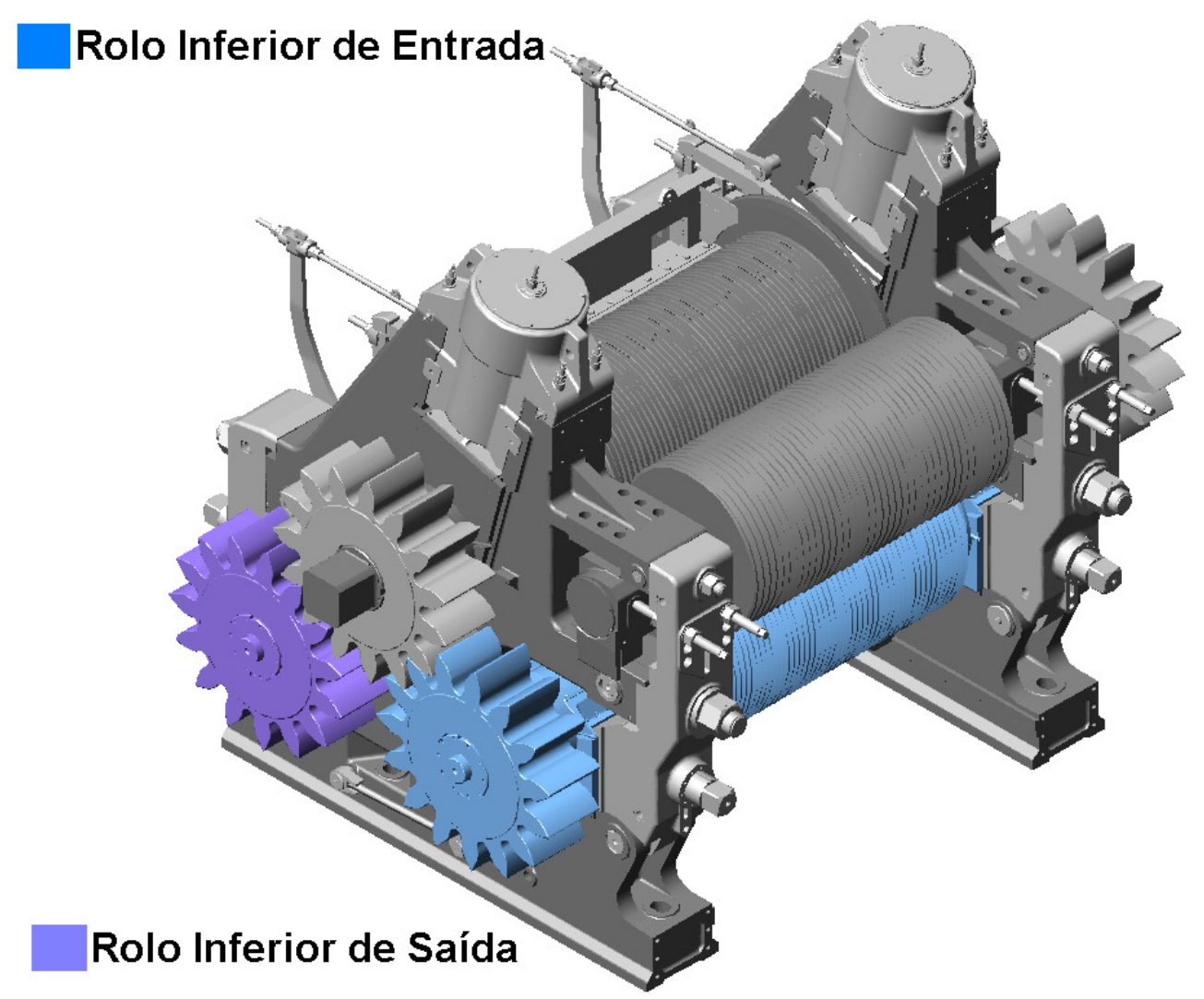

Figura 32: Localização dos rolos inferiores de entrada e saída do terno de moenda (DEDINI, 2007). 


\subsubsection{Rolo de Pressão}

Localizados na parte superior do castelo, ao lado do rolo superior, tem a função de compactar a camada de entrada de cana para o início do processo de moagem. Assim com os rolos inferiores, o rolo de pressão é um subconjunto do terno de moenda constituído de eixo, camisa, mancais de deslizamentos e rodete. Os materiais dos componentes são os mesmos dos rolos inferiores. A Figura 33 mostra os componentes do subconjunto do rolo de pressão.

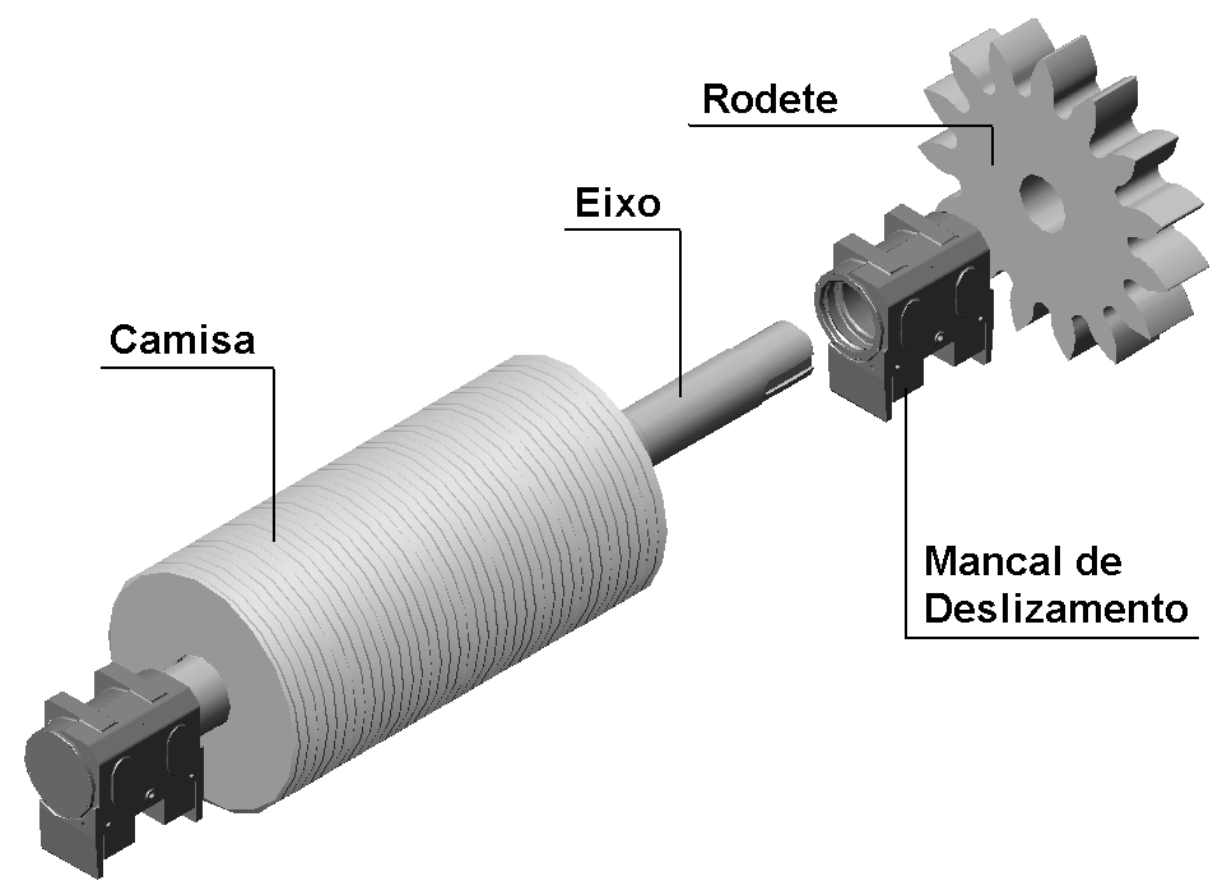

Figura 33: Componentes do rolo de pressão (DEDINI, 2007).

Os mancais do rolo de pressão são regulados, na horizontal, por um dispositivo de regulagem dos cabeçotes laterais de entrada. A Figura 34 mostra o rolo de pressão (em azul) no conjunto do terno de moenda. 


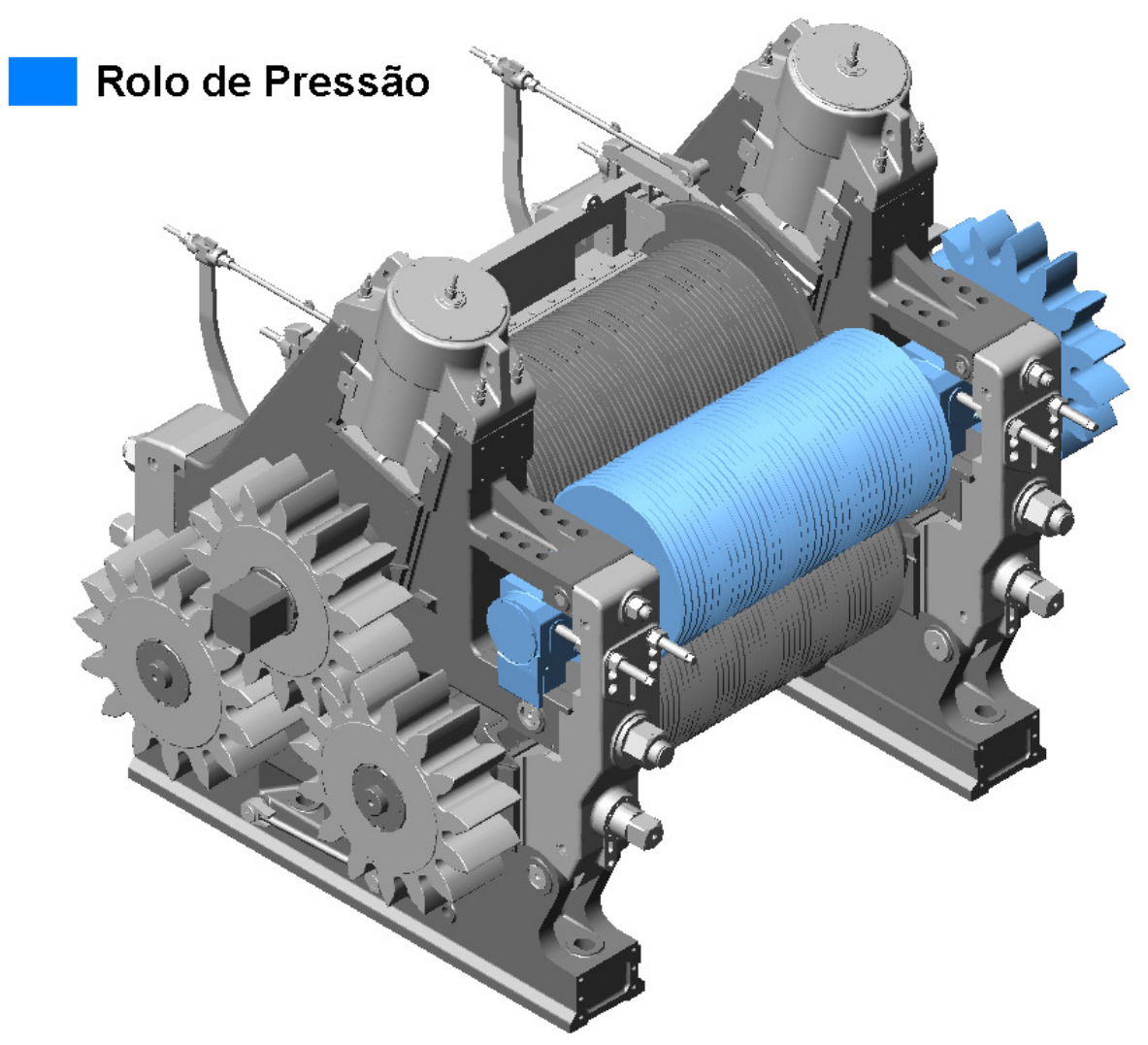

Figura 34: Localização do rolo de pressão no terno de moenda (DEDINI, 2007).

\subsubsection{Rolo Superior}

Outro subconjunto do terno de moenda, também é dotado de eixo, camisa, mancais de deslizamentos com seus respectivos sistemas de vedação, flanges e rodetes. Os materiais são os mesmos dos rolos inferiores e o rolo de pressão. As caixas dos mancais, assim como nos rolos inferiores, também possuem guias para o auxilio da movimentação do rolo superior no garfo do castelo. Essa oscilação do rolo superior é de suma importância no processo de moagem, pois, mantém uma pressão constante no colchão de cana, mesmo quando a mesma não é constante, evitando assim sobrecargas nos equipamentos. A Figura 35 mostra os componentes do subconjunto do rolo superior. 


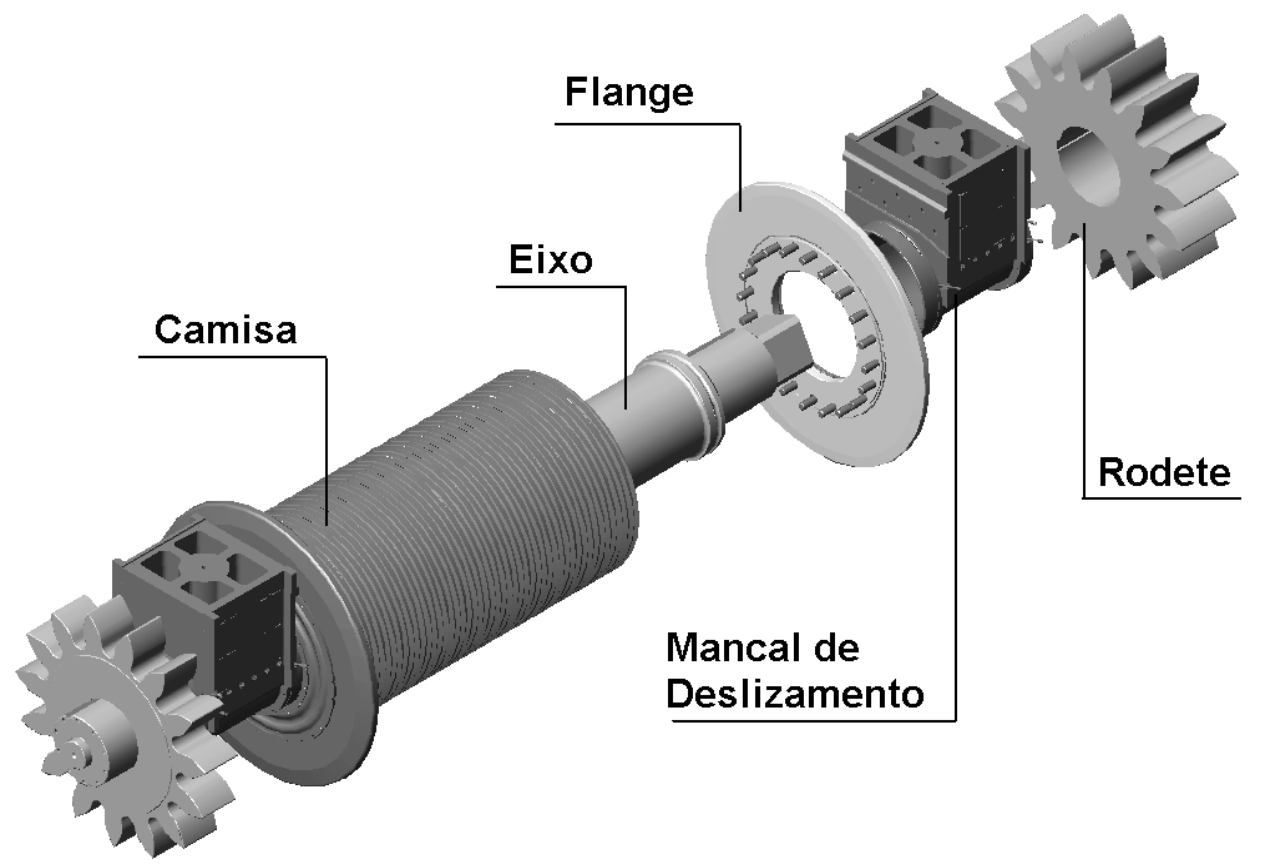

Figura 35: Componentes do rolo superior (DEDINI, 2007).

O rolo superior tem grande importância no terno de moenda, pois é com ele que o bagaço tem um maior contato. É responsável pelo recebimento do torque e pela transmissão, para os demais rolos, por meio dos rodetes quando os mesmos não são acionados independentemente por motores elétricos, ou hidráulicos. A Figura 36 mostra o rolo superior (em azul) no conjunto do terno de moenda.

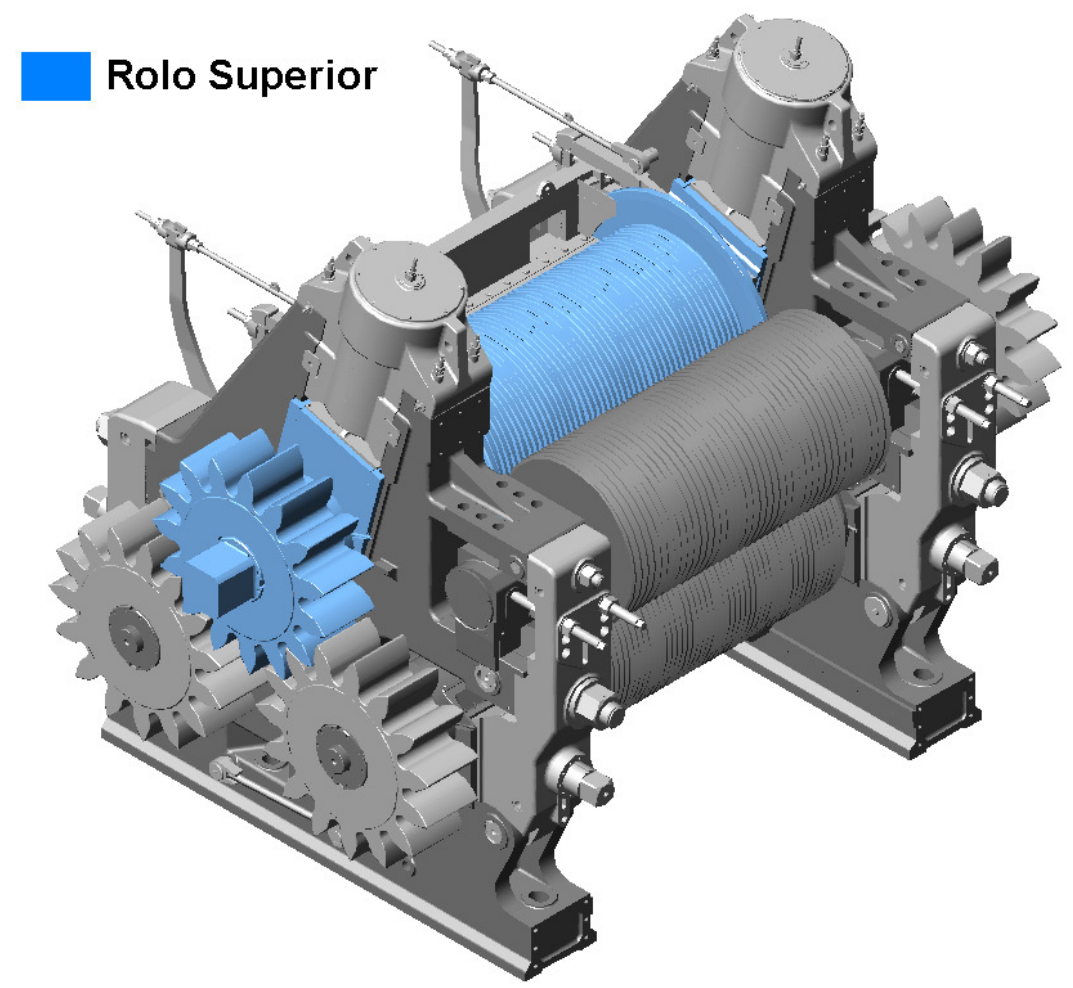

Figura 36: Localização do rolo superior no terno de moenda (DEDINI, 2007). 


\subsubsection{Cabeçotes Hidráulicos}

Projetados para suportar altas pressões, sua finalidade é fornecer uma pressão constante na camada de cana ou bagaço para cada terno de moenda, independentemente da oscilação desse colchão. Os esforços são transmitidos para as caixas dos mancais superiores por um pistão com ponta esférica para eliminar esforços laterais. Os componentes que compõe o cabeçote hidráulico geralmente são:

- Corpo;

- Bucha de Bronze;

- Pistão / Rótula

- Bloco de fechamento.

A Figura 37 ilustra os componentes de um cabeçote hidráulico para o terno de moenda.

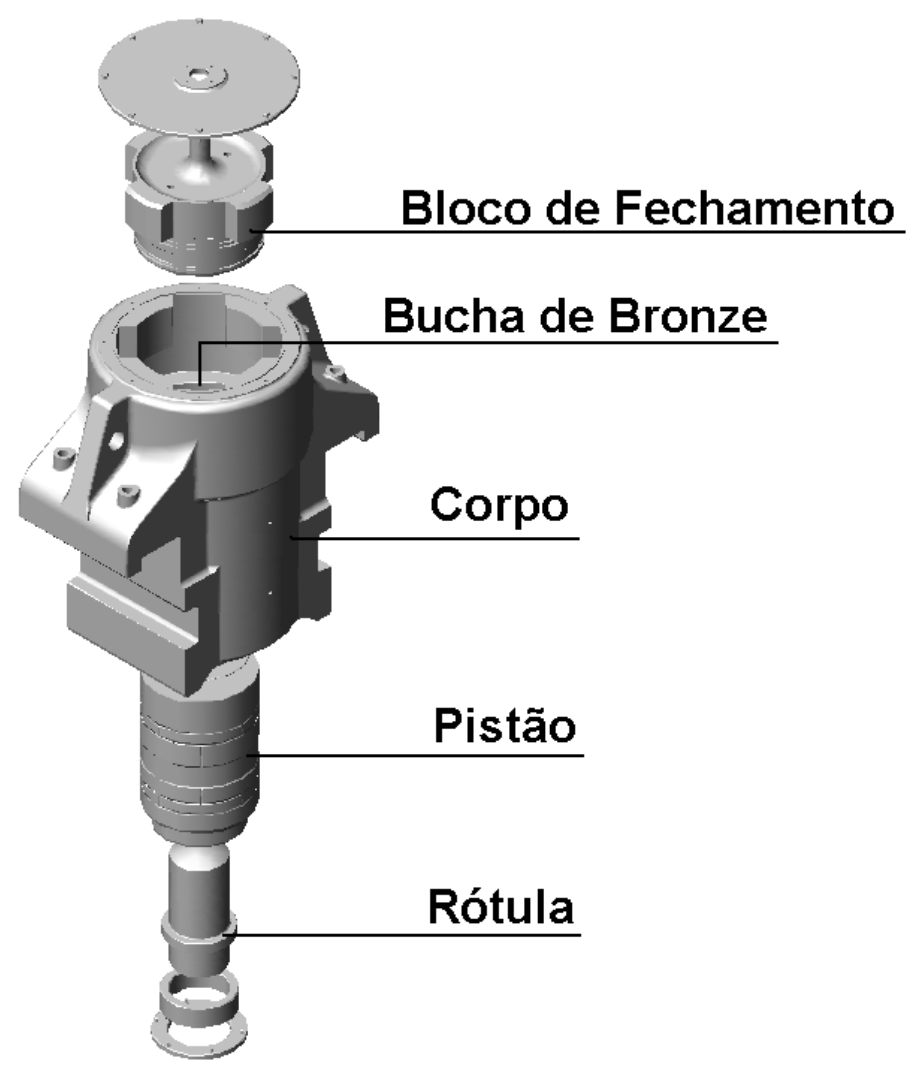

Figura 37: Componentes do cabeçote hidráulico (DEDINI, 2007).

Na Figura 38 são mostrados os cabeçotes hidráulicos (em azul) no conjunto do terno de moenda. 


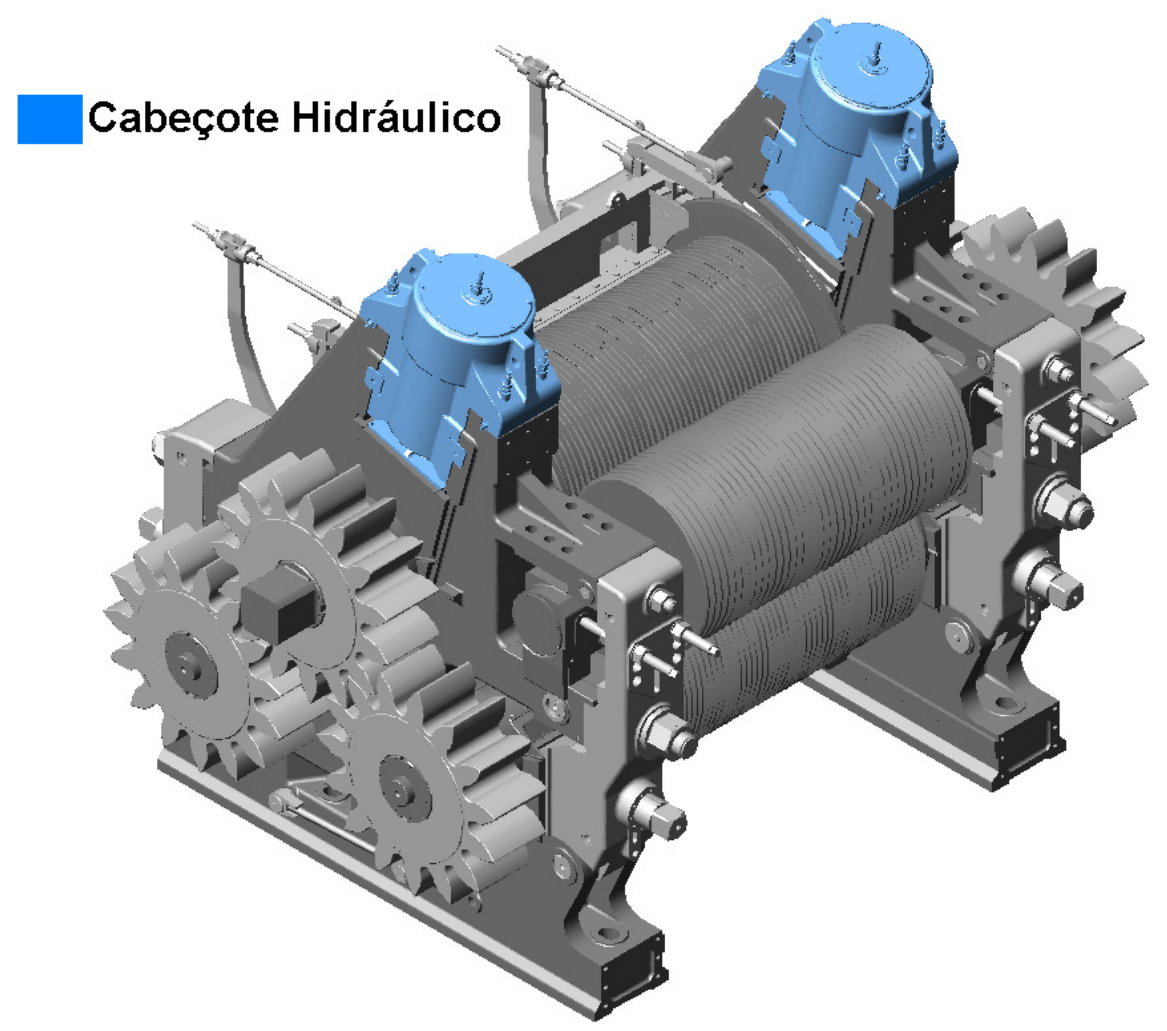

Figura 38: Localização dos cabeçotes hidráulicos no terno de moenda (DEDINI, 2007).

\subsubsection{Pente Superior e Inferior}

Fabricados geralmente em ferro fundido o pente inferior e em aço fundido o pente superior, são componentes com a finalidade de limpar as ranhuras ou frisos das camisas dos rolos de moenda. Tanto o pente inferior como o pente superior são localizados na parte traseira (saída) do terno. O pente inferior é responsável pela limpeza dos frisos do rolo inferior de saída, evitando assim o acúmulo de bagaço nos mesmo. O pente superior é responsável pela limpeza dos frisos da camisa do rolo superior e também pela drenagem do caldo através de um sistema de calhas. Os pentes são providos de um sistema de regulagem que assegura o posicionamento correto dos mesmos durante todo o período de moagem. A Figura 39 mostra o pente superior (em azul) e o pente inferior (em roxo) no conjunto do terno de moenda. 


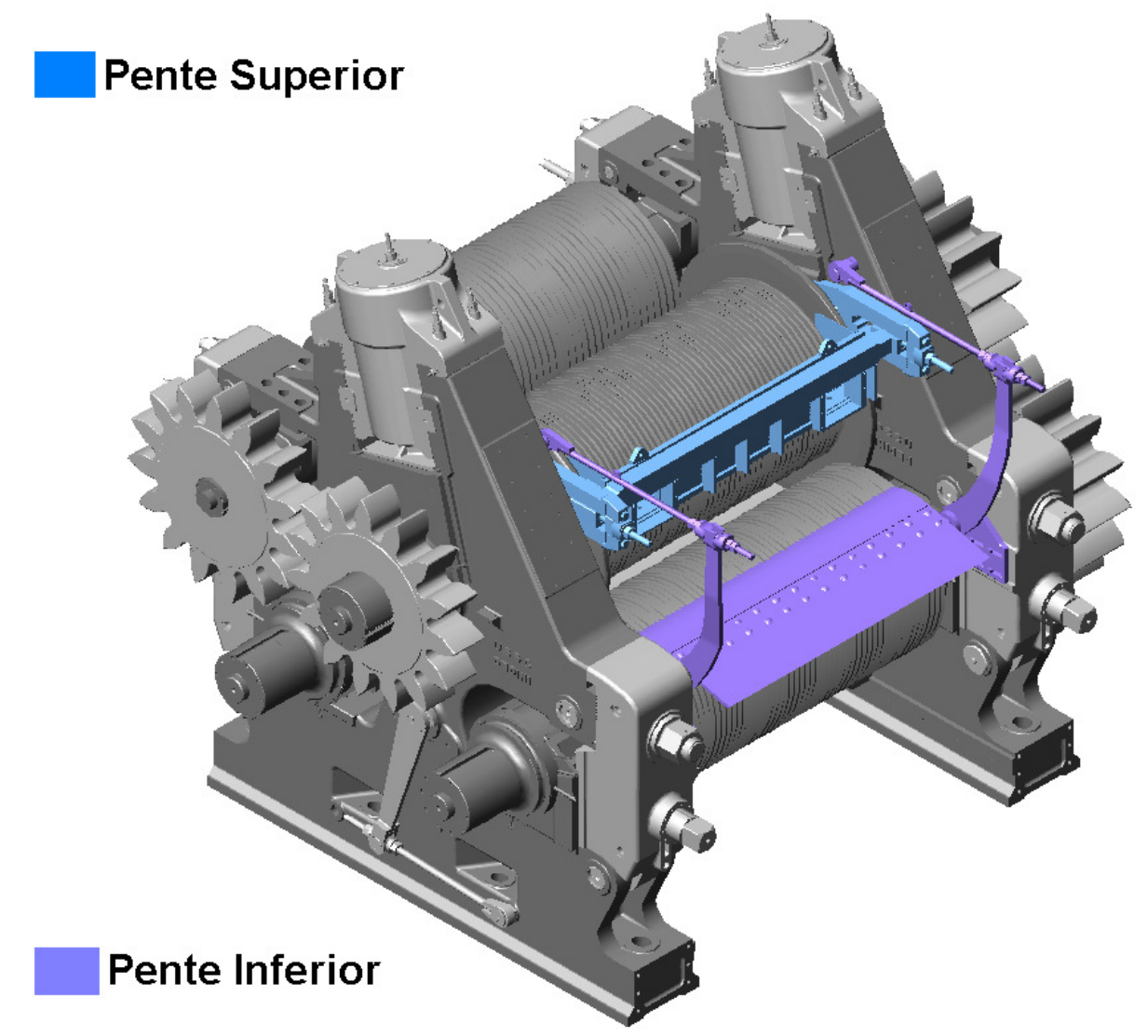

Figura 39: Pente superior e pente inferior do terno de moenda (DEDINI, 2007). 


\section{Materiais para Construção Mecânica}

Materiais são utilizados, na indústria, para a fabricação de produtos, transformando-os para melhorar o padrão de vida da sociedade. Os principais tipos de materiais utilizados pelo homem para a fabricação dos mais variados produtos são: madeira, aço, vidro, plásticos, borracha, alumínio, cobre, etc. (SMITH, 1998). Conforme Chung (2001), a aplicação dos materiais na engenharia requer que eles possuam algumas propriedades segundo as diferentes aplicações nos diversos campos da engenharia. O termo propriedade de um material está atrelado à característica do mesmo, em termos de tipo e magnitude, de responder a condições nas quais estará exposto durante o trabalho. As importantes propriedades de um material podem ser agrupadas em: mecânica, elétrica, térmica, magnética, ótica e deteriorativa. Para cada categoria há um estimulo que provoca diferentes respostas (CALLISTER, 1991).

Para Cheremisinoff (1996), a seleção e avaliação de materiais para a execução de projetos são de fundamental importância. Se realizado de uma maneira correta, podese economizar tempo e dinheiro na execução do projeto e ainda evitar erros. Os materiais utilizados devem, não só satisfazer as exigências de funcionalidade do produto, mas devem também satisfazer condições de segurança e ambientais. Algumas restrições e limitações para materiais na execução de projetos são

- Velocidade;

- Temperatura;

- Composição dos componentes;

- Carregamento estático e cíclico;

- Compatibilidade com materiais adjacentes.

$\mathrm{Na}$ engenharia, os materiais sólidos podem ser agrupados convenientemente em três grupos, a saber: materiais metálicos, poliméricos e cerâmicos. Por sua vez, os materiais metálicos são habitualmente divididos em duas classes: ferrosos e não ferrosos. A Figura 40 mostra os grupos de materiais. 


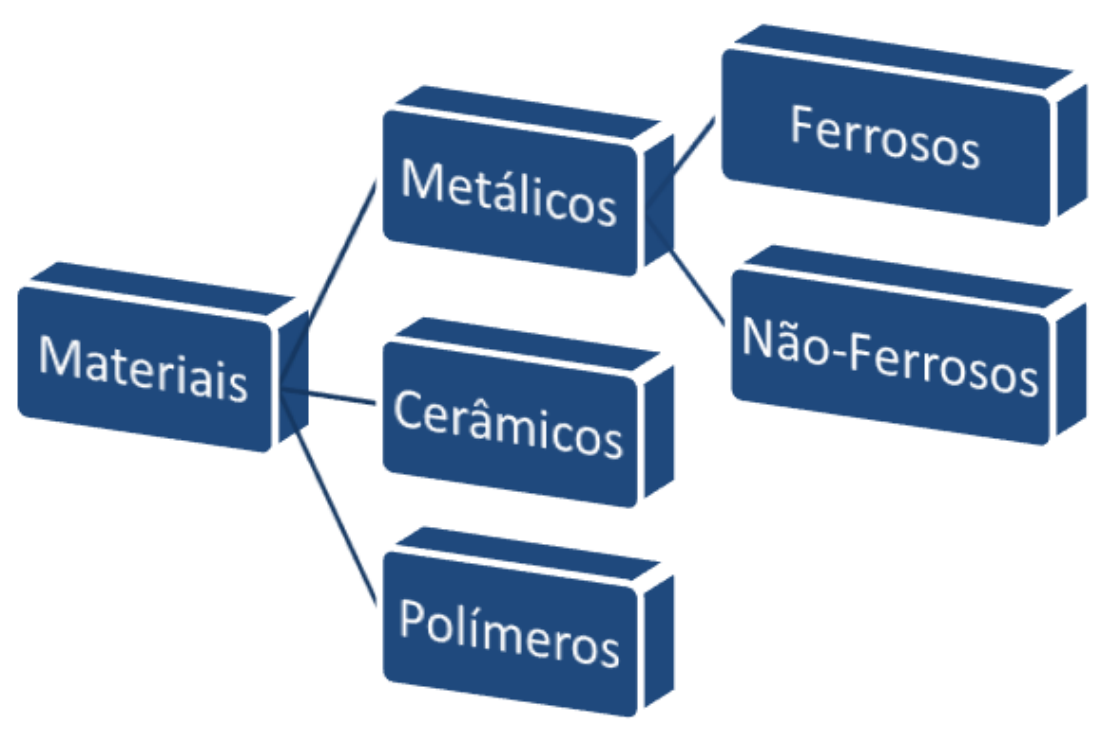

Figura 40: Classificação dos materiais.

Segundo Smith (1998), os materiais metálicos recebem este nome por conterem um, ou mais, elementos metálicos em sua composição podendo, também, conter alguns elementos não-metálicos. Os metais são geralmente bons condutores elétricos e possuem uma estrutura cristalina ${ }^{1}$ onde os átomos se dispõem ordenadamente. Como elementos metálicos podem-se citar alguns como o ferro, o alumínio, o níquel, o cobre, o titânio entre outros e, elementos não-metálicos pode-se citar o carbono, o oxigênio e outros. Os materias metálicos, como citado acima, são divididos em ferrosos, que posuem uma porcentagem de ferro elevada em sua composição, tais como o aço e os ferros fundidos, e os não-ferrosos, que não contém (ou a porcentagem é muito baixa) de ferro, como o alumínio, o cobre, o zinco e suas respectivas ligas.

A maioria dos materiais poliméricos é constituida por cadeias longas de moléculas orgânicas que possuem estruturas não-cristalinas ${ }^{2}$. Em termos de resistência mecânica, esta pode variar bastante, principalmente em diferentes temperaturas. São utilizados em larga escala em aplicações elétricas por serem bons isolantes e de baixo custo.

\footnotetext{
${ }^{1}$ Um material possui estrutura cristalina quando o arranjo dos átomos, íons e moléculas encontram-se num padrão que se repete nas três dimensões.

${ }^{2}$ Um material possui estrutura não-cristalina quando o arranjo dos átomos, íons e moléculas não encontram-se num padrão que se repete nas três dimensões.
} 
Segundo Callister (1991) os materiais cerâmicos são tipicamente isolantes à passagem de eletricidade e de calor. São constituído por elementos metálicos e nãometálicos, possuem boa resistência a temperaturas e são muito frágeis.

Os materiais possuem diversas aplicações em diferentes áreas, como exemplos são utilizados para aplicações estruturais, aplicações elétricas, aplicações civis entre outras. Em cada aplicação específica algumas propriedades são de vital importância. No presente capítulo será dada ênfase às aplicações estruturais e, assim serão discorridas propriedades relacionadas a esse fim.

Aplicações estruturais requerem do material desempenho mecânico, o qual é, geralmente, a capacidade do material suportar cargas, vibrações, etc. Como estruturas podem-se citar automóveis, aviões, navios e também componentes dessas estruturas. Outras propriedades além das mecânicas bastante utilizadas para materiais em estruturas é a baixa densidade e a resistência à corrosão. A primeira é importante quando o peso é uma característica desejável na estrutura e a segunda propriedade fundamental para a durabilidade da mesma (CHUNG, 2001).

\subsection{Propriedades Mecânicas dos Materiais}

Cada material possui alguns atributos agrupados sob o nome de propriedades mecânicas para o uso na engenharia. Assim, há a necessidade de uma combinação desses atributos a fim de satisfazer a real necessidade do presente projeto. Pode-se dividir as propriedades dos materiais em classes, cada qual contendo um grupo de propriedades para a utilização em diferentes áreas da engenharia como, por exemplo, na área mecânica onde algumas propriedades como as tensões de escoamento e tensão de ruptura, dureza, tenacidade, resistência à fadiga têm relevância sobre outras propriedades como, calor especifico, condutividade térmica, resistência ao choque térmico que são propriedades importantes para a área térmica (ASHBY, 1999).

Para Garcia (2000), as propriedades mecânicas de um material são o comportamento do mesmo quando submetido a uma carga externa, e são expressas em tensões e deformações. Entre as principais propriedades mecânicas pode-se citar a resistência, a elasticidade, a plasticidade, a resiliência e a tenacidade. 


\subsubsection{Conceito de Tensão e Deformação}

Conforme Callister (1991), um material solicitado por uma carga estática, ou aplicada lentamente no tempo, gera no mesmo uma deformação. Esse comportamento mecânico pode ser determinado por um simples teste de tensão-deformação na grande maioria dos casos. O sentido desta deformação é uma consequiência do tipo de carga aplicada ao material que pode se caracterizar por três tipos:

- Tensão de tração, gerando no material uma deformação linear positiva junto com uma elongação do material;

- Tensão de compressão, gerando no material uma deformação linear negativa junto com uma contração;

- Tensão de cisalhamento que na grande maioria dos casos na prática é substituído por uma tensão de torção, gerando uma deformação angular no material.

A Figura 41 mostra as deformações decorrente das cargas aplicadas aos materiais.
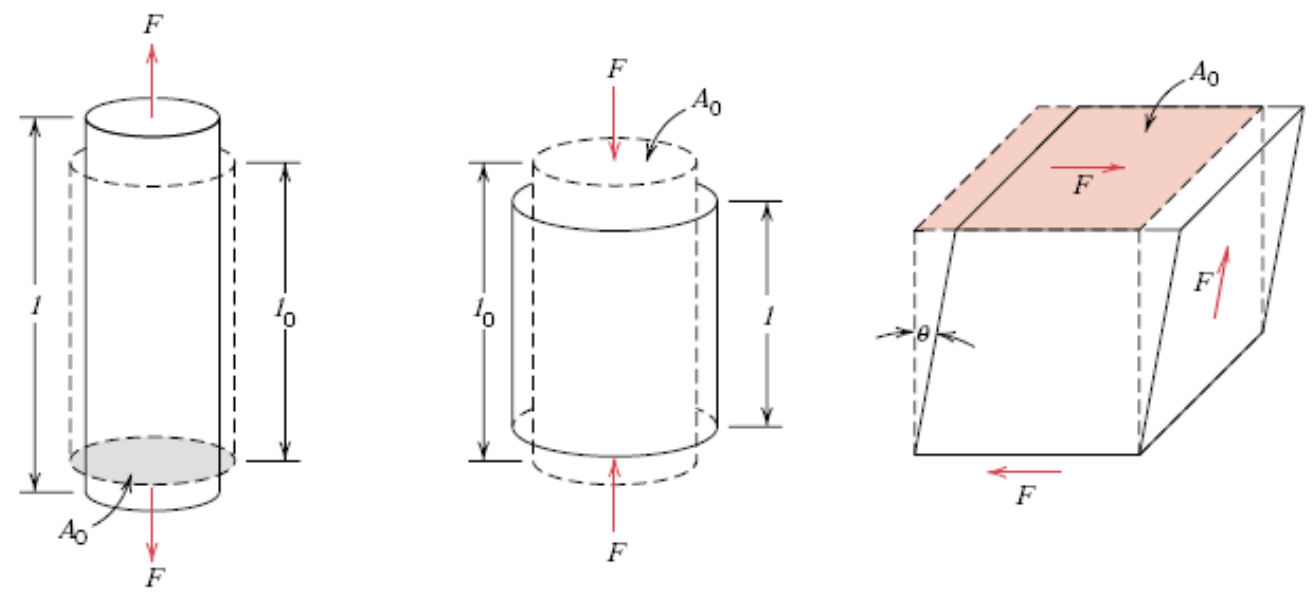

Figura 41: Tensão de tração, tensão de compressão e tensão de cisalhamento respectivamente. As linhas tracejadas representam o material sem aplicação de cargas e as linhas cheias representam o material deformado após a aplicação das cargas (CALLISTER, 1991).

Tanto a tensão de tração como a tensão de compressão podem ser definidas como:

$$
\sigma=\frac{F}{A_{0}}
$$

Onde: $\sigma=$ tensão $(\mathrm{Pa})$; 
$\mathrm{F}$ = força aplicada normal á área $\mathrm{A}_{0}(\mathrm{~N})$;

$\mathrm{A}_{0}=$ área perpendicular a aplicação da força $\left(\mathrm{m}^{2}\right)$.

A deformação linear positiva ou negativa, em engenharia, decorrente da tensão de tração ou de compressão, ambas, podem ser expressas como:

$$
\varepsilon=\frac{l-l_{0}}{l_{0}}
$$

Onde: $\varepsilon=$ deformação (adimensional);

$1_{0}=$ comprimento inicial de referência sem aplicação da força $(\mathrm{m}) ;$

1 = comprimento após a aplicação da força (m).

A tensão de cisalhamento é calculada conforme a relação:

$$
\tau=\frac{F}{A_{0}}
$$

Onde: $\tau=$ tensão de cisalhamento $(\mathrm{Pa})$;

$\mathrm{F}=$ força aplicada tangencial à área $\mathrm{A}_{0}(\mathrm{~N}) ;$

$\mathrm{A}_{0}=$ área paralela a aplicação da força $\left(\mathrm{m}^{2}\right)$.

A deformação quando aplicada uma tensão de cisalhamento pode ser obtida através da seguinte expressão:

$$
\gamma=\tan \theta
$$

Onde: $\gamma=$ deformação cisalhante (adimensional);

$\theta$ = ângulo de deformação (radianos);

\subsubsection{Materiais Elásticos e Materiais Plásticos}


Diz-se que um material é elástico quando aplicada uma carga, o mesmo sofre deformação e, após a retirada dessa carga retorna as dimensões originais. Isso é possível, pois os átomos do material se afastam das posições originais sem, no entanto ocuparem novas posições. A maioria dos materiais de engenharia possui características elásticas em certo limite de tensão e deformação.

Materiais totalmente plásticos são matérias que, ao receberem uma carga se deformam definitivamente. Isso é consequiência do deslocamento permanente dos átomos que constituem o mesmo. A capacidade de deformação plástica dos materiais é uma das mais importantes propriedades, pois permite a confecções de peças, ou componentes, usando-se esta propriedade sem que haja ruptura (MEGSON, 1996 \& SMITH, 1998).

Segundo Garcia (2000) numa curva típica de tensão por deformação, há a existência de quatro regiões de comportamentos distintos, a saber:

- Região de comportamento elástico, OA;

- Região de escoamento de discordâncias, $\mathrm{AB}$;

- Região de encruamento uniforme, BU;

- Região de encruamento não-uniforme, UF.

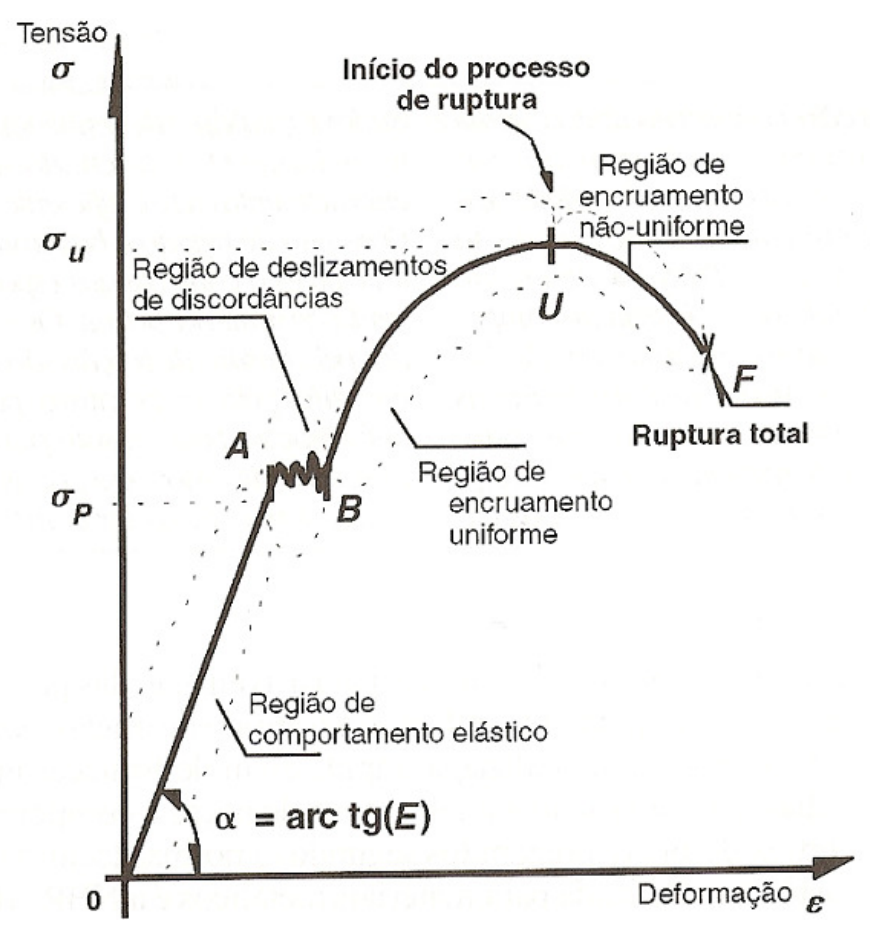

Figura 42: Curva típica da tensão- deformação (GARCIA e SANTOS, 2000) 
Em Chistopher (2000), são visualizados alguns pontos importantes na curva tensão-deformação dos materias como o limite proporcional (A), onde começa a divergir a proporcionalidade da relação tensão-deformação, limite de escoamento localizado logo após o limite proporcional, que é a máxima tensão que pode ser apliacada ao material sem que ele sofra deformação permanente e por fim o limite de ruptura (U) que representa a tensão máxima obtida na curva tensão-deformação. $\mathrm{Na}$ prática observa-se grande variação da curva tensão-deformação para diferentes materiais como ilustrado na Figura 43.

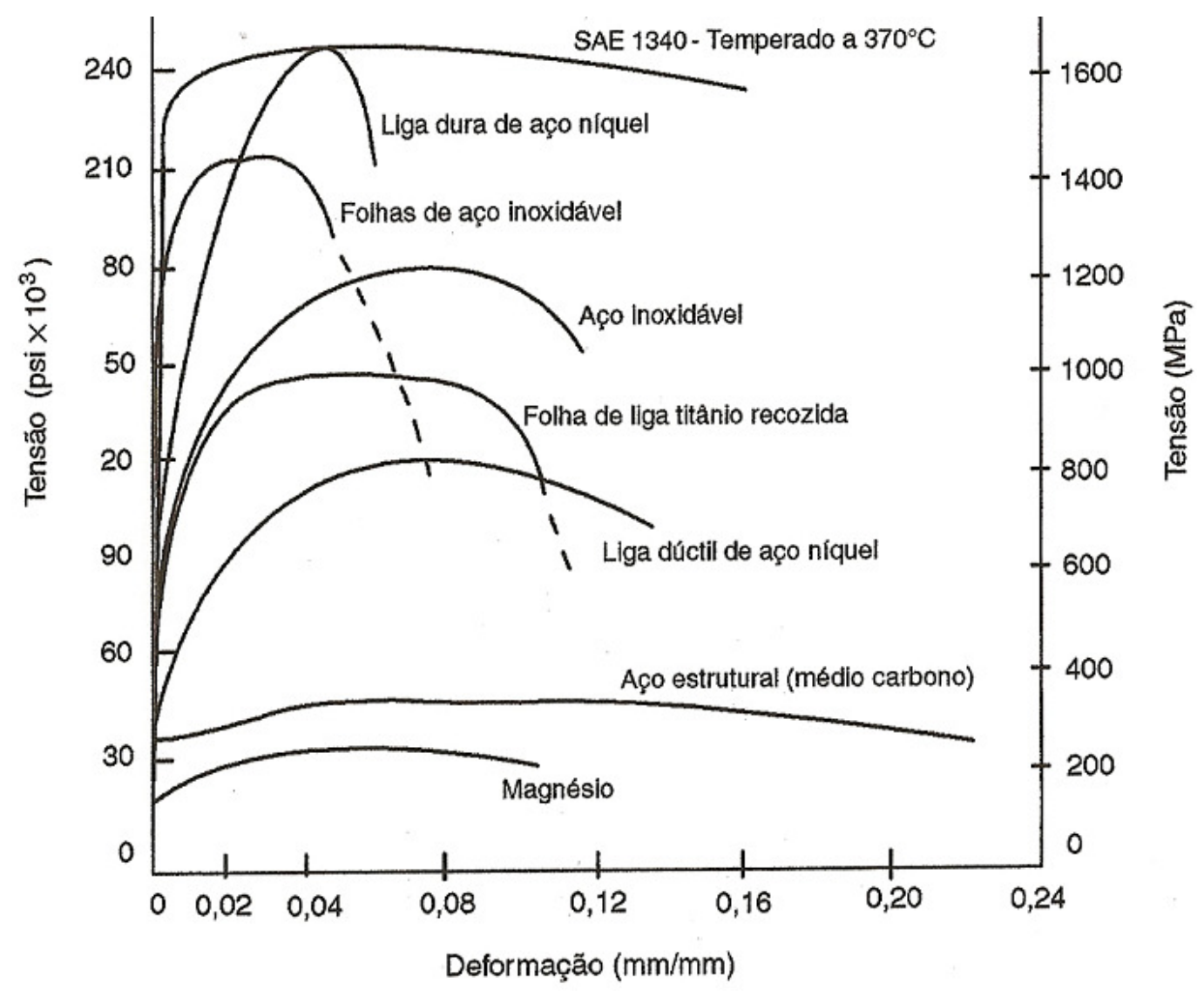

Figura 43: Curva tensão- deformação para alguns materiais (GARCIA e SANTOS, 2000)

\subsubsection{Módulo de Elasticidade}

Para Hearn (1997) uma forma particular da elasticidade que se aplica à grande maioria dos materiais submetidos a tração ou compressão, é que as deformações são 
proporcionais às tensões aplicadas e vice-versa. A lei de Hooke, em sua forma mais simples nos dá:

$$
\frac{\text { Tensão }}{\text { Deformação }}=\text { Const } \text {. }
$$

Está lei é obedecida pela maioria dos materiais dentro da região elástica. Assim, dentro dos limites elásticos dos materiais, isto é, dentro dos limites em que a lei de Hooke é aplicável, tem-se:

$$
E=\frac{\sigma}{\varepsilon}=\frac{\text { Tensão }}{\text { Deformação }}=\frac{F}{A_{0}} \times \frac{l_{0}}{l-l_{0}}
$$

Onde: $\mathrm{E}=$ módulo de elasticidade $(\mathrm{Pa})$;

$\sigma=$ tensão de tração ou compressão $(\mathrm{Pa})$;

$\varepsilon=$ deformação (adimensional).

O módulo de elasticidade $E$ como visto, é a constante que define a relação entre tensão e deformação, dentro do limite elástico, aplicável para a maioria dos materiais. O valor do módulo de elasticidade para o aço é de aproximadamente $207 \mathrm{GPa}$. Segundo Callister (1991) o módulo de elasticidade pode ser interpretado como a resistência do material à deformação no regime elástico para uma dada carga aplicada. A Figura 44 correlaciona linearmente a tensão e a deformação, sendo que a inclinação desse segmento corresponde ao módulo de elasticidade $E$.

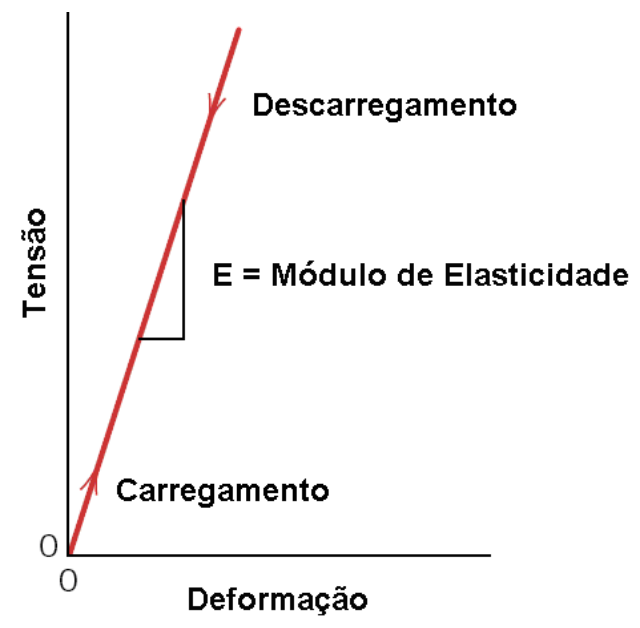

Figura 44: Diagrama Esquemático tensão-deformação mostrando deformação elástica linear para ciclos de carregamento e descarregamento (CALLISTER, 1991). 
A tabela abaixo dá o módulo de elasticidade de alguns dos principais materiais de uso na engenharia.

\begin{tabular}{|c|c|}
\hline Material & $\begin{array}{c}\text { Módulo de Elasticidade } \\
\text { E (GPA) }\end{array}$ \\
\hline \hline Aço & 210 \\
\hline Ferro Fundido & 100 \\
\hline Bronze & 112 \\
\hline Alumínio & 70 \\
\hline Cobre & 112 \\
\hline
\end{tabular}

Tabela 5: Módulo de elasticidade (E) dos materiais utilizado na engenharia (MELCONIAN, 2006)

\subsubsection{Módulo de Elasticidade Transversal}

Corresponde a um caso particular do módulo de elasticidade onde a força aplicada nesta situação é a de cisalhamento e não de compressão ou tração. Assim, dentro do regime elástico a tensão de cisalhamento é proporcional a deformação angular. Como o módulo de elasticidade, pela lei de Hooke, a tensão de cisalhamento em qualquer ponto do material no regime elástico é dada por: (GARCIA, 2000).

$$
G=\frac{\tau}{\gamma}=\frac{\text { Tensão }}{\text { Deformação }}=\frac{F}{A_{0}} \times \frac{l_{0}}{l-l_{0}}
$$

Onde: $\mathrm{G}=$ módulo de elasticidade transversal $(\mathrm{Pa})$;

$\tau=$ tensão de cisalhamento $(\mathrm{Pa})$;

$\gamma=$ deformação angular (adimensional).

A tabela abaixo dá o módulo de elasticidade transversal dos principais materiais de uso na engenharia. 


\begin{tabular}{|c|c|}
\hline Material & $\begin{array}{c}\text { Módulo de Elasticidade } \\
\text { Transversal G (GPA) }\end{array}$ \\
\hline \hline Aço & 80 \\
\hline Ferro Fundido & 88 \\
\hline Bronze & 50 \\
\hline Alumínio & 26 \\
\hline Cobre & 45 \\
\hline
\end{tabular}

Tabela 6: Módulo de elasticidade transversal (G) dos materiais utilizado na engenharia (MELCONIAN, 2006)

\subsubsection{Coeficiente de Poisson}

Segundo Megson (1996), na região onde a curva tensão-deformação de um material é linear, a relação da deformação lateral com a deformação longitudinal é uma constante denominada coeficiente de Poisson, ou seja, esse coeficiente mede a rigidez do material na direção perpendicular à direção de aplicação da carga. O efeito é ilustrado na Figura 45.

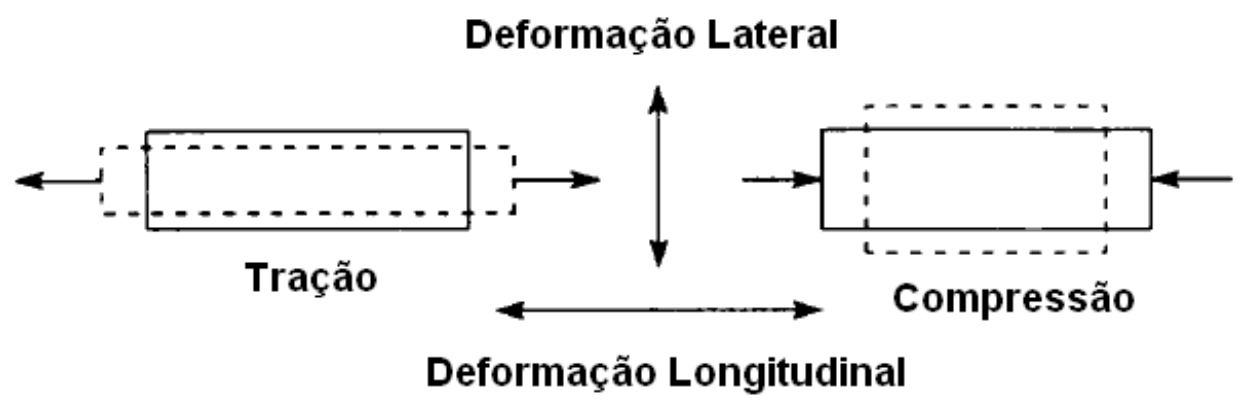

Figura 45: Efeito do coeficiente de Poisson. As linhas tracejadas representam o material com a carga aplicada e as linhas cheias representam o material sem carga aplicada. Fonte: (MEGSON, 1996).

O valor numérico do coeficiente de Poisson, considerando a aplicação da carga na direção de $Z$, é determinado por: 


$$
v=-\frac{\varepsilon_{x}}{\varepsilon_{z}}=-\frac{\varepsilon_{y}}{\varepsilon_{z}}
$$

Onde: $v=$ coeficiente de Poisson (adimensional);

$\varepsilon_{\mathrm{x}}-\varepsilon_{\mathrm{y}}=$ deformação transversal (adimensional);

$\varepsilon_{\mathrm{z}}=$ deformação longitudinal (adimensional).

O módulo de elasticidade e o módulo de elasticidade transversal, juntamente com o coeficiente de Poisson, estão relacionados entre si de acordo com a equação:

$$
E=2 \times G \times(1+v) \quad \text { ou } \quad G=\frac{E}{2 \times(1+v)}
$$

Onde: $\mathrm{E}=$ módulo de elasticidade $(\mathrm{Pa})$;

$\mathrm{G}=$ módulo de elasticidade transversal $(\mathrm{Pa})$;

$v=$ coeficiente de Poisson (adimensional).

A Tabela 07 dá o coeficiente de Poisson dos principais materiais de uso na engenharia.

\begin{tabular}{|c|c|}
\hline Material & $\begin{array}{c}\text { Coeficiente de Poisson } \\
(\mathbf{v})\end{array}$ \\
\hline \hline Aço & $0,25-0,33$ \\
\hline Ferro Fundido & $0,23-0,27$ \\
\hline Bronze & $0,32-0,35$ \\
\hline Alumínio & $0,32-0,36$ \\
\hline Cobre & $0,31-0,34$ \\
\hline
\end{tabular}

Tabela 7: Coeficiente de Poisson (v) dos materiais utilizado na engenharia (MELCONIAN, 2006) 


\subsection{Principais Materiais Utilizados na Construção Mecânica}

\subsubsection{Aços ao Carbono}

Aços ao carbono são ligas de ferro e carbono, com o carbono dentro de um teor de até $2 \%$ mais silício, cobre e manganês limitados a determinadas porcentagens. São encontrados comercialmente nas mais variadas formas, como por exemplo, chapas, eixos, tubos entre outros. São utilizados em grande escala nas indústrias automobilísticas, eletrodomésticos, projeto de máquinas, membros estruturais, etc. (HARPER, 2001). Nas palavras de Melconian (2006, p.70) "aço é um produto siderúrgico que se obtém por via líquida, cujo teor de carbono não supera a $2 \%$ ". Ainda segundo Melconian (2006), o aço pode ser classificado de acordo com a porcentagem de carbono existente, assim, aço extra doce contém até $0,15 \% \mathrm{C}$, aço doce entre $0,15 \%$ a $0,30 \% \mathrm{C}$, aço meio doce com $0,30 \%$ a $0,40 \% \mathrm{C}$, aço meio duro $0,40 \%$ a $0,60 \% \mathrm{C}$, aço duro $0,60 \%$ a $0,70 \% \mathrm{C}$ e o aço extra duro com uma porcentagem acima de $0,70 \% \mathrm{C}$.

Conforme Faires (1974), aço fundido é um material ferroso com teores de carbono que se situam em torno de 0,25 a 0,50\%. Nos aços fundidos consegue-se uma boa combinação de alta resistência e alta ductibilidade. Normalmente são tratados termicamente após sua confecção. De um modo geral há uma grande variedade de aços, pois além dos aços simplesmente ao carbono há também os aços ligados. Assim para facilitar sua seleção, associações técnicas classificaram os aços pela sua composição química dando origem aos sistemas: Society of Automotive Engineers - SAE, American Iron Steel Institute - AISI, Deutsche Industrie Normen - DIN e a Associação Brasileira de Normas Técnicas - ABNT (CUNHA, 2002). Segundo ainda Cunha (2002), na ABNT os aços são indicados por quatro algarismos, cada qual com seu significado. O primeiro algarismo indica a classe do aço, o segundo algarismo indica a porcentagem do elemento de liga e os dois últimos algarismos indicam a porcentagem de carbono. A Figura 46 mostra a designação de um aço segundo a norma ABNT. 


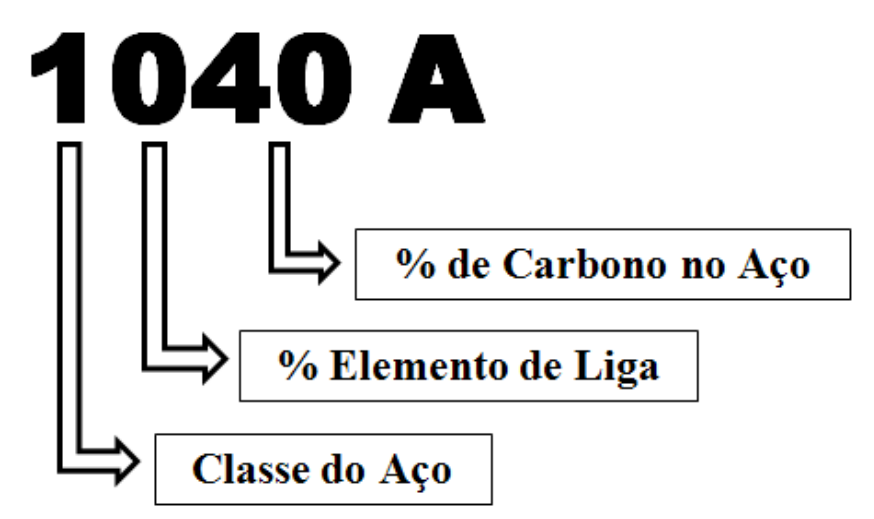

Figura 46: Designação do aço conforme o sistema ABNT.

\subsubsection{Ferro Fundido}

De acordo com Chiaverini (1986), pode-se considerar ferro fundido como uma liga de ferro e carbono cujo teor de carbono ultrapassa os $2 \%$. Sua composição química é um fator importante para a determinação da estrutura dos mesmos. Dois fatores têm grande importância sob o ponto de vista da estrutura: o teor de silício, o qual favorece a decomposição do carboneto de ferro transformando-o em ferro fundido cinzento ou branco, e a velocidade de resfriamento que, quando elevada causa pouca, ou nenhuma, decomposição de cementita levando ao aparecimento do ferro fundido branco. Quando a velocidade de resfriamento é lenta, dá-se tempo para a decomposição da cementita favorecendo o aparecimento do ferro fundido cinzento. A maioria dos ferros fundidos comercialmente disponíveis possui entre $2,5-4 \%$ de carbono e suas propriedades mecânicas são determinadas pela estrutura ferrita-perlita, sendo a ferrita responsável pela ductilidade e a perlita pela fragilidade do ferro fundido (CHEREMISINOFF, 1996).

Segundo ainda Chiaverini (1986), os ferros fundidos mais comuns são:

- Ferro fundido branco - caracteriza-se pela cor devido ao carbono quase que inteiramente combinado na forma $\mathrm{Fe}_{3} \mathrm{C}$. Possui elevada dureza e resistência ao desgaste.

- Ferro fundido cinzento - é o mais usual dos ferros fundidos. Possui excelente usinabilidade combinada a resistência mecânica satisfatória e boa capacidade de amortecimento a vibrações e boa resistência ao desgaste. 
- Ferro fundido nodular - sua principal característica é a elevada resistência mecânica, tenacidade e ductilidade. Possui também limite de escoamento maior dos que os outros ferros fundidos.

\subsubsection{Bronze}

O bronze é uma liga de cobre e estanho e, quando oferecida comercialmente tem o teor de estanho entre 2- 10\%. Possui elevada resistência à corrosão, o que eleva sua frequiência de utilização nos diferentes campos da engenharia. Em sua composição química, o aumento do teor de estanho aumenta também a resistência mecânica sem afetar sua ductilidade. Essas propriedades são ainda melhoradas com a adição de até 0,40\% de fósforo. Uma importante utilização dos bronzes em peças fundidas é para fabricação de mancais, atingindo um limite de escoamento que varia de $98 \mathrm{MPa}$ a 176 MPa para as ligas que contém maior teor de chumbo (CHIAVERINI, 1986).

\subsection{Materiais dos Componentes do Terno de Moenda e suas Propriedades}

A maioria dos componentes do terno de moenda é fabricada em aço fundido, sendo também utilizados materiais como o ferro fundido e o bronze, entre outros. Nesta seção serão especificadas algumas propriedades mecânicas dos materiais particularmente utilizados nos componentes do terno de moenda. Serão abordadas as principais propriedade necessárias para do cumprimento dos objetivos do presente trabalho.

\subsubsection{Material dos Castelos}

Os castelos são fabricados em aço carbono ADZ-25, material este desenvolvido pela Dedini Indústrias de base, sendo suas principais propriedades mecânicas citadas abaixo: 
- Limite de resistência $\left(\sigma_{t}\right)$

$\Longrightarrow \quad 490 \mathrm{MPa}$

- Limite de escoamento $\left(\sigma_{\mathrm{e}}\right) \quad \Longrightarrow \quad 255 \mathrm{MPa}$;

- Módulo de elasticidade (E) $\quad \longrightarrow \quad 206 \mathrm{GPa}$;

- Coeficiente de Poisson (v) $\quad \longrightarrow \quad 0,30$;

- Densidade $(\gamma) \quad \longrightarrow \quad 7800 \mathrm{~kg} / \mathrm{m}^{3}$.

\subsubsection{Materiais do Sistema de Regulagem da Bagaceira}

O sistema de regulagem da bagaceira é composto pelos componentes: bagaceira, balança, suporte da balança e pino excêntrico conforme já mencionado e ilustrado na Figura 25. A bagaceira, principal componente deste sistema, é fabricada em aço fundido ADZ-45, cujas propriedades mecânicas são:

- Limite de resistência $\left(\sigma_{\mathrm{t}}\right) \quad \Longrightarrow \quad 590 \mathrm{MPa}$;

- Limite de escoamento $\left(\sigma_{\mathrm{e}}\right) \quad \Longrightarrow \quad 314 \mathrm{MPa}$;

- Módulo de elasticidade (E) $\quad \longrightarrow \quad 206 \mathrm{GPa}$;

- Coeficiente de Poisson (v) $\quad \longrightarrow \quad 0,30$;

- Densidade $(\gamma) \quad \longrightarrow \quad 7800 \mathrm{~kg} / \mathrm{m}^{3}$.

O suporte da balança e a balança são fabricados em aço fundido ADZ-20, o qual possui as seguintes propriedades mecânicas:

- Limite de resistência $\left(\sigma_{\mathrm{t}}\right) \quad \Longrightarrow \quad 510 \mathrm{MPa}$;

- Limite de escoamento $\left(\sigma_{\mathrm{e}}\right) \quad \Longrightarrow \quad 275 \mathrm{MPa}$;

- Módulo de elasticidade (E) $\quad \longrightarrow \quad 206 \mathrm{GPa}$;

- Coeficiente de Poisson $(v) \quad \longrightarrow \quad 0,30$;

- Densidade $(\gamma) \quad \longrightarrow \quad 7800 \mathrm{~kg} / \mathrm{m}^{3}$.

Por fim o pino excêntrico é fabrico em aço médio carbono SAE-1045 com as seguintes propriedades mecânicas:

$\begin{array}{lll}\text { - Limite de resistência }\left(\sigma_{\mathrm{t}}\right) & \longrightarrow & 615 \mathrm{MPa} ; \\ \text { - Limite de escoamento }\left(\sigma_{\mathrm{e}}\right) & \longrightarrow & 274 \mathrm{MPa} ;\end{array}$ 
$\begin{array}{lll}\text { - Módulo de elasticidade (E) } & \longrightarrow & 206 \mathrm{GPa} ; \\ \text { - Coeficiente de Poisson }(v) & \longrightarrow & 0,30 ; \\ \text { - Densidade }(\gamma) & \longrightarrow & 7800 \mathrm{~kg} / \mathrm{m}^{3} .\end{array}$

\subsubsection{Material dos Cabeçotes Laterais}

Os cabeçotes laterais, conforme ilustrado na Figura 27, tanto os de entrada como os de saída são fabricados em aço fundido ADZ-25 com as seguintes propriedades mecânicas:

- Limite de resistência $\left(\sigma_{\mathrm{t}}\right) \quad \Longrightarrow \quad 490 \mathrm{MPa}$;

- Limite de escoamento $\left(\sigma_{\mathrm{e}}\right) \quad \Longrightarrow 255 \mathrm{MPa}$;

- Módulo de elasticidade (E) $\quad \longrightarrow \quad 206 \mathrm{GPa}$;

- Coeficiente de Poisson $(v) \quad \longrightarrow \quad 0,30$;

- Densidade $(\gamma) \quad \longrightarrow \quad 7800 \mathrm{~kg} / \mathrm{m}^{3}$.

\subsubsection{Materiais dos Rolos do Terno de Moeda}

Todos os rolos de moenda (inferiores, superior e de pressão), conforme descritos nos itens 4.1.4 a 4.1.6, possuem os seguintes componentes: eixo, camisa, rodete, caixa de mancal, semi-casquilho.

Os eixos de moendas são fabricados em aço forjado SAE-1045 que possuem as seguintes propriedades mecânicas:

- Limite de resistência $\left(\sigma_{\mathrm{t}}\right) \quad \Longrightarrow \quad 580 \mathrm{MPa}$;

- Limite de escoamento $\left(\sigma_{\mathrm{e}}\right) \quad \Longrightarrow \quad 280 \mathrm{MPa}$;

- Módulo de elasticidade (E) $\quad \Longrightarrow \quad 206 \mathrm{GPa}$;

- Coeficiente de Poisson (v) $\quad \longrightarrow \quad 0,30$;

- Densidade $(\gamma) \quad \Longrightarrow \quad 7800 \mathrm{~kg} / \mathrm{m}^{3}$.

As camisas para os rolos de moendas são fabricadas em ferro fundido FDZ-25, cujas propriedades mecânicas são: 
- Limite de resistência $\left(\sigma_{\mathrm{t}}\right)$

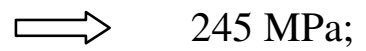

- Módulo de elasticidade (E)

$\Longrightarrow \quad 100 \mathrm{GPa}$;

- Coeficiente de Poisson (v)

$\Longrightarrow \quad 0,25$;

- Densidade $(\gamma)$

$7700 \mathrm{~kg} / \mathrm{m}^{3}$.

Os rodetes de moenda, cuja função é transmissão de torque, são fabricados em aço fundido ADZ-40, o qual possui as seguintes propriedades mecânicas:

- Limite de resistência $\left(\sigma_{\mathrm{t}}\right) \quad \Longrightarrow \quad 620 \mathrm{MPa}$;

- Limite de escoamento $\left(\sigma_{\mathrm{e}}\right) \quad \Longrightarrow \quad 410 \mathrm{MPa}$;

- Módulo de elasticidade (E) $\quad \Longrightarrow \quad 206 \mathrm{GPa}$;

- Coeficiente de Poisson (v) $\quad \longrightarrow \quad 0,30$;

- Densidade $(\gamma) \quad \Longrightarrow \quad 7800 \mathrm{~kg} / \mathrm{m}^{3}$.

As caixas de mancais, tanto para os rolos inferiores como para o rolo superior e o rolo de pressão são fabricadas em aço fundido ADZ-25 que possui as seguintes propriedades mecânicas:

- Limite de resistência $\left(\sigma_{\mathrm{t}}\right) \quad \Longrightarrow \quad 490 \mathrm{MPa}$;

- Limite de escoamento $\left(\sigma_{\mathrm{e}}\right) \quad \Longrightarrow \quad 255 \mathrm{MPa}$;

- Módulo de elasticidade (E) $\quad \Longrightarrow \quad 206 \mathrm{GPa}$;

- Coeficiente de Poisson $(v) \quad \Longrightarrow \quad 0,30$;

- Densidade $(\gamma) \quad \Longrightarrow \quad 7800 \mathrm{~kg} / \mathrm{m}^{3}$.

Por fim os semi-casquilhos dos mancais dos rolos de moenda são fabricados em bronze BD-01, cujas propriedades mecânicas são:

- Limite de resistência $\left(\sigma_{\mathrm{t}}\right) \quad \Longrightarrow \quad 195 \mathrm{MPa}$;

- Limite de escoamento $\left(\sigma_{\mathrm{e}}\right) \quad \Longrightarrow \quad 98 \mathrm{MPa}$;

- Módulo de elasticidade (E) $\quad \Longrightarrow \quad 109 \mathrm{GPa}$;

- Coeficiente de Poisson (v) $\quad \longrightarrow \quad 0,30$;

- Densidade $(\gamma) \quad \Longrightarrow \quad 8700 \mathrm{~kg} / \mathrm{m}^{3}$. 


\subsubsection{Materiais dos Cabeçotes Hidráulicos}

Conforme mostra a Figura 36, os principais componentes dos cabeçotes hidráulicos são: corpo, bucha, bloco de fechamento, pistão e rótula.

Os corpos dos cabeçotes hidráulicos são fabricados em aço fundido ADZ-25, o qual possui as seguintes propriedades mecânicas:

$\begin{array}{lll}\text { - Limite de resistência }\left(\sigma_{\mathrm{t}}\right) & \longrightarrow & 490 \mathrm{MPa} ; \\ \text { - Limite de escoamento }\left(\sigma_{\mathrm{e}}\right) & \longrightarrow & 255 \mathrm{MPa} ; \\ \text { - Módulo de elasticidade }(\mathrm{E}) & \longrightarrow & 206 \mathrm{GPa} ; \\ \text { - Coeficiente de Poisson }(v) & \longrightarrow & 0,30 ; \\ \text { - Densidade }(\gamma) & \longrightarrow & 7800 \mathrm{~kg} / \mathrm{m}^{3} \text {. }\end{array}$

As buchas dos cabeçotes hidráulicos, sobre a qual o pistão se movimenta, são fabricadas em bronze BD-01 com as seguintes propriedades mecânicas:

- Limite de resistência $\left(\sigma_{\mathrm{t}}\right) \quad \longrightarrow \quad \longrightarrow 195 \mathrm{MPa}$;

- Limite de escoamento $\left(\sigma_{\mathrm{e}}\right) \quad \Longrightarrow \quad 98 \mathrm{MPa}$;

- Módulo de elasticidade (E) $\quad \Longrightarrow \quad 109 \mathrm{GPa}$;

- Coeficiente de Poisson (v) $\quad \longrightarrow \quad 0,30$;

- Densidade $(\gamma) \quad \longleftrightarrow \quad 8700 \mathrm{~kg} / \mathrm{m}^{3}$.

Os blocos de fechamento são fabricados em aço fundido ADZ-35 que possui as seguintes propriedades mecânicas:

- Limite de resistência $\left(\sigma_{\mathrm{t}}\right) \quad \Longrightarrow \quad 550 \mathrm{MPa}$;

- Limite de escoamento $\left(\sigma_{\mathrm{e}}\right) \quad \Longrightarrow \quad 354 \mathrm{MPa}$;

- Módulo de elasticidade (E) $\quad \longrightarrow \quad 206 \mathrm{GPa}$;

- Coeficiente de Poisson $(v) \quad \longrightarrow \quad 0,30$;

- Densidade $(\gamma) \quad \longrightarrow \quad 7800 \mathrm{~kg} / \mathrm{m}^{3}$.

Os pistões, responsáveis pela transmissão da pressão hidráulica para o rolo superior, são fabricados em aço fundido ADZ-45, cujas propriedades mecânicas são:

- Limite de resistência $\left(\sigma_{\mathrm{t}}\right) \quad \Longrightarrow \quad 590 \mathrm{MPa}$; 
- Limite de escoamento $\left(\sigma_{\mathrm{e}}\right) \quad \Longrightarrow \quad 314 \mathrm{MPa}$;

- Módulo de elasticidade (E) $\quad \longrightarrow \quad 206 \mathrm{GPa}$;

- Coeficiente de Poisson (v) $\quad \longrightarrow \quad 0,30$;

- Densidade $(\gamma) \quad \Longrightarrow \quad 7800 \mathrm{~kg} / \mathrm{m}^{3}$.

Por fim as rótulas, que possuem nas extremidades geometria esféricas para anular esforços laterais na transmissão da pressão hidráulica para o rolo superior, são fabricadas em aço médio carbono SAE-1045 com as seguintes propriedades mecânicas:

- Limite de resistência $\left(\sigma_{\mathrm{t}}\right) \quad \Longrightarrow \quad 615 \mathrm{MPa}$

- Limite de escoamento $\left(\sigma_{\mathrm{e}}\right) \quad \Longrightarrow \quad 274 \mathrm{MPa}$;

- Módulo de elasticidade (E) $\quad \longrightarrow \quad 206 \mathrm{GPa}$;

- Coeficiente de Poisson $(v) \quad \Longrightarrow \quad 0,30$;

- Densidade $(\gamma) \quad \Longrightarrow \quad 7800 \mathrm{~kg} / \mathrm{m}^{3}$.

\subsubsection{Materiais dos Pentes}

O pente superior como mostra a Figura 38, é fabricados em aço fundido ADZ-

45, o qual possui as seguintes propriedades mecânicas:

- Limite de resistência $\left(\sigma_{\mathrm{t}}\right) \quad \Longrightarrow \quad 590 \mathrm{MPa}$;

- Limite de escoamento $\left(\sigma_{\mathrm{e}}\right) \quad \Longrightarrow \quad 314 \mathrm{MPa}$;

- Módulo de elasticidade (E) $\quad \longrightarrow \quad 206 \mathrm{GPa}$;

- Coeficiente de Poisson $(v) \quad \longrightarrow \quad 0,30$;

- Densidade $(\gamma) \quad \longleftrightarrow \quad 7800 \mathrm{~kg} / \mathrm{m}^{3}$.

O pente inferior como também mostra a Figura 38, é fabricados em ferro fundido FDZ-25, cujas propriedades mecânicas são:

- Limite de resistência $\left(\sigma_{\mathrm{t}}\right) \quad \Longrightarrow \quad 245 \mathrm{MPa}$;

- Módulo de elasticidade (E) $\quad \longrightarrow \quad 100 \mathrm{GPa}$;

- Coeficiente de Poisson (v) $\quad \longrightarrow \quad 0,25$;

- Densidade $(\gamma) \quad \Longleftrightarrow \quad 7700 \mathrm{~kg} / \mathrm{m}^{3}$. 


\subsubsection{Materiais de outros Componentes}

Materiais de outros componentes do terno de moenda serão apresentados por serem de suma importância ao objetivo deste trabalho . Estes componentes, na sua grande maioria são responsáveis pela fixação e movimentação dos principais componentes, citados até então, do terno de moenda. Os componentes a que se refere o presente item são:

- Placas guias laterais e centrais;

- Placa de apoio do pistão;

- Parafusos articulado;

- Parafusos de regulagem;

- Pinos de articulação;

- Porcas;

- Chavetas.

Os componentes acima citados são mostrado na Figura 47, bem como suas localizações no terno de moenda. 


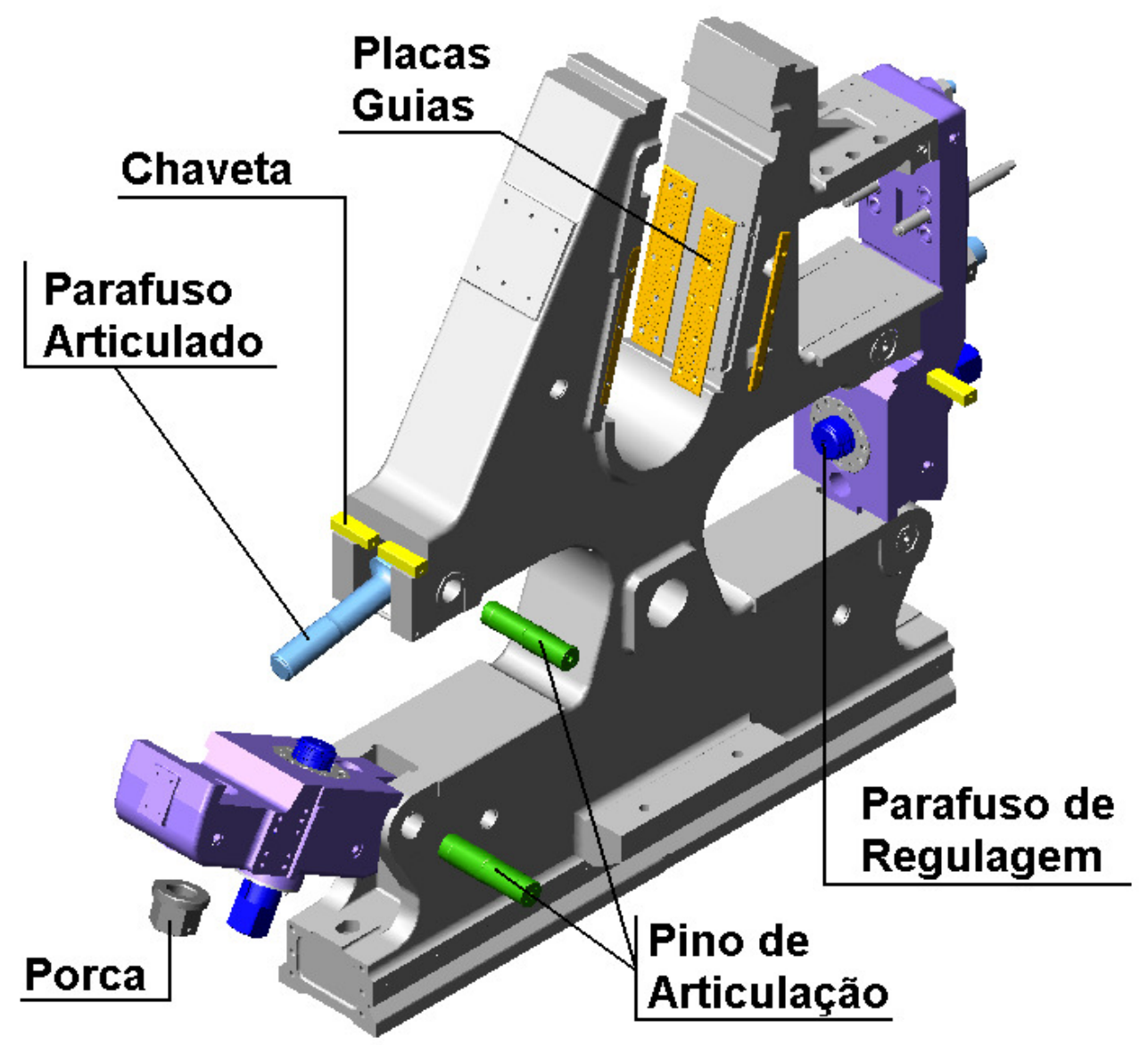

Figura 47: Outros componentes do terno de moenda.

As placas guias laterais e centrais revestem o garfo do castelo e, sobre elas, é que acontece o movimento de oscilação do rolo superior. Tais placas dão fabricadas em bronze BD-01 com as seguintes propriedades mecânicas:

- Limite de resistência $\left(\sigma_{\mathrm{t}}\right) \quad \Longrightarrow \quad 195 \mathrm{MPa}$;

- Limite de escoamento $\left(\sigma_{\mathrm{e}}\right) \quad \Longrightarrow \quad 98 \mathrm{MPa}$;

- Módulo de elasticidade (E) $\quad \longrightarrow \quad 109 \mathrm{GPa}$;

- Coeficiente de Poisson $(v) \quad \longrightarrow \quad 0,30$;

- Densidade $(\gamma) \quad \Longrightarrow \quad 8700 \mathrm{~kg} / \mathrm{m}^{3}$.

As placas de apoio do pistão fazem a interface entre a ponta de geometria esférica das rótulas com as faces superiores das caixas de mancal do rolo superior. Estas placas, conforme mostra a Figura 48, são fabricadas em aço fundido ADZ-25, cujas propriedades mecânicas são: 
- Limite de resistência $\left(\sigma_{\mathrm{t}}\right) \quad \Longrightarrow \quad 490 \mathrm{MPa}$;

- Limite de escoamento $\left(\sigma_{\mathrm{e}}\right) \quad \longrightarrow \quad 255 \mathrm{MPa}$;

- Módulo de elasticidade (E) $\quad \longrightarrow \quad 206 \mathrm{GPa}$;

- Coeficiente de Poisson (v) $\quad \longrightarrow \quad 0,30$;

- Densidade $(\gamma) \quad \longrightarrow \quad 7800 \mathrm{~kg} / \mathrm{m}^{3}$.

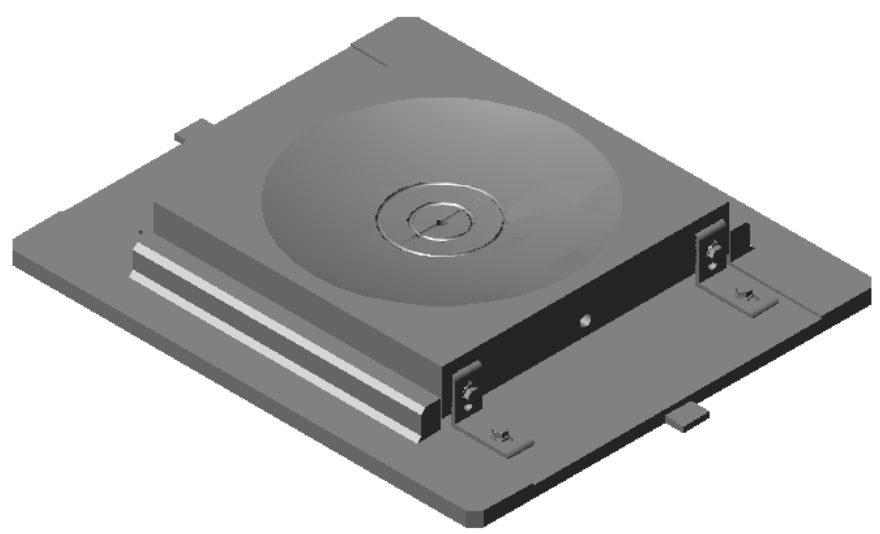

Figura 48: Esquema de uma placa de apoio do pistão.

Os parafusos articulados têm a função de, após montado os rolos inferiores e o rolo de pressão, fixar os cabeçotes laterais. Os parafusos articulados são fabricados em aço forjado SAE-1045 e, possuem as seguintes propriedades mecânicas:

- Limite de escoamento $\left(\sigma_{\mathrm{e}}\right) \quad \Longrightarrow \quad 280 \mathrm{MPa}$;

- Módulo de elasticidade (E) $\quad \Longrightarrow \quad 206 \mathrm{GPa}$;

- Coeficiente de Poisson (v) $\quad \longrightarrow \quad 0,30$;

- Densidade $(\gamma) \quad \Longrightarrow \quad 7800 \mathrm{~kg} / \mathrm{m}^{3}$.

Os parafusos de regulagem possuem a finalidade de regular o posicionamento dos rolos inferiores. Após o posicionamento, os mesmos são travados e servem de apoio para que os rolos inferiores não percam seu posicionamento original com o terno de moenda em funcionamento. $\mathrm{O}$ material dos parafusos de regulagem é o aço médio carbono SAE-1045 que possui as seguintes propriedades mecânicas: 
$\begin{array}{lll}\text { - Limite de resistência }\left(\sigma_{\mathrm{t}}\right) & \longrightarrow & 615 \mathrm{MPa} ; \\ \text { - Limite de escoamento }\left(\sigma_{\mathrm{e}}\right) & \longrightarrow & 274 \mathrm{MPa} ; \\ \text { - Módulo de elasticidade }(\mathrm{E}) & \longrightarrow & 206 \mathrm{GPa} ; \\ \text { - Coeficiente de Poisson }(v) & \longrightarrow & 0,30 ; \\ \text { - Densidade }(\gamma) & \longrightarrow & 7800 \mathrm{~kg} / \mathrm{m}^{3} .\end{array}$

Os pinos de articulação, cuja função é propiciar à articulação dos cabeçotes laterais, assim como as chavetas e porcas utilizadas na montagem dos componentes do terno de moenda também são fabricadas em aço médio carbono SAE-1045, cujas propriedades mecânicas são as mesmas relacionadas aos parafusos de regulagem. 


\section{Projeto de Máquinas - Terno de Moenda}

\subsection{Processo para o Projeto de Máquinas}

Segundo Norton (2004), projeto de máquinas ou design de máquinas, como também é muito comum, é a criação e fabricação de uma máquina que funcione perfeitamente com segurança e confiabilidade, e que proporcione os resultados desejados na idealização do mesmo. No conceito de máquina está explícito um aparato que consiste em unidades inter-relacionadas (elementos de máquinas) ou um dispositivo que modifique a força ou movimento.

O primeiro passo para a criação do projeto de uma máquina é a necessidade. Quando houver a falta ou até mesmo uma mudança de tecnologia há a necessidade do projeto de uma máquina. Em seguida, uma pesquisa de suporte é importante para o desenvolvimento das informações, ou seja, compreender completamente o problema. Os passos seguintes são estabelecer o objetivo e criar um conjunto de especificações de tarefas.

$\mathrm{Na}$ etapa denominada síntese a busca das diversas soluções, geralmente, sem considerar seu valor ou qualidade para o problema é o objetivo principal. Logo após a síntese a análise das alternativas é efetuada e, a solução mais promissora é então selecionada. Com a seleção da solução mais promissora, um projeto detalhado pode ser realizado.

Após o projeto detalhado, a próxima etapa é a construção de um protótipo para em seguida realizar a produção do projeto em quantidade compatível com as necessidades.

Para Juvinall e Marshek (1991), a maioria dos projetos de engenharia envolve múltiplas considerações que, quase sempre, são um desafio ao engenheiro pela dificuldade em conhecer todas elas em sua real grandeza. Embora nenhuma lista de considerações possa ser elaborada para todos os projetos mecânicos, algumas considerações podem ser organizadas entre as principais categorias, a saber: 


\section{Considerações Tradicionais}

1. Para a geometria de um componente:

- Força

- Desvio

- Peso

- Tamanho e forma

2. Para a superfície de um componente:

- Uso

- Lubrificação

- Corrosão

- Atrito

- Calor gerado pelo atrito

3. Custo

\section{Considerações modernas}

\section{Segurança}

2. Meio ambiente

3. Qualidade de vida

\section{Considerações diversas}

1. Confiança e manutenção

2. Estética

De acordo com Krutz, Schueller e Claar (1994), num projeto seguro, é importante a utilização de um fator de segurança que relaciona a tensão atuante com a resistência do material. $\mathrm{O}$ valor numérico para esse coeficiente precisa ser maior que 1 (um) assumindo as piores condições de tensões atuantes no componente. Para a maioria dos casos com carregamento linear estático o fator de segurança pode ser expresso da seguinte maneira:

$$
F s=\frac{\sigma_{\text {Escoamento }}}{\sigma_{\text {Atuante }}}
$$


Onde: $\mathrm{Fs}=$ fator de segurança (adimensional);

$\sigma_{\text {Escoamento }}=$ tensão de escoamento do material $(\mathrm{Pa})$;

$\sigma_{\text {Atuante }}=$ tensão atuante no componente calculada $(\mathrm{Pa})$.

O fator de segurança pode ser entendido como uma medida de incerteza quanto às informações obtidas para a realização do projeto, ou seja, propriedades dos materiais utilizadas, modelos analíticos utilizados, teorias de falhas, entre outros. Alguns valores para orientação da escolha do coeficiente de segurança podem ser definidos com base na qualidade e disponibilidade de dados adequados. A tabela 08 mostra um conjunto de fatores aos quais devem ser considerados (NORTON, 2004).

Tabela 8: Coeficientes de segurança para materiais dúcteis baseados nas informações obtidas (Adaptação NORTON, 2004).

\begin{tabular}{|l|c|}
\hline \multicolumn{2}{|c|}{ Fatores utilizados para determinar um coeficiente de segurança } \\
\hline \hline \multicolumn{1}{|c|}{ Informações } & Fs \\
\hline $\begin{array}{l}\text { O material realmente foi testado } \\
\text { Condições ambientais são idênticas ao dos testes dos materiais } \\
\text { Os modelos foram testados em experimento }\end{array}$ & 1,3 \\
\hline $\begin{array}{l}\text { Dados representativos de testes do material estão disponíveis } \\
\text { Condições ambientais essencialmente iguais ao do laboratório } \\
\text { Os modelos representam precisamente o sistema }\end{array}$ & 2 \\
\hline $\begin{array}{l}\text { Dados razoavelmente representativos dos materiais } \\
\text { Ambiente moderadamente desafiador } \\
\text { Modelos representam aproximadamente o sistema }\end{array}$ & 3 \\
\hline $\begin{array}{l}\text { Dados insuficientemente representativos dos materiais } \\
\text { Ambiente extremamente desafiador } \\
\text { Modelos são aproximações grosseiras }\end{array}$ & $5+$ \\
\hline
\end{tabular}

Em situações onde a segurança humana está envolvida, o coeficiente de segurança pode alcançar valores altos em relação aos apresentados na tabela anterior. 
Valores da ordem de 10 a 15 para coeficiente de segurança para tais situações são absolutamente normais.

Em Shigley, Mischke e Budynas (2004), a vida de um componente depende de como as tensões máximas suportadas pelos materiais são exigidas em locais específicos, assim a tensão máxima atuante deve ser menor do que aquela especificada no material com uma margem suficiente de modo a não ocorrerem falhas. Assim, o American Institute of Steel Construction (AISC) estabelece algumas relações entre as tensões admissíveis do material com as que devem ser utilizadas nos projetos.

$\begin{array}{ll}\text { TENSÃO } & 0,45 \sigma_{\text {escoamento }} \leq \sigma_{\text {admissível }} \leq 0,60 \sigma_{\text {escoamento }} \\ \text { CISALHAMENTO } & 0,40 \sigma_{\text {escoamento }} \\ \text { FLEXÃO } & 0,60 \sigma_{\text {escoamento }} \leq \sigma_{\text {admissível }} \leq 0,75 \sigma_{\text {escoamento }} \\ \text { TORÇÃO } & 0,90 \sigma_{\text {escoamento }}\end{array}$

\subsection{Solicitações no Terno de Moenda}

Nos primeiros projetos de ternos de moendas, os rolos superiores permaneciam fixos nos castelos, sendo a camada de cana preparada a responsável pela determinação da pressão necessária para a extração da sacarose. Essa configuração dos ternos de moendas tinha um inconveniente que era a passagem de corpos estranhos junto com a camada de cana preparada e, conseqüentemente, na grande maioria das vezes, acarretava em falhas mecânicas nos componentes do terno de moenda.

Com a utilização da pressão hidráulica nos projetos de ternos de moenda, mantendo a pressão constante na camada de cana, independentemente da variação na espessura dessa camada, esse problema foi solucionado. Cada mancal recebe a pressão hidráulica exercida por um pistão que desliza dentro do cabeçote como ilustrado na Figura 49. 


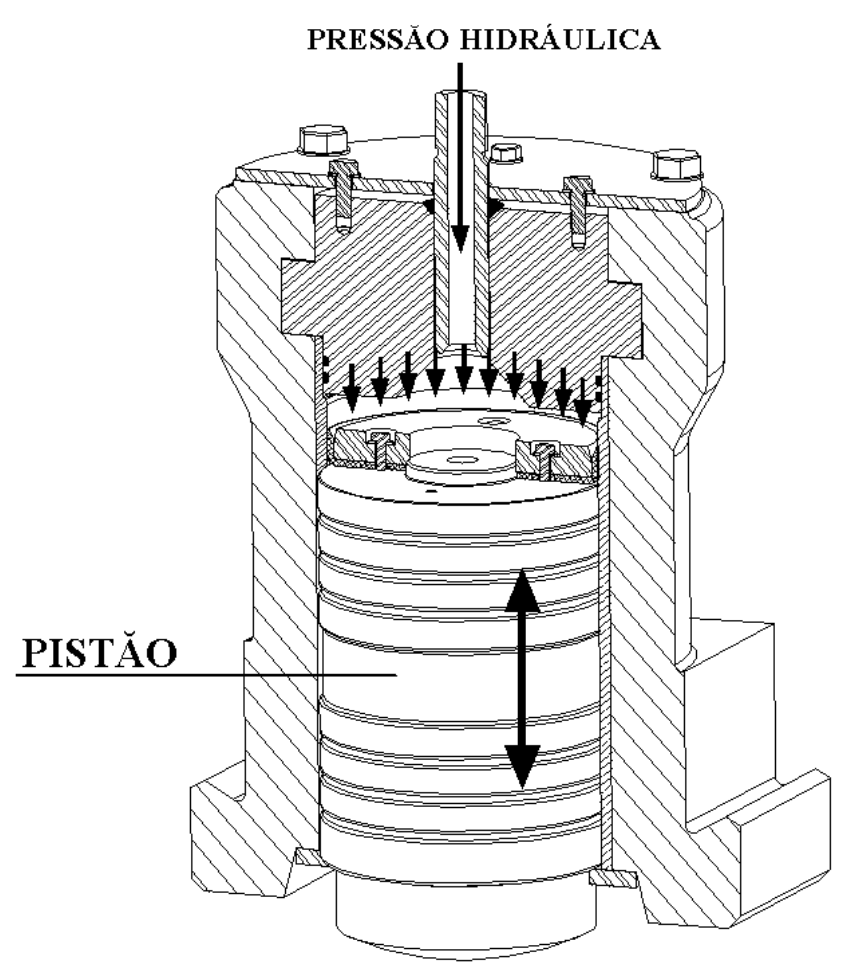

Figura 49: Esquema da pressão hidráulica atuando no pistão.

\subsubsection{Pressão Hidráulica Específica (PHE)}

Conforme Operação (1991) admite-se a hipótese, para as espessuras que passam normalmente entre os rolos de moenda, que a pressão média exercida sobre a camada de cana preparada é semelhante a uma carga hidráulica total (CHT), uniformemente distribuída sobre uma superfície plana de comprimento L, representando o comprimento da camisa do rolo de moenda. Também com largura de um décimo do diâmetro da camisa do rolo de moenda, ou seja, D/10. Assim, pode-se definir a pressão hidráulica específica (PHE) como:

$$
P H E=\frac{C H T}{0,1 \times L \times D}
$$

Onde: $\mathrm{PHE}=$ pressão hidráulica especifica $\left(\mathrm{Ton} / \mathrm{dm}^{2}\right)$;

CHT = carga hidráulica total (Ton);

$\mathrm{L}=$ comprimento da camisa do rolo de moenda $(\mathrm{dm})$;

$\mathrm{D}=$ Diâmetro da camisa do rolo de moenda (dm). 
A CHT é dividida entre os dois mancais superiores e, reescrevendo a expressão [1] obtém-se:

$$
P H E=\frac{2 \times F}{0,1 \times L \times D}
$$

Onde: $\mathrm{PHE}=$ pressão hidráulica especifica $\left(\mathrm{Ton} / \mathrm{dm}^{2}\right)$;

$\mathrm{F}=$ carga aplicada a cada um dos mancais superiores (Ton);

$\mathrm{L}=$ largura da camisa do rolo de moenda $(\mathrm{dm}) ;$

$\mathrm{D}=$ Diâmetro da camisa do rolo de moenda $(\mathrm{dm})$.

Ainda segundo Operação (1991), considera-se que a carga aplicada F distribui-se na superfície projetada do casquilho do mancal superior (comprimento $\mathrm{X}$ largura) conforme Figura 50 e que esta pressão resultante deverá estar dentro do limite da pressão admissível do material do mancal superior, geralmente o bronze. Assim, a pressão em cada mancal superior é calculada a partir da carga F plicada a superfície do pistão como mostrado abaixo:

$$
P_{\text {mancal }}=\frac{F}{A_{\text {pistão }}}=\frac{F}{\frac{P i \times D_{\text {pistão }}}{4}} \leq P_{a d m}
$$

Onde: $\mathrm{P}_{\text {mancal }}=$ pressão sobre cada mancal superior $\left(\mathrm{Kgf} / \mathrm{cm}^{2}\right)$;

$\mathrm{F}=$ carga aplicada a cada um dos mancais superiores (Kgf);

$\mathrm{A}_{\text {pistão }}=$ área do pistão sob a carga $\mathrm{F}\left(\mathrm{cm}^{2}\right)$;

$\mathrm{D}_{\text {pistão }}=$ diâmetro do pistão $(\mathrm{cm})$;

$\mathrm{P}_{\mathrm{adm}}=$ pressão admissível do material do mancal (Bronze $\sim 90-100 \mathrm{Kgf} / \mathrm{cm}^{2}$ ) 


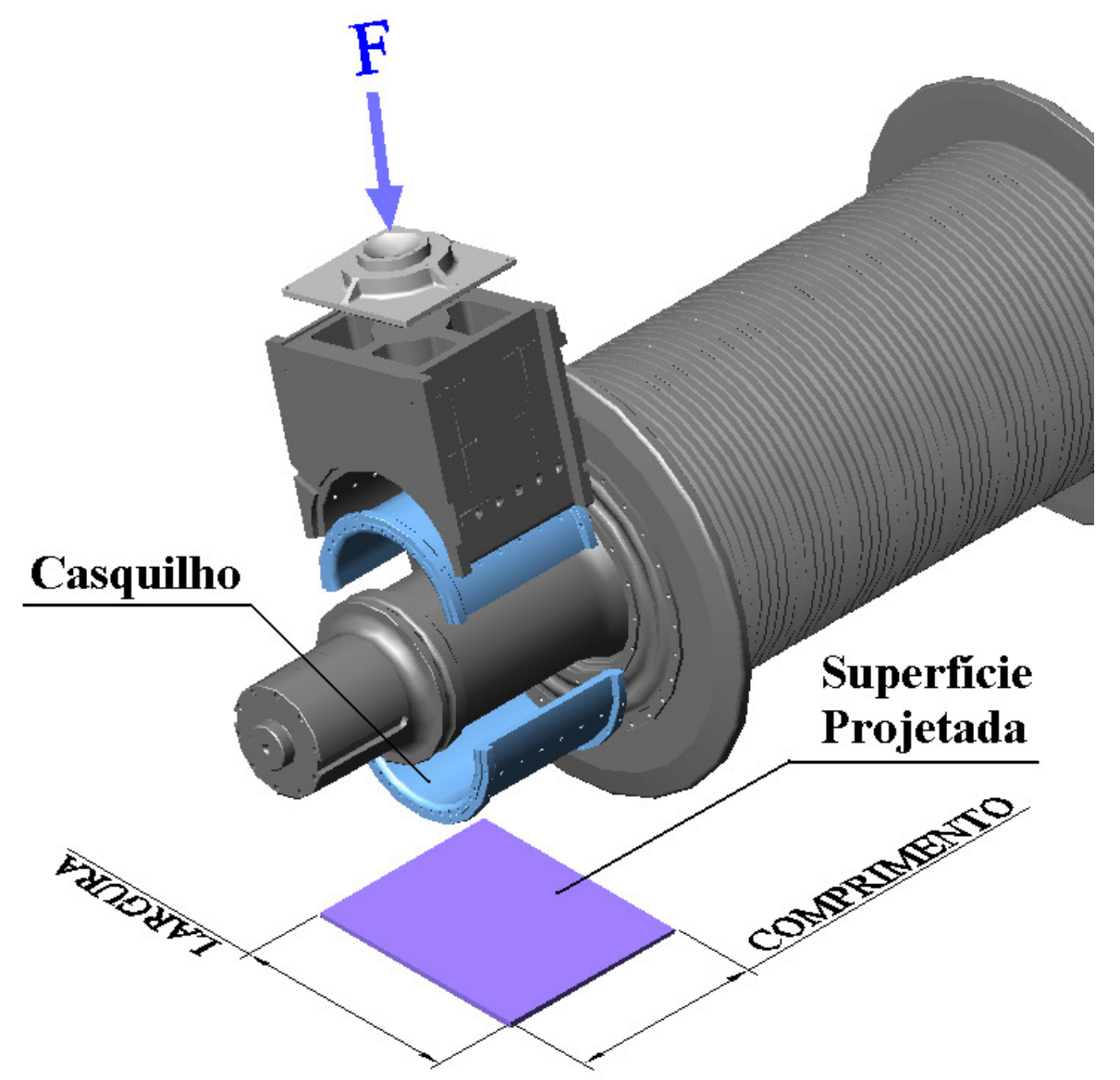

Figura 50: Carga distribuida sobre a superficie projeta do casquilho.

Valores usuais de PHE em terno de moenda, para esmagamento eficiente, está em torno de 20 a $25 \mathrm{Ton} / \mathrm{dm}^{2}$. Para o projeto do terno de moenda utiliza-se um PHE equivalente a $30 \mathrm{Ton} / \mathrm{dm}^{2}$ em virtude da segurança e preservação dos componentes, com isso determina-se a área necessária do mancal para suportar a carga F.

De acordo com Rain (2007), as reações provenientes da pressão hidráulica sobre o rolo superior, assim como suas magnitudes são transpostas para um diagrama conforme Figura 51, sendo $F_{\text {vert }}$ a carga total aplicada no rolo superior e as reações assim descritas:

- $\mathrm{F}_{\mathrm{D}}$ - é a reação decorrente do rolo inferior de saída, tendo como influência a reabsorção. Sua magnitude é aproximadamente $0,72 \mathrm{xF}_{\text {vert }}$.

- $\mathrm{F}_{\mathrm{TP}}$ - é a reação decorrente da bagaceira. Sua magnitude é aproximadamente $0,25 \mathrm{xF}_{\text {vert }}$.

- $\mathrm{F}_{\mathrm{F}}$ - é a reação decorrente do rolo inferior de entrada. Sua magnitude é de aproximadamente $0,17 \mathrm{xF}_{\mathrm{vert}}$. 
- $\mathrm{F}_{\text {horiz }}$ - é a resultante horizontal das forças dos mancais do rolo superior, tendo como magnitude $0,26 \mathrm{xF}_{\mathrm{vert}}$.

- $\mathrm{F}_{\mathrm{G}}$ - é a força da gravidade atuando no rolo superior. Sua magnitude é de aproximadamente $0,03 \mathrm{xF}_{\mathrm{vert}}$.

- $\mathrm{F}_{\mathrm{R}}$ - é a resultante do polígono. Encontra-se a cerca de $15^{\circ}$ atrás da vertical, ângulo geralmente adotado para a inclinação do garfo do castelo onde é posicionado o rolo superior.

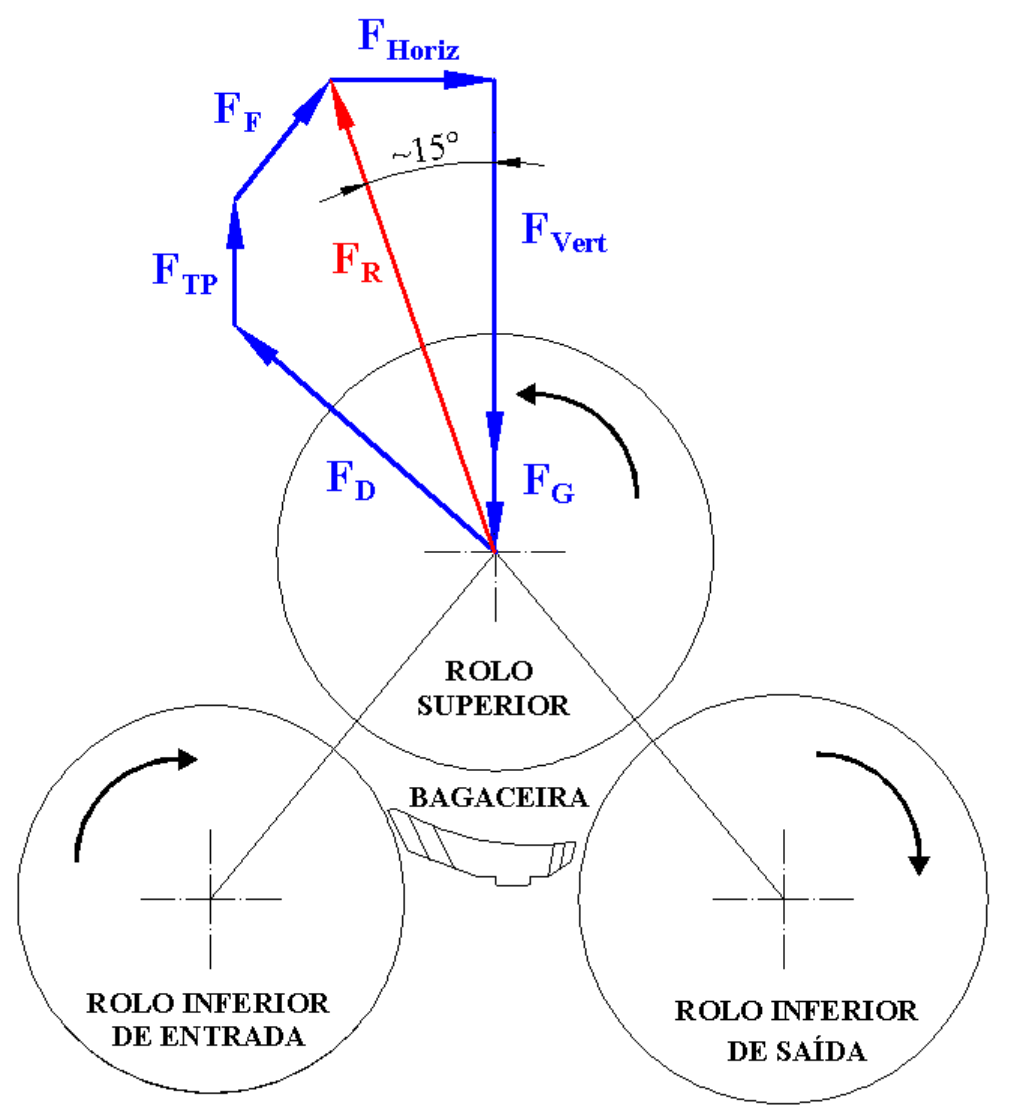

Figura 51: Direçao das forças de reação sobre o rolo superior (RAIN, 2007).

\subsection{Capacidade de Moagem}

A capacidade de moagem é a quantidade que um tandem ${ }^{1}$ é capaz de moer, geralmente expressa em tonelada de cana por hora $(\mathrm{TCH})$ ou tonelada de cana por dia (TCD), esta última menos usual.

\footnotetext{
1Tandem é um conjunto de ternos de moenda alinhados com a finalidade de aumentar a eficiência de extração da sacarose. Números usuais de ternos de moenda que compõem um tangem é de quatro a seis, salva algumas exceções.
} 
Vários são os fatores que influenciam a capacidade de moagem, entre eles:

- Fibra da cana;

- Dimensões e velocidades dos rolos;

- Número de rolos no tandem;

- Preparação da cana;

- Embebição;

- Ranhuras nos rolos;

- Pressão hidráulica equivalente (PHE);

- Tipo de alimentação de cana no terno;

- Conservação dos equipamentos;

- Regulagem dos componentes do terno de moenda;

- Etc.

Muitas fórmulas são propostas para o cálculo da capacidade de moagem, porém será apresentada a expressão que leva em consideração o maior número de fatores que influenciam a moagem, citados anteriormente. Esta, segundo Hugot (1969) é dada por:

$$
C=0,8 \times\left(\frac{c \times n \times(1-0,06 \times n \times D) \times L \times D^{2} \times \sqrt{N}}{f}\right)
$$

Onde: $\mathrm{C}=$ capacidade de moagem $(\mathrm{TCH})$;

$\mathrm{c}=$ coeficiente relativo aos equipamentos de preparação da cana, dado pela tabela 09 (adimensional);

$\mathrm{n}=$ velocidade de rotação dos rolos (RPM);

$\mathrm{D}=$ diâmetro médio das camisas dos rolos $(\mathrm{m})$;

$\mathrm{L}=$ Comprimento das camisas dos rolos de moenda $(\mathrm{m})$;

$\mathrm{N}$ = número de rolos constituindo o tandem (adimensional);

$\mathrm{f}=$ fibra da cana, em relação à unidade. 
Tabela 9: Coeficiente relativo aos equipamentos de preparação da cana (Adaptação de HUGOT, 1969).

\begin{tabular}{|c|c|}
\hline \multicolumn{2}{|c|}{ Coeficiente de Preparação } \\
\hline Equipamentos & $c$ \\
\hline 1 Picador & 1,15 \\
\hline 2 Picadores & 1,2 \\
\hline 2 Picadores e 1 Desfibrador & 1,25 \\
\hline
\end{tabular}

A expressão apresentada acima leva em consideração que o tandem possui todos os ternos de moenda de mesma bitola, ou seja, com dimensões iguais para a largura das camisas dos rolos de moenda e diâmetros das camisas dos rolos de moenda, além de terem a mesma velocidade.

Para um tandem com ternos de moenda de bitolas e velocidades diferentes, prática bastante usual, é necessário substituir o grupo:

$T=n \times(1-0,006 \times n \times D) \times L \times D^{2}$

Pelo grupo:

$T_{m}=\frac{(N-1) \times T_{1}+T_{2}+T_{3}+\ldots .+T_{n}}{2 \times(N-1)}$

Onde: $\mathrm{T}_{1}, \mathrm{~T}_{2}, \mathrm{~T}_{3} \ldots . \mathrm{T}_{\mathrm{n}}$ são os valores relacionados ao $1,2,3, \ldots . \mathrm{n}$ moendas;

$\mathrm{N}$ é o número de ternos constituinte do tandem.

\subsection{Velocidade dos Rolos do Terno de Moenda}

Referindo-se aos ternos de moenda, há duas maneiras de calcular a velocidade:

- Pela velocidade periférica dos rolos, ou seja, velocidade linear em um ponto no diâmetro médio das camisas dos rolos de moenda, geralmente expressa em $\mathrm{m} / \mathrm{min}$; 
- Pela velocidade de rotação dos rolos, ou seja, o número de rotações efetuadas pelo rolo de moenda numa unidade de tempo, geralmente expressa em rotações por minuto (RPM).

A relação entre essas duas velocidades, assim como a expressão de cálculo da velocidade dos rolos estão de acordo com Hugot (1969), a saber:

$$
V=\pi \times D \times n \quad \text { ou } \quad n=\frac{V}{\pi \times D}
$$

Onde: $\mathrm{V}=$ velocidade periférica $(\mathrm{m} / \mathrm{min})$;

$\mathrm{D}=$ diâmetro médio da camisa do rolo de moenda $(\mathrm{m})$;

$\mathrm{N}$ = velocidade de rotação $(\mathrm{RPM})$.

A respeito da velocidade dos rolos do terno de moenda, a tendência é, sobretudo, utilizar a velocidade periférica, a qual marca a velocidade de progressão da cana e do bagaço em seus respectivos condutores. Entretanto, vários autores atribuem maior importância à velocidade de rotação dos rolos dos ternos de moenda assim como a utilização da velocidade de rotação em diversos cálculos a respeito do assunto. Essa discussão está diretamente relacionada ao fabricante dos equipamentos tanto quanto ao usuário destes e, não se conhece nenhuma experiência realizada neste sentido em escala industrial.

Por motivos relacionados tanto à eficiência na extração da sacarose quanto à economia na rentabilidade dos ternos de moenda, não se pode adotar exclusivamente, como limite para a velocidade dos rolos dos ternos de moenda, nem a velocidade periférica nem a velocidade de rotação, porém um compromisso entre ambas.

Com o passar do tempo, percebe-se uma preferência na utilização da velocidade de rotação nos rolos dos ternos de moenda, assim a expressão para o calculo dessa velocidade segundo Hugot (1969) é dada por:

$$
n=\sqrt{65-21,4 \times D}
$$

Onde: $\mathrm{n}$ = velocidade de rotação $(\mathrm{RPM})$;

$\mathrm{D}=$ diâmetro médio das camisas dos rolos de moenda $(\mathrm{m})$. 


\subsection{Potência Consumida pelos Ternos de Moenda}

O cálculo da potência consumida pelos ternos de moenda é complexo e depende de vários fatores como:

- Potência consumida pela compressão da cana e/ou bagaço;

- Potência consumida pelas fricções entre eixos e mancais;

- Potência consumida pela fricção entre o bagaço e a bagaceira;

- Potência consumida pela fricção dos frisos dos pentes e bagaceira com os frisos das camisas dos rolos de moenda, a qual se acrescenta a energia necessária para o desprendimento do bagaço nesses locais;

Por sua vez esses fatores apresentados dependem de outros que são difíceis de serem calculados ou medidos, como por exemplo, a variedade de cana, estado das superfícies em fricções, regulagem dos componentes dos ternos de moenda entre outros.

Para o cálculo da potência necessária ao acionamento dos ternos de moenda, decompõem-se os fatores apresentados anteriormente, sendo as expressões apresentadas referentes à Hugot (1969), assim temos:

$$
P_{1}=0,4 \times\left(\frac{6 \times r-5}{\sqrt{r} \times(1+\sqrt{r-1})}\right) \times F \times n \times D \times \sqrt{\frac{e_{A}}{D}}
$$

Onde: $\mathrm{P}_{1}=$ potência consumida pela compressão do bagaço $(\mathrm{CV})$;

$\mathrm{r}=$ coeficiente de supervelocidade (adimensional);

$\mathrm{F}=$ carga hidráulica (Ton);

$\mathrm{n}=$ velocidade de rotação dos rolos de moenda (RPM);

$\mathrm{D}=$ diâmetro da camisa dos rolos de moenda $(\mathrm{m})$;

$\mathrm{e}_{\mathrm{A}}=$ abertura axial entre as camisas dos rolos na saída $(\mathrm{m})$.

O coeficiente de supervelocidade " $r$ " é a relação entre a velocidade média na abertura de saída e a velocidade periférica das camisas dos rolos. Este coeficiente é estabelecido conhecendo o volume do bagaço quando da sua passagem pela abertura entre as camisas na saída e o volume arrastado pelas camisas dos rolos. Valores comuns de " $r$ " variam entre 1,0 e 2,0. 
Seja $\mathrm{f}_{1}$ o coeficiente de atrito entre o aço (material do eixo) e o bronze (material dos mancais), cujo valor varia entre 0.05 a 0.10 , a expressão para potência consumida pelas fricções entre o eixo e os mancais é dada como:

$$
P_{2}=1,9 \times 1000 \times F \times f_{1} \times\left(\frac{\pi \times d \times n}{60 \times 75}\right)
$$

Onde: $\mathrm{P}_{2}=$ potência consumida pela fricção entre o eixo e os mancais $(\mathrm{CV})$;

$\mathrm{F}$ = carga hidráulica total sobre o rolo superior de moenda (Ton);

$\mathrm{f}_{1}=$ coeficiente de atrito entre o aço e o bronze (adimensional);

$\mathrm{d}=$ diâmetro do eixo em contato com o mancal (m);

$\mathrm{n}=$ velocidade de rotação dos rolos de moenda (RPM).

Seja $\mathrm{f}_{2}$ o coeficiente de atrito entre o bagaço e o metal, valor este da ordem de 0,35 encontrado em estudos realizados por Bullock e Murry e com a bagaceira suportando aproximadamente $25 \%$ da carga hidráulica total conforme citado na seção6.2.1, a potência absorvida pela fricção entre o bagaço e a bagaceira é dada por:

$$
P_{3}=0,25 \times 1000 \times F \times f_{2} \times\left(\frac{2 \pi \times d \times n \times 0,75}{60 \times 75}\right)
$$

Onde: $\mathrm{P}_{3}=$ potência consumida pela fricção entre o bagaço e a bagaceira $(\mathrm{CV})$;

$\mathrm{F}$ = carga hidráulica total sobre o rolo superior de moenda (Ton);

$\mathrm{f}_{2}=$ coeficiente de atrito entre o bagaço e o metal (adimensional);

$\mathrm{d}=$ distância do centro do rolo superior de moenda a superfície da bagaceira, na vertical (m);

$\mathrm{n}=$ velocidade de rotação dos rolos de moenda (RPM).

Como ocorre um deslizamento da massa do bagaço em trânsito e, conseqüentemente o bagaço situado em contato com a bagaceira não possui a mesma velocidade do que aquele em contato com a camisa do rolo superior, estima-se um valor o deslizamento da ordem de $25 \%$, assim na expressão da potência consumida pela fricção entre o bagaço e a bagaceira é incorporado o termo 0.75 . 
Considerando que o bagaço necessite de uma pressão determinada por centímetro de comprimento para o seu desprendimento e que, $\mathrm{f}_{3}$ e $\mathrm{f}_{3}$, são os coeficientes de fricção entre aço/ferro fundido e aço/aço, respectivamente, a expressão para o cálculo da potência consumida pela fricção dos frisos dos pentes e bagaceiras com os frisos das camisas dos rolos de moenda é:

$$
P_{4}=\left(2 \times p+p^{\prime}\right) \times 100 \times L \times\left(f_{3}+f_{3}^{\prime}\right) \times\left(\frac{\pi \times D \times n}{60 \times 75}\right)
$$

Onde: $\mathrm{P}_{4}=$ potência consumida pela fricção dos frisos dos pentes e bagaceira com os frisos das camisas dos rolos de moenda (CV);

$\mathrm{p}=$ pressão para o desprendimento do bagaço por centímetro de comprimento $(\mathrm{Kg} / \mathrm{cm})$

p' = pressão para o desprendimento do bagaço entre o rolo de entrada e a bagaceira com $p^{\prime} \approx \frac{4}{3} \times p(\mathrm{Kg} / \mathrm{cm}) ;$

$\mathrm{f}_{3}$ e $\mathrm{f}_{3}$ ' - coeficientes de fricção entre aço/ferro fundido e aço/aço, respectivamente (adimensional);

$\mathrm{L}=$ comprimento da camisa do rolo de moenda $(\mathrm{m}) ;$

$\mathrm{D}=$ diâmetro da camisa do rolo de moenda $(\mathrm{m})$;

$\mathrm{n}=$ velocidade de rotação dos rolos de moenda (RPM).

Reunindo as expressões [7], [8], [9] e [10] para as potências e, por motivos análogos aos precedentes, obtém-se a potência total consumida pelo terno de moenda com a seguinte expressão:

$$
P=\frac{n \times D}{\rho}\left[F \times\left(0,4 \times \frac{6 \times r-5}{\sqrt{r}(1+\sqrt{r-1})} \times \frac{\sqrt{e_{A}}}{D}+0,08\right)+4 \times L\right]
$$

Onde: $\mathrm{P}=$ potência total consumida em um terno de moenda $(\mathrm{CV})$;

$\mathrm{n}$ = velocidade de rotação dos rolos de moenda (RPM);

$\mathrm{D}=$ diâmetro da camisa do rolo de moenda $(\mathrm{m})$;

$\rho=$ rendimento das engrenagens e/ou rodetes, quando aplicáveis; 
$\mathrm{F}$ = carga hidráulica total sobre o rolo superior de moenda (Ton);

$\mathrm{r}=$ coeficiente de supervelocidade (adimensional);

$\mathrm{e}_{\mathrm{A}}=$ abertura axial entre as camisas dos rolos na saída $(\mathrm{m})$;

$\mathrm{L}=$ comprimento da camisa do rolo de moenda $(\mathrm{m})$;

\subsection{Regulagem do Terno de Moenda}

A regulagem do terno de moenda visa determinação das posições mais favoráveis dos rolos de moenda (entrada, saída e superior) e da bagaceira a fim de obter as melhores condições de moagem e, conseqüentemente proporcionar um bom rendimento aos ternos de moenda. Está regulagem é composta por duas etapas principais, a saber:

- Regulagem da abertura de entrada (entre o rolo superior e o rolo de entrada) e saída (entre o rolo superior e o rolo de saída), sendo que as mesmas possuem medidas com o terno de moenda em atividade e em descanso;

- Regulagem da bagaceira

\subsubsection{Regulagem das Aberturas entre os Rolos do Terno de Moenda}

Pode-se considerar que o rolo de entrada da moenda é um equipamento de alimentação e, o rolo de saída da moenda um equipamento de pressão, sendo assim, é evidente que a abertura de entrada deve ser maior do que a abertura de saída. Sobretudo há uma relação entre as aberturas, a qual deve ser calculada para que a moagem seja eficiente.

As aberturas entre os rolos de moenda são medidas por meio dos diâmetros médios das camisas de moenda, conforme Figura 52. 


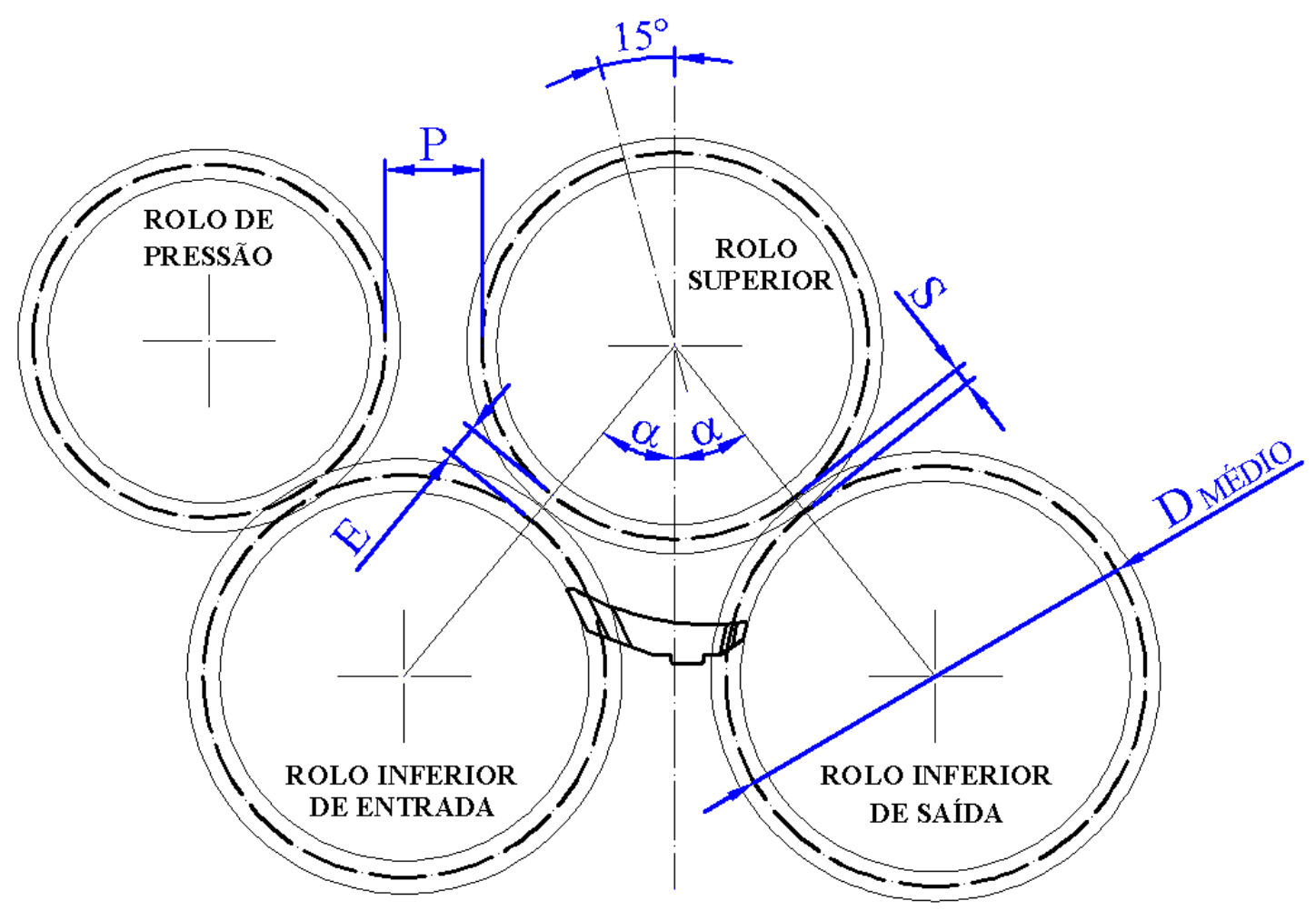

Figura 52: Esquema das aberturas entre os rolos de moenda com o terno em atividade.

A expressão para o cálculo da abertura de saída com o terno de moenda em atividade, segundo Operação (1991) e Hugot (1969) é dada como:

$$
S=\frac{M \times f}{330 \times n \times D \times L \times f^{\prime}}
$$

Onde: $\mathrm{S}=$ abertura de saída entre o rolo superior e o rolo de saída com o terno de moenda em atividade (m);

$\mathrm{M}=$ moagem horária de trabalho do terno de moenda $(\mathrm{TCH}) ;$

$\mathrm{f}=$ fibra da cana em relação a unidade (adimensional);

$\mathrm{n}=$ velocidade de rotação dos rolos de moenda (RPM);

$\mathrm{D}=$ diâmetro médio das camisas dos rolos de moenda $(\mathrm{m})$;

$\mathrm{L}=$ comprimento das camisas dos rolos de moenda $(\mathrm{m})$;

$\mathrm{f}^{\prime}=$ fibra do bagaço em relação a unidade, dados na tabela 10. 
Tabela 10: Fibra do bagaço nos ternos de moenda (Adaptação de OPERAÇÂO, 1991).

\begin{tabular}{|l|c|c|c|c|c|c|}
\hline \multicolumn{7}{|c|}{ Variação da fibra do bagaço (f') ao longo do tandem } \\
\hline \hline & $1^{\circ}$ Terno & $2^{\circ}$ Terno & $3^{\circ}$ Terno & $4^{\circ}$ Terno & $5^{\circ}$ Terno & $6^{\text {o }}$ Terno \\
\hline Tandem com: & & & & & & \\
\hline 12 Rolos & 0,33 & 0,42 & 0,47 & 0,51 & & \\
\hline 15 Rolos & 0,33 & 0,42 & 0,46 & 0,5 & 0,52 & \\
\hline 18 Rolos & 0,33 & 0,42 & 0,45 & 0,48 & 0,5 & 0,52 \\
\hline
\end{tabular}

A expressão [12], como mencionada, é para a abertura de saída (entre o rolo superior e o rolo de saída) com o terno de moenda em atividade. Para o cálculo da abertura de saída com o terno de moenda em descanso e, supondo que o rolo superior tenha um valor médio de levantamento de $30 \%$ do valor da abertura de saída com o terno em atividade, a expressão é dada por:

$$
S^{\prime}=\left[(0,3 \times S) \times \cos \frac{\alpha}{2}\right]-S
$$

Onde: $S^{\prime}=$ abertura de saída entre o rolo superior e o rolo de saída com o terno de moenda em descanso $(\mathrm{m})$;

$\mathrm{S}=$ abertura de saída entre o rolo superior e o rolo de saída com o terno de moenda em atividade $(\mathrm{m})$;

$\alpha=$ ângulo referente à abertura do rolo de saída e o rolo superior $\left(^{\circ}\right)$.

Para o cálculo da abertura de entrada (entre o rolo superior e o rolo de entrada) com o terno de moenda em atividade, Hugot (1969) estabelece uma relação (m) entre as aberturas, a saber:

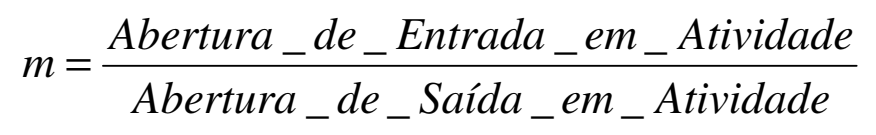

Os valores me "m" estão na tabela 11 . 


\begin{tabular}{|l|c|}
\hline \multicolumn{2}{|c|}{ Relação $(\mathrm{m})$ entre as aberturas em atividade } \\
\hline \hline Para o $1^{\circ}$ Terno & $\mathrm{m}=2,2$ \\
\hline Para o $2^{\circ}$ Terno & $\mathrm{m}=1,9$ \\
\hline Para o $3^{\circ}$ Terno & $\mathrm{m}=1,8$ \\
\hline Para o $4^{\circ}$ Terno e seguintes & $\mathrm{m}=1,7$ \\
\hline
\end{tabular}

Como as aberturas de entrada e de saída não aumentam na mesma proporção, devido à trajetória do rolo superior ser inclinada de $15^{\circ}$ para o lado de entrada da cana no terno de moenda, deve-se considerar ainda, além relação "m", uma relação entre o aumento da abertura de saída com o aumento da abertura de entrada.

Assumindo um semi-ângulo $(\alpha)$ referente à abertura dos rolos no terno de moenda de $35^{\circ}$, a relação entre o aumento das aberturas, segundo Hugot (1969), é de 0.7, assim, para o cálculo da abertura de entrada com o terno em atividade a expressão é dada por:

$$
E=0,7 \times(S \times m)
$$

Onde: $\mathrm{E}=$ abertura de entrada entre o rolo superior e o rolo de entrada com o terno em atividade (m);

$\mathrm{S}=$ abertura de saída entre o rolo superior e o rolo de saída com o terno de moenda em atividade $(\mathrm{m})$;

$\mathrm{m}=$ relação entre as abertura de entrada e saída com o terno em atividade (adimensional).

Por meio da abertura de entrada com o terno em atividade, definidas por meio da relação "m" e da expressão [15], estabelece a abertura de entrada com o terno de moenda em descanso utilizando a expressão [13] modificada, assim: 


$$
E^{\prime}=\left[(0,3 \times E) \times \cos \frac{\alpha}{2}\right]-E
$$

Onde: $\mathrm{E}^{\prime}$ = abertura de entrada entre o rolo superior e o rolo de entrada com o terno de moenda em descanso $(\mathrm{m})$;

$E=$ abertura de entrada entre o rolo superior e o rolo de entrada com o terno de moenda em atividade $(\mathrm{m})$;

$\alpha=$ ângulo referente à abertura do rolo de entrada e o rolo superior $\left(^{\circ}\right)$.

Finalmente para o calculo da abertura entre o rolo de pressão e o rolo superior, de acordo com operação (1991), a expressão é:

$$
P=5 \times S
$$

Onde: $\mathrm{P}=$ abertura de entrada entre o rolo superior e o rolo de pressão $(\mathrm{m})$;

$\mathrm{S}=$ abertura de saída entre o rolo superior e o rolo de saída com o terno de moenda em atividade $(\mathrm{m})$;

Obtidas todas as aberturas entre os rolos de moenda, calculam-se as distâncias entre os centros dos rolos de moenda, conforme Figura 53, obtendo-se assim a "triangulação da moenda". 


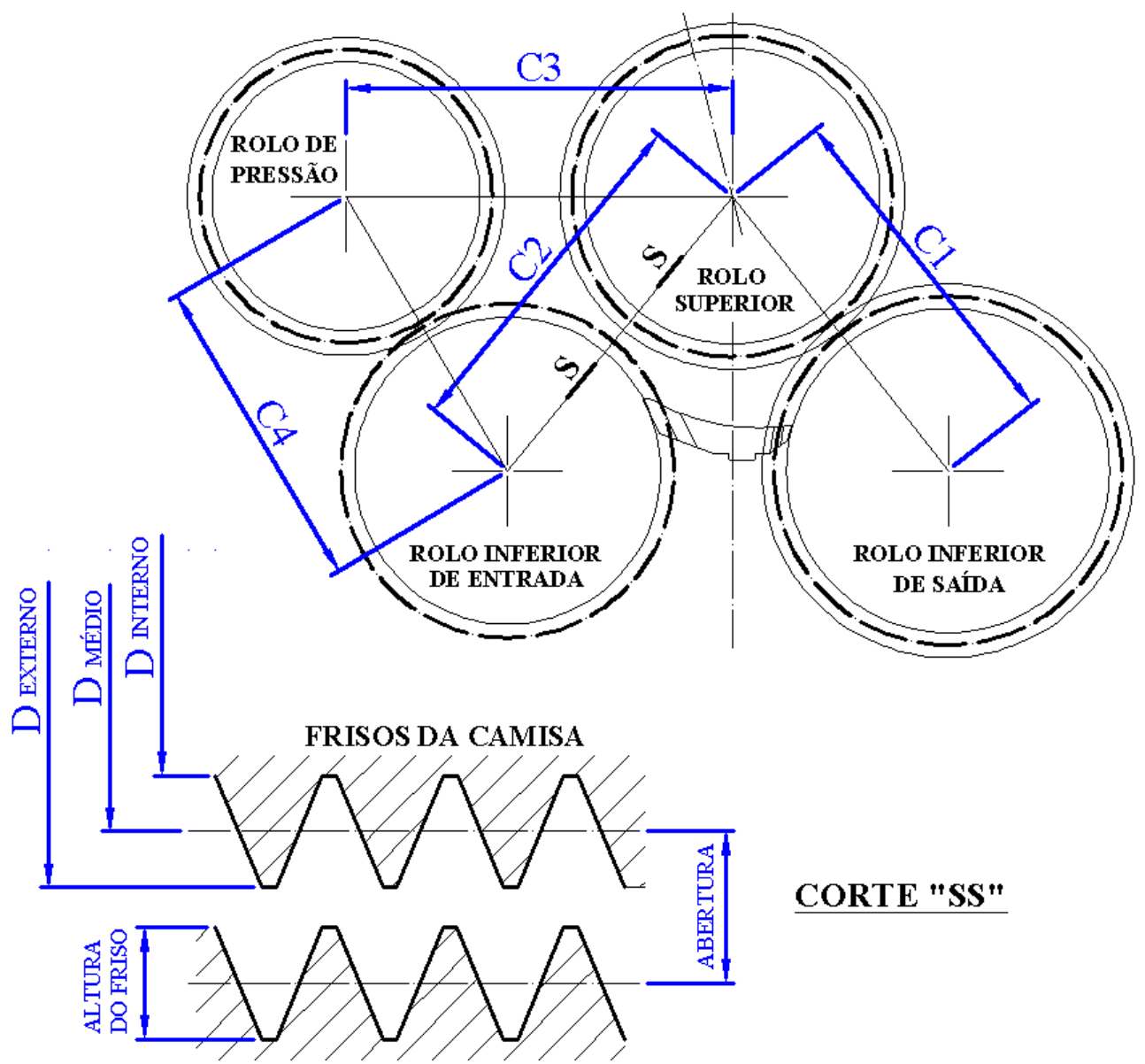

Figura 53: Esquema da triangulação do terno de moenda (OPERAÇÂA, 1991).

Segundo Operação (1991), as expressões para os cálculos das distâncias entre centros são dadas por:

$$
\begin{gathered}
C 1=\frac{D_{E T}-H_{T}}{2}+\frac{D_{E S}-H_{S}}{2}+S \\
C 2=\frac{D_{E T}-H_{T}}{2}+\frac{D_{E E}-H_{E}}{2}+E \\
C 3=\frac{D_{E T}-H_{T}}{2}+\frac{D_{E P}-H_{P}}{2}+P \\
C 4=\frac{D_{E E}+D_{E P}}{2}+15-H_{P} \quad \text { Para, } \mathrm{H}_{\mathrm{E}}>\mathrm{H}_{\mathrm{P}}
\end{gathered}
$$




$$
C 4=\frac{D_{E E}+D_{E P}}{2}+15-H_{E} \quad \text { Para, } \quad \mathrm{H}_{\mathrm{E}}<\mathrm{H}_{\mathrm{P}}
$$

Onde: $\mathrm{C} 1$ = centro a centro entre o rolo superior e o rolo inferior de saída $(\mathrm{m})$;

$\mathrm{C} 2$ = centro a centro entre o rolo superior e o rolo inferior de entrada $(\mathrm{m})$;

C3 = centro a centro entre o rolo superior e o rolo de pressão $(\mathrm{m})$;

$\mathrm{C} 4$ = centro a centro entre o rolo de pressão e o rolo inferior de entrada (m);

$\mathrm{D}_{\mathrm{ET}}=$ diâmetro externo da camisa do rolo superior $(\mathrm{m})$;

$\mathrm{D}_{\mathrm{ES}}=$ diâmetro externo da camisa do rolo inferior de saída $(\mathrm{m})$;

$\mathrm{D}_{\mathrm{EE}}=$ diâmetro externo da camisa do rolo inferior de entrada (m);

$\mathrm{D}_{\mathrm{EP}}=$ diâmetro externo da camisa do rolo de pressão $(\mathrm{m})$;

$\mathrm{H}_{\mathrm{T}}=$ altura do friso da camisa do rolo superior (m);

$\mathrm{H}_{\mathrm{S}}=$ altura do friso da camisa do rolo inferior de saída (m);

$\mathrm{H}_{\mathrm{E}}=$ altura do friso da camisa do rolo inferior de entrada $(\mathrm{m})$;

$\mathrm{H}_{\mathrm{P}}=$ altura do friso da camisa do rolo de pressão $(\mathrm{m})$;

\subsubsection{Regulagem da Bagaceira}

A posição da bagaceira é muito importante para que o terno de moenda possua uma boa extração de sacarose da cana, assim é preciso determinar exatamente sua posição através das cotas de alguns pontos conforme Figura 54, a saber:

- Posição do ponto B, local onde os frisos da bagaceira encaixam nos frisos da camisa do rolo de entrada;

- Cota A, distância da ponta dos frisos da bagaceira (parte dianteira) em relação ao rolo superior;

- Cota M, distância do rolo superior a superfície da bagaceira, tomada no plano axial vertical;

- Cota Z, distância da ponta dos frisos da bagaceira (parte traseira) em relação ao rolo superior;

- Cota T, distância da ponta dos frisos da bagaceira (parte traseira) em relação ao rolo de saída. 


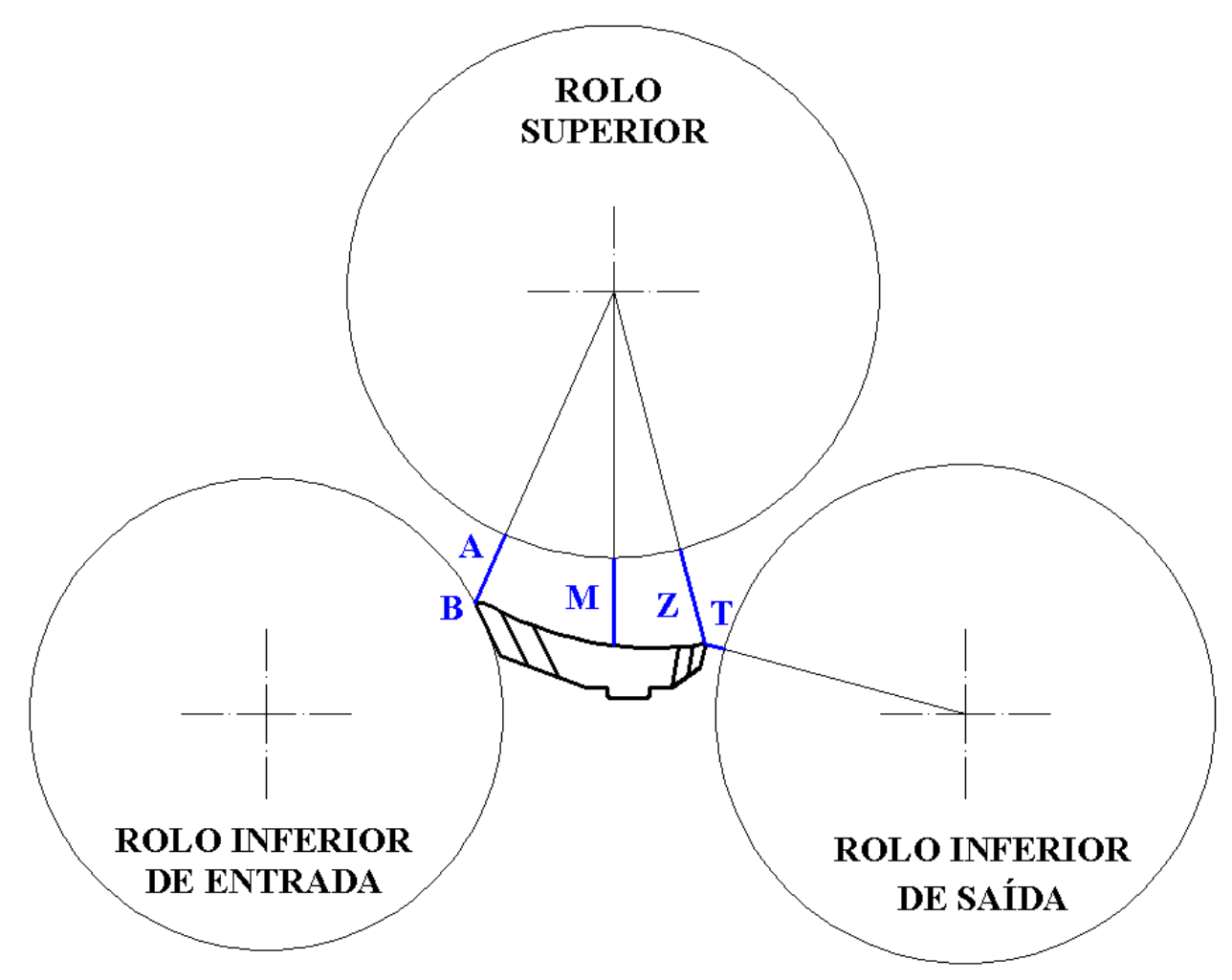

Figura 54: Esquema para a localização da bagaceira (HUGOT, 1969).

Para a determinação dos pontos e cotas, a orientação definida em Hugot (1969) é dada a seguir:

A bagaceira será o círculo traçado, tendo W como centro e WB como raio conforme Figura 55. O ponto B, onde os frisos da bagaceira encaixam nos frisos da camisa do rolo de entrada é obtido:

$$
M O^{\prime} B=\beta=\frac{\alpha}{6}
$$

Assim, o arco MB tem o seguinte valor:

$$
M B=\pi \times D \times \frac{\beta}{360}=\frac{\pi \times D \times \alpha}{6 \times 360}=0,0145 \times D \times \alpha
$$

Onde: $\mathrm{D}=$ diâmetro médio da camisa do rolo de moenda $(\mathrm{mm})$;

$\alpha=$ ângulo de abertura dos rolos inferiores de moenda com relação ao rolo superior de moenda $\left({ }^{\circ}\right)$. 


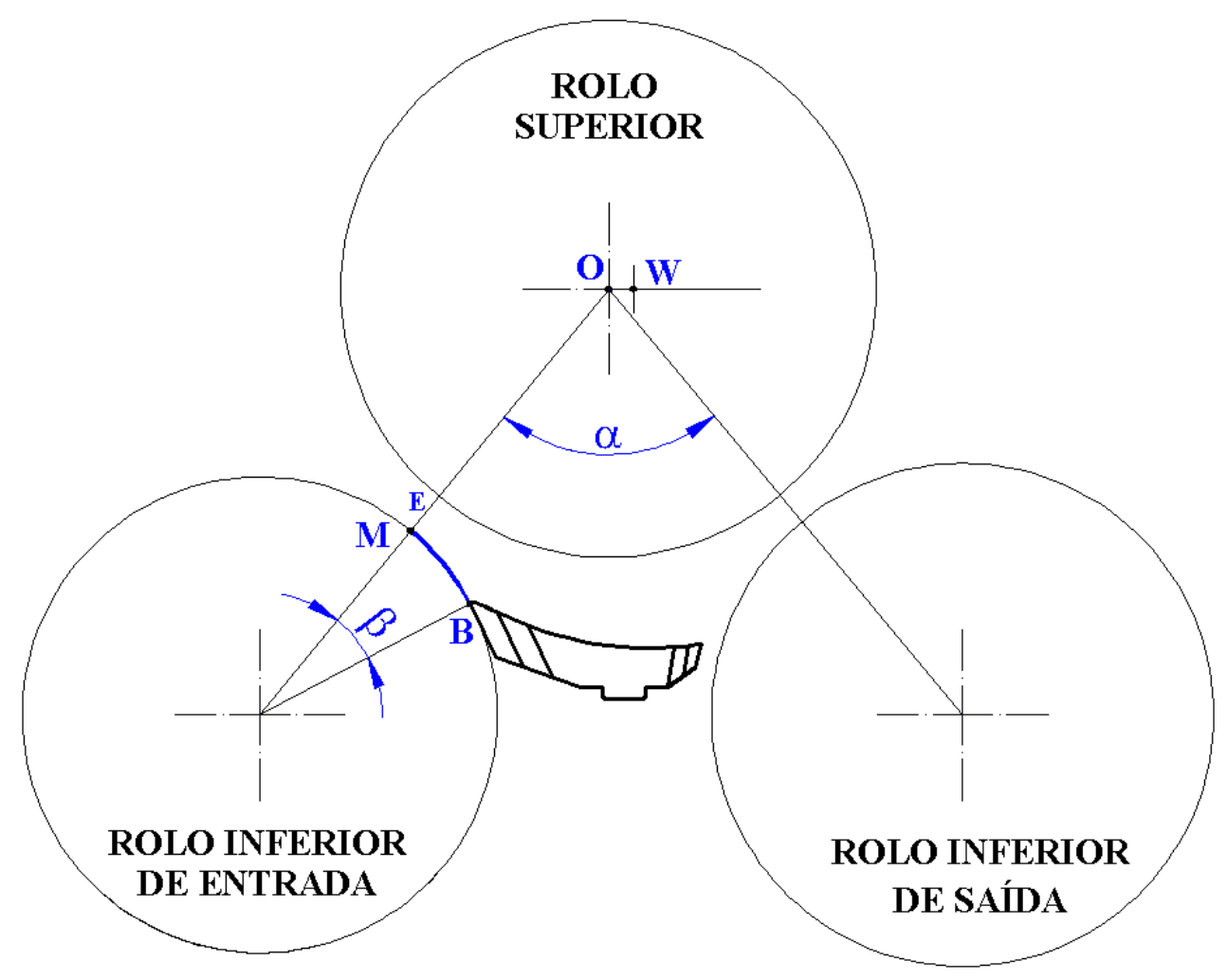

Figura 55: Esquema para traçado da bagaceira (HUGOT, 1969).

A Figura 55 propõe o rolo superior com o terno de moenda em atividade, então $\mathrm{E}=$ abertura de entrada com o terno em atividade, assim, após encontrado a posição do ponto $\mathrm{B}$ através do comprimento do arco MB da expressão [24], procede com a determinação das cotas $\mathrm{A}, \mathrm{M}, \mathrm{Z}$ e $\mathrm{T}$, todas relacionadas com $\mathrm{E}$.

Hugot (1969) relaciona essas cotas tomando como base $\mathrm{E}=100$, assim temos:

Cota $\mathrm{A}=150$, ou seja, $\mathrm{A}=1,5 \times \mathrm{E}$;

Cota $\mathrm{M}=175$, ou seja, $\mathrm{M}=1,75 \mathrm{x} \mathrm{E}$;

Cota $Z=190$, ou seja, $Z=1,9 \times E$;

Cota $\mathrm{T}=80$, ou seja, $\mathrm{T}=0,8 \times \mathrm{E}$;

Os valores obtidos com o auxílio dessas relações representam o terno de moenda em atividade, como já mencionado. Para obter os valores com o terno de moenda em descanso, toma-se a diferença em milímetros entre a abertura de entrada em atividade (E) e a abertura de entrada em descanso (E') e acresce esse valor de 20 a 30\%, deduzindo de cada uma das cotas $\mathrm{A}, \mathrm{M}$, e $\mathrm{Z}$ o resultado obtido. A cota $\mathrm{T}$ se mantém a mesma. 


\subsection{Eixos dos Rolos do Terno de Moenda}

Segundo Brunelli e Teramoto [199-], estudos realizados nos eixos dos rolos do terno de moenda revelam que as fraturas dos mesmos ocorrem por fadiga devido aos esforços cíclicos simétricos e elevado fator de concentração de tensões periférica, sendo que, aproximadamente $25 \%$ dos casos de ruptura dão-se na seção 1 da Figura 56, devido à mudança de dimensão do eixo e, o restante dos casos, cerca de $75 \%$, a ruptura dá-se na seção 2, conforme Figura 56, devido a concentração de tensão pela montagem com interferência da camisa no eixo somado ao acúmulo de caldo, altamente corrosivo, contido nesta região resultante do processo de moagem,

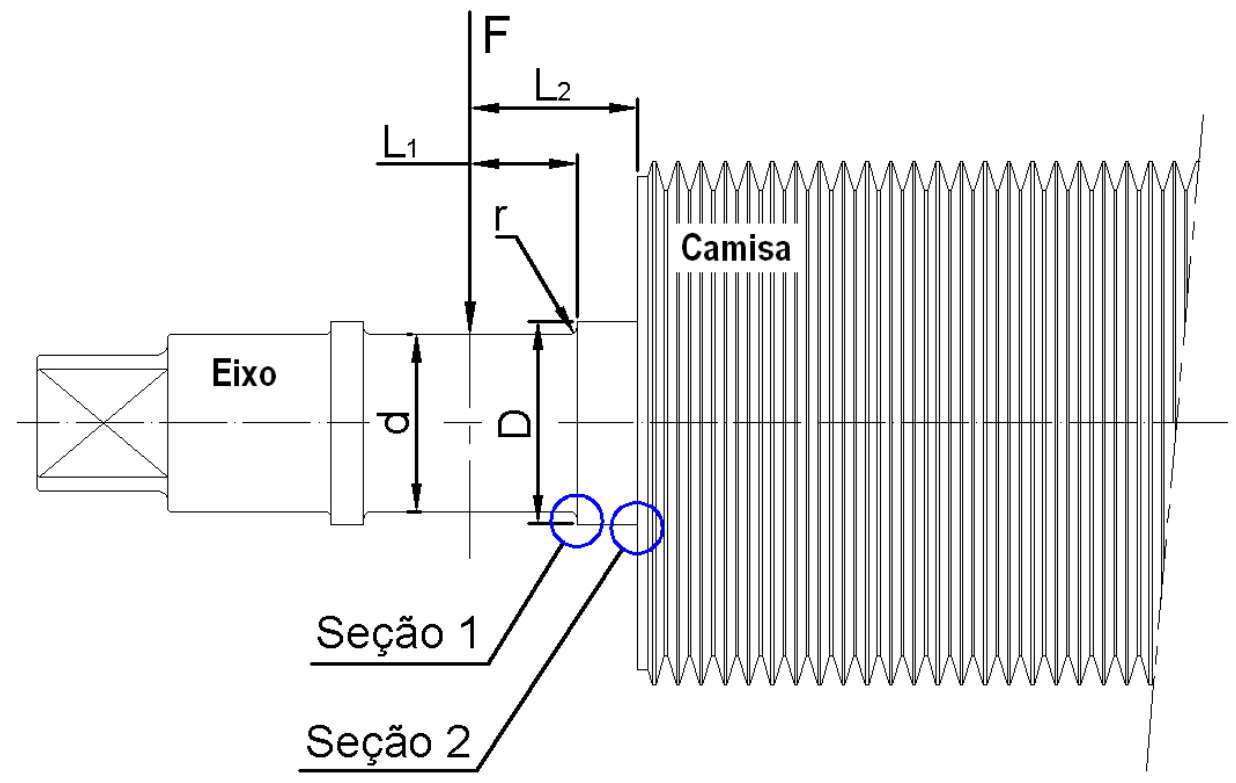

Figura 56: Seções onde ocorrem as fraturas nos eixos dos rolos do terno de moenda.

Assim, os eixos para ternos de moenda devem ser dimensionados considerando o limite à fadiga, ou seja, a máxima tensão em que o eixo pode ser submetido a um número infinito de ciclos sem que haja falha no material. O cálculo é desenvolvido com o objetivo de determinar o coeficiente de segurança apropriado à fadiga nos eixos para ternos de moenda. Em Brunelli e Teramoto [199-], a expressão para o cálculo do fator de segurança é dado como:

$$
F_{S}=\frac{\beta \times \sigma_{F}}{\frac{K_{\sigma}}{\xi} \times \sigma_{a}}
$$


Onde: $F_{S}=$ fator de segurança a fadiga (adimensional);

$\beta=$ coeficiente de endurecimento superficial encontrado na tabela 12 (adimensional);

$\sigma_{\mathrm{F}}=$ limite de resistência a fadiga $\left(\mathrm{Kgf} / \mathrm{cm}^{2}\right)$;

$\mathrm{K}_{\sigma}=$ fator de concentração de tensão (adimensional);

$\xi=$ coeficiente de escala, encontrado no Gráfico 01 (adimensional);

$\sigma_{\mathrm{a}}=$ tensão causada pelo momento fletor no eixo $\left(\mathrm{Kgf} / \mathrm{cm}^{2}\right)$.

Tabela 12: Valores do coeficiente de endurecimento superficial (BRUNELLI, TERAMOTO [199-]).

Coeficiente de endurecimento superficial

\begin{tabular}{|c|c|c|c|}
\hline \hline \multirow{2}{*}{$\begin{array}{c}\text { Tensão de } \\
\text { Ruptura } \\
\left(\mathbf{K g f} / \mathbf{m m}^{2}\right)\end{array}$} & $\begin{array}{c}\text { Processo de } \\
\text { Endurecimento Superficial }\end{array}$ & \multicolumn{2}{|c|}{$\begin{array}{c}\text { Eixo com coeficiente de } \\
\text { concentração de tensão }\end{array}$} \\
\cline { 3 - 4 } & Tratamento de esferas & 1,1 a 1,25 & 1,7 a 2,1 \\
\hline \multirow{2}{*}{60 a 150} & Ecruamento por rolete & 1,2 a 1,3 & 1,8 a 2,0 \\
\cline { 2 - 4 } & & & \\
\hline
\end{tabular}




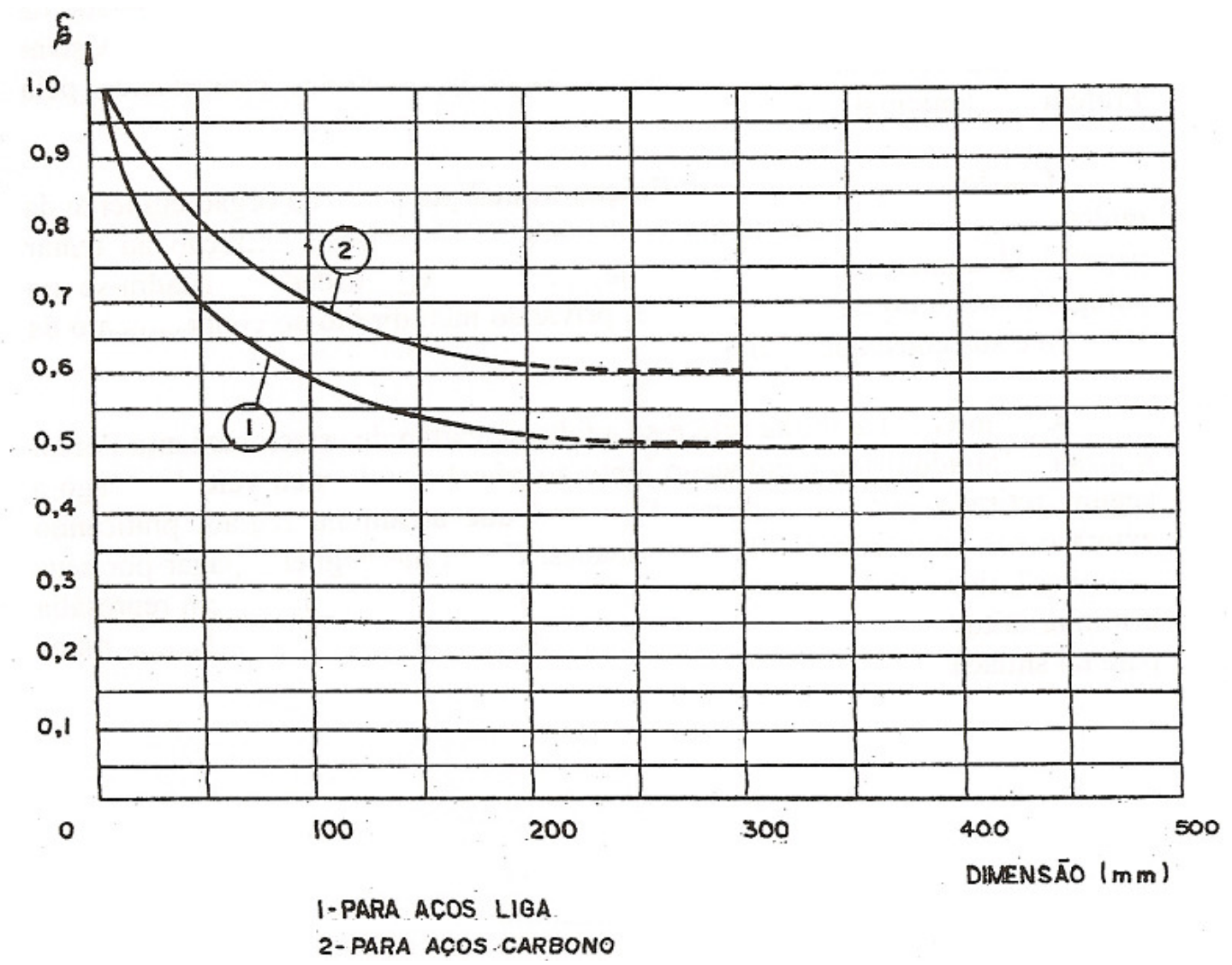

Gráfico 1: Coeficiente de escala (BRUNELLI, TERAMOTO [199-]).

Segundo ensaios realizados, os valores do limite de resistência a fadiga $\sigma_{\mathrm{F}}$ para os materiais recomendados para eixos dos rolos dos ternos de moenda são:

Material: $\quad$ SAE-1045 $\longrightarrow \sigma_{\mathrm{F}}=0,45 \sigma_{\text {rup }}$

$\mathrm{SAE}-8640 \longrightarrow \sigma_{\mathrm{F}}=0,45 \sigma_{\text {rup }}$

SAE-4340 $\longrightarrow \sigma_{\mathrm{F}}=0,45 \sigma_{\text {rup }}$

Onde $\sigma_{\text {rup }}$ é a tensão de ruptura do material utilizado

Considerando a Figura 56, a tensão causada pelo momento fletor é expressa como:

Seção 1 


$$
\sigma_{a 1}=\frac{M_{1}}{W_{1}}=\frac{F \times L_{1}}{\left(\frac{\pi \times d^{3}}{32}\right)}
$$

Onde: $\sigma_{\mathrm{a} 1}=$ tensão causada pelo momento fletor na seção $1\left(\mathrm{Kgf} / \mathrm{cm}^{2}\right)$;

$\mathrm{M}_{1}=$ momento fletor na seção 1 ( $\left.\mathrm{Kgf} \mathrm{x} \mathrm{cm}\right)$;

$\mathrm{W}_{1}=$ módulo de resistência polar $\left(\mathrm{cm}^{3}\right)$;

$\mathrm{F}=$ carga aplicada ao eixo (Kgf);

$\mathrm{L}_{1}=$ distância da carga $\mathrm{F}$ a seção $1(\mathrm{~cm})$;

$\mathrm{d}=$ diâmetro menor do eixo na seção $1(\mathrm{~cm})$.

$\underline{\text { Seção } 2}$

$$
\sigma_{a 2}=\frac{M_{2}}{W_{2}}=\frac{F \times L_{2}}{\left(\frac{\pi \times D^{3}}{32}\right)}
$$

Onde: $\sigma_{\mathrm{a} 2}=$ tensão causada pelo momento fletor na seção $2\left(\mathrm{Kgf} / \mathrm{cm}^{2}\right)$;

$\mathrm{M}_{2}=$ momento fletor na seção 2 ( $\mathrm{Kgf} \mathrm{x} \mathrm{cm}$ );

$\mathrm{W}_{2}=$ módulo de resistência polar $\left(\mathrm{cm}^{3}\right)$;

$\mathrm{F}=$ carga aplicada ao eixo (Kgf);

$\mathrm{L}_{2}=$ distância da carga $\mathrm{F}$ a seção $2(\mathrm{~cm})$;

$\mathrm{D}=$ diâmetro do eixo na seção $2(\mathrm{~cm})$.

O fator de concentração Ko é calculado para a seção 1 através da expressão:

$$
K \sigma_{1}=K \sigma_{\text {Loc }}+K \sigma_{\text {Rug }}-1
$$

Sendo que:

$$
\left.K \sigma_{\text {Loc }}=1+\left(K_{t}\right)-1\right) \times q
$$

Onde: $\mathrm{K} \sigma_{1}=$ fator de concentração de tensão (adimensional); 
$K \sigma_{\text {Loc }}=$ fator de concentração de tensão devido à geometria local (adimensional);

$K \sigma_{\text {Rug }}=$ fator de concentração de tensão devido à rugosidade superficial, encontrado na tabela 13 (adimensional);

$\mathrm{K}_{\mathrm{t}}$ = fator teórico de concentração em função da mudança de dimensão do eixo dado no Gráfico 02 (adimensional);

$q=$ coeficiente de sensibilidade do material em função dos valores de $K_{t}$ e a tensão de ruptura do material, encontrado no Gráfico 03 (adimensional).

Tabela 13: Valores do fator de concentração $K \sigma_{\text {Rug }}$ devido à rugosidade superficial e o limite de resistência do material (BRUNELLI, TERAMOTO [199-]).

\begin{tabular}{|c|c|c|c|}
\hline \multirow{2}{*}{ Acabamento } & \multicolumn{3}{|c|}{ Limite de Resistência (Kgf/mm $\left.{ }^{\mathbf{2}}\right)$} \\
\cline { 2 - 4 } & $\mathbf{4 0}$ & $\mathbf{8 0}$ & $\mathbf{1 2 0}$ \\
\hline & 1 & 1 & 1 \\
\hline & 1,05 & 1,1 & 1,25 \\
\hline & 1,2 & 1,25 & 1,5 \\
\hline & 1,35 & 1,5 & 2,2 \\
\hline
\end{tabular}

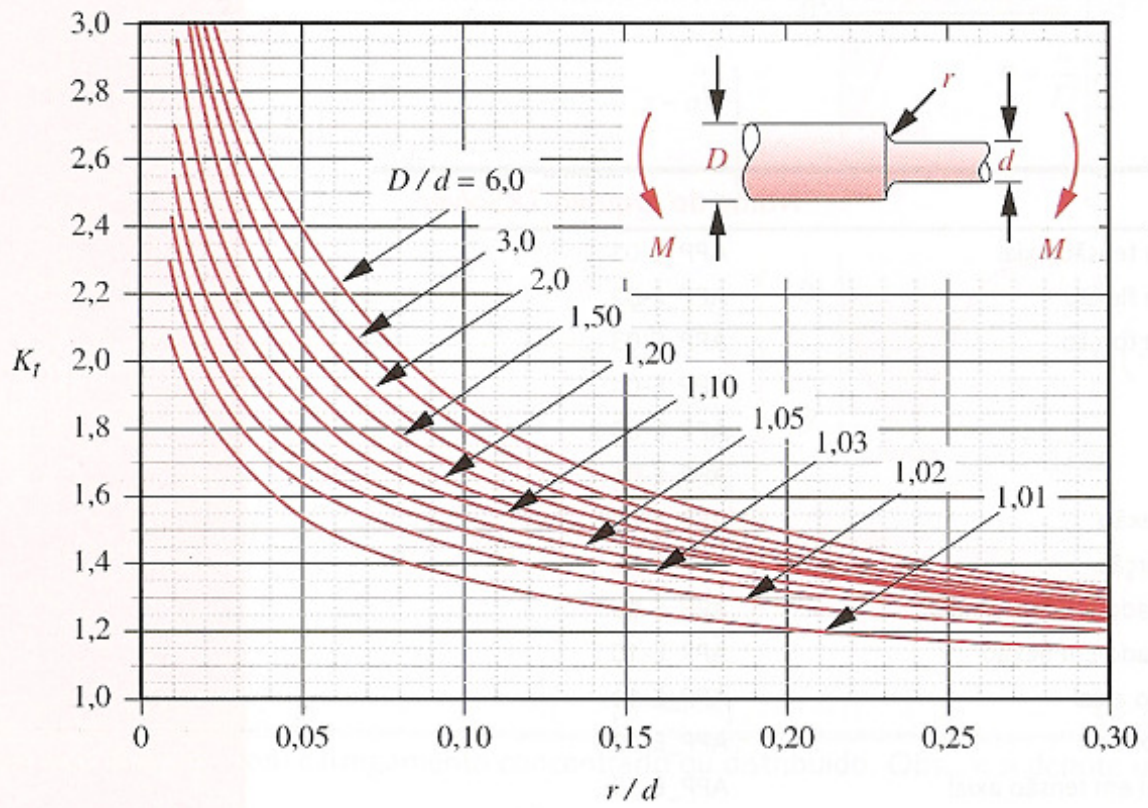

$K_{l} \cong A\left(\frac{r}{d}\right)^{b}$

onde:

\begin{tabular}{lcc}
$D / d$ & $A$ & $b$ \\
\hline 6,00 & 0,87868 & $-0,33243$
\end{tabular}

$3,00 \quad 0,89334-0,30860$

$2,00 \quad 0,90879-0,28598$

$1,50 \quad 0,93836-0,25759$

$1,20 \quad 0,97098 \quad-0,21796$

$1,10 \quad 0,95120 \quad-0,23757$

$1,07 \quad 0,97527 \quad-0,20958$

$1,05 \quad 0,98137 \quad-0,19653$

$1,03 \quad 0,98061 \quad-0,18381$

$1,02 \quad 0,96048 \quad-0,17711$

$1,01 \quad 0,91938-0,17032$

Gráfico 2: Fator de concentração de tensão $\mathrm{K}_{\mathrm{t}}$ para eixo com rebaixo arredondado em flexão (NORTON, 2004). 


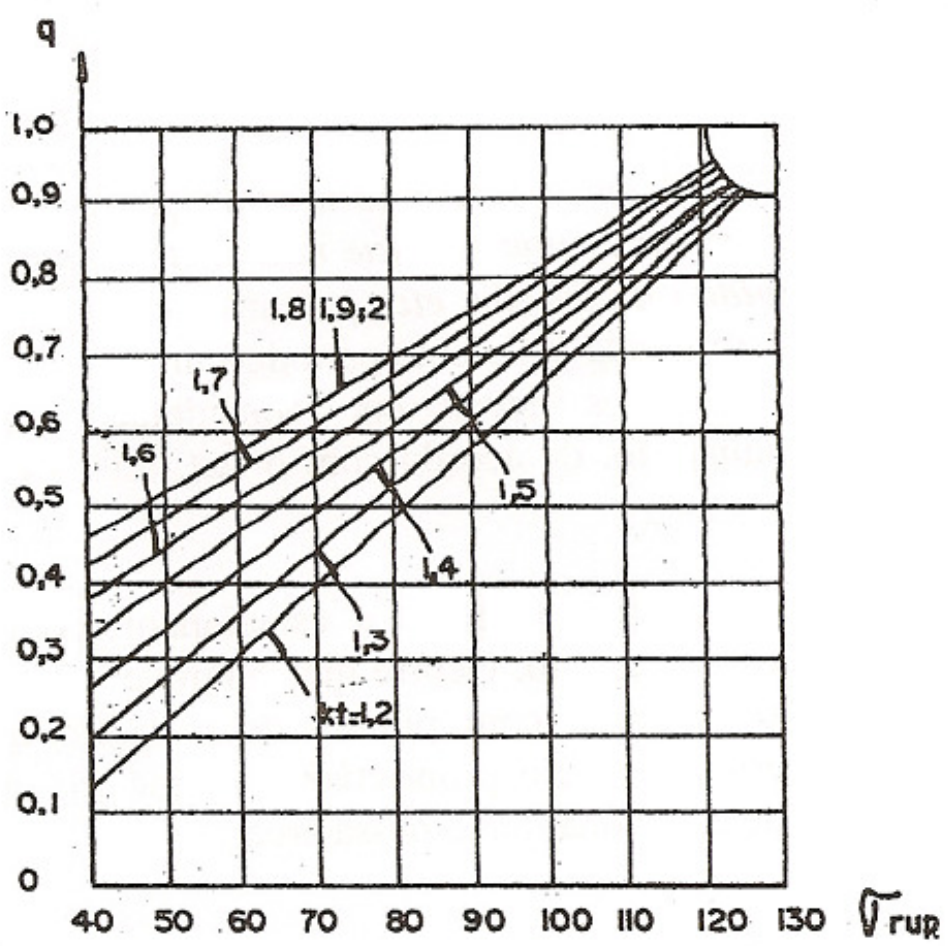

Gráfico 3: Fator de sensibilidade do material (BRUNELLI, TERAMOTO [199-]).

Na seção 2, a concentração de tensões, conforme já mencionado, é causada pela montagem com interferência entre a camisa e o eixo. Os valores do fator de concentração de tensões na seção $2\left(\mathrm{~K}_{2}\right)$, são encontrados na tabela 14 , já levando em conta o coeficiente de escala $\frac{K \sigma}{\xi}$, conforme Brunelli e Teramoto [199-].

Tabela 14: Valores do fator de concentração $\mathrm{K \sigma}_{2}$ (BRUNELLI, TERAMOTO [199-]).

\begin{tabular}{|c|c|c|c|c|c|c|c|}
\hline \multicolumn{7}{|c|}{ Fator de concentração $\left(\mathbf{K \sigma}_{\mathbf{2}}\right)$} \\
\hline \hline \multirow{7}{*}{$\begin{array}{c}\text { Interferência } \\
\text { (ISO) }\end{array}$} & \multicolumn{7}{|c|}{ Tensão de Ruptura $\left(\mathbf{K g f} / \mathbf{m m}^{2}\right)$} \\
\cline { 2 - 9 } & $\mathbf{5 0}$ & $\mathbf{6 0}$ & $\mathbf{7 0}$ & $\mathbf{8 0}$ & $\mathbf{9 0}$ & $\mathbf{1 0 0}$ & $\mathbf{1 2 0}$ \\
\hline H7 / r6 & 3,3 & 3,6 & 3,95 & 4,25 & 4,6 & 4,9 & 5,6 \\
\hline H7 / k6 & 2,45 & 2,7 & 2,95 & 3,2 & 3,45 & 4 & 4,2 \\
\hline H7 / h6 & 2,15 & 2,35 & 2,55 & 2,75 & 3 & 3,2 & 3,6 \\
\hline
\end{tabular}

Com o valor já calculado do fator de segurança $\mathrm{F}_{\mathrm{S}}$, deve-se compará-lo com os valores recomendados, derivados da expressão: 


$$
F_{\operatorname{Re} c}=S_{1} \times S_{2} \times S_{3}
$$

Onde: $F_{\text {Rec }}=$ fator de segurança a fadiga recomendado (adimensional);

$\mathrm{e}$

$\mathrm{S}_{1}=1,10 \longrightarrow$ Cargas bem limitadas e tensões bem conhecidas

$\mathrm{S}_{2}=1,40 \longrightarrow$ Material bem conhecido

$\mathrm{S}_{2}=1,20 \longrightarrow$ Material bem especificado e testado em todos os requisitos

$\mathrm{S}_{3}=1,50 \longrightarrow$ Prejuízos humanos e financeiros

Sendo assim:

$\mathrm{F}_{\mathrm{Rec}}=2,31 \quad \longrightarrow \quad$ Para eixo de material bem conhecido

$\mathrm{F}_{\mathrm{Rec}}=1,98 \quad \longrightarrow \quad$ Para eixo de material bem especificado e testado

\subsection{Projeto de Pinhões para Acionamento dos Rolos do Terno de Moenda}

Com a constante ruptura de pinhões, conhecidos também como rodetes, para o acionamento dos rolos do terno de moenda, foi desenvolvido um projeto específico para a transmissão do torque necessário aos eixos de moenda. A Figura 57 caracteriza um rodete para acionamento dos rolos do terno de moenda. 


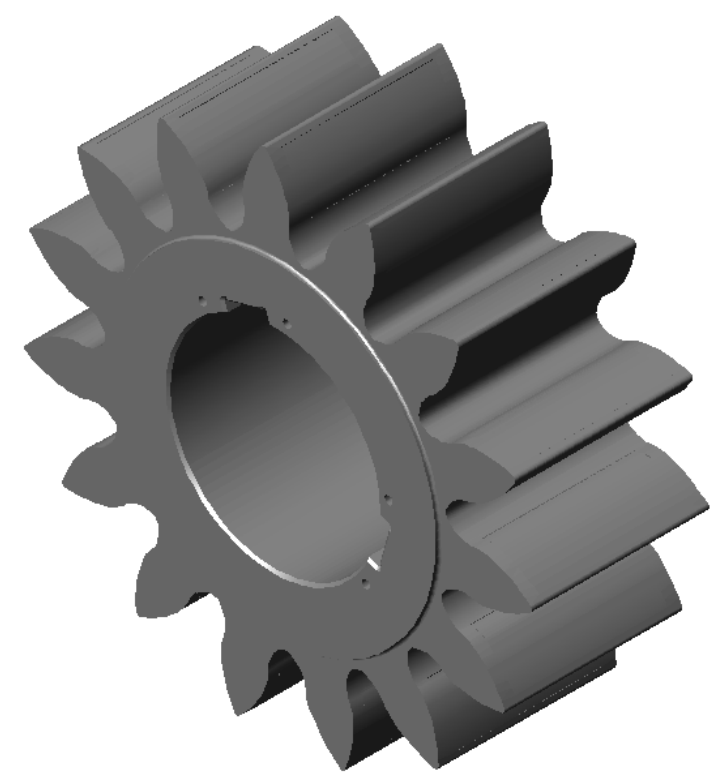

Figura 57: Rodete de acionamento para rolos de moenda.

Quanto à montagem dos rodetes, existem duas alternativas, que são:

- 6 rodetes, sendo montados três de cada lado do terno de moenda;

- 3 rodetes, sendo montados de um único lado do terno de moenda.

Como se pode imaginar, quanto a resistência, a alternativa com 6 rodetes seria a melhor, pois os esforços seriam divididos pelos dois grupos. Entretanto, na prática, essa divisão não acontece devido a incorreções no passo dos dentes, dificuldade de se executar os rasgos de chaveta perfeitamente alinhados e ocorrerem oscilações desiguais nos eixos superiores.

Outro fator importante é o econômico, assim a alternativa com 6 rodetes é praticamente descartada. Com isso, a configuração de montagem tipicamente usual é a com 3 rodetes, montados de um único lado do terno de moenda com ilustrado na Figura 58. 


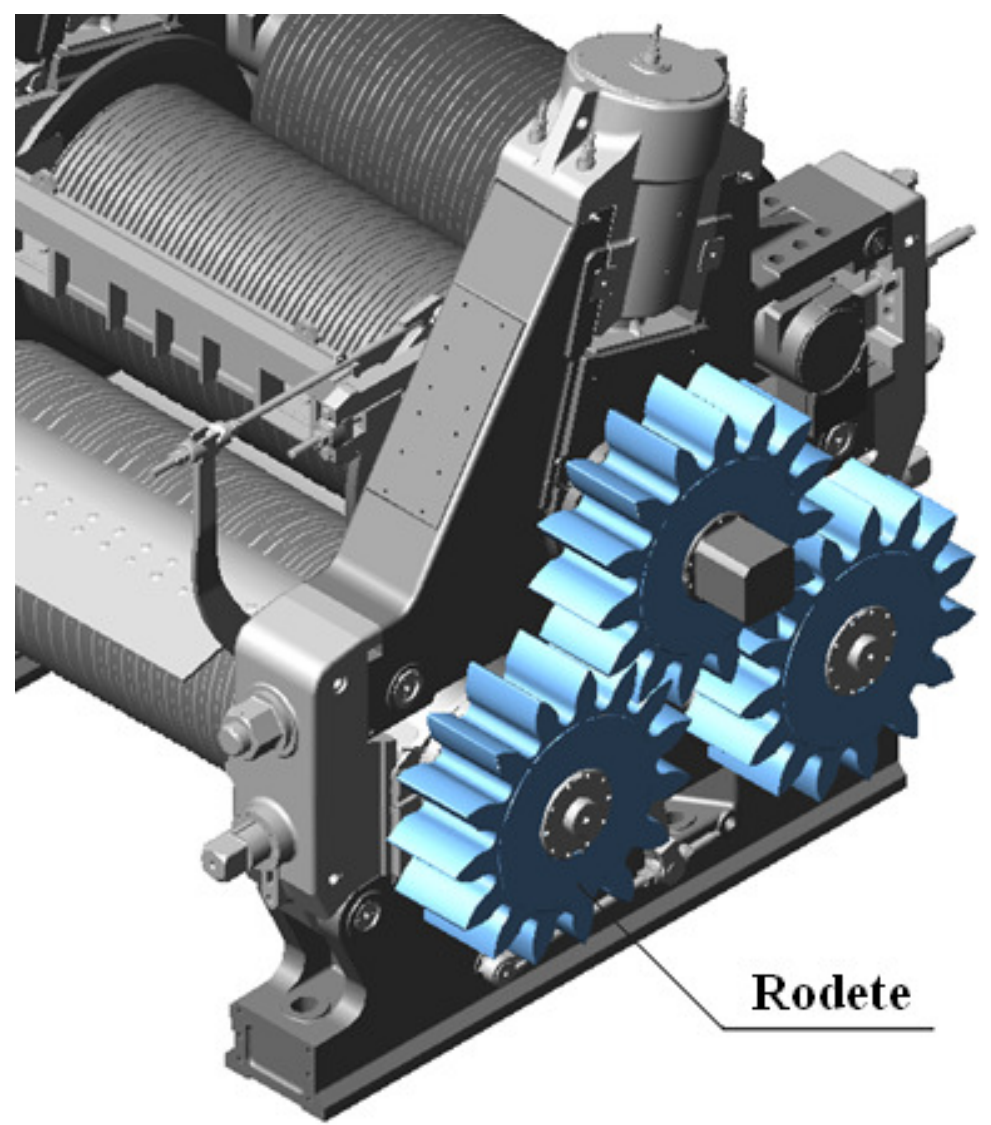

Figura 58: Montagem de 3 rodetes de um único lado do terno de moenda.

Há também o rodete para o acionamento do rolo de pressão, que é projetado com os mesmos princípios dos demais e, no presente trabalho não será discutido seu projeto, pois o mesmo aciona o rolo de pressão que tem a finalidade de auxiliar na alimentação do terno de moenda sendo o torque necessário a esse rolo bem menor que nos demais rolos do terno de moenda.

\subsubsection{Perfil de Evolvente dos Rodetes}

Segundo Finzi (1963), o processo consiste em gerar os perfis do par conjugado com trajetórias ortogonais dos feixes de normais, que formam com as primitivas, ângulos de incidência prefixada. Ainda segundo Finzi (1963), a evolvente é uma linha gerada por um ponto de uma reta que rola, sem escorregar, sobre uma circunferência conforme Figura 59. 


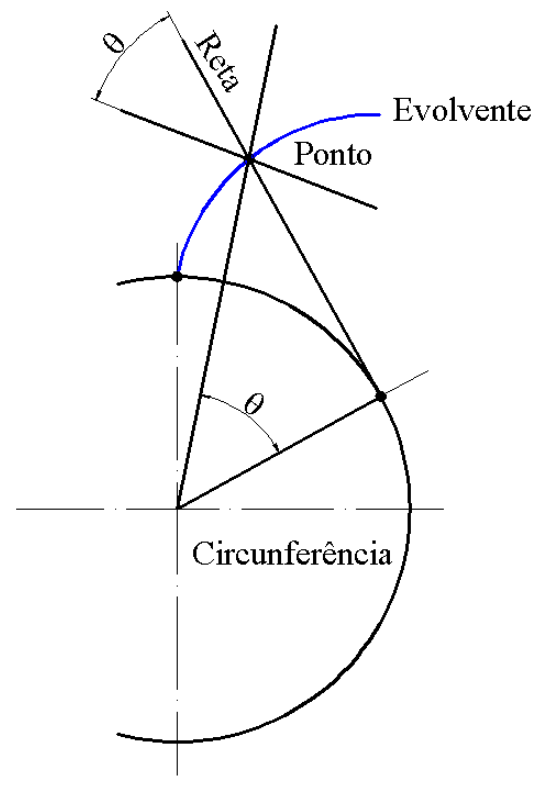

Figura 59: Curva evolvente (ADAPTAÇÃO - FINZI, 1963).

Para a construção da evolvente, em Oliveira (1980), dada uma circunferência com origem em "A" da evolvente, conforme Figura 60 toma-se n pontos arbitrários, 1, $2,3, \ldots$, sobre a circunferência e traça tangentes. Com centro em 1, traça-se o arco “ $A B$ " estando "B" aproximadamente sobre a bissetriz do ângulo formado pelas retas $\mathrm{t}_{1} \mathrm{e}$ $\mathrm{t}_{2}$ e assim sucessivamente. É conveniente que os primeiros pontos sejam próximos de “A”, ou seja, com pequenos espaçamentos pois, próximo a origem "A" a evolvente varia rapidamente de raio.

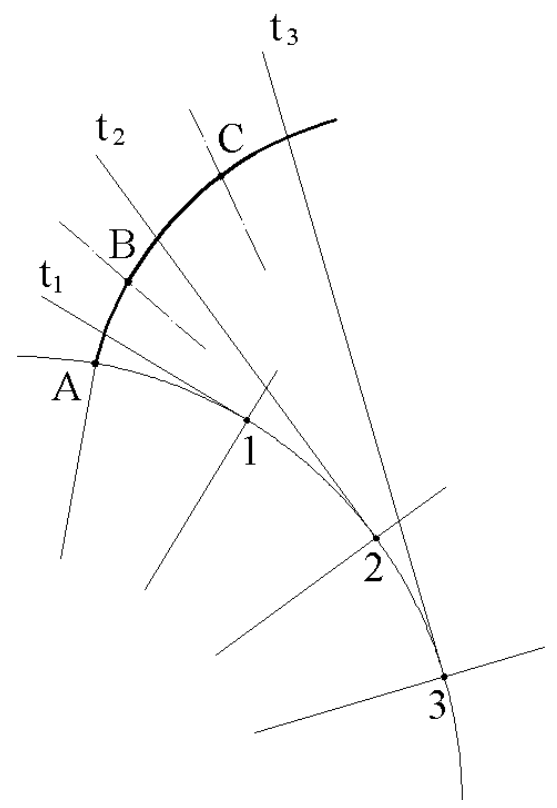

Figura 60: Construção da curva evolvente (OLIVEIRA, 1980). 


\subsubsection{Relações de Engrenamento}

Conforme Brunelli e Miayesi [199-], segue as seguintes relações de engrenamento utilizadas em rodetes de acionamento de eixos do terno de moenda e ilustradas na Figura 61.

$$
\begin{aligned}
& d_{p}=m \times Z \\
& d_{b}=d_{p} \times \cos \alpha_{o} \\
& d_{e x t}=d_{p}+2(K+x) \times m \\
& d_{\text {int }}=d_{p}-2\left(K^{\prime}-2\right) \times m \\
& e=\frac{\pi \times m}{2}+2 \times x \times m \times \tan \alpha_{o} \\
& P=\pi \times m
\end{aligned}
$$

Onde: $\mathrm{d}_{\mathrm{p}}=$ diâmetro primitivo do rodete $(\mathrm{cm})$;

$\mathrm{d}_{\mathrm{b}}=$ diâmetro de base do rodete $(\mathrm{cm})$;

$\mathrm{d}_{\mathrm{ext}}=$ diâmetro externo do rodete $(\mathrm{cm})$;

$\mathrm{d}_{\text {int }}=$ diâmetro interno do rodete $(\mathrm{cm})$;

$\alpha_{o}=$ ângulo de pressão do rodete $\left(^{\circ}\right)$;

$\mathrm{m}=$ módulo (adimensional);

$\mathrm{Z}=$ número de dentes do rodete;

$\mathrm{x}=$ fator de correção do perfil (adimensional);

$\mathrm{e}=$ espessura do dente medido no diâmetro primitivo do rodete $(\mathrm{cm})$;

$\mathrm{P}=$ passo entre dentes medido no diâmetro primitivo do rodete $(\mathrm{cm})$;

$\mathrm{K}$ e $\mathrm{K}^{\prime}$ = fatores que definem a altura do dente

Onde: $\quad K^{\prime}=K+2$ 


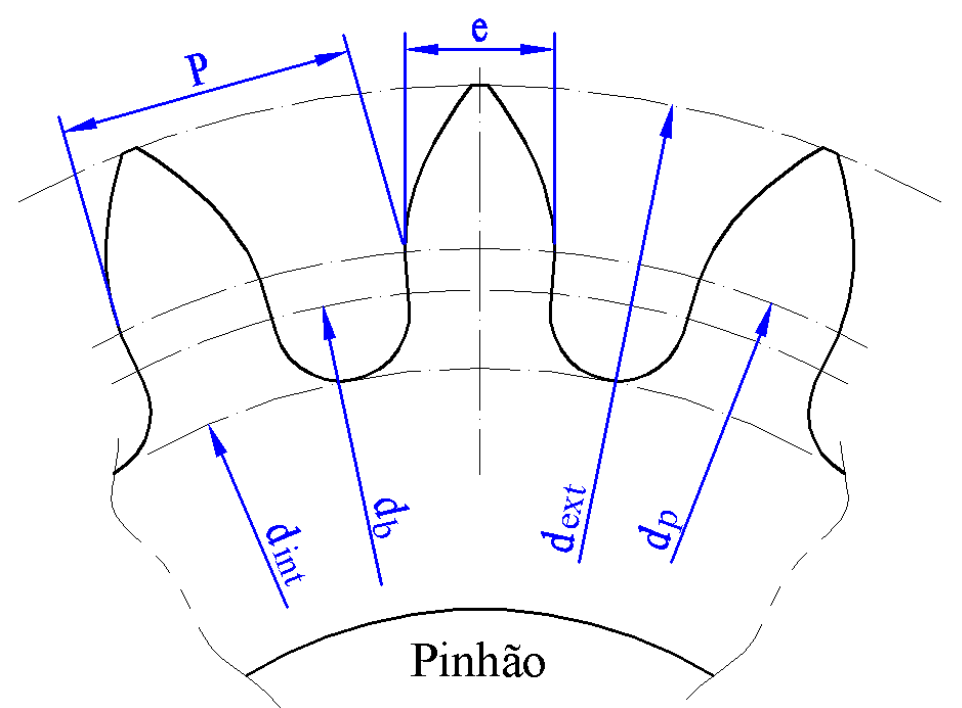

Figura 61: Esquema construtivo de um rodete (pinhão) para acionamento dos rolos de moenda.

\subsubsection{Dimensionamento de Rodetes}

Para o dimensionamento dos rodetes, que acionam os eixos do terno de moenda, verifica-se a tensão de flexão na seção critica do dente, admitindo-o como uma viga engastada. Deve-se também levar em conta a tensão admissível à fadiga, pois, no engrenamento os esforços de flexão não são constantes e sim variam segundo o ciclo pulsante.

A situação mais desfavorável ocorre quando um único par de dentes está engrenado e a força de contato está aplicada na extremidade do dente, conforme Figura 62.

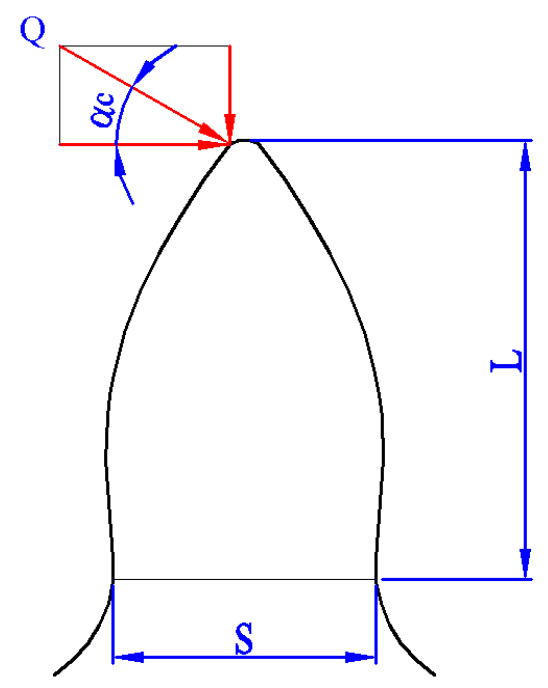

Figura 62: Força normal a superfície do dente do rodete. 
As expressões para o dimensionamento dos rodetes estão de acordo com Brunelli e Miayesi [199-]. Assim a força normal (Q) atuante na superfície do dente é dada por:

$$
Q=\frac{2 \times M_{t}}{d_{p} \times \cos \alpha_{o}}
$$

Onde: $\mathrm{Q}=$ força normal a superfície do dente $(\mathrm{Kgf})$;

$\mathrm{Mt}=$ torque a ser transmitido pelo rodete $(\mathrm{Kgf} \mathrm{x} \mathrm{m})$;

$\mathrm{d}_{\mathrm{p}}=$ diâmetro primitivo do rodete $(\mathrm{cm})$;

$\alpha_{0}=$ ângulo de pressão do rodete $\left({ }^{\circ}\right)$.

Decompondo a força normal Q, tem-se a tensão de compressão $\sigma_{c}$ e a tensão de flexão $\sigma_{\text {flex }}$ como:

$$
\begin{gathered}
\sigma_{c}=\frac{Q \times \operatorname{sen} \alpha_{c}}{B \times S} \\
\sigma_{f l e x}=\frac{Q \times \cos \alpha_{c} \times L}{W}
\end{gathered}
$$

Onde: $\mathrm{Q}=$ força normal a superfície do dente $(\mathrm{Kgf})$;

$\alpha_{c}=$ ângulo de pressão na cabeça do dente $\left({ }^{\circ}\right)$;

$\sigma_{\mathrm{c}}=$ tensão de compressão $\left(\mathrm{Kgf} / \mathrm{cm}^{2}\right)$;

$\sigma_{\text {flex }}=$ tensão de flexão $\left(\mathrm{Kgf} / \mathrm{cm}^{2}\right)$;

$\mathrm{B}=$ largura do dente $(\mathrm{cm})$;

$\mathrm{S}=$ espessura do dente na seção crítica $(\mathrm{cm})$;

$\mathrm{W}=$ momento de resistência a flexão na seção crítica $\left(\mathrm{cm}^{3}\right)$.

Com:

$L=2,24 \times m$ 
$W=\frac{B \times S^{2}}{6}$

$\cos \alpha_{c}=\frac{Z \times \cos \alpha_{o}}{Z+2(K+x)}$

Sendo K o fator que define a altura máxima do dente e seu valor encontrado na tabela 15 em função do ângulo de pressão $\left(\alpha_{0}\right)$, número de dentes $(Z)$ e fator de correção do perfil (x).

Tabela 15: Valores do fator K (Brunelli e Miayesi, [199-]).

\begin{tabular}{|c|c|c|c|c|c|c|c|c|c|c|}
\hline \multicolumn{11}{|c|}{ Fator $\mathrm{K}$} \\
\hline & & \multicolumn{9}{|c|}{$\alpha_{0}$} \\
\hline & & \multicolumn{3}{|c|}{$10^{\circ}$} & \multicolumn{3}{|c|}{$15^{\circ}$} & \multicolumn{3}{|c|}{$20^{\circ}$} \\
\hline & & $Z=14$ & $Z=15$ & $Z=16$ & $Z=14$ & $\mathrm{Z}=15$ & $\mathrm{Z}=16$ & $Z=14$ & $Z=15$ & $\mathrm{Z}=16$ \\
\hline \multirow{6}{*}{$x$} & $\mathbf{0}$ & 0,31 & 0,33 & 0,35 & 0,67 & 0,72 & 0,77 & 1,14 & 1,22 & 1,3 \\
\hline & 0,1 & 0,59 & 0,61 & 0,63 & 0,93 & 0,98 & 1,03 & 1,38 & 1,46 & 1,54 \\
\hline & 0,2 & 0,85 & 0,87 & 0,9 & 1,18 & 1,23 & 1,28 & 1,61 & 1,69 & 1,77 \\
\hline & 0,3 & 1,1 & 1,13 & 1,15 & 1,42 & 1,47 & 1,52 & 1,83 & 1,91 & 2 \\
\hline & 0,4 & 1,34 & 1,37 & 1,4 & 1,65 & 1,7 & 1,75 & 2,05 & 2,13 & 2,22 \\
\hline & 0,5 & 1,52 & 1,61 & 1,64 & 1,87 & 1,93 & 1,98 & 2,26 & 2,34 & 2,43 \\
\hline
\end{tabular}

Sabe-se que a fadiga é mais sensível a tração do que a compressão, assim verifica-se a tensão de traça $\sigma$, dada por:

$$
\sigma=\left(\sigma_{\text {flex }}-\sigma_{c}\right) \times K_{c} \times K_{D}
$$

Onde: $\sigma=$ tensão de tração $\left(\mathrm{Kgf} / \mathrm{cm}^{2}\right)$;

$$
\sigma_{\text {flex }}=\text { tensão de flexão }\left(\mathrm{Kgf} / \mathrm{cm}^{2}\right) \text {; }
$$


$\sigma_{\mathrm{c}}=$ tensão de compressão $\left(\mathrm{Kgf} / \mathrm{cm}^{2}\right)$;

$\mathrm{K}_{\mathrm{c}}=$ coeficiente relativo a distribuição de carga não uniforme na largura do dente (adimensional);

$\mathrm{K}_{\mathrm{D}}=$ coeficiente relativo ao aparecimento de forças dinâmicas adicionais (adimensional).

Para os rodetes de acionamento dos eixos do terno de moenda, adota-se $\mathrm{K}_{\mathrm{c}}=$ 1,80 devido ao não paralelismo entre os eixos e a erros de paralelismo na execução dos dentes. Para o coeficiente $K_{D}$, adota-se $K_{D}=1,0$ devido a velocidade periférica ser baixa, $\mathrm{V}<0,5 \mathrm{~m} / \mathrm{s}$.

A tensão admissível a fadiga é dada por:

$$
\sigma_{a d m}=\frac{\sigma_{o}}{k \times n}
$$

Onde: $\sigma_{\mathrm{adm}}=$ tensão admissível a fadiga $\left(\mathrm{Kgf} / \mathrm{cm}^{2}\right)$;

$\mathrm{k}=$ coeficiente de concentração de tensão na raiz do dente (adota $\mathrm{k}=1,25$ para);

$\mathrm{n}=$ coeficiente de segurança (para aço fundido, material dos rodetes, adota-se $1,80)$;

$\sigma_{\mathrm{o}}=$ limite de resistência a fadiga $(\mathrm{Kgf} / \mathrm{cm} 2) ;$

Com:

$\sigma_{o}=0,6 \times \sigma_{t} \quad$ sendo, $\sigma_{\mathrm{t}}=$ limite de resistência a tração $\left(\mathrm{Kgf} / \mathrm{cm}^{2}\right)-$ ver seção 5.3 .4

Sendo que:

$$
\sigma \leq \sigma_{a d m}
$$




\section{Validação de Projetos}

\subsection{Critérios de Resistência}

Ao se projetar deve-se levar em conta o esforço ou o conjunto de esforços que determinará o colapso do componente em análise, ou seja, quando o componente atinge a tensão de escoamento se deforma excessivamente, de tal forma a inutilizá-lo. No contexto geral, os esforços atuantes no componente são multiplicados por um valor maior que um denominado coeficiente de segurança, o qual determinará o colapso do componente. A fixação do coeficiente de segurança leva em conta as aproximações introduzidas nos cálculos, a variação dos materiais de construção dos componentes, a importância do componente no projeto, a incerteza quanto às cargas aplicadas ao componente, entre outros. (JÚNIOR, 1962).

De acordo com Laier (2003), o diagrama de tensão x deformação mostra três níveis característicos de tensão, a saber:

- Tensão limite de proporcionalidade;

- Tensão de escoamento;

- Tensão de ruptura.

Para tensões abaixo do limite de proporcionalidade, é aplicável a lei de Hooke, ou seja, há uma proporcionalidade entre tensão e deformação. Entre a tensão limite de proporcionalidade e a tensão de escoamento, a proporcionalidade entre tensão e deformação deixa de existir, manifestando-se grandes deformações sem aumento excessivo da tensão. Assim, nos materiais classificados como dúcteis, a ruptura já é qualificada na tensão de escoamento, inutilizando o componente nesta fase devido aos deslocamentos excessivos e deformações residuais indesejáveis no descarregamento.

Por diversos fatores, como defeitos internos de diferentes naturezas nos materiais e a heterogeneidade do meio, podem afetar a resposta mecânica do material, que pode ser diferente, dependendo do tipo de solicitação. Assim, por esses motivos e outros, a resistência dos componentes, de um dado projeto, é o resultado de uma combinação de efeitos, uns mais importantes, outros menos, o que torna difícil a formulação matemática de relações que permitam prever limites para tais componentes em situações de solicitações mais complexas. Porém, a identificação das solicitações 
que possam exceder a capacidade de resistência dos materiais empregados é de grande importância para a realização de um projeto seguro.

Com tais dificuldades de obter uma formulação matemática para a identificação de situações limites de resistência dos materiais, uma alternativa é a busca de interpretações mais simples, porém plausíveis, para os fenômenos responsáveis a ruptura ou colapso dos materiais, daí resultando os critérios de resistência (PROENÇA, 2007).

\subsubsection{Critério de Mohr-Coulomb}

De acordo com Laier (2003), o critério de Mohr-Coulomb parte da definição de que a integridade do material é resultado de um atrito interno existente entre as partículas que o compõe e é formulado inicialmente para materiais pulverulentos, como a areia. Assim, o estado de tensão suportado pelo material, deve em todos os planos, atender a condição de:

$$
\tau \leq \sigma \times \operatorname{tg} \phi_{a}
$$

Onde: $\tau=$ tensão de cisalhamento;

$\sigma=$ tensão normal;

$\phi_{\mathrm{a}}=$ ângulo de atrito.

Com isso representa-se o critério na Figura 63.

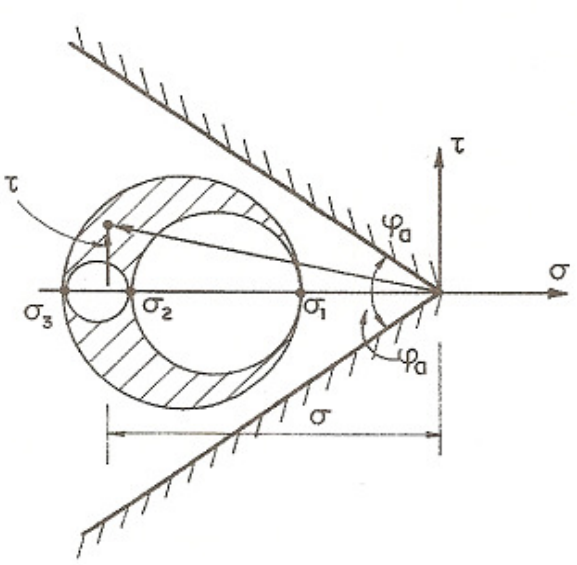

a) Circulos de Mohr

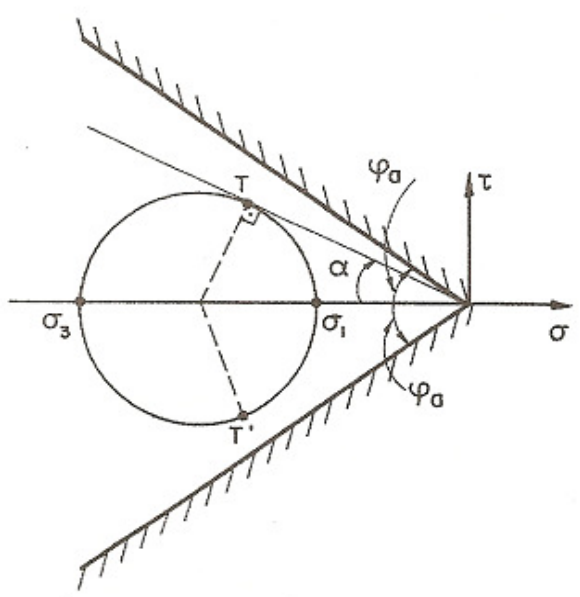

b) Estado mais critico

Figura 63: Critério de Mohr-Coulomb para materiais pulverulentos (LAIER, 2003). 
No plano $\sigma / \tau$ o estado de tensão é representado pela parte hachurada da Figura 63-a, assim, fica claro que o plano mais crítico em relação ao deslizamento, ou seja, a ruptura, é o correspondente par de pontos $\mathrm{T}$ indicados na Figura 63-b, sendo condição para a não ruptura:

$$
\alpha \leq \phi_{a}
$$

sendo $\alpha$ o ângulo referente ao ponto T, conforme Figura 63-b, ou

$$
\operatorname{sen} \alpha \leq \operatorname{sen} \phi_{a}
$$

ou ainda, por considerações geométricas

$$
\frac{\sigma_{3}-\sigma_{1}}{\sigma_{3}+\sigma_{1}}=\operatorname{sen} \alpha \leq \operatorname{sen} \phi_{a}
$$

sendo uma maneira mais cômoda de expressar o critério dado pela expressão:

$$
\frac{\sigma_{1}}{\sigma_{2}} \geq \frac{1-\operatorname{sen} \phi_{a}}{1+\operatorname{sen} \phi_{a}}
$$

Para atender materiais frágeis coesivos, ou seja, materiais que tem pouca resistência a tração e partindo do princípio que há uma atração existente entre as partículas responsável pela resistência a tração, a compressão efetiva na superfície de contato passa a ser aplicada mais decorrente daquela atração, assim, a expressão 05 para esses materiais é dada por:

$$
\frac{\sigma_{1}-\sigma^{*}}{\sigma_{2}-\sigma^{*}} \geq \frac{1-\operatorname{sen} \phi_{a}}{1+\operatorname{sen} \phi_{a}}
$$

sendo $\sigma^{*}$ representada pela contribuição decorrente da atração mencionada.

A Figura 64-a ilustra o critério em questão, dando ênfase a translação do eixo $\tau$ em relação à Figura 63-a. No critério em questão, dois são os parâmetros necessários 
para sua definição sendo que, na Figura 64-b é ilustrado a tensão de ruptura a tração simples $\sigma_{\mathrm{t}}$ e a compressão simples $\sigma_{\mathrm{c}}$.

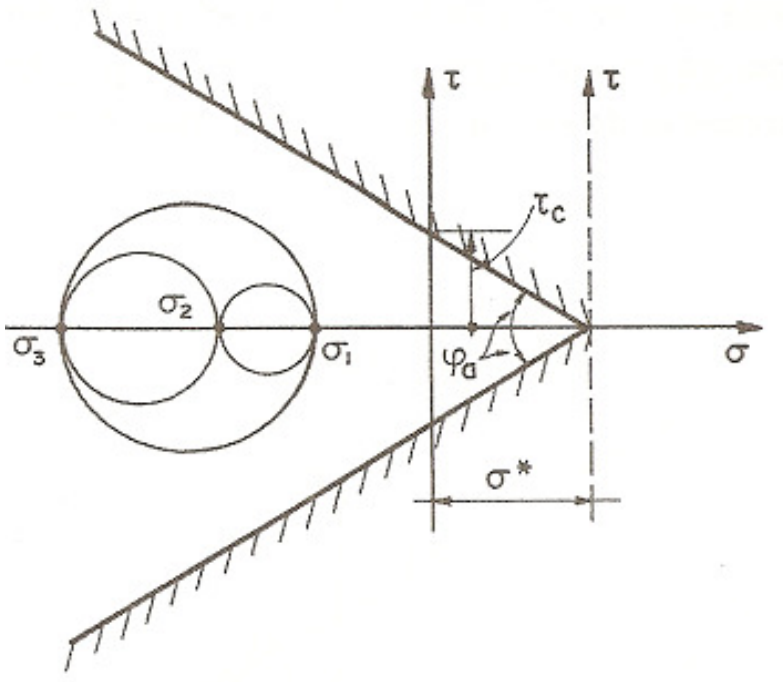

a) Translaçōo do Eixo $\tau$

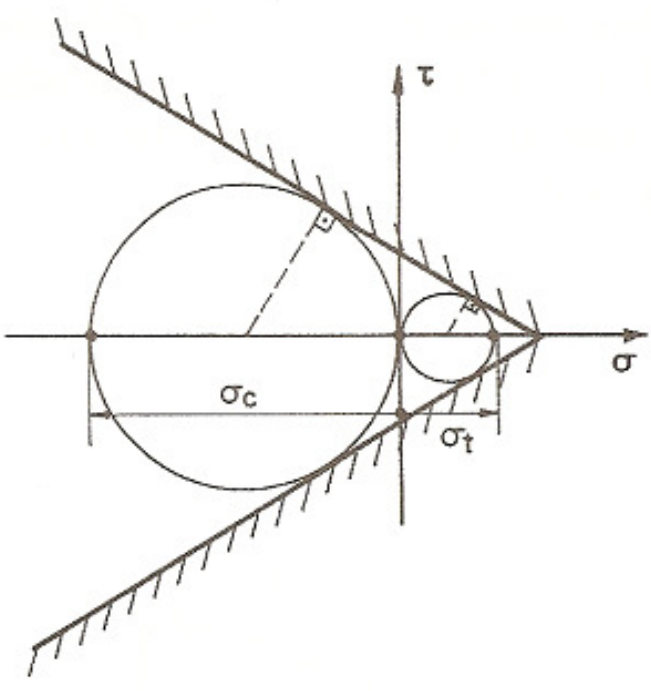

b) Circulos de Mohr de Traçōo e Compressāo

Figura 64: Critério de Mohr-Coulomb para materiais coesivos (LAIER, 2003).

Como na prática, o estado plano de tensão é o mais encontrado, é interessante buscar uma representação mais cômoda desse critério. Assim, como no caso plano uma das tensões principais é nula e assumindo $\sigma_{1}$ e $\sigma_{2}$ não nulas e, deixando de lado a convenção $\sigma_{1}>\sigma_{2}<\sigma_{3}$, o critério é ilustrado na Figura 65-a.

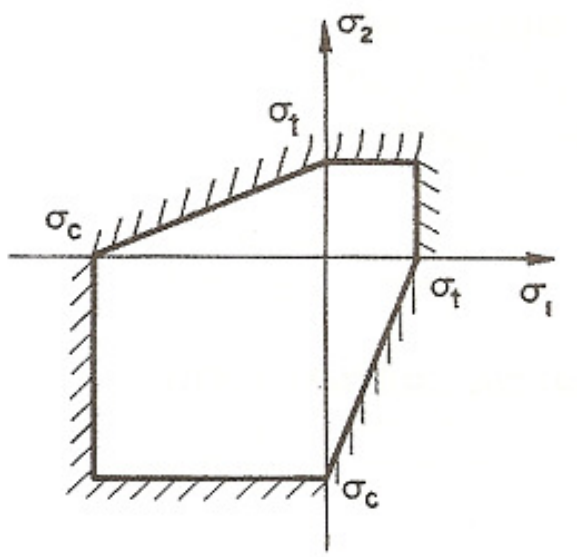

a) Critério de Mohr-Coulomb no plano $\sigma_{1} / \sigma_{2}$

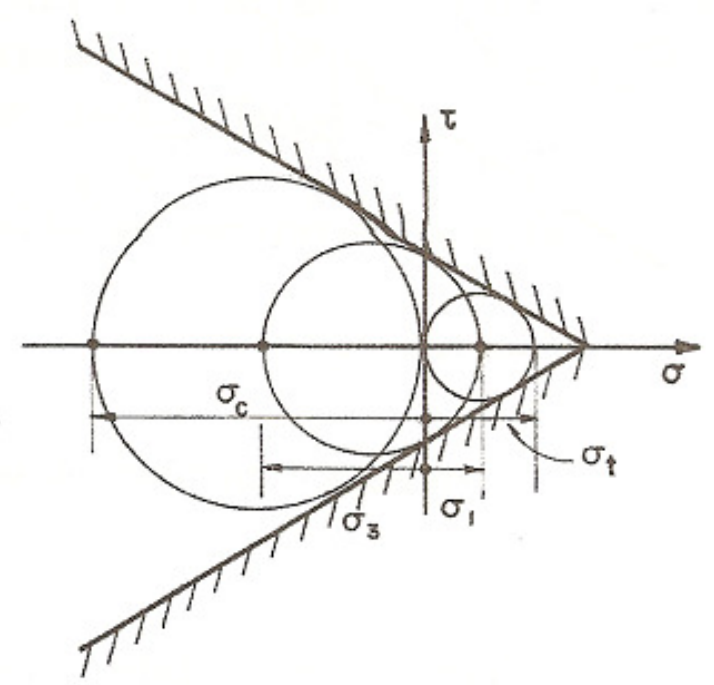

b) Posiçäo Relativa dos Circulos de Mohr

Figura 65: Critério de Mohr-Coulomb para estado plano (LAIER, 2003). 
Tendo $\sigma_{1}$ e $\sigma_{2}$ de tração, este par tem que estar contido na região $\sigma_{2} \leq \sigma_{\mathrm{t}}$ e $\sigma_{1} \leq \sigma_{\mathrm{t}}$, pois o maior circulo de Mohr possível não pode superar ao correspondente ao do ensaio de tração simples, conforme ilustra a Figura 65-b. O mesmo se repete quanto $\sigma_{1}$ e $\sigma_{2}$ são de compressão. Para $\sigma_{1}$ de tração e $\sigma_{2}$ de compressão tem-se conforme expressão 06:

$$
\sigma_{1} \geq \frac{1-\operatorname{sen} \phi_{a}}{1+\operatorname{sen} \phi_{a}} \times \sigma_{2}+\sigma^{*} \times \frac{2 \times \operatorname{sen} \phi_{a}}{1+\operatorname{sen} \phi_{a}}
$$

\subsubsection{Critério de Von Mises}

De acordo com Proença (2007), o critério de Von Mises, também chamado de critério da máxima energia, postula que a ruptura se dá quando a energia de distorção capaz de ser absorvida no processo de deformação atinge um valor limite. É necessário considerar as decomposições aditivas dos tensores de tensão e deformação em partes esféricas e anti-esféricas para definir a energia de distorção. Tais decomposições são expressas como:

$$
\begin{gathered}
{\left[\begin{array}{ccc}
\sigma_{1} & 0 & 0 \\
0 & \sigma_{2} & 0 \\
0 & 0 & \sigma_{3}
\end{array}\right]=[A]+[B]+\left[\begin{array}{ccc}
\sigma_{m} & 0 & 0 \\
0 & \sigma_{m} & 0 \\
0 & 0 & \sigma_{m}
\end{array}\right]+\left[\begin{array}{ccc}
\sigma_{1}-\sigma_{m} & 0 & 0 \\
0 & \sigma_{2}-\sigma_{m} & 0 \\
0 & 0 & \sigma_{3}-\sigma_{m}
\end{array}\right]} \\
{\left[\begin{array}{ccc}
\varepsilon_{1} & 0 & 0 \\
0 & \varepsilon_{2} & 0 \\
0 & 0 & \varepsilon_{3}
\end{array}\right]=[C]+[D]+\left[\begin{array}{ccc}
\varepsilon_{m} & 0 & 0 \\
0 & \varepsilon_{m} & 0 \\
0 & 0 & \varepsilon_{m}
\end{array}\right]+\left[\begin{array}{ccc}
\varepsilon_{1}-\varepsilon_{m} & 0 & 0 \\
0 & \varepsilon_{2}-\varepsilon_{m} & 0 \\
0 & 0 & \varepsilon_{3}-\varepsilon_{m}
\end{array}\right]}
\end{gathered}
$$

O produto das tensões pelas respectivas deformações resulta na energia de deformação por unidade (u) e, levando em conta a decomposição apresentada para os tensores, essa energia é composta por duas parcelas que são: uma relaciona a variação de volume e a outra a variação de forma. Com isso, as expressões [08] e [09], por definição são: 


$$
u=\frac{1}{2} \times\left(\sigma_{1} \varepsilon_{1}+\sigma_{2} \varepsilon_{2}+\sigma_{3} \varepsilon_{3}\right)=u_{V}+u_{D}
$$

Onde: $\mathrm{u}_{\mathrm{V}}=$ energia de volume calculada pelo produto das matrizes $\mathrm{A}$ e $\mathrm{C}$;

$\mathrm{u}_{\mathrm{D}}=$ energia de forma calculada pelo produto das matrizes B e D.

explicitando-se a parcela correspondente a energia de forma, ou de distorção, temos:

$$
u_{D}=\frac{1}{2} \times\left[\left(\sigma_{1}-\sigma_{m}\right) \times\left(\varepsilon_{1}-\varepsilon_{m}\right)+\left(\sigma_{2}-\sigma_{m}\right) \times\left(\varepsilon_{2}-\varepsilon_{m}\right)+\left(\sigma_{3}-\sigma_{m}\right) \times\left(\varepsilon_{3}-\varepsilon_{m}\right)\right]_{[1}
$$

escrevendo a expressão [11] somente em função dos componentes de tensão, tendo em vista a lei de Hooke generalizada, as componentes principais são dadas por:

$$
\begin{aligned}
& \varepsilon_{1}=\frac{1}{E} \times\left[\sigma_{1}-v \times\left(\sigma_{2}+\sigma_{3}\right)\right] ; \\
& \varepsilon_{2}=\frac{1}{E} \times\left[\sigma_{2}-v \times\left(\sigma_{1}+\sigma_{3}\right)\right] ; \\
& \varepsilon_{3}=\frac{1}{E} \times\left[\sigma_{3}-v \times\left(\sigma_{2}+\sigma_{1}\right)\right] ;
\end{aligned}
$$

substituindo as expressões [12], [13] e [14] na expressão [11] e, após algumas simplificações, obtém-se:

$$
u_{D}=\frac{1+v}{6 \times E} \times\left[\left(\sigma_{1}-\sigma_{2}\right)^{2}+\left(\sigma_{1}-\sigma_{3}\right)^{2}+\left(\sigma_{2}-\sigma_{3}\right)^{2}\right]
$$

A expressão [15] é aplicada aos estados tridimensionais de tensão e, para encontrar um valor de referência com o qual se pode comparar, considera-se o caso de ruptura por tração uniaxial. Neste caso as componentes principais de tensão são: $\sigma_{1}=$ $\sigma_{T} ; \sigma_{2}=\sigma_{3}=0$. Assim o valor de referência à energia de forma, ou distorção, é dada por: 


$$
u_{D}=\frac{1+v}{6 \times E} \times\left[\left(\sigma_{T}\right)^{2}+\left(\sigma_{T}\right)^{2}\right]=\frac{1+v}{3 \times E} \times \sigma_{T}^{2}
$$

assim o critério de Von Mises passa a ter a expressão dada por:

$$
\frac{1+v}{6 \times E} \times\left[\left(\sigma_{1}-\sigma_{2}\right)^{2}+\left(\sigma_{1}-\sigma_{3}\right)^{2}+\left(\sigma_{2}-\sigma_{3}\right)^{2}\right] \leq \frac{1+v}{3 \times E} \times \sigma_{T}^{2}
$$

ou ainda:

$$
\frac{1}{2} \times\left[\left(\sigma_{1}-\sigma_{2}\right)^{2}+\left(\sigma_{1}-\sigma_{3}\right)^{2}+\left(\sigma_{2}-\sigma_{3}\right)^{2}\right] \leq \sigma_{T}^{2}
$$

De acordo com Laier (2003), a verificação da ruptura pelo critério de Von Mises é, por conveniência, formulada definindo o parâmetro:

$$
\sigma_{i}=\sqrt{\frac{1}{2} \times\left[\left(\sigma_{1}-\sigma_{2}\right)^{2}+\left(\sigma_{1}-\sigma_{3}\right)^{2}+\left(\sigma_{2}-\sigma_{3}\right)^{2}\right]}
$$

onde: $\sigma_{i}=$ tensão ideal

Assim a não ruptura do material passa a ser dada pela condição:

$$
\sigma_{i} \leq \sigma_{T}
$$

onde: $\sigma_{\mathrm{T}}=$ Tensão de ruptura do material, ou a tensão na qual se admite o componente como em estado de ruptura.

Em Stemmer (1979), para materiais dúcteis sobre carregamento estático, em temperatura normal, onde a tensão limite é correspondente a tensão de escoamento $\sigma_{\mathrm{e}}$, para projetos de componentes de máquinas, verifica-se através de inúmeras investigações experimentais que, com o critério de Von Mises obtêm-se ótimas aproximações. 


\subsection{O Método dos Elementos Finitos em Projetos}

O método dos elementos finitos surgiu com o objetivo de resolver problemas da teoria da elasticidade, nos casos em que alguns métodos, como o de Rayleigh-Ritz, Galerkin, Diferenças finitas, entre outros, possuíam dificuldades. O método dos elementos finitos tem como base o método de Rayleigh-Ritz e, divide o domínio de integração, continuo, em um número finito de pequenas regiões denominadas elementos finitos, o que é ilustrado na Figura 66. O método dos elementos finitos torna o meio continuo em discreto (ASSAN, 2003).

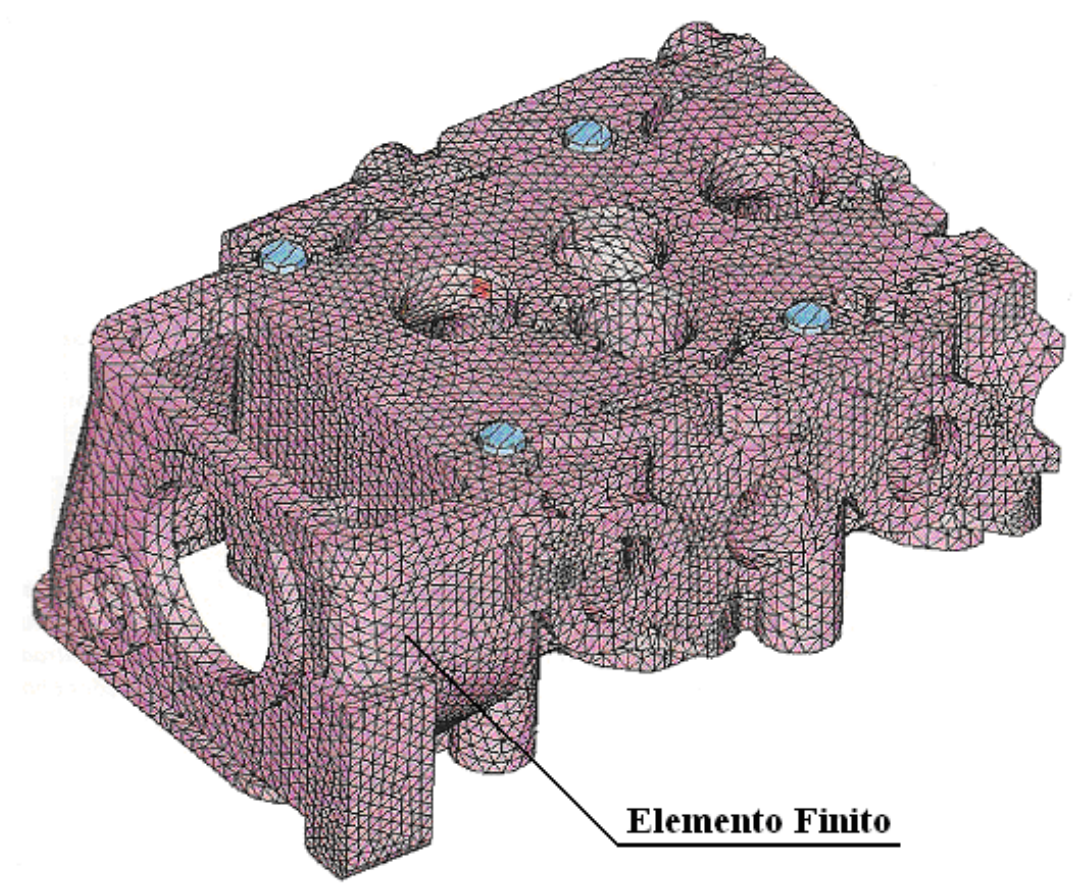

Figura 66: Esquema de um componente divido em pequenas regiões (ALVES FILHO,2006).

O termo elemento finito foi para dar ênfase à diferença de tratamento daquele utilizado na formulação local, feita sobre elementos infinitesimais. No método dos elementos finitos, obtêm-se o relacionamento aproximado entre os deslocamentos dos nós dos elementos com suas respectivas forças por meio dos procedimentos diretos da mecânica ou com formulações variacionais ou, ainda, de resíduos ponderados. Para o estudo do conjunto, basta montar os elementos e considerar as respectivas equações algébricas que representam o relacionamento entre os deslocamentos e as forças (SAVASSI, 1996).

Conforme Knight (1993), o método dos elementos finitos é utilizado em diversas aplicações na engenharia. Inicialmente este método foi desenvolvido para análises 
estruturais, no entanto, é agora utilizado para resolução de problemas de diversos campos da engenharia, como por exemplo, transferência de calor, mecânica dos fluidos, acústica, eletromagnetismo, entre outros.

Diferentes tipos de elementos são formulados nesse método, sendo que, dão soluções para os mais diferentes problemas encontrados na engenharia, igualmente às teorias convencionais, entretanto com uma facilidade maior.

De acordo com Holand e Bell (1970), alguns tipos de elementos, assim como o numero de nós e graus de liberdade de cada um, usuais para a aplicação do método dos elementos finitos encontram-se na tabela 16:

Tabela 16: Tipos de elementos (HOLAND; BELL, 1970).

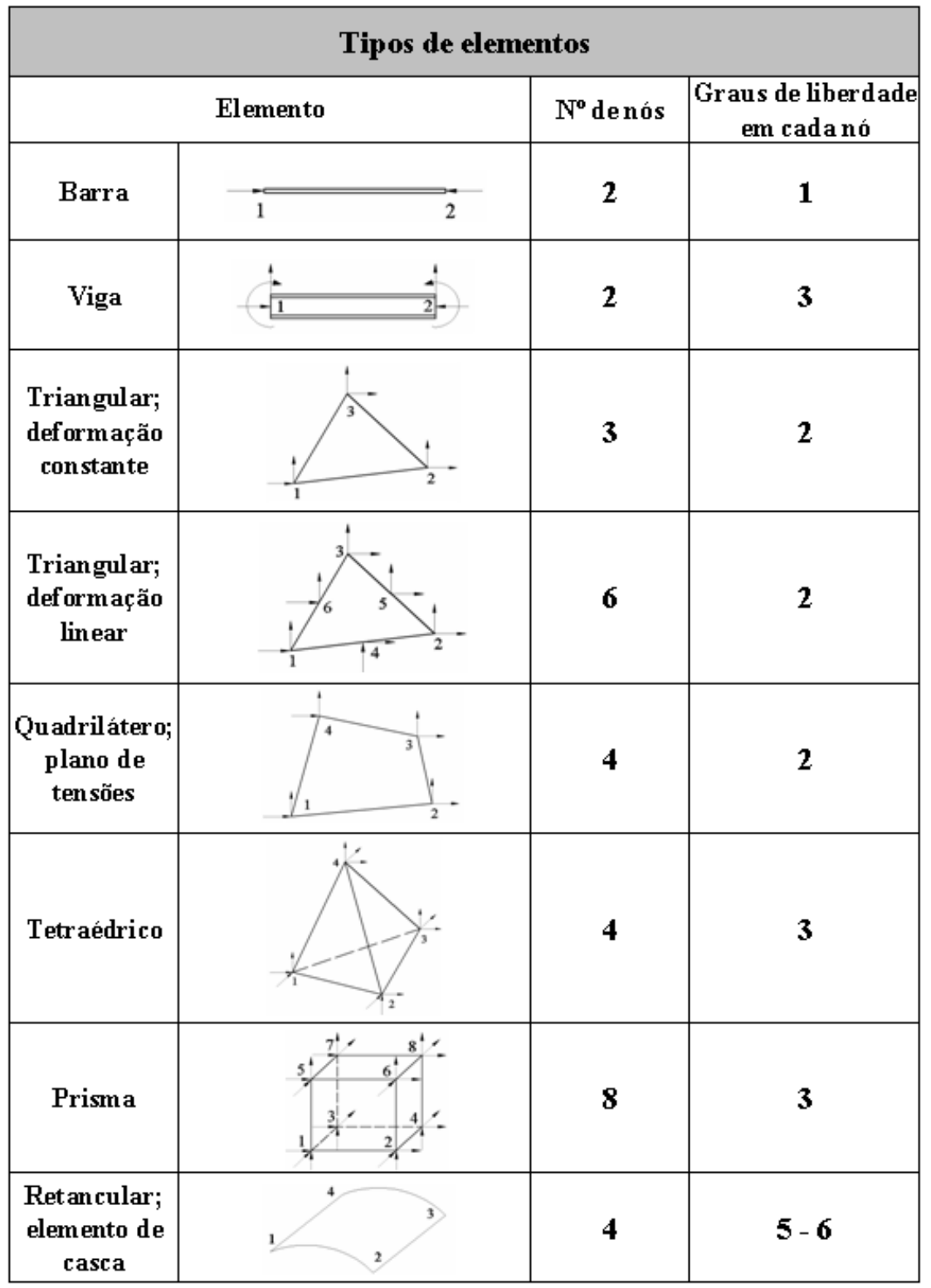


Quando o estudo trata de componentes em que nenhuma das dimensões seja pequena em relação às demais, ou não se respeita as hipóteses das teorias simplificadas, os elementos tridimensionais devem ser utilizados (SAVASSI, 1996).

A formulação dos elementos utilizados no método dos elementos finitos pode ser encontrada em obras especificas no assunto, contudo o presente trabalho traz a formulação do elemento tetraédrico linear e tetraédrico parabólico, utilizado na grande maioria dos casos e no decorrer do presente trabalho.

\subsubsection{Formulação do Elemento Tetraédrico Linear}

De acordo com Alves Filho (2006) devido à versatilidade de geometria do tetraedro, qualquer corpo sólido continuo pode ser representado por um conjunto de tetraedros. A Figura 67 ilustra um corpo sólido continuo dividido artificialmente por um número finito de elementos tetraédricos lineares, conectados por seus nós.

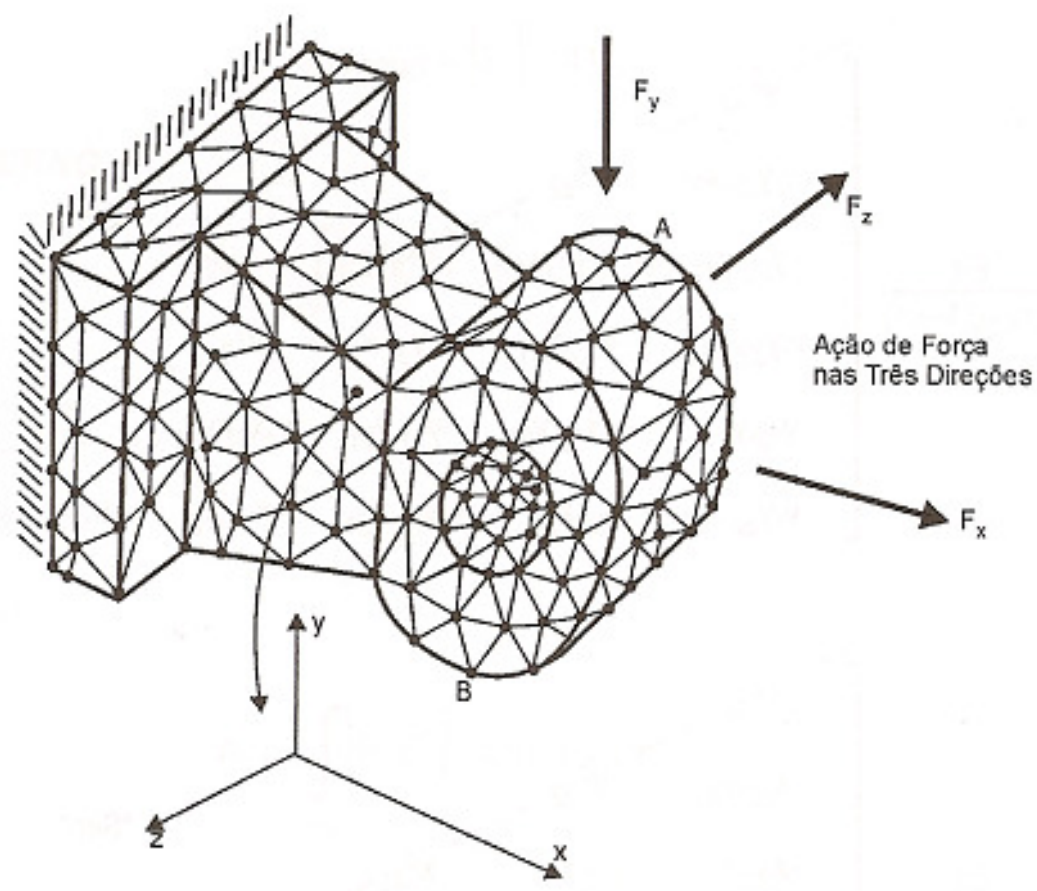

Figura 67: Divisão de um componente em elementos tetraédrico linear (ALVES FILHO,2006).

O elemento finito tetraédrico linear possui quatro nós, conforme Figura 68, e seus movimentos podem ser descritos componentes u, v e w, pois a definição, segundo a teoria da elasticidade, de deslocamentos em um sólido sob o estado triaxial de tensão é efetuada por três componentes de deslocamento. Assim o elemento tetraédrico linear 
que apresenta quatro nós, possui 12 graus de liberdade, com isso a matriz coluna representada pelas forças nodais, ou seja, forças atuantes nos nós, tem dimensão 12 x 1 , e da mesma forma a matriz coluna representada pelos deslocamentos nodais tem dimensão 12 x 1. A conseqüência é uma matriz de rigidez, que relaciona o comportamento entre as forças e os deslocamentos, tem dimensão 12 x 12, como segue:

$$
\{f\}_{12 \times 1}=[K]_{12 \times 12} \times\{\delta\}_{12 \times 1}
$$
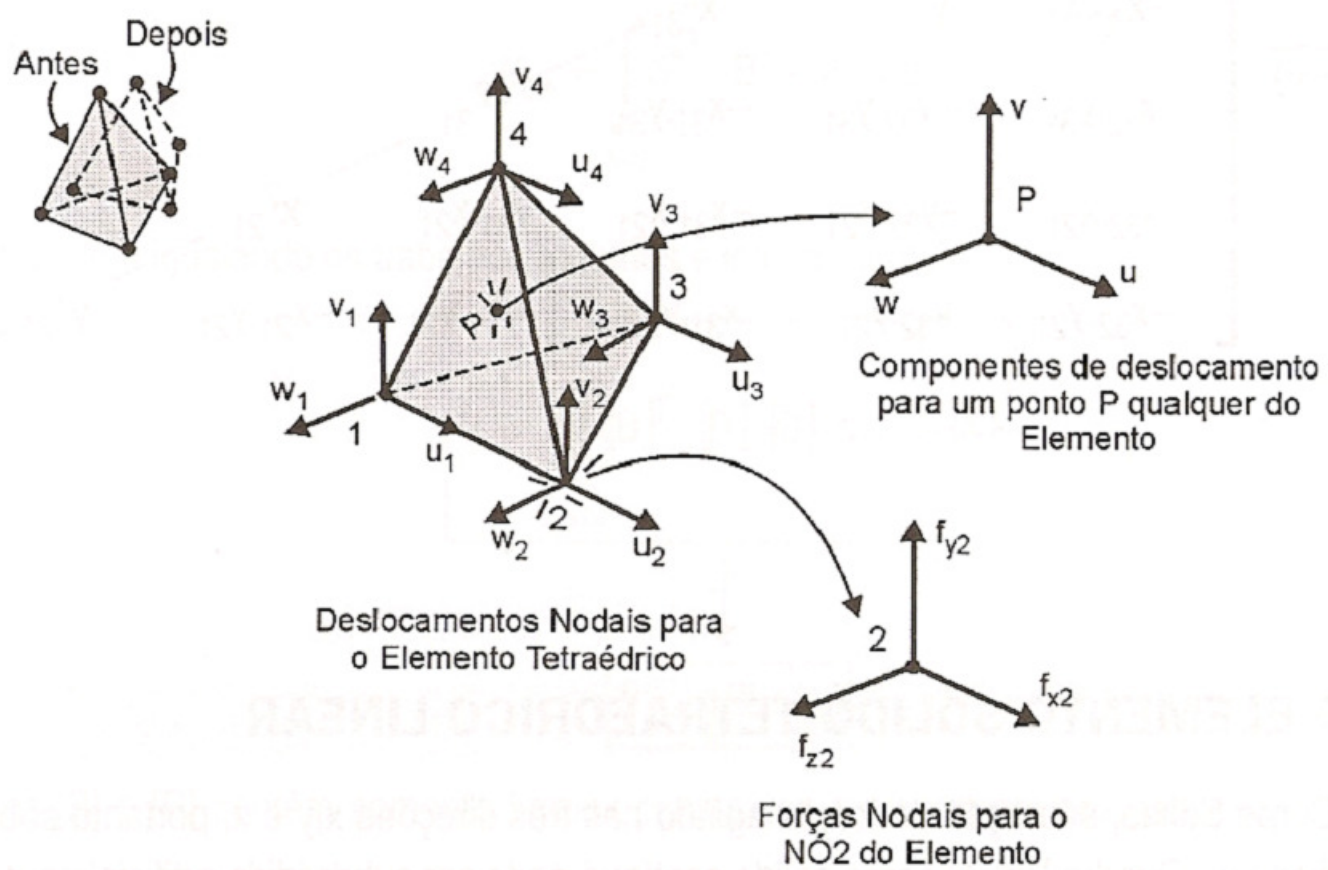

Figura 68: Elemento finito tetraédrico linear (ALVES FILHO,2006).

Para a formulação segue três passos fundamentais que são:

- Definição das funções de interpolação;

- Cálculo das deformações;

- Cálculo das tensões

\section{a) Definição das funções de interpolação}

O grau do polinômio de interpolação é definido pelo número de graus de liberdade do elemento tetraédrico, assim, o polinômio escolhido deverá conter 12 coeficientes desconhecidos. No estado triaxial de tensões, o deslocamento de um ponto qualquer é definido pelas componentes $\mathrm{u}, \mathrm{v}$ e w nas direções $\mathrm{x}, \mathrm{y}$ e $\mathrm{z}$ respectivamente e 
o deslocamento do ponto depende da localização do mesmo no sólido. Como se tem três componentes de deslocamento em cada nó, tem-se três funções para representar o campo de deslocamentos. Assim, com os 12 coeficientes, tem-se três funções para os deslocamentos u, v e w respectivamente e cada função utilizará quatro coeficientes. Como cada uma das funções depende de x, y e z, ou seja, o deslocamento varia linearmente com x, com y e com z, as funções serão de três variáveis. O conjunto das três funções é expressa por:

$$
\begin{aligned}
& u(x, y, z)=C_{1}+C_{2} x+C_{3} y+C_{4} z \\
& v(x, y, z)=C_{5}+C_{6} x+C_{7} y+C_{8} z \\
& w(x, y, z)=C_{9}+C_{10} x+C_{11} y+C_{12} z
\end{aligned}
$$

\section{b) Cálculo das deformações}

Da teoria da elasticidade, calcula-se as deformações em qualquer ponto dentro do elemento finito sólido, dentro das hipóteses das funções de interpolação adotadas. Temos então:

$$
\varepsilon_{x}=\frac{\partial u}{\partial x} ; \varepsilon_{y}=\frac{\partial v}{\partial y} ; \varepsilon_{z}=\frac{\partial w}{\partial z} ; \gamma_{x y}=\frac{\partial u}{\partial y}+\frac{\partial v}{\partial x} ; \gamma_{x z}=\frac{\partial u}{\partial z}+\frac{\partial v}{\partial x} ; \gamma_{y z}=\frac{\partial u}{\partial z}+\frac{\partial v}{\partial y}
$$

Essas funções contêm derivadas parciais, assim, efetuando as derivadas das funções $\mathrm{u}, \mathrm{v}$ e w que fornecem o deslocamento em todos os pontos, tem-se:

$$
\begin{aligned}
& \varepsilon_{x}=\frac{\partial u}{\partial x}=C_{2}=\text { CONSTANTE } \\
& \varepsilon_{y}=\frac{\partial v}{\partial y}=C_{7}=\text { CONSTANTE } \\
& \varepsilon_{z}=\frac{\partial w}{\partial z}=C_{12}=\text { CONSTANTE }
\end{aligned}
$$




$$
\begin{aligned}
& \gamma_{x y}=\frac{\partial u}{\partial y}+\frac{\partial v}{\partial x}=C_{3}+C_{6}=\text { CONSTANTE } \\
& \gamma_{x z}=\frac{\partial u}{\partial z}+\frac{\partial v}{\partial x}=C_{4}+C_{10}=\text { CONSTANTE } \\
& \gamma_{y z}=\frac{\partial u}{\partial z}+\frac{\partial v}{\partial y}=C_{8}+C_{11}=\text { CONSTANTE }
\end{aligned}
$$

Assim, o elemento sólido tetraédrico é um elemento de deformações constantes.

\section{c) Cálculo das tensões}

O cálculo das tensões decorre imediatamente a partir do cálculo das deformações, utilizando, da teoria da elasticidade, a equação:

$$
\{\sigma(x, y, z)\}=[D] \times\{\varepsilon(x, y, z)\}
$$

Onde [D] é a matriz de elasticidade para o estado triaxial de tensões dada por:

$$
[D]=\frac{E(1-v)}{(1+v)(1-2 v)} \times\left[\begin{array}{cccccc}
1 & \frac{v}{1-v} & \frac{v}{1-v} & 0 & 0 & 0 \\
\frac{v}{1-v} & 1 & \frac{v}{1-v} & 0 & 0 & 0 \\
\frac{v}{1-v} & \frac{v}{1-v} & 1 & 0 & 0 & 0 \\
0 & 0 & 0 & \frac{1-2 v}{2(1-v)} & 0 & 0 \\
0 & 0 & 0 & 0 & \frac{1-2 v}{2(1-v)} & 0 \\
0 & 0 & 0 & 0 & 0 & \frac{1-2 v}{2(1-v)}
\end{array}\right]
$$

Para exemplificar, o calculo da tensão $\sigma_{x}$ em qualquer ponto do elemento é efetuado pelo produto matricial em [31], assim a tensão $\sigma_{\mathrm{x}}$ é dada por: 


$$
\sigma_{x}=\frac{E(1-v)}{(1+v)(1-2 v)} \times\left(\varepsilon_{x}+\frac{v}{1-v} \times \varepsilon_{y}+\frac{v}{1-v} \times \varepsilon_{z}\right)=\text { CONSTANTE }
$$

As expressões para o cálculos das tensões são válidas para qualquer ponto submetido a um estado triaxial de tensões e, foi desenvolvido a partir da teoria da elasticidade. Em particular no caso do elemento tetraédrico, foram utilizados os valores de deformações $\varepsilon_{x}, \varepsilon_{y}$ e $\varepsilon_{z}$ que resultam no campo de deslocamento.

\subsubsection{Formulação do Elemento Tetraédrico Parabólico}

A Figura 69 ilustra um corpo sólido continuo dividido artificialmente por um número finito de elementos tetraédricos parabólicos, conectados através de seus nós.

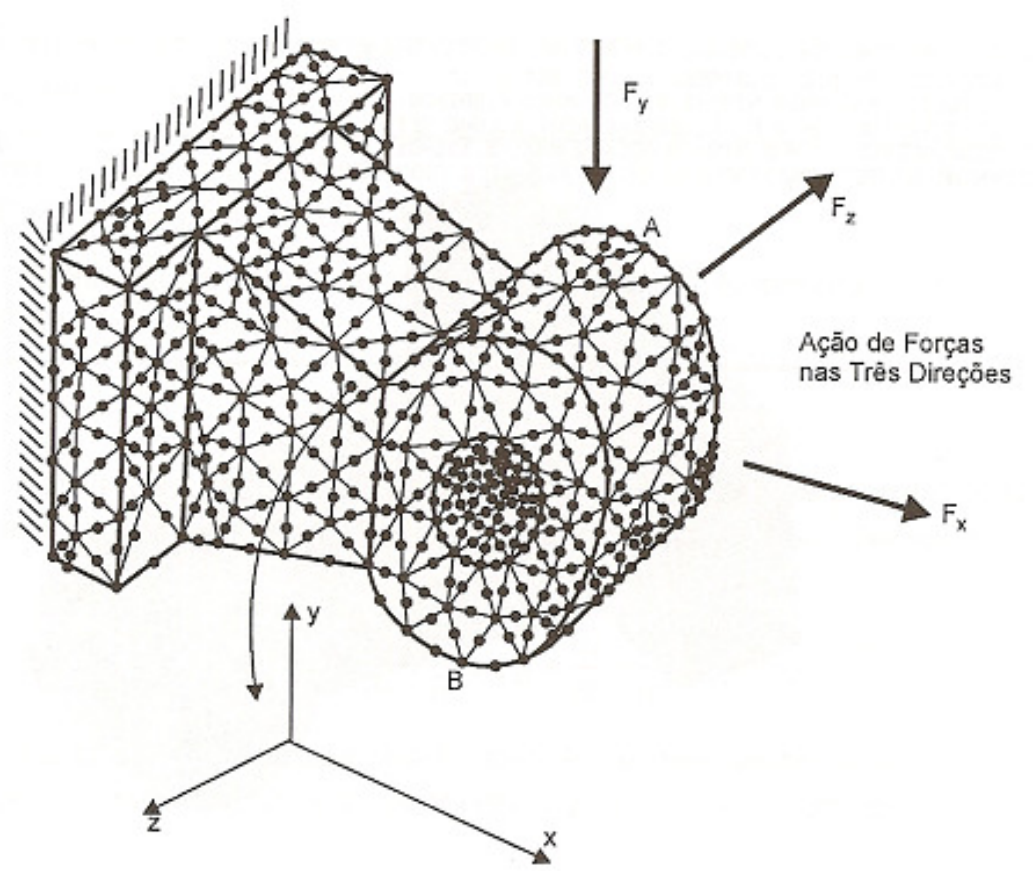

Figura 69: Divisão de um componente em elementos tetraédrico parabólicos (ALVES FILHO,2006).

O elemento finito tetraédrico parabólico possui dez nós, conforme Figura 70, e seus movimentos podem ser descritos componentes $\mathrm{u}, \mathrm{v}$ e w, pois a definição, segundo a teoria da elasticidade, de deslocamentos em um sólido sob o estado triaxial de tensão é efetuada por três componentes de deslocamento. Assim o elemento tetraédrico parabólico que apresenta dez nós, possui 30 graus de liberdade, com isso a matriz coluna representada pelas forças nodais, ou seja, forças atuantes nos nós, tem dimensão $30 \times 1$, e da mesma forma a matriz coluna representada pelos deslocamentos nodais tem 
dimensão 30 x 1. A consequiência é uma matriz de rigidez, que relaciona o comportamento entre as forças e os deslocamentos, tem dimensão 30 x 30, como segue:

$$
\{f\}_{30 \times 1}=[K]_{30 \times 30} \times\{\delta\}_{30 \times 1}
$$

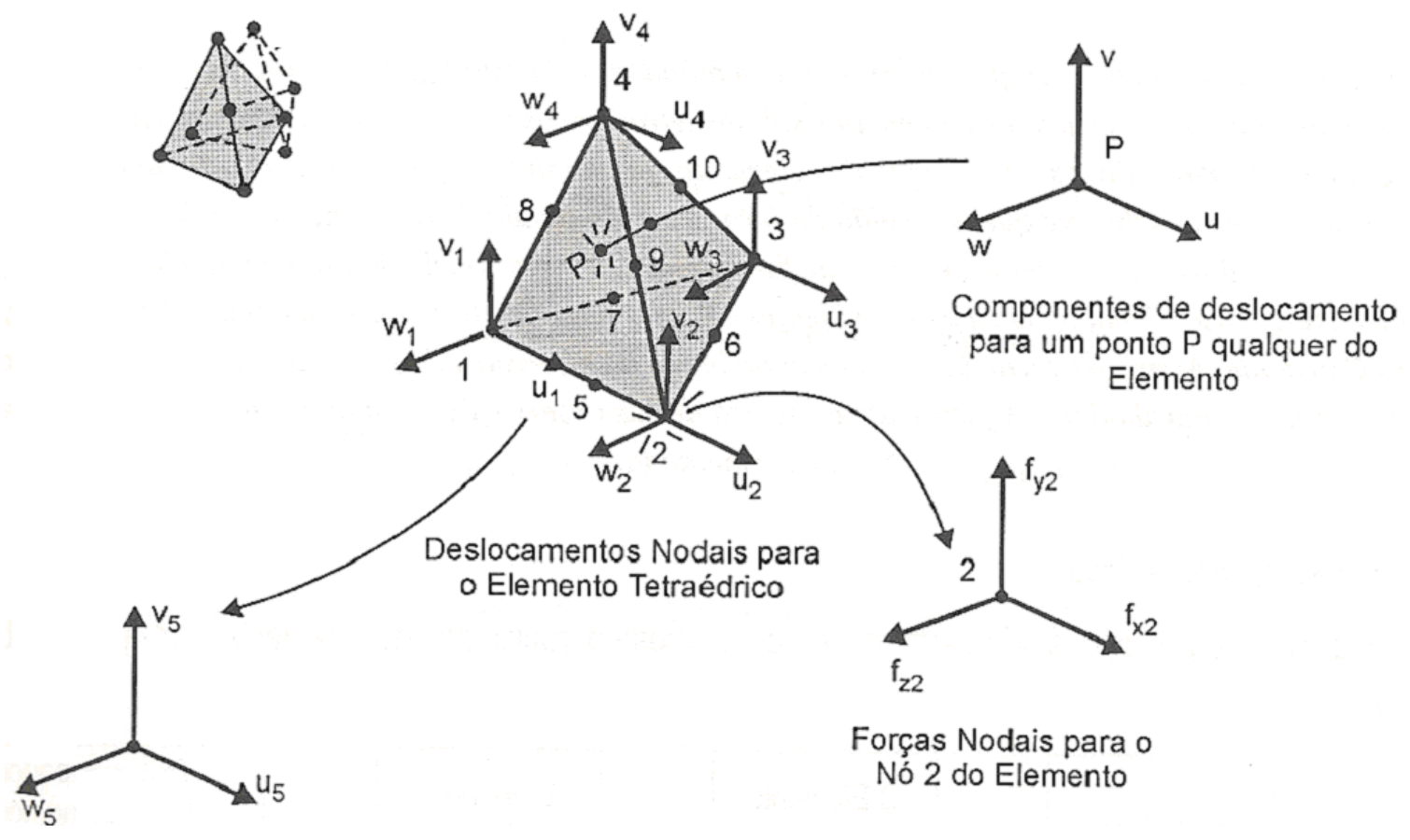

Figura 70: Elemento finito tetraédrico parabólico (ALVES FILHO,2006).

Para a formulação segue três passos fundamentais, tais como para a formulação do elemento tetraédrico linear.

\section{a) Definição das funções de interpolação}

O grau do polinômio de interpolação é definido pelo número de graus de liberdade do elemento tetraédrico, assim, o polinômio escolhido deverá conter 30 coeficientes desconhecidos. No estado triaxial de tensões, o deslocamento de um ponto qualquer é definido pelas componentes $\mathrm{u}, \mathrm{v}$ e w nas direções $\mathrm{x}, \mathrm{y}$ e $\mathrm{z}$ respectivamente $\mathrm{e}$ o deslocamento do ponto depende da localização do mesmo no sólido. Como se tem três componentes de deslocamento em cada nó, tem-se três funções para representar o campo de deslocamentos. Assim, com os 30 coeficientes, tem-se três funções para os deslocamentos $\mathrm{u}, \mathrm{v}$ e w respectivamente e cada função utilizará dez coeficientes. Neste caso, o campo de deslocamento u, v e w variam de acordo com uma função do segundo 
grau, daí o elemento ser chamado de elemento tetraédrico parabólico. O conjunto das três funções é expresso por:

$u(x, y, z)=C_{1}+C_{2} x+C_{3} y+C_{4} z+C_{5} x \cdot y+C_{6} x . z+C_{7} y \cdot z+C_{8} x^{2}+C_{9} y^{2}+C_{10} z^{2}$

$v(x, y, z)=C_{11}+C_{12} x+C_{13} y+C_{14} z+C_{15} x \cdot y+C_{16} x . z+C_{17} y \cdot z+C_{18} x^{2}+C_{19} y^{2}+C_{20} z^{2}$

$w(x, y, z)=C_{21}+C_{22} x+C_{23} y+C_{24} z+C_{25} x \cdot y+C_{26} x \cdot z+C_{27} y \cdot z+C_{28} x^{2}+C_{29} y^{2}+C_{30} z^{2}$ [36]

\section{b) Cálculo das deformações}

Da mesma forma com os elementos tetraédricos lineares, da teoria da elasticidade, calcula-se as deformações em qualquer ponto dentro do elemento finito sólido, dentro das hipóteses das funções de interpolação adotadas. Temos então:

$\varepsilon_{x}=\frac{\partial u}{\partial x} ; \varepsilon_{y}=\frac{\partial v}{\partial y} ; \varepsilon_{z}=\frac{\partial w}{\partial z} ; \gamma_{x y}=\frac{\partial u}{\partial y}+\frac{\partial v}{\partial x} ; \gamma_{x z}=\frac{\partial u}{\partial z}+\frac{\partial v}{\partial x} ; \gamma_{y z}=\frac{\partial u}{\partial z}+\frac{\partial v}{\partial y}$

Como já mencionado, essas funções contêm derivadas parciais, assim, efetuando as derivadas das funções $\mathrm{u}, \mathrm{v}$ e $\mathrm{w}$ que fornecem o deslocamento em todos os pontos, tem-se:

$$
\begin{aligned}
& \varepsilon_{x}=\frac{\partial u}{\partial x}=C_{2}+C_{5} y+C_{6} z+2 . C_{8} x \\
& \varepsilon_{y}=\frac{\partial v}{\partial y}=C_{13}+C_{15} x+C_{17} z+2 . C_{19} y \\
& \varepsilon_{z}=\frac{\partial w}{\partial z}=C_{24}+C_{26} x+C_{27} y+2 . C_{30} z \\
& \gamma_{x y}=\frac{\partial u}{\partial y}+\frac{\partial v}{\partial x}=C_{3}+C_{5} x+C_{7} z+2 . C_{9} y+C_{12}+C_{15} y+C_{16} z+2 . C_{18} x
\end{aligned}
$$




$$
\begin{aligned}
& \gamma_{x z}=\frac{\partial u}{\partial z}+\frac{\partial v}{\partial x}=C_{4}+C_{6} x+C_{7} y+2 . C_{10} z+C_{22}+C_{25} y+C_{26} z+2 . C_{28} x \\
& \gamma_{y z}=\frac{\partial u}{\partial z}+\frac{\partial v}{\partial y}=C_{14}+C_{16} x+C_{17} y+2 . C_{20} z+C_{23}+C_{25} x+C_{27} z+2 . C_{29} y
\end{aligned}
$$

Assim, o elemento sólido tetraédrico é um elemento de deformações que variam linearmente com $\mathrm{x}, \mathrm{y}$ e $\mathrm{z}$.

\section{c) Cálculo das tensões}

O cálculo das tensões decorre imediatamente a partir do cálculo das deformações, utilizando, da teoria da elasticidade, a equação 31 utilizada para o caso dos elementos tetraédricos lineares, onde [D] é a matriz de elasticidade para o estado triaxial de tensões.

Para exemplificar, o cálculo da tensão $\sigma_{\mathrm{x}}$ em qualquer ponto do elemento é efetuado pelo produto matricial em [31], assim a tensão $\sigma_{\mathrm{x}}$ é dada por:

$$
\begin{gathered}
\sigma_{x}=\frac{E(1-v)}{(1+v)(1-2 v)} \times\left(\varepsilon_{x}+\frac{v}{1-v} \times \varepsilon_{y}+\frac{v}{1-v} \times \varepsilon_{z}\right) \\
\sigma_{x}=\frac{E(1-v)}{(1+v)(1-2 v)} \times\left\{C_{2}+C_{5} y+C_{6} z+2 . C_{8} x+\frac{v}{1-v} \times\left(C_{13}+C_{15} x+C_{17} z+2 . C_{19} y\right)+\frac{v}{1-v} \times\left(C_{24}+C_{26} x+C_{27} y+2 . C_{30} z\right)\right\}
\end{gathered}
$$

As expressões das tensões $\sigma_{\mathrm{x}}, \sigma_{\mathrm{y}} \mathrm{e} \sigma_{\mathrm{z}}$ assim como as tensões de cisalhamento, variam com $\mathrm{x}, \mathrm{y}, \mathrm{e} \mathrm{z}$.

Para a formulação dos demais elementos tridimensionais, como também os bidimensionais, que neste trabalho não o será, segue os mesmos procedimentos utilizados para a formulação dos elementos tetraédricos lineares e parabólicos. A Figura 71 resume um procedimento padrão na formulação dos elementos finitos. 


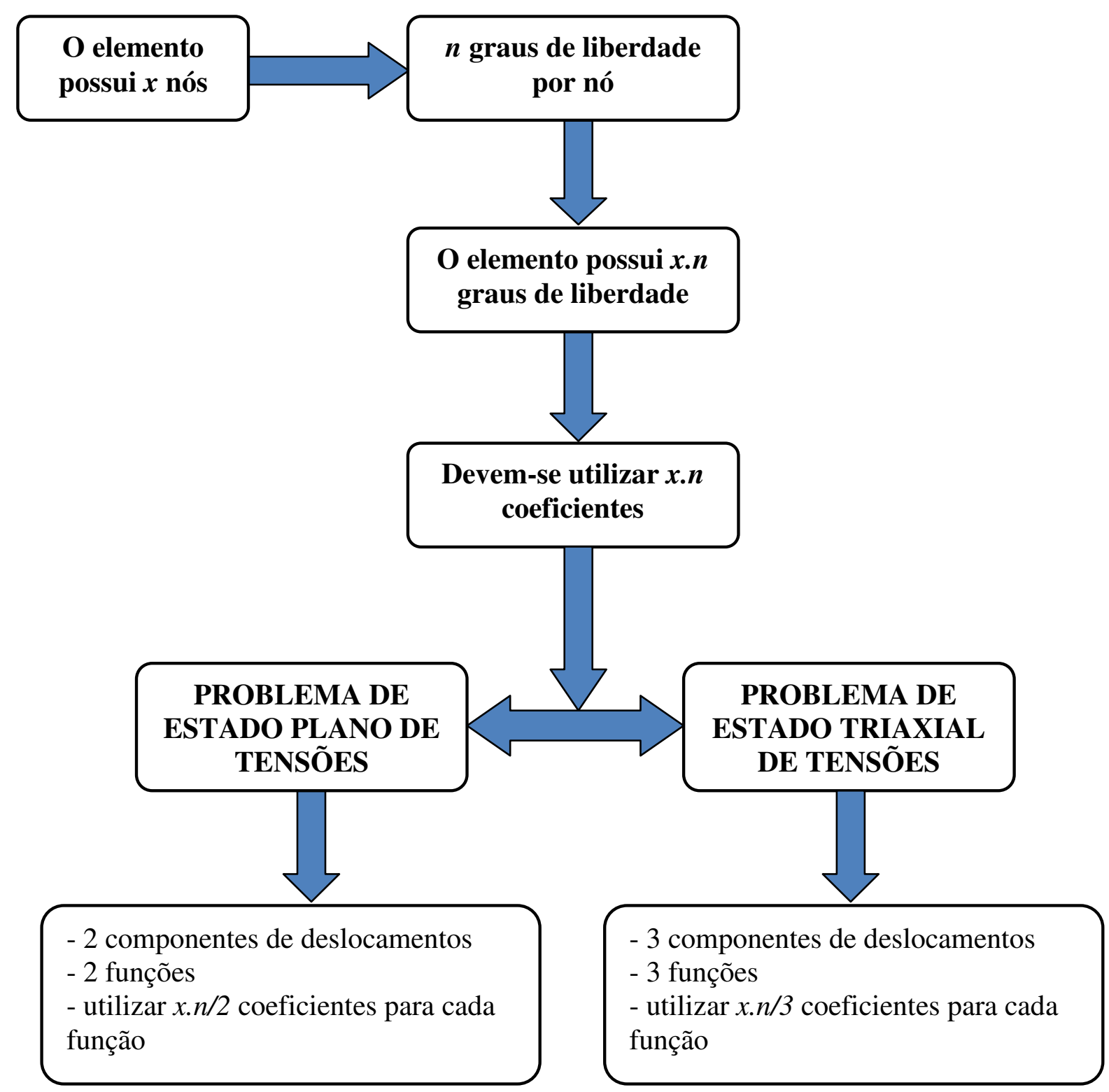

Figura 71: Procedimento padrão para formulação dos elementos finitos (ADAPTAÇÂO - ALVES FILHO,2006). 


\section{Metodologia}

A simulação é realizada em um terno de moenda convencional de bitola 53”x90”, conforme mostra Figura 72, fornecido pela Dedini Indústrias de Base.

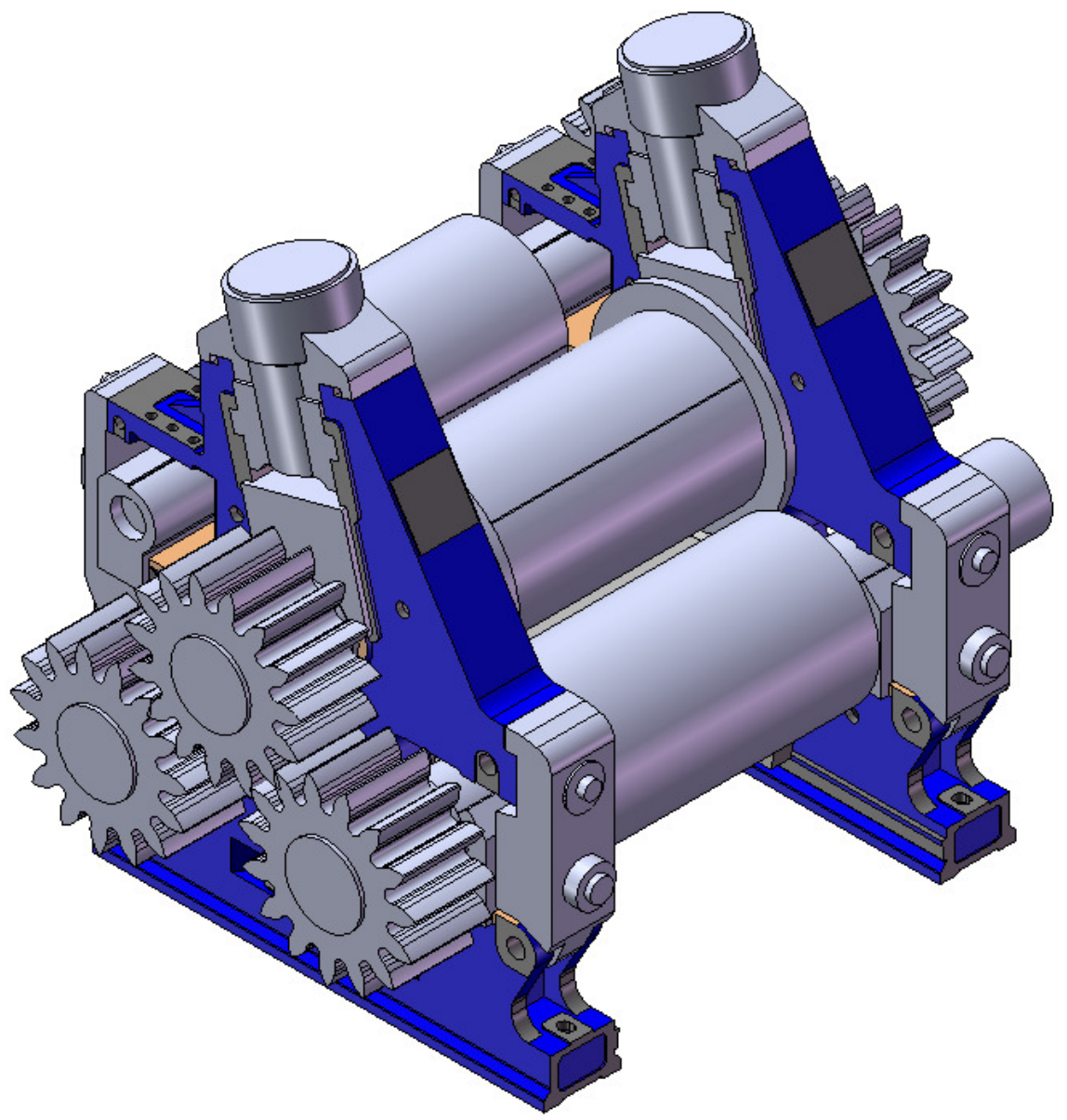

Figura 72: Esquema de uma moenda convencional de bitola 53"x90" (DEDINI, 2007).

Os componentes da moenda como os conjuntos dos rolos inferiores, conjunto do rolo superior, conjunto do rolo de pressão, sistema de regulagem da bagaceira, cabeçotes laterais de entrada e de saída e cabeçotes hidráulicos foram adequados para a simulação em elementos finitos. Essa adequação resulta em agrupar todas as peças em um único componente e utilizar o mesmo material para o conjunto. $\mathrm{O}$ resultado das adequações assim como o material utilizado para os conjuntos citados são ilustrados nas Figuras 73, 74, 75, 76, 77 e 78, respectivamente. 


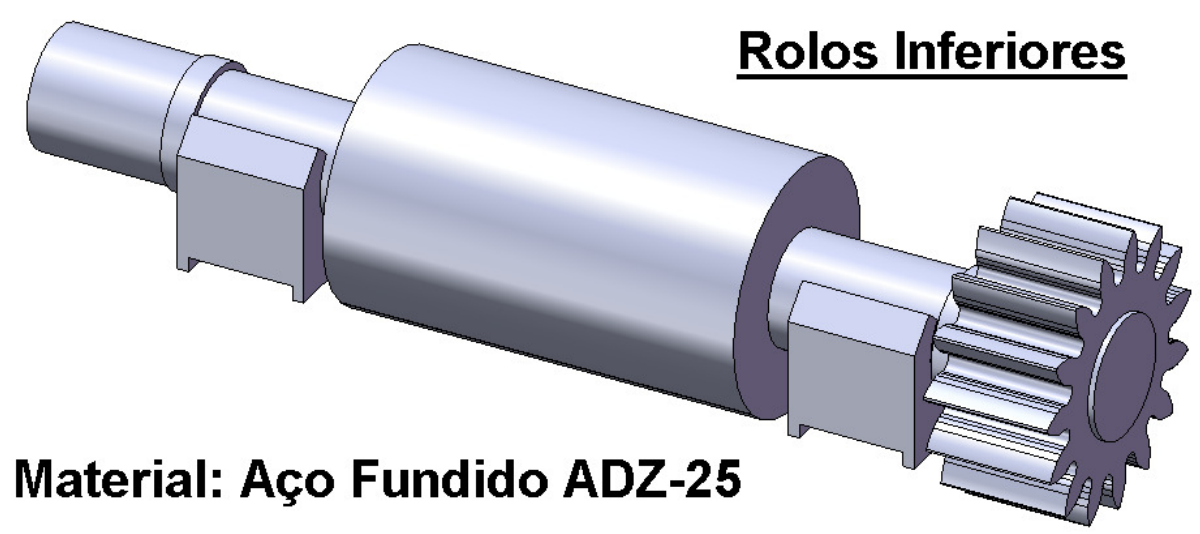

Figura 73: Conjunto do rolo inferior adequado para análise em elementos finitos.

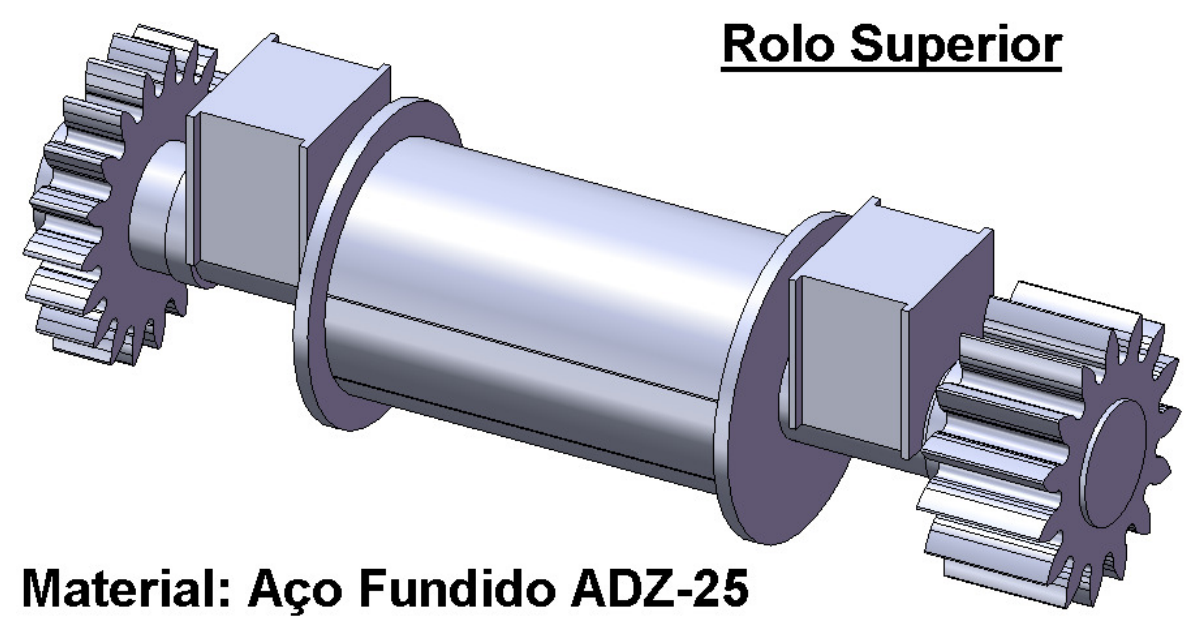

Figura 74: Conjunto do rolo superior adequado para análise em elementos finitos.

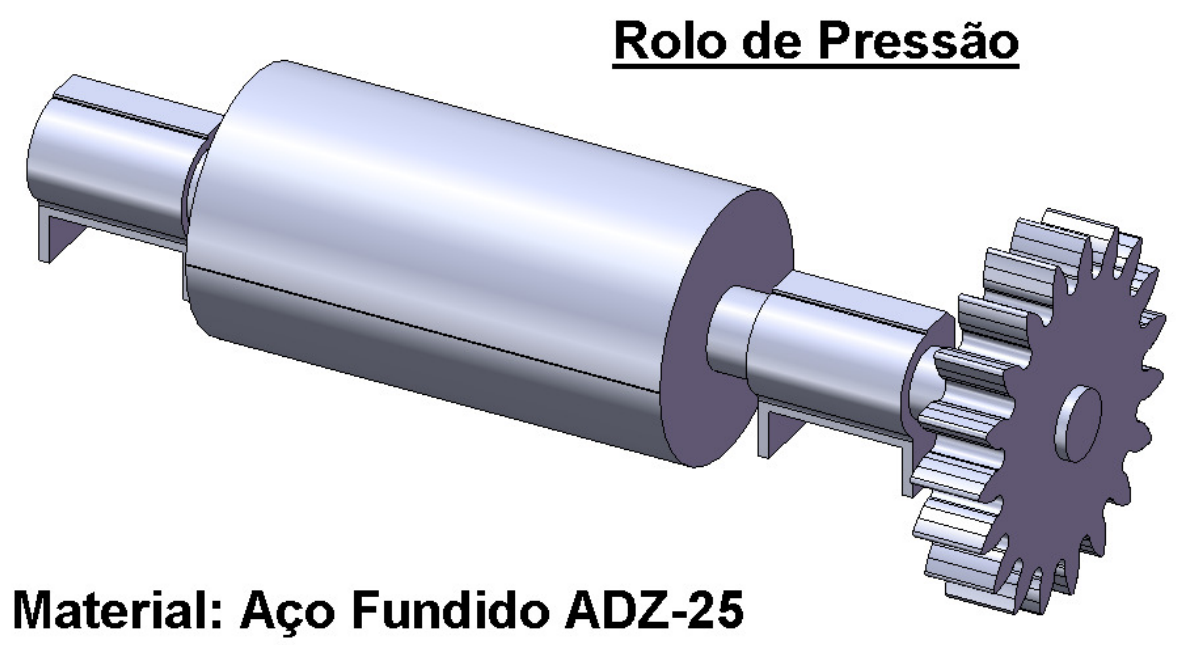

Figura 75: Conjunto do rolo de pressão adequado para análise em elementos finitos. 


\section{Sistema de Regulagem da bagaceira}

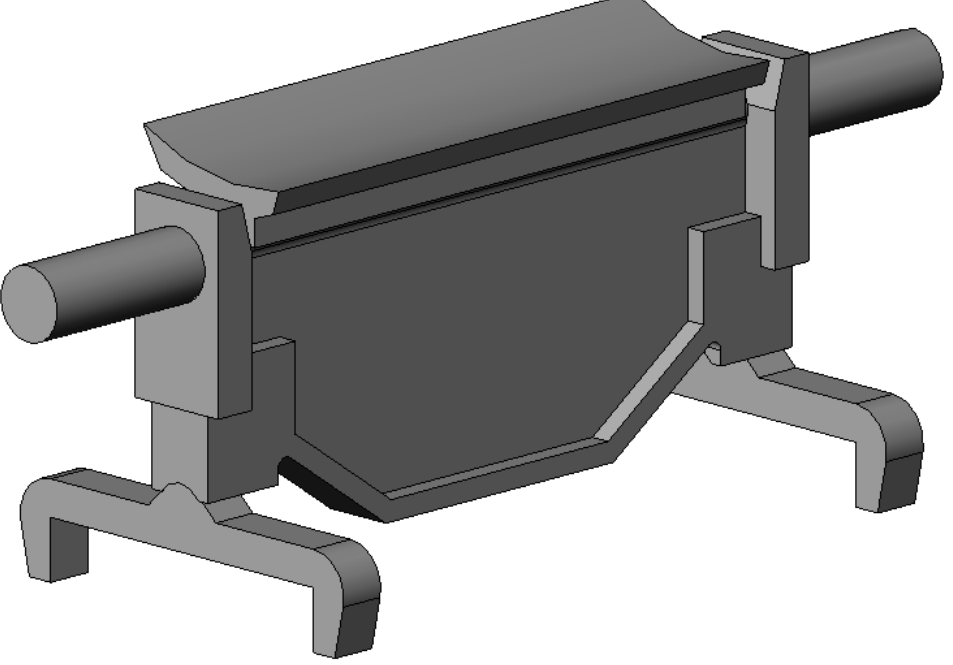

Material: SAE - 1045

Figura 76: Sistema de regulagem da bagaceira adequado para análise em elementos finitos.

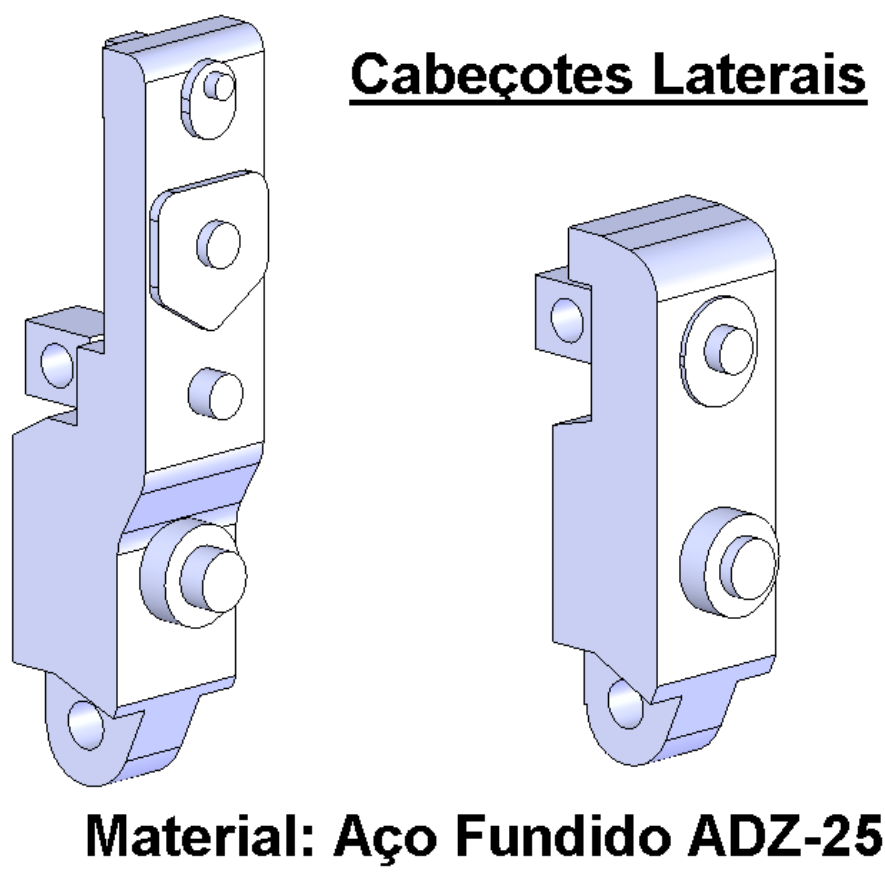

Figura 77: Cabeçote lateral de entrada (à esquerda) e cabeçote lateral de saída (à direita) adequados para análise em elementos finitos. 


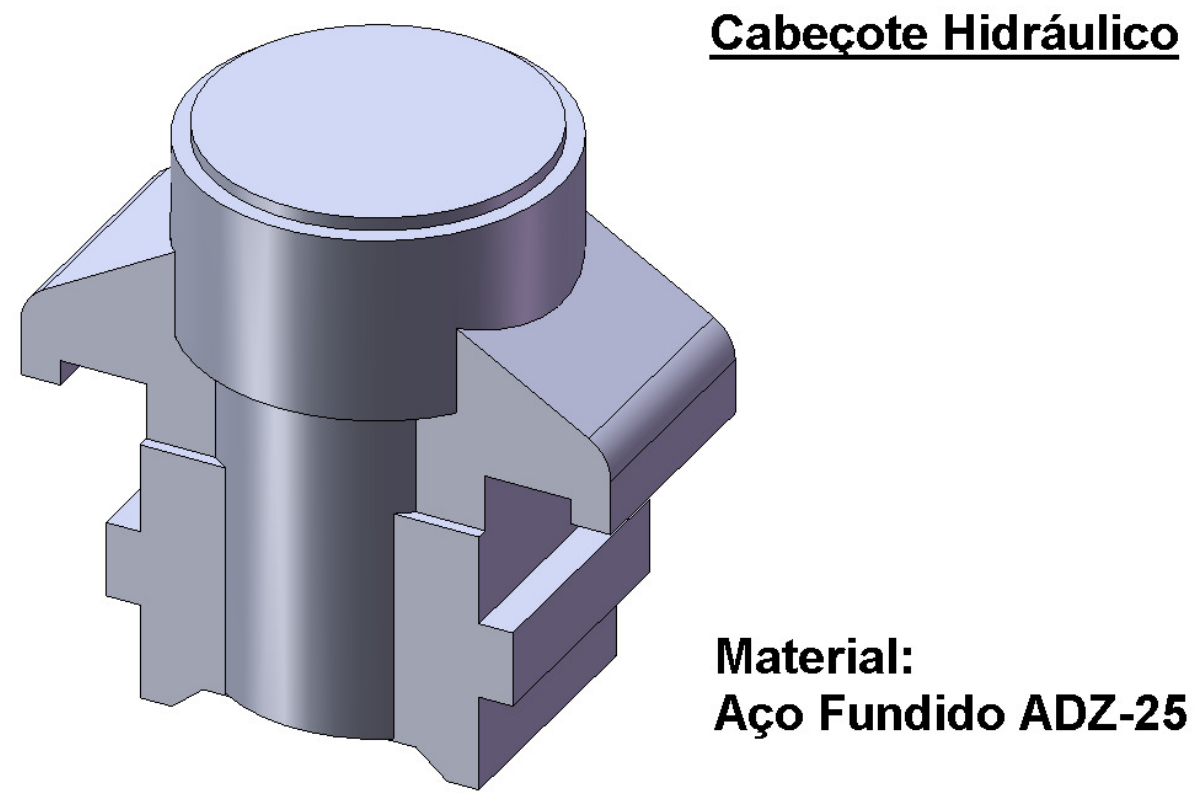

Figura 78: Cabeçote hidráulico adequado para análise em elementos finitos.

\subsection{Esforços Externo no Terno de Moenda}

Os valores de projeto para o terno de moenda são:

Inclinação do garfo do castelo $=15^{\circ}$, no sentido anti-horário, em relação a vertical $\mathrm{PHE}=30 \mathrm{Ton} / \mathrm{dm}$

$\mathrm{C} / \mathrm{C}$ entre o rolo inferior e o rolo superior na horizontal $=980 \mathrm{~mm}$

$\mathrm{C} / \mathrm{C}$ do rolo superior em relação aos inferiores na vertical $=1000 \mathrm{~mm}$

$\mathrm{C} / \mathrm{C}$ do rolo superior em relação ao rolo de pressão na horizontal $=1600 \mathrm{~mm}$

$\mathrm{C} / \mathrm{C}$ dos mancais dos rolos de moenda $=3400 \mathrm{~mm}$

$\mathrm{C} / \mathrm{C}$ dos rodetes em relação aos mancais $=892 \mathrm{~mm}$

Torque necessário para o acionamento do rolo Superior $=120$ Ton $\mathrm{x} \mathrm{m}$

Torque necessário para o acionamento dos rolos inferiores $=60$ Ton $\mathrm{x} \mathrm{m}$

Torque necessário para o acionamento do rolo de pressão $=36$ Ton $\mathrm{x} \mathrm{m}$

Compressão do bagaço de alimentação do terno no rolo de pressão e rolo superior $=110$ Ton

Diâmetro primitivo dos rodetes de moenda $=1400 \mathrm{~mm}$

Diâmetro primitivo dos rodetes de pressão $=1600 \mathrm{~mm}$

Ângulo de pressão dos dentes dos rodetes $=20^{\circ}$ 
Os pesos dos subconjuntos que serão utilizados na simulação estão ilustrados na Figura 79.

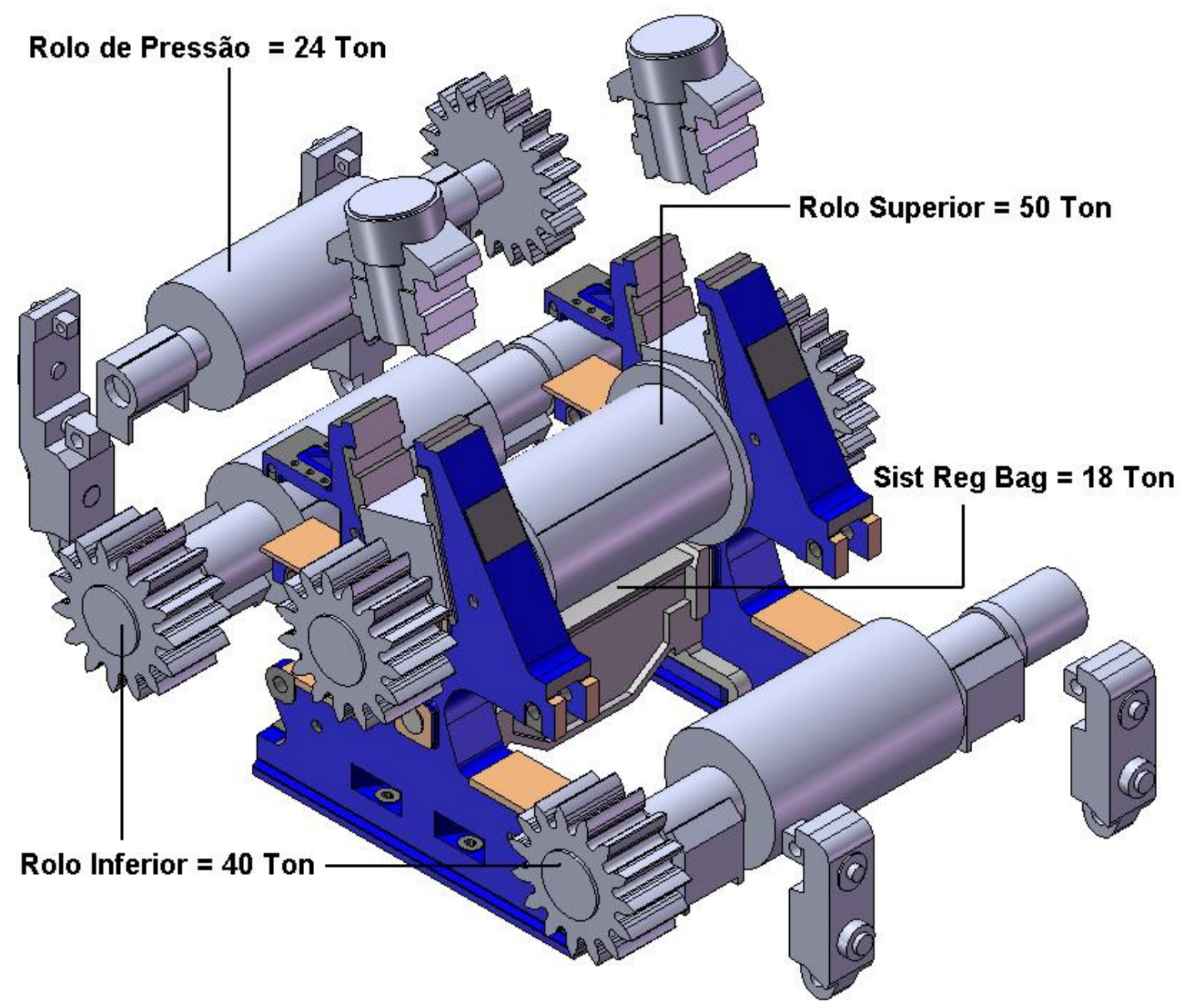

Figura 79: Peso dos principais componentes a serem considerados na simulação do terno de moenda convencional.

Assim, conforme equação [1] da seção 6.2.1, tem-se:

$C H T=P H E \times 0,1 \times L \times D$

CHT $=30 \times 0,1 \times 22,86 \times 13,46 \quad \underline{\text { CHT } \cong 925 T o n}$

A CHT é decomposta para achar as reações no ponto A e B conforme ilustra a Figura 80. Para a decomposição utiliza-se os recursos da estática conforme Hibbeler (1998). 


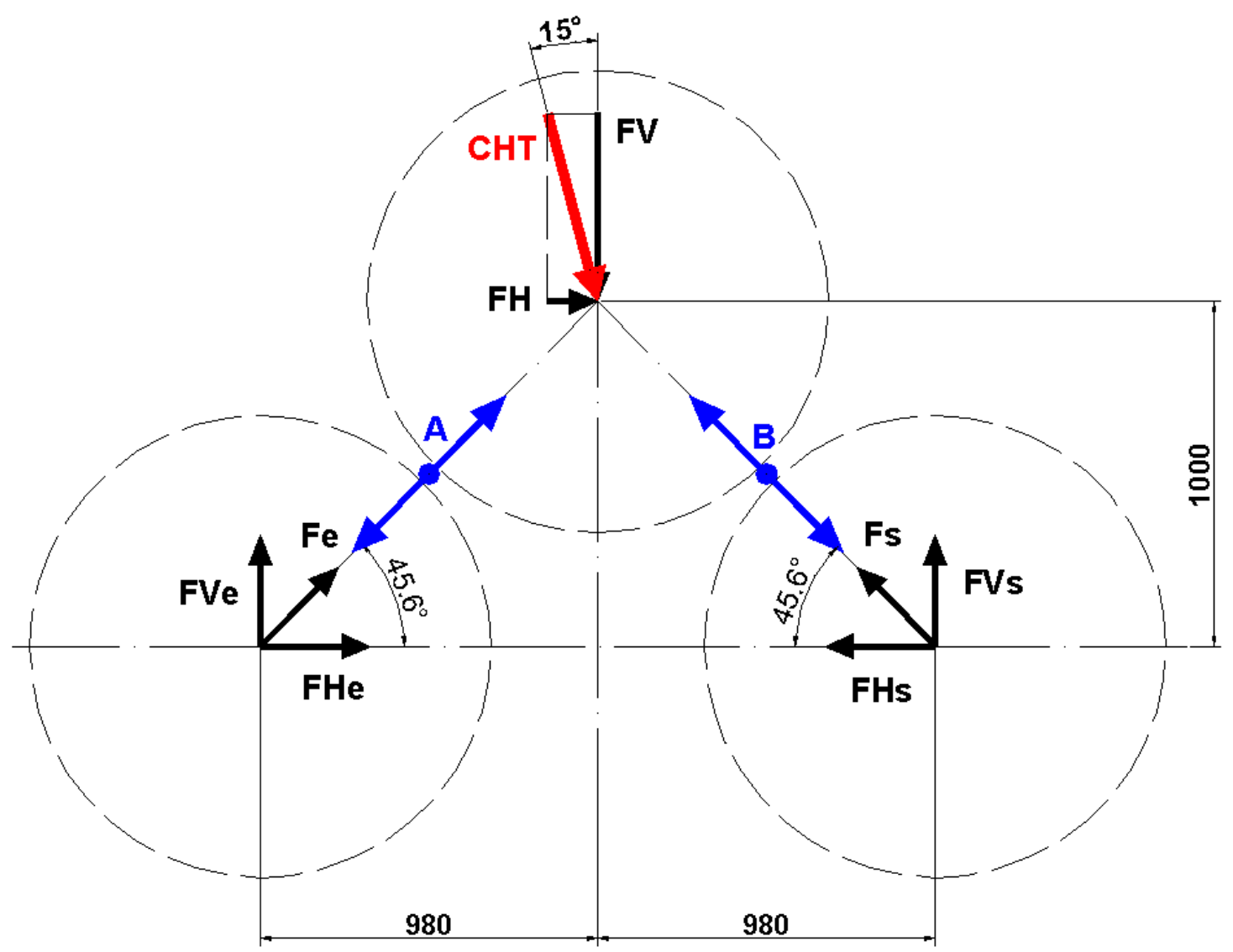

Figura 80: Decomposição da CHT.

$$
\begin{aligned}
F H= & C H T \times \operatorname{sen} 15^{\circ} \\
F H= & 925 \times \operatorname{sen} 15^{\circ} \\
F H \cong & 240 \text { Ton } \\
& F V=C H T \times \cos 15 \\
& F V=925 \times \cos 15^{\circ} \\
& F V \cong 894 \text { Ton }+ \text { Peso_Rolo_Superior } \\
& F V \cong 944 T \text { Ton }
\end{aligned}
$$

Faz-se $\sum F_{V}=0, \sum F_{H}=0$ e $\sum M=0$ para encontrar os valores de FVe, $\mathrm{FHe}$, FVs e FHs, com isso tem-se:

$$
F V e \cong 350 T o n \quad F H e \cong 342 T o n \quad F V s \cong 594 T o n \quad F H s \cong 582 T o n
$$

Para o cálculo de Fe e Fs procede-se: 


$$
\begin{array}{ll}
F e=\sqrt{F H e^{2}+F V e^{2}} & F e \cong 490 T o n \\
F s=\sqrt{F H s^{2}+F V s^{2}} & F s \cong 830 T o n
\end{array}
$$

Com isso tem-se nos pontos A e B as reações correspondentes Fe entre os rolos na entrada e Fs entre os rolos na saída.

As forças de engrenamento nos rolos inferiores entre os rodetes do lado do acionamento são expressas na Figura 81. Para o cálculo das mesmas assim como as reações nos mancais, seguem-se as etapas conforme Melconian (2000).

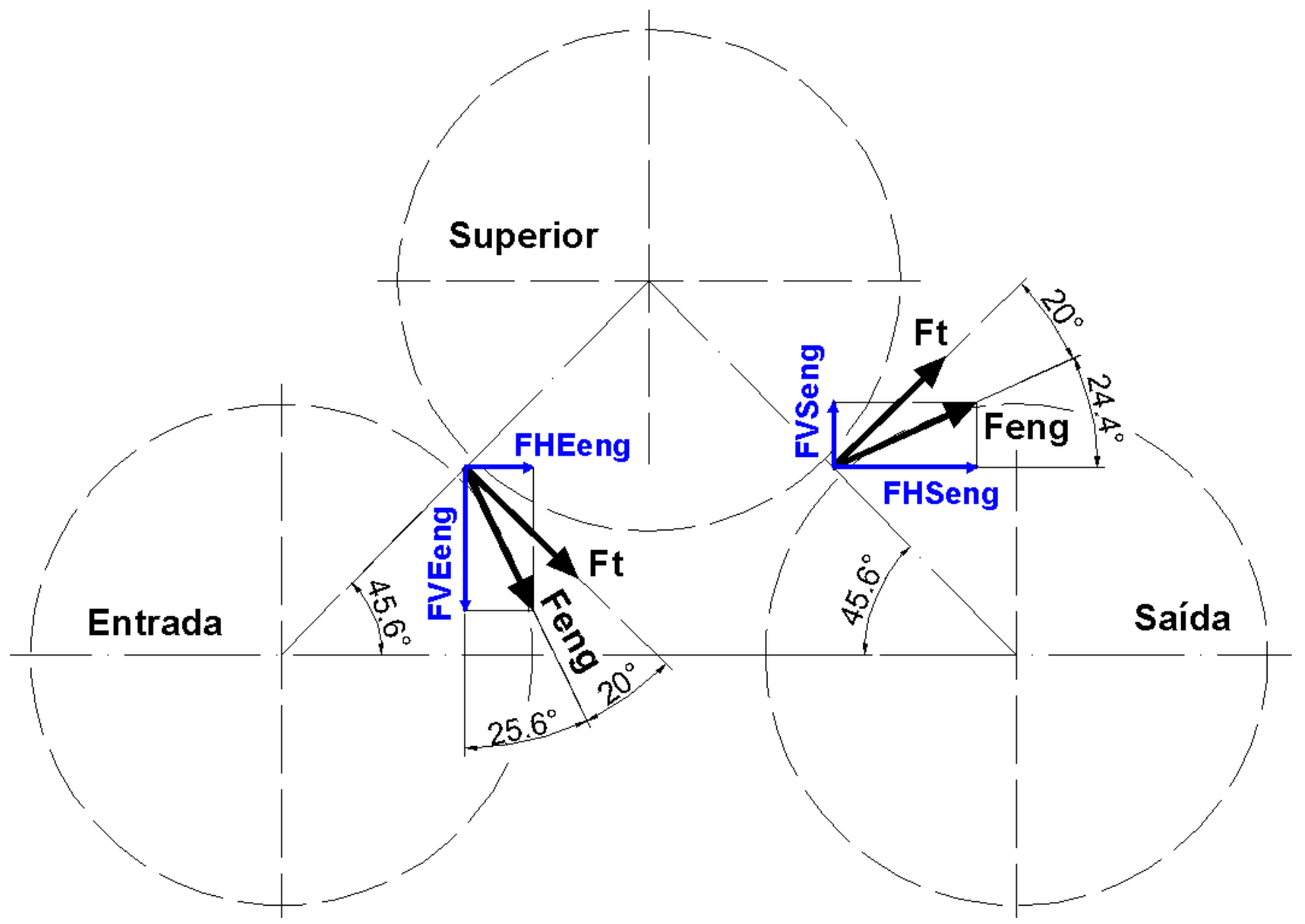

Figura 81: Forças de engrenamento nos rodetes dos rolos inferiores e rolo superior do lado do acionamento.

- Força Tangencial

$$
F t=\frac{2 \times M t}{\text { Dprim }} \quad=\quad F t=\frac{2 \times 60 \mathrm{Ton} / \mathrm{m}}{1,4 \mathrm{~m}} \quad=\quad F t \cong 86 \mathrm{Ton}
$$


- Força de engrenamento

Feng $=\frac{F t}{\cos \alpha} \quad=\quad$ Feng $=\frac{86}{\cos 20^{\circ}} \quad=\quad$ Feng $\cong 91,5$ Ton

Assim, para o rolo de entrada tem-se:

FHEeng $=$ Feng $\times \operatorname{sen} 25,6^{\circ}=$ FHEeng $\cong 39,5$ Ton

FVEeng $=$ Feng $\times \cos 25,6^{\circ} \quad=\quad$ FVEeng $\cong 82,5$ Ton

No rolo de saída obtém-se:

FHSeng $=$ Feng $\times \cos 24,4^{\circ}=\quad$ FHSeng $\cong 83,5$ Ton

FVSeng $=$ Feng $\times \operatorname{sen} 24,4^{\circ} \quad=\quad$ FVSeng $\cong 38 T$ on

Por fim, no rolo superior tem-se:

Aplicando $\sum M=0, \sum F_{V}=0, \sum F_{H}=0$, tem-se para o rolo superior:

FHeng $\cong 123$ Ton (da direita para a esquerda)

FVeng $\cong 44,5$ Ton (de baixo para cima)

- Reações na horizontal nos mancais: 


\section{Entrada:}

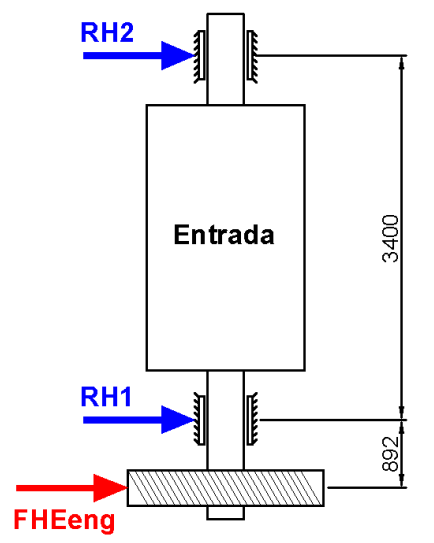

$$
\sum M_{R H 2}=39,5 \times 4292+R H 1 \times 3400=0
$$

$R H 1 \cong-50$ Ton

[4]

$\sum F_{H}=39,5-50+R H 2=0$

RH $2 \cong 10,5 T$ on

\section{Saída:}

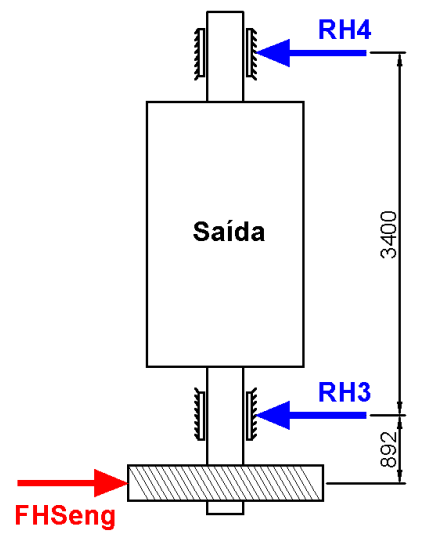

$$
\begin{aligned}
& \sum M_{R H 4}=83,5 \times 4292-R H 3 \times 3400=0 \\
& R H 3 \cong 105,5 \text { Ton }
\end{aligned}
$$

\section{Superior:}

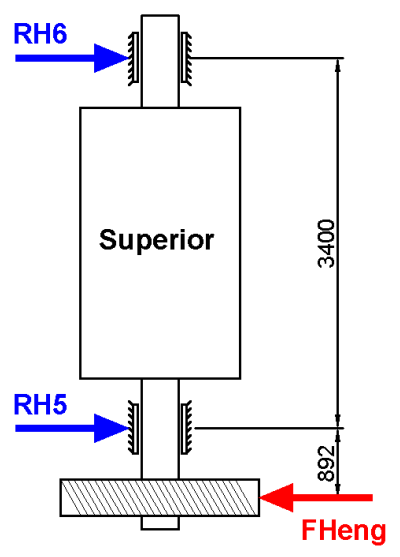

$$
\begin{aligned}
& \sum M_{R H 6}=-123 \times 4292+R H 5 \times 3400=0 \\
& \text { RH } 5 \cong 155 \text { Ton } \\
& \text { [8] } \\
& \sum F_{H}=-123+155+R H 6=0 \\
& \text { RH } 6 \cong-32 \text { Ton }
\end{aligned}
$$


- Reações na vertical nos mancais

\section{Entrada:}

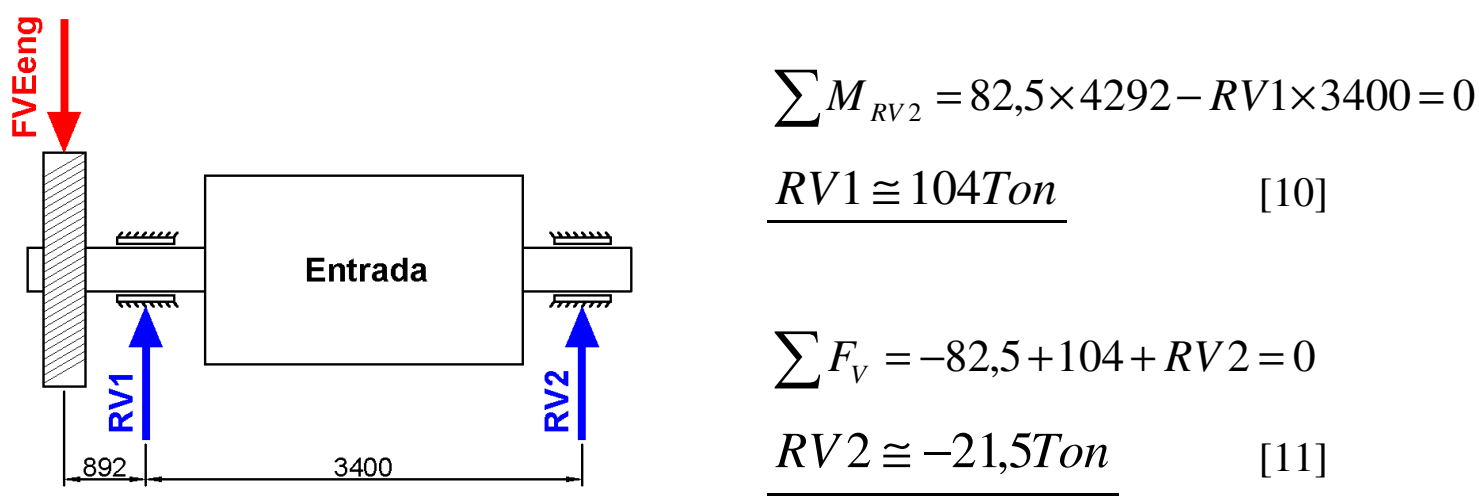

Saída:

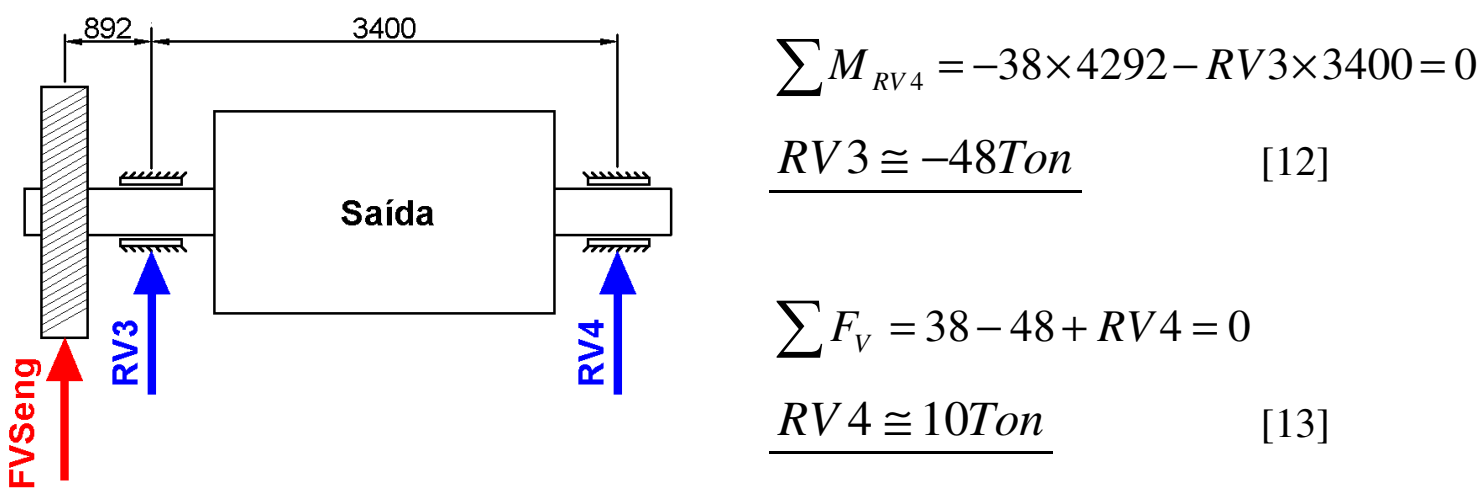

Superior

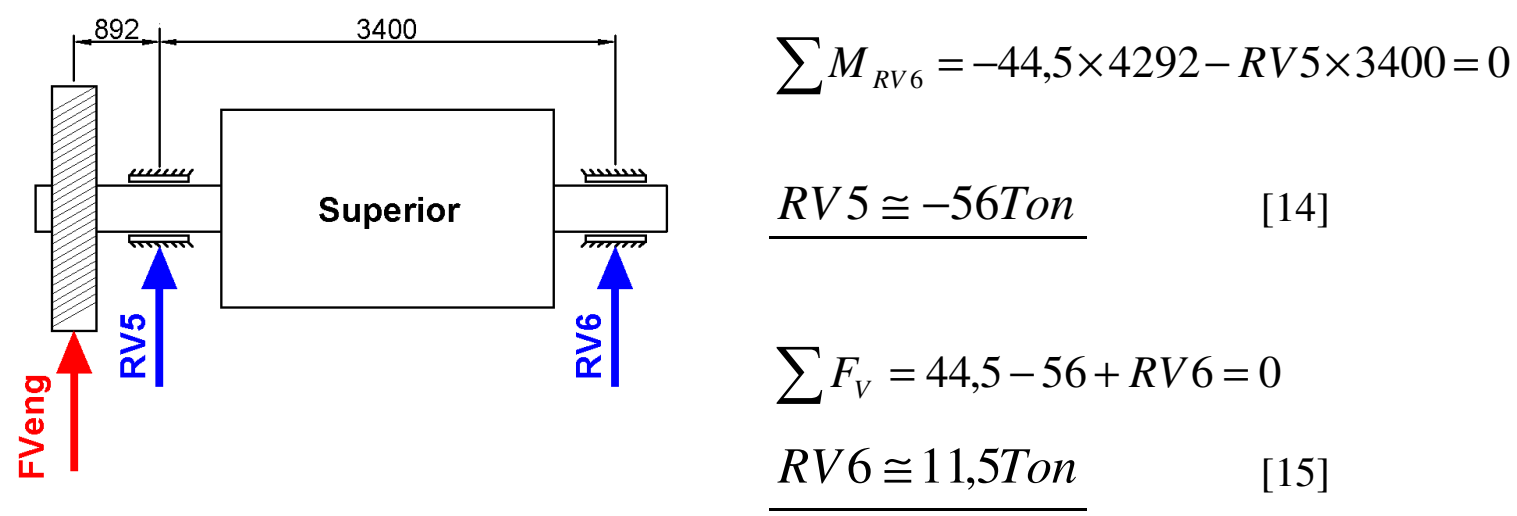


Decompondo as reações dos mancais do rolo superior do lado do acionamento obtidas em [8] e [14] em relação à face inclinada de $15^{\circ}$ do garfo do castelo, obtém-se:

$R 1_{\text {GARFO }} \cong 163 T$ Ton $\quad$ (da direita para a esquerda)

O mesmo procedimento é realizado para o lado oposto do acionamento utilizando as reações obtidas em [9] e [15], assim:

$R 2_{\text {GARFO }} \cong 34$ Ton $\quad$ (da esquerda para a direita)

As forças de engrenamento entre o rolo de pressão e o rolo superior são ilustrada na Figura 82.

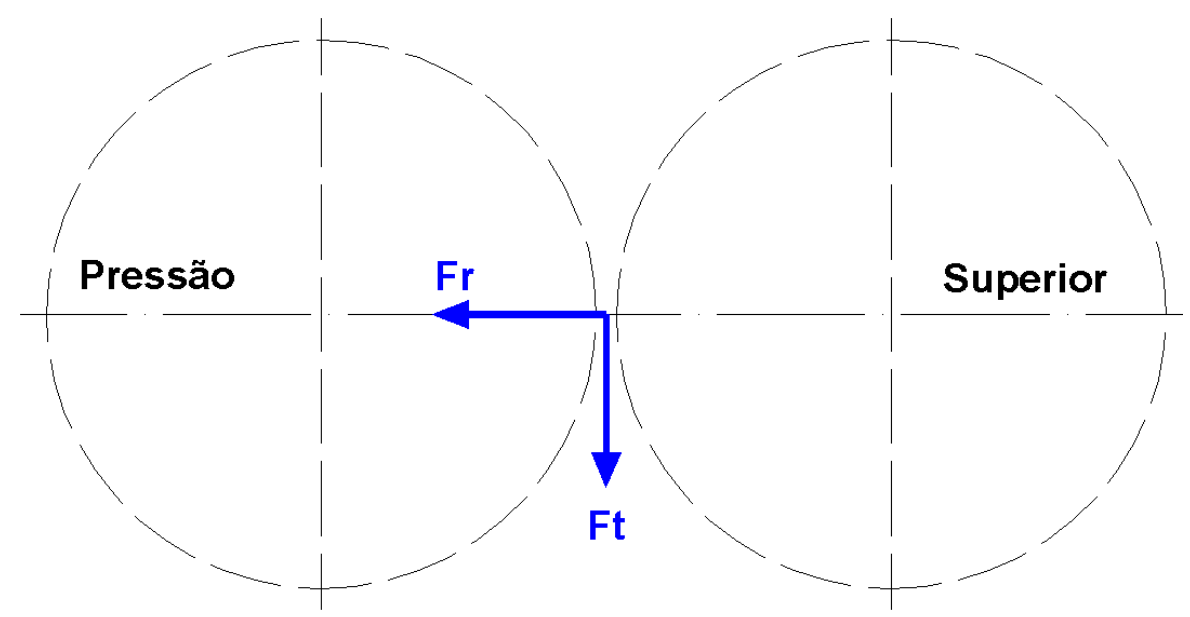

Figura 82: Força de engrenamento entre o rolo de pressão e o rolo superior do lado oposto do acionamento.

- Força tangencial do lado oposto do acionamento

$F t=\frac{2 \times M t}{D \text { prim }} \quad=\quad F t=\frac{2 \times 36 \text { Ton } / m}{1,6 m} \quad=\quad F t \cong 45$ Ton

- Força radial do lado oposto do acionamento

$F r=F t \times \operatorname{Tan} \alpha \quad=\quad F r=36 \times \operatorname{Tan} 20^{\circ}=F r \cong 17$ Ton 
- Reações na horizontal nos mancais devido ao engrenamento do lado oposto do acionamento

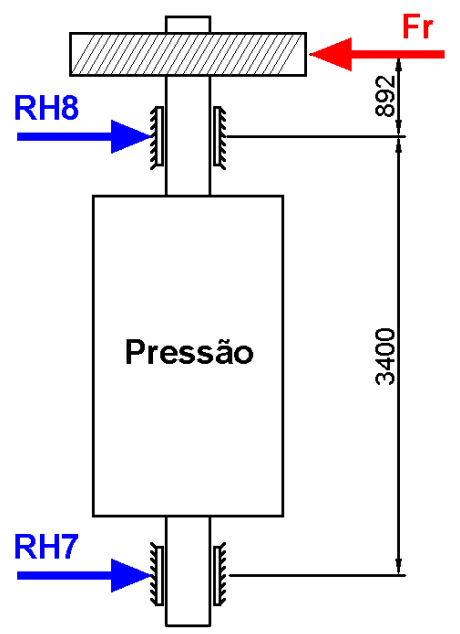

$$
\begin{aligned}
& \sum M_{R H 7}=17 \times 4292-R H 8 \times 3400=0 \\
& R H 8 \cong 21,5 \text { Ton } \\
& \sum F_{H}=21,5-17+R H 7=0 \\
& R H 7 \cong-4,5 \text { Ton }
\end{aligned}
$$

- Reações na vertical nos mancais devido ao engrenamento do lado oposto do acionamento

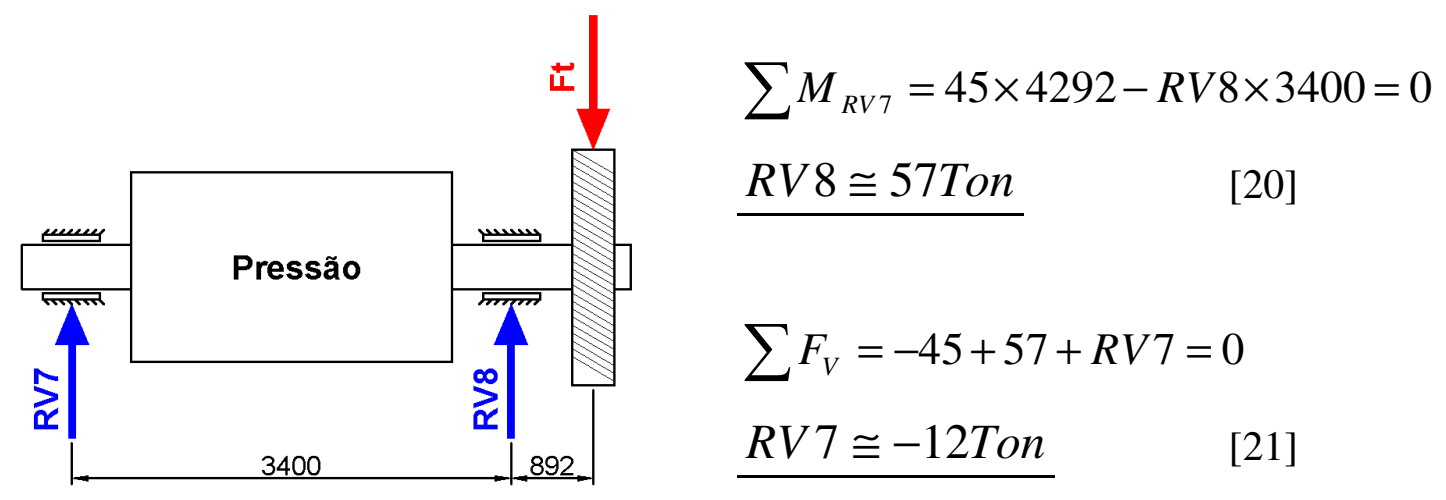

As forças atuantes no rolo superior proveniente do engrenamento entre o rolo de pressão e o rolo superior são de mesma intensidade na vertical e na horizontal assim tem-se:
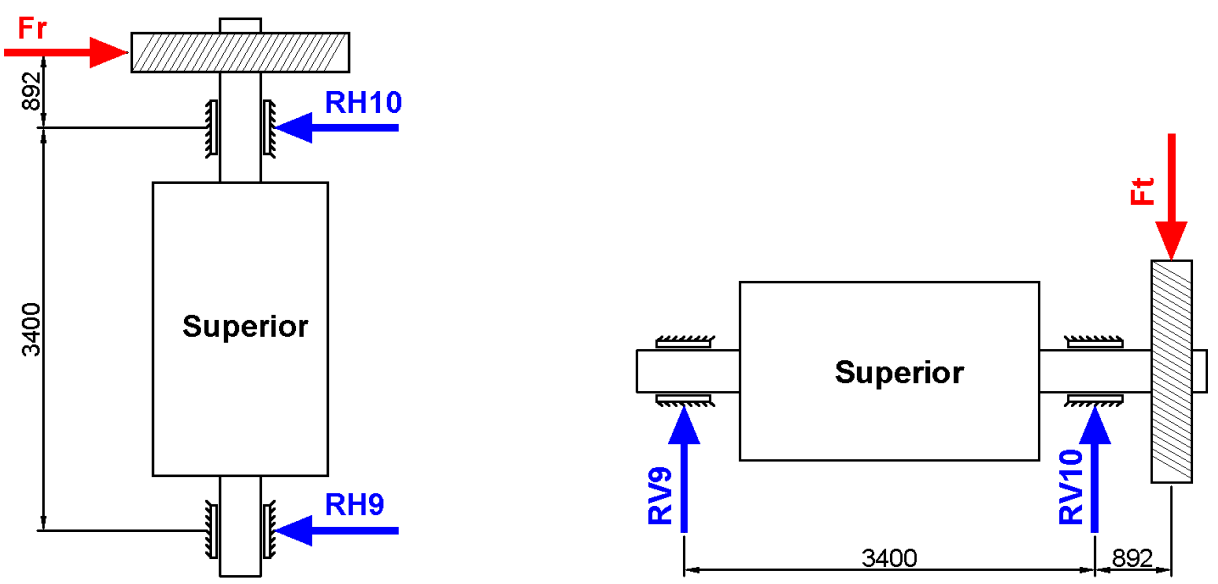
RH9 $\cong-4,5$ Ton

$R V 10 \cong 57$ Ton

$R V 9 \cong-12 T o n$

Decompondo as reações dos mancais do rolo superior do lado oposto ao do acionamento obtidas em [22] e [24] em relação à face inclinada de $15^{\circ}$ do garfo do castelo, obtém-se:

$R 3_{\text {GARFO }} \cong 33$ Ton $\quad$ (da esquerda para a direita)

O mesmo procedimento é realizado para o lado do acionamento utilizando as reações obtidas em [23] e [25], assim:

$R 4_{\text {GARFO }} \cong 7,5$ Ton $\quad$ (da direita para a esquerda)

[27]

\subsection{Software Utilizado para a Análise em Elementos Finitos}

O software utilizado para a análise é o Cosmosworks 2007 SPO.0, date code 2006/200, licenciado para a Dedini Indústrias de Base, cujo numero de serie é 00100045-5200-7884, comercializado pela empresa Assessocom, uma ferramenta para análise de esforços (componentes individuais e ou montagens) baseado no MEF (método dos elementos finitos, FEM - Finite Element Method). É um programa com rotina de solução numérica utilizado para resolver problemas de análise de esforços mecânicos com boa precisão nos resultados.

Para a análise numérica, seguem os seguintes passos, segundo sua estrutura de programa: 
- Construção do modelo matemático;

- Construção do modelo de elementos finitos (malha);

- Resolução do modelo;

- Visualização dos resultados.

\subsubsection{Construção do Modelo Físico Geométrico}

É representado por uma geometria sólida da peça, ou uma montagem de modelos 3D. Essa geometria deve ser a mais simplificada possível para facilitar a criação da "malha”. Assim, em alguns casos, pode-se suprimir, ou até mesmo eliminar, partes menos importantes da geometria como raios, chanfros, logotipos, furos, desde que os mesmos não afetem a análise estrutural da geometria das peças. Tem-se que assegurar que a geometria seja capaz de ser "malhada" e que as mesmas produzam resultados confiáveis e de interesse como, tensões, deslocamentos, distribuição de temperatura, etc.

\subsubsection{Construção do Modelo de Elementos Finitos}

São inseridos nesta etapa todos os carregamentos, forças, pressões ou qualquer outro tipo de solicitação sobre a geometria bem como as restrições da mesma, conhecidas como condições de contorno. As propriedades mecânicas dos materiais componentes da geometria também são configuradas nessa etapa. A operação seguinte consiste em dividir a geometria em elementos finitos por um processo de discretização ou mais conhecido como "malha". Essa operação é feita automaticamente pelo programa segundo algumas regras do sistema Delaunay-Voronoi Triangulation.

O COSMOSWorks disponibiliza quatro diferentes tipos de elemento para as análises: elementos tetraédricos de primeira ordem, elementos tetraédricos de segunda ordem, elementos triangulares de primeira ordem e por fim elementos triangulares de segunda ordem. A terminologia utilizada pelo software refere-se a elementos de primeira ordem como Draft Quality e a elementos de segunda ordem como High Quality.

Os elementos tetraédricos são utilizados, preferencialmente, para analisar geometrias sólidas e os elementos triangulares para analisar geometrias de superfície. 
Os elementos tetraédricos de primeira ordem possuem quatro nós (um em cada extremidade) e cada nó possui três graus de liberdade. Suas extremidades são retas e suas faces planas, tendo que permanecerem neste estado sob a solicitação da carga. Essa situação impõe uma limitação severa para a aplicação deste elemento em análises, principalmente quando o objetivo é a verificação dos deslocamentos, pois as extremidades retas e faces planas não simulam corretamente geometrias de forma curvilínea.

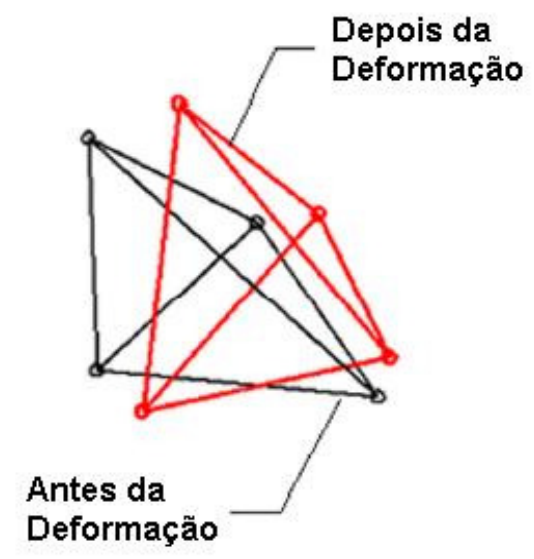

Figura 83: Elemento tetraédrico de primeira ordem.

Os elementos tetraédricos de segunda ordem possuem dez nós (quatro nos cantos e seis no meio) e cada nó possui três graus de liberdade. Suas extremidades e faces podem assumir uma forma curvilínea quando submetidos aos esforços traçando perfeitamente uma geometria curvilínea. Por esse motivo, esses elementos são utilizados em grande escala para os diversos tipos de análises realizadas pelo software.

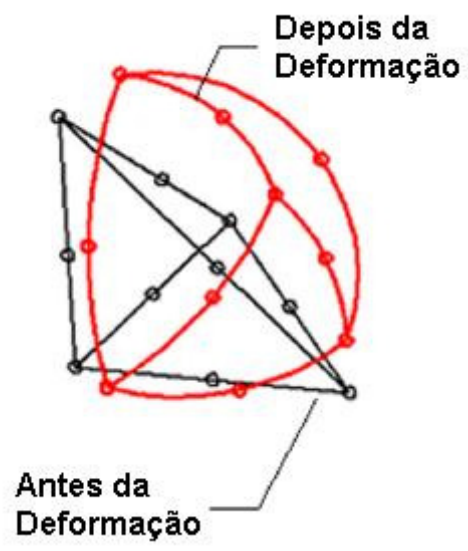

Figura 84: Elemento tetraédrico de segunda ordem. 
Os elementos triangulares de primeira ordem possuem três nós (um em cada extremidade) e cada nó possui seis graus de liberdade. Suas extremidades são retas, tendo que permanecerem neste estado sob a solicitação da carga. Essa situação impõe limitações em geometrias curvilíneas como já descritas no elemento tetraédrico de primeira ordem.

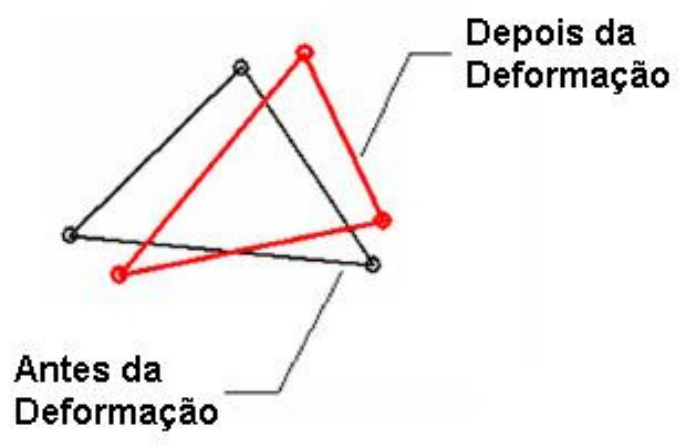

Figura 85: Elementos triangulares de primeira ordem.

Os elementos triangulares de segunda ordem possuem seis nós (três nas extremidades e três no meio) e cada nó possui seis graus de liberdade. Igualmente como nos elementos tetraédricos de segunda ordem, eles podem assumir formas curvilíneas sob a solicitação de cargas, assim são amplamente utilizados em análise quando a mesma requer elementos triangulares.

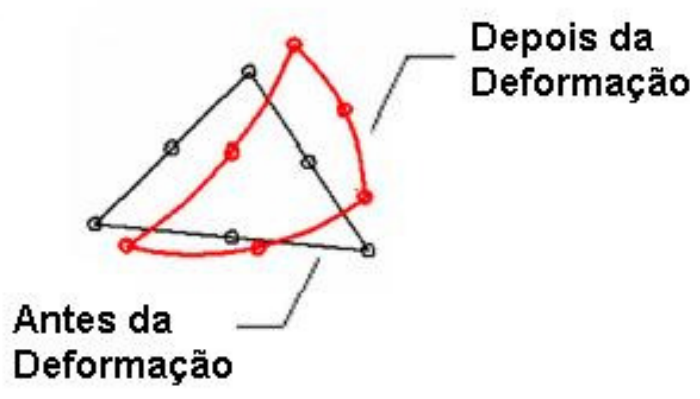

Figura 86: Elemento triangular de segunda ordem.

Os graus de liberdade de um nó numa malha de elementos finitos determinam a habilidade do mesmo para executar translações ou rotações. O número de graus de liberdade que um nó possui depende do tipo de elemento, como já descrito. Assim os elementos tetraédricos possuem três graus de liberdade, sendo os três de translação. Já os elementos triangulares possuem seis graus de liberdade, sendo três de translação e três de rotação. 


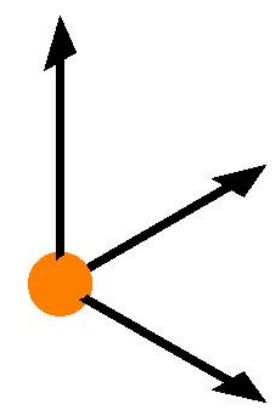

Nó com 3 graus de liberdade

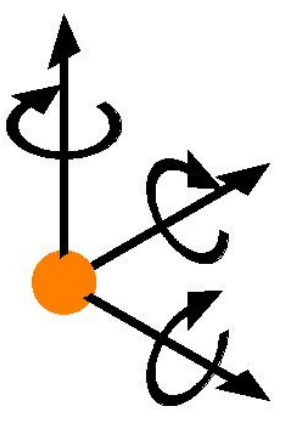

Nó com seis graus de liberdade

Figura 87: Graus de liberdades do nó numa malha de elementos finitos.

\subsubsection{Resolução do Modelo}

Após a criação da malha o software executa o processamento interno para produzir os dados de interesse como deformações, tensões, etc. O programa em questão se utiliza do método numérico conhecido como Sparse Solver ou o FFE Plus Solver para resolver as equações de equilíbrio $\{\mathrm{f}\}=[\mathrm{k}] \mathrm{x}[\mathrm{d}]$ onde:

$\{f\}=$ matriz coluna onde são representadas as forças que atuam nos nós dos elementos;

$[\mathrm{k}]$ = matriz quadrada contento os coeficientes de rigidez, também conhecida como matriz de rigidez do elemento;

[d] = matriz coluna onde são representados os deslocamentos associados aos nós dos elementos.

\subsubsection{Visualização dos Resultados}

Os resultados apresentados pelo software são mostrados na forma de geometrias 3D com cores para os níveis de tensão, deformação, etc. Os resultados devem ser interpretados levando-se em conta as suposições, simplificações e erros introduzidos nos três primeiros passos. Assim, a análise dos resultados é a etapa mais árdua de todo o processo, obrigando assim o engenheiro a testar seus conhecimentos mais específicos para que não ocorram erros nas interpretações. 


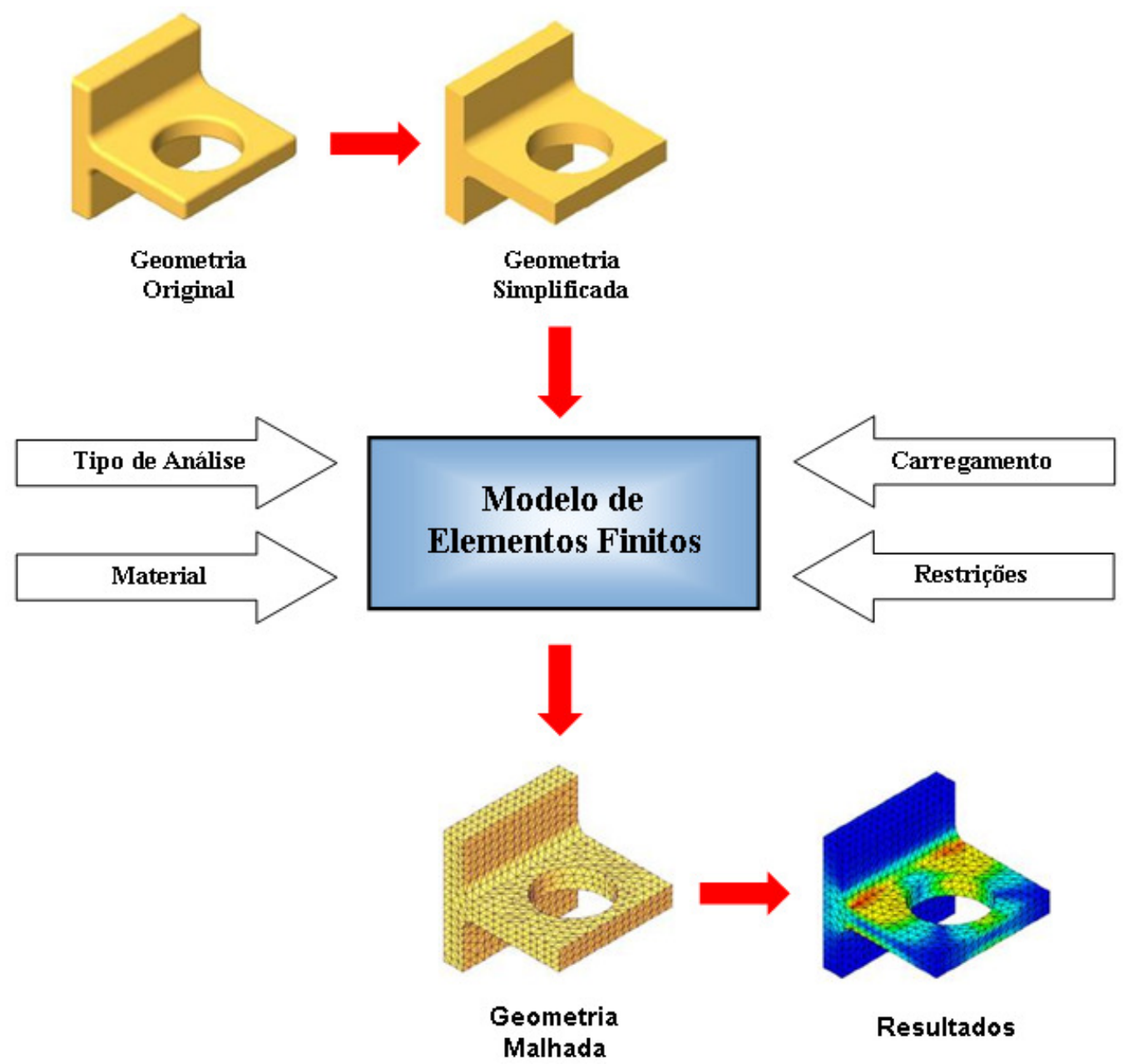

Figura 88: Processo para análises através do Cosmosworks.

Os trabalhos no Cosmosworks podem ser realizados por meio de três sistemas de unidades: O sistema Internacional, o sistema Métrico e o sistema Inglês, cujas siglas utilizadas pelo software são respectivamente SI, MKS e IPS. Porém, vale lembrar que uma vez configurado um sistema de unidades no software, todas as variáveis seguemno.

Os resultados advindos da análise podem ser expressos por deslocamentos, deformações e tensões para análises estruturais ou na forma de temperatura, fluxo de calor para análises térmicas. Para interpretação dos resultados em uma estrutura, por exemplo, verificar se a geometria analisada suportou as cargas exercidas sobre a mesma, há a necessidade de se estabelecer alguns critérios. Quando estes tratam de deslocamentos são fáceis de determinar, porém quando tratam de tensões, esses critérios não são tão fáceis assim, requerendo do analisador conhecimentos específicos para tal trabalho. 


\subsection{Procedimento para a Análise em Elementos Finitos}

Para a análise do terno de moenda no software CosmosWorks, segue-se as seguintes etapas:

i. Na guia CosmosWorks criar um novo estudo com as propriedades: type $=$ static e mesh type $=$ solid mesh, conforme Figura 89;

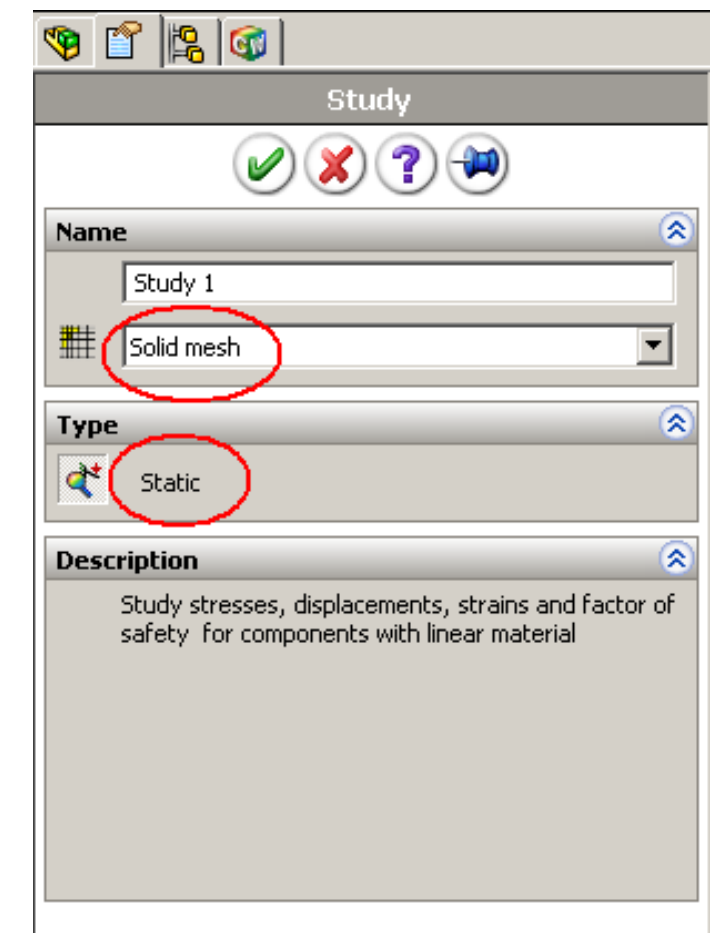

Figura 89: Criação de um novo estudo no Cosmosworks.

ii. Criar dois materiais chamados ADZ-25 e SAE-1045, tipo linear elastic isotropic com as propriedades mecânicas das seções 5.3.1 - castelo e 5.3 .2 - pino excêntrico, respectivamente. Para o presente trabalho é necessário o preenchimento dos campos: EX (módulo de elasticidade), NUXY (coeficiente de Poisson), SIGXT (limite de resistência) e SIGYLD (limite de escoamento, conforme Figura 90. Pode-se preencher o campo DENS (densidade do material) com o valor de $7800 \mathrm{Kg} / \mathrm{m}^{3}$ (valor correspondente ao aço). 


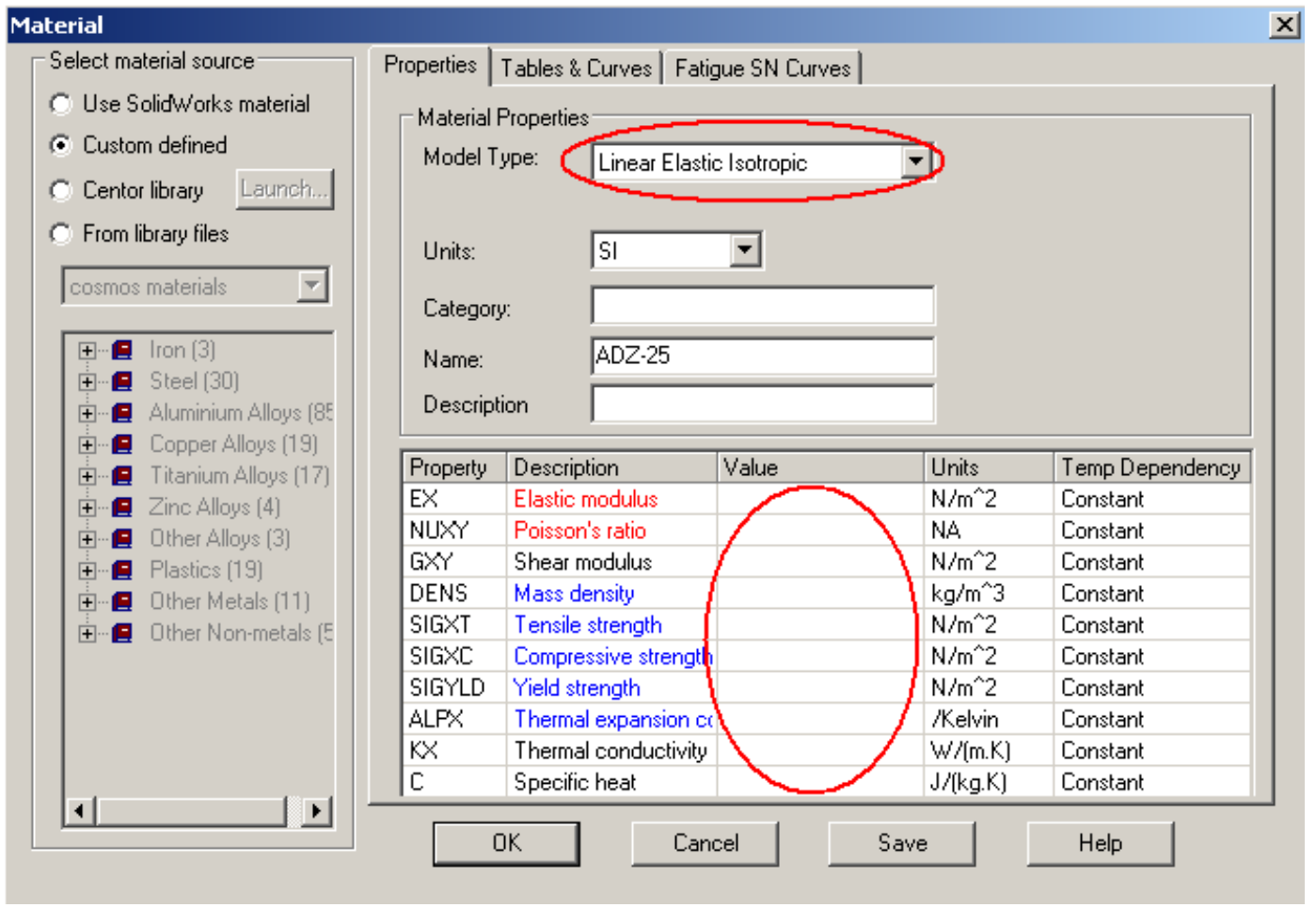

Figura 90: Campos para preenchimento das propriedades mecânicas dos materiais no Cosmosworks.

iii. Atribuir o material ADZ-25 a todos os componentes do terno de moenda, exceto o sistema de regulagem da bagaceira que será atribuído o material SAE-1045;

iv. Criar 5 (cinco) connectors = pin, um por vez, para a substituição dos pinos de articulação entre os castelos e os cabeçotes laterais. No campo component 1 selecione as faces cilíndricas do castelo e no campo component 2 selecione a face cilíndrica do cabeçote lateral conforme Figura 91. Em connection type, marcar a opção no translation. Idem para os pin restantes; 


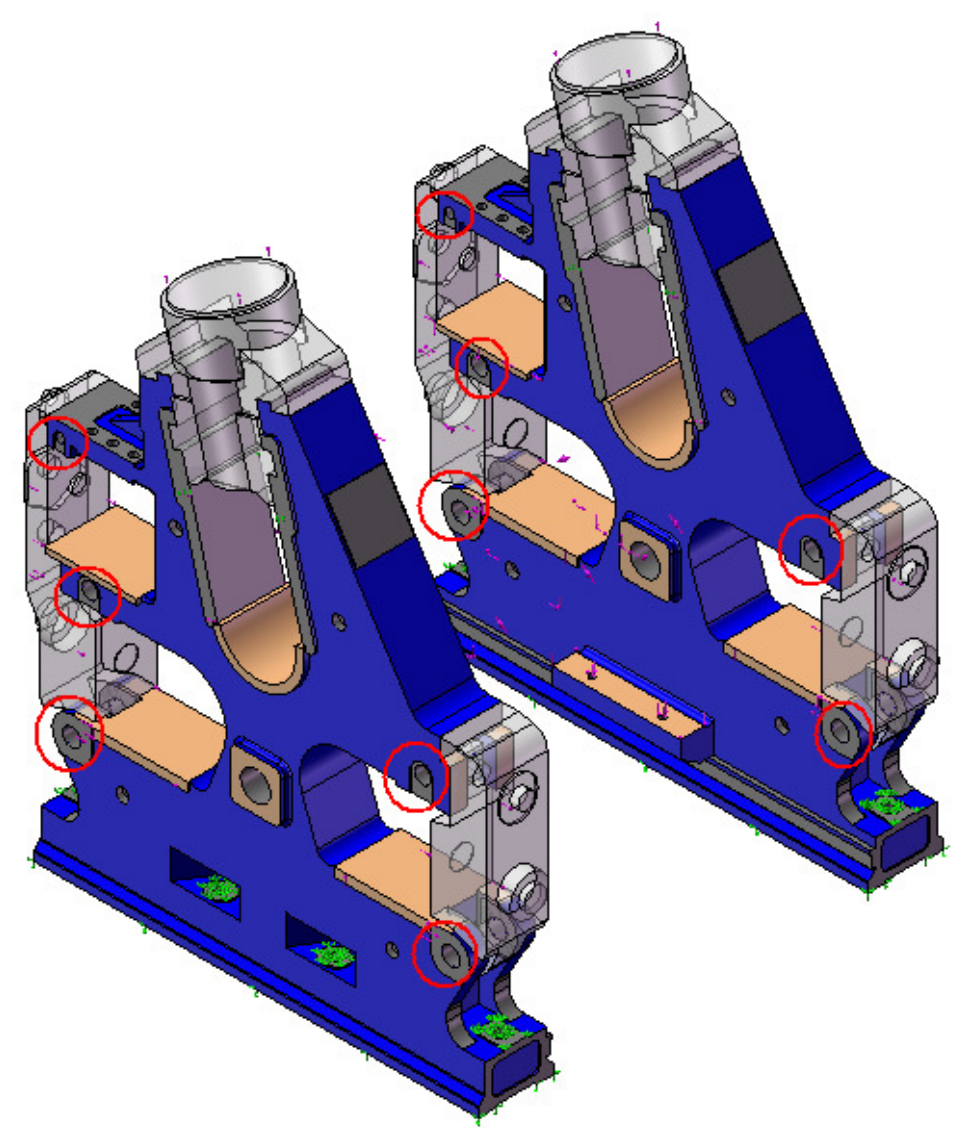

Figura 91: Locais (circulados em vermelho) onde serão criados os pin.

v. Aplicar restraints $=$ Fixed nas bases dos castelos e nos assentos das porcas dos varões de fixação dos castelos conforme indicados na Figura 92;

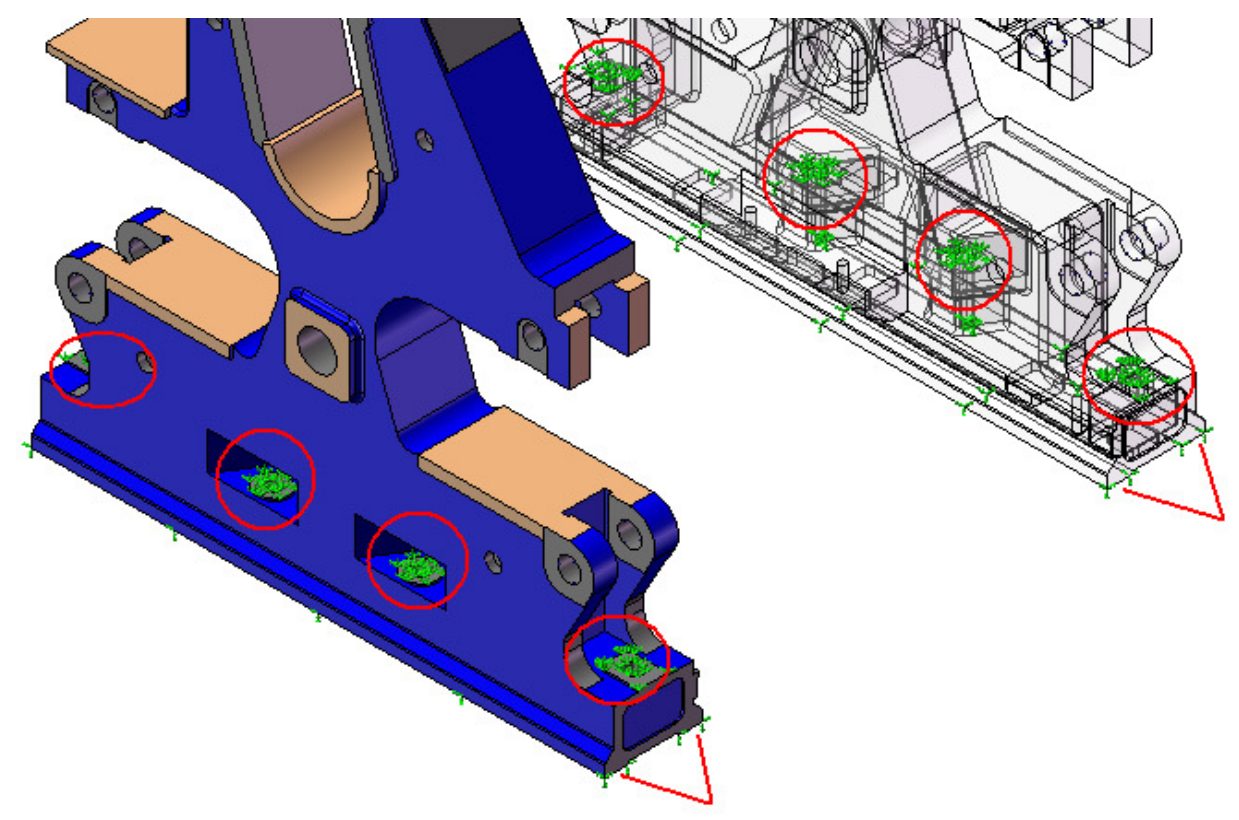

Figura 92: Locais (circulados em vermelho) onde serão aplicadas restrições. 
vi. Aplicar restraints = use reference geometry nas faces das caixas dos mancais superiores conforme Figura 93. No campo faces for restraint selecione as faces (em verde) da Figura 93. No campo axis for direction selecione uma aresta inclinada a $15^{\circ}$ para direcionar a restrição neste sentido;

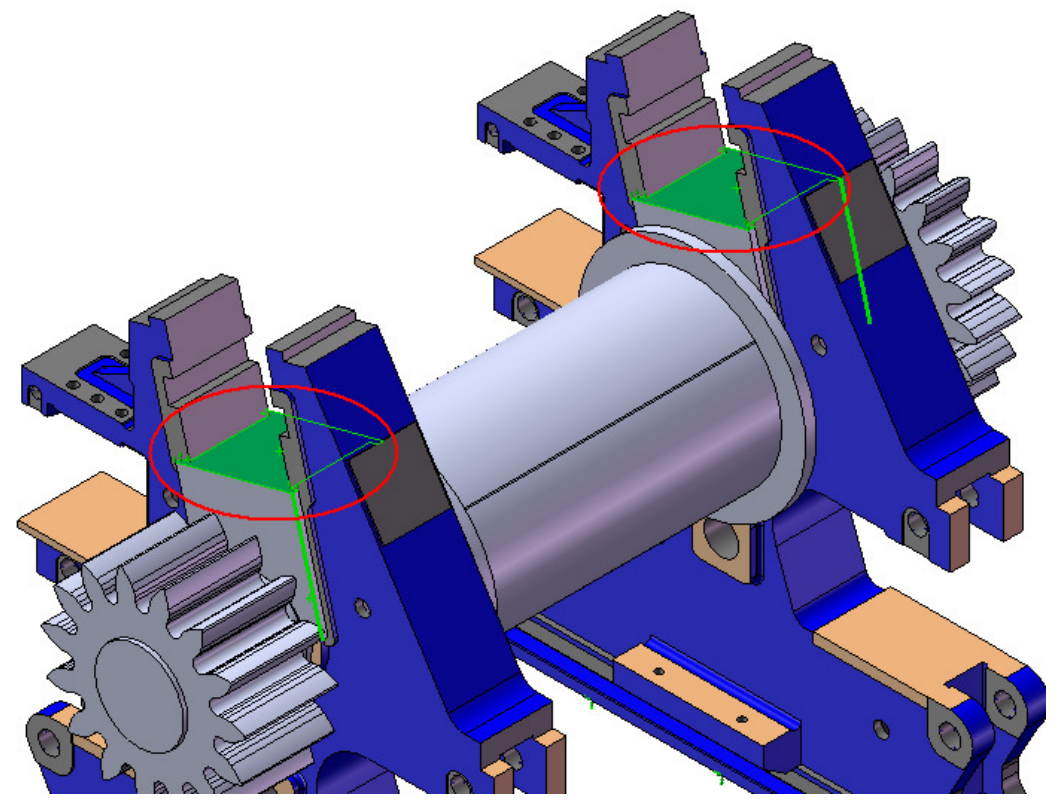

Figura 93: Locais (circulados em vermelho) onde será aplicada restrição de translação em apenas uma direção.

vii. Aplicar load $=$ force e no campo type marcar a opção apply normal force. No campo normal force/torque (per entity) entrar com a metade do valor obtido em [1] da seção 8.1. No campo faces for normal force selecionar as faces superiores dos cabeçotes hidráulicos (circuladas em vermelho) conforme Figura 94. O sentido da força deverá ser de baixo para cima;

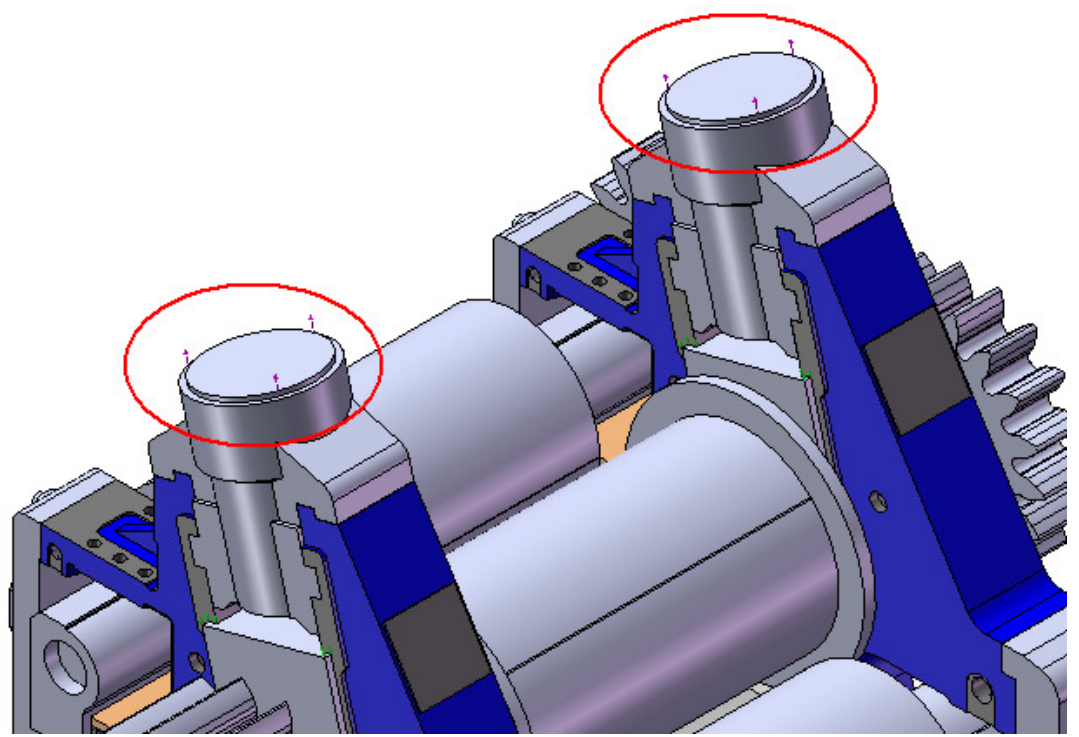

Figura 94: Locais (circulados em vermelho) onde serão aplicadas as forças correspondente a CHT. 
viii. Aplicar load $=$ force e no campo type marcar a opção apply normal force. No campo normal force/torque (per entity) entrar com o valor obtido em [2] da seção 8.1. No campo faces for normal force selecionar as faces das camisas (previamente criadas) no local onde se tocam conforme Figura 95. O sentido das forças deverá ser tal modo a proporcionar a abertura dos rolos, simulando a entrada da cana. Idem para o lado de saída mudando o valor do campo normal force/torque (per entity) para o obtido em [3] da seção 8.1;

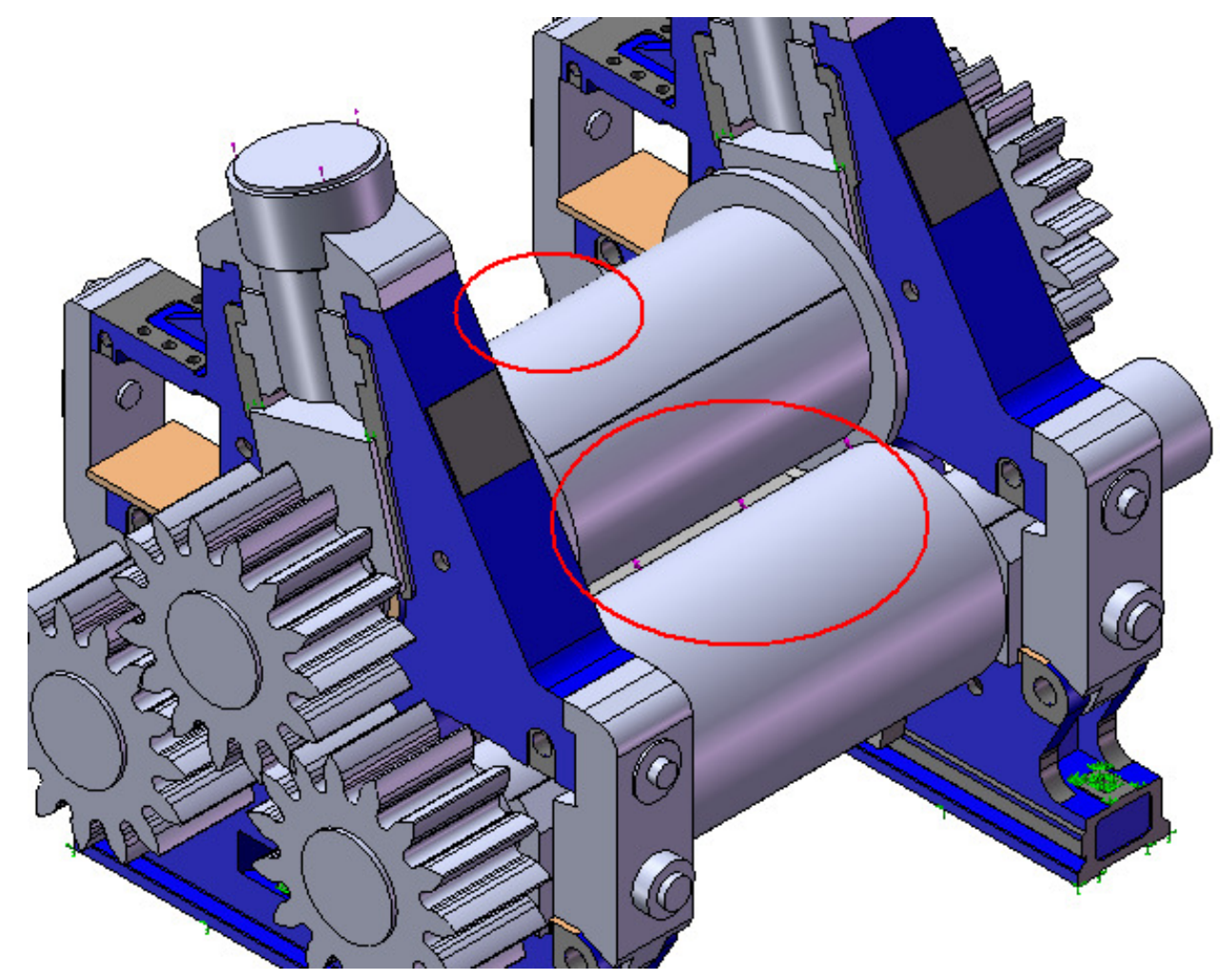

Figura 95: Locais (circulados em vermelho) onde serão aplicadas as forças obtidas em [2] e [3] correspondente ao esmagamento da cana pelos rolos.

ix. Aplicar load $=$ force e no campo type marcar a opção apply normal force. No campo normal force/torque (per entity) entrar com o valor de $110000 \mathrm{Kg}$, dado do projeto conforme seção 8.1. No campo faces for normal force selecionar as faces das camisas (previamente criadas) na altura do centro dos rolos conforme Figura 96. O sentido das forças deverá ser tal modo a proporcionar a pressão exercida pela cana na entrada do terno; 


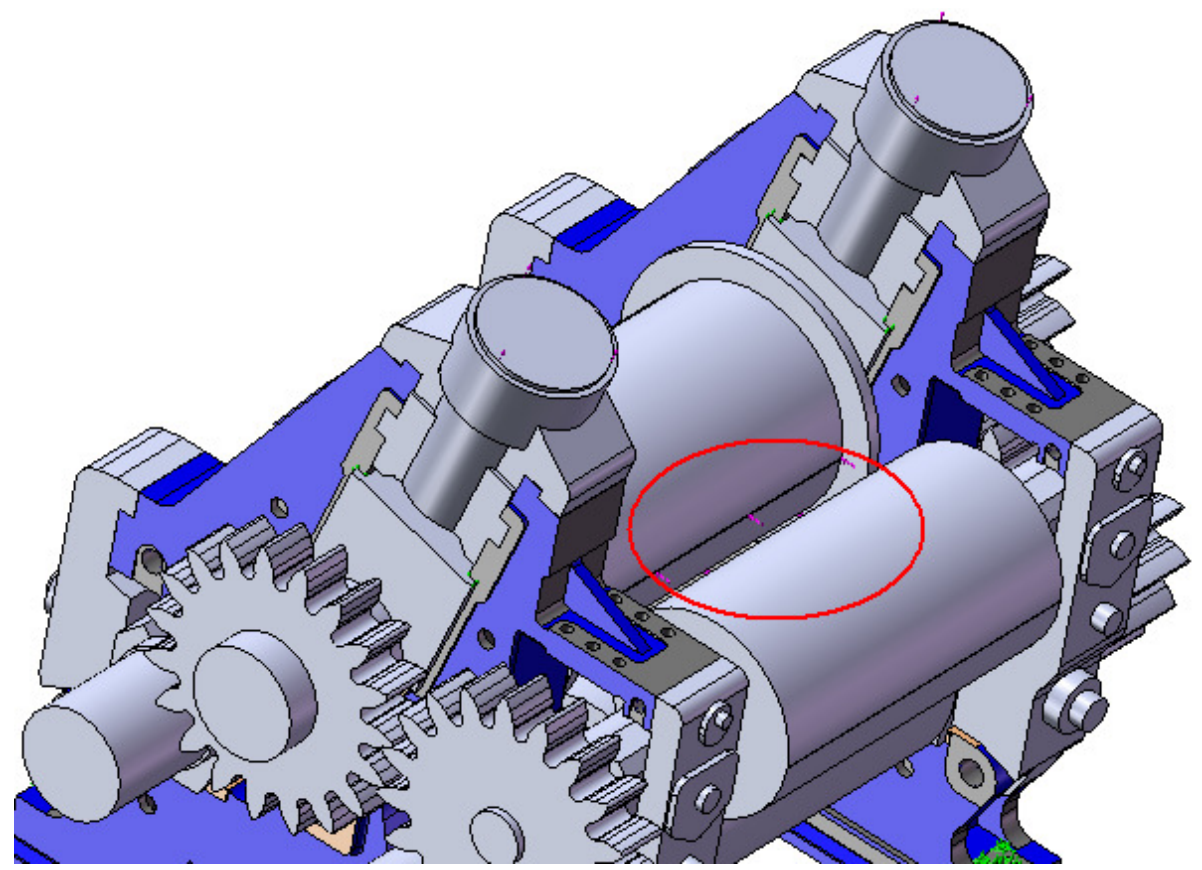

Figura 96: Locais (circulados em vermelho) onde serão aplicadas as forças correspondentes a pressão da cana na entrada do terno.

x. Aplicar load = force e no campo type marcar a opção apply force/moment. No campo force (per entity) entrar com $15 \%$ do valor obtido em [1], dado do projeto conforme seção 8.1. No campo faces for force selecionar a face superior da bagaceira conforme Figura 97. O sentido da força deverá ser verticalmente de cima para baixo. Na mesma face aplicar uma segunda força que terá como valor $10 \%$ de [1] e sentido horizontalmente da esquerda para a direita conforme Figura 97;

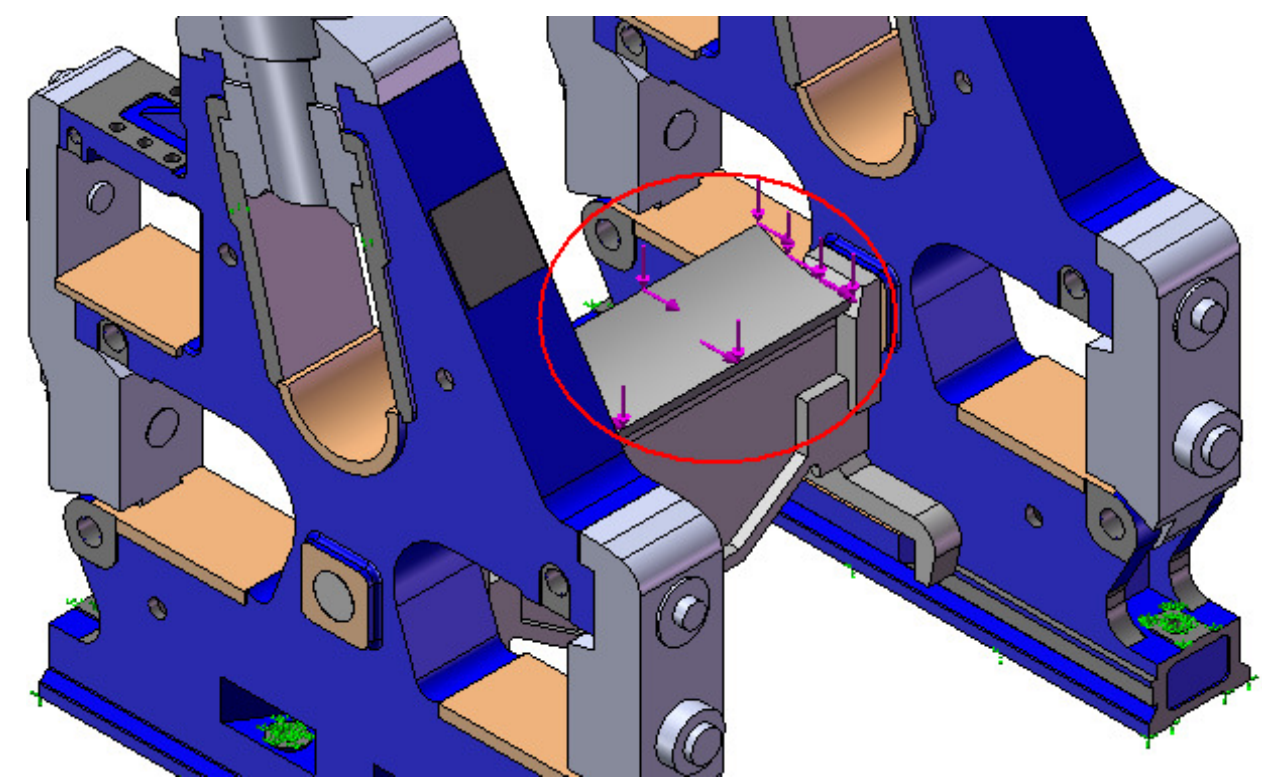

Figura 97: Face superior da bagaceira (circulados em vermelho) onde serão aplicadas as forças. 
xi. Para cada face (vertical, horizontal e inclinada a $15^{\circ}$ ) das caixas dos mancais dos rolos de moenda, aplicar load = force e no campo type marcar a opção apply normal force. No campo normal force/torque (per entity) entrar com os valores correspondentes a face selecionada conforme Figuras 98, 99 e 100. No campo faces for normal force selecionar as faces onde serão aplicadas as forças conforme Figura 98, 99 e 100. Os valores das forças foram obtidas do engrenamento dos rodetes e dos pesos próprios dos componentes conforme item 8.1. As direções das forças para cada face dos mancais estão ilustradas nas Figuras 98, 99 e 100;

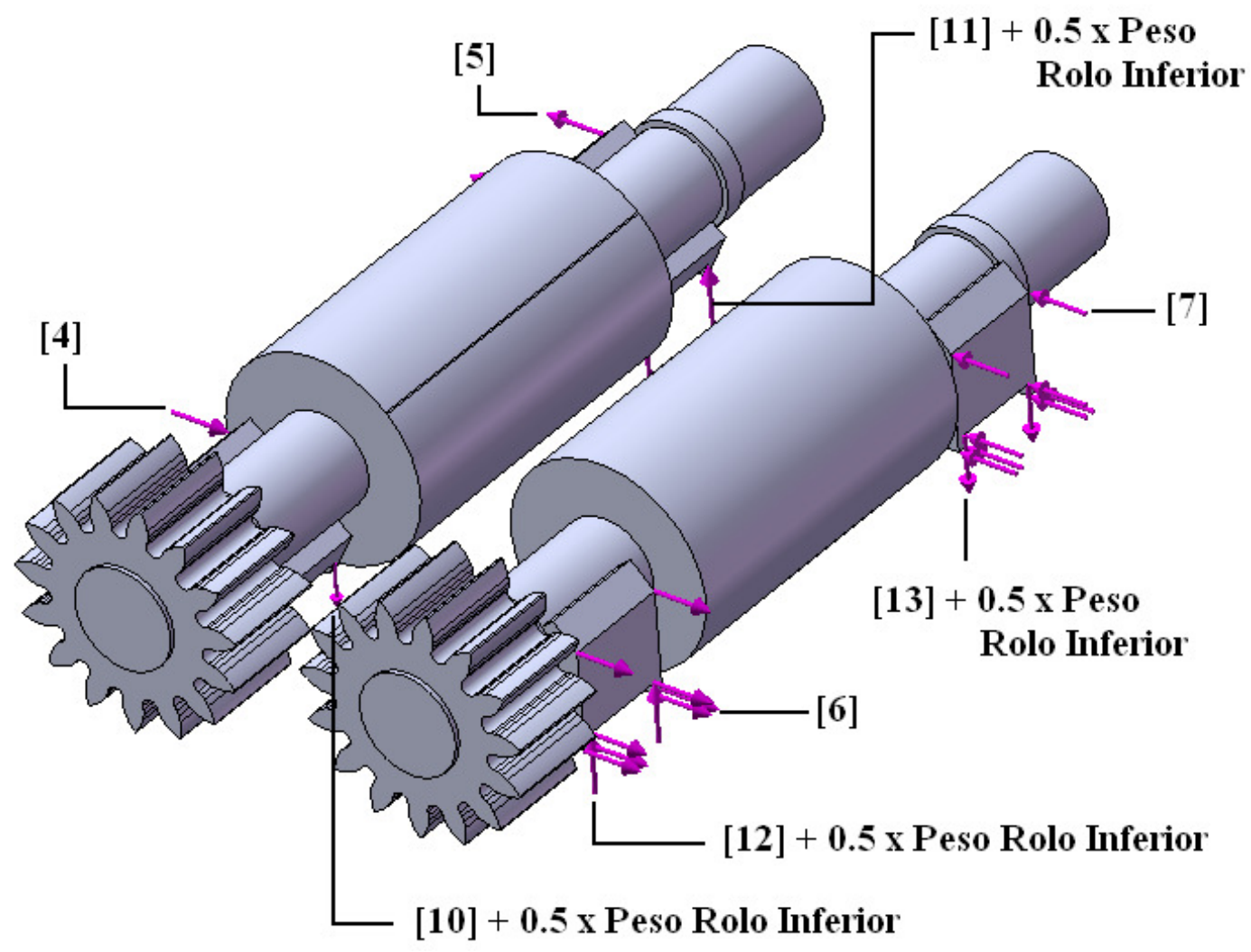

Figura 98: Faces horizontais e verticais das caixas dos mancais dos rolos inferiores com suas respectivas forças e direções a serem aplicadas. 


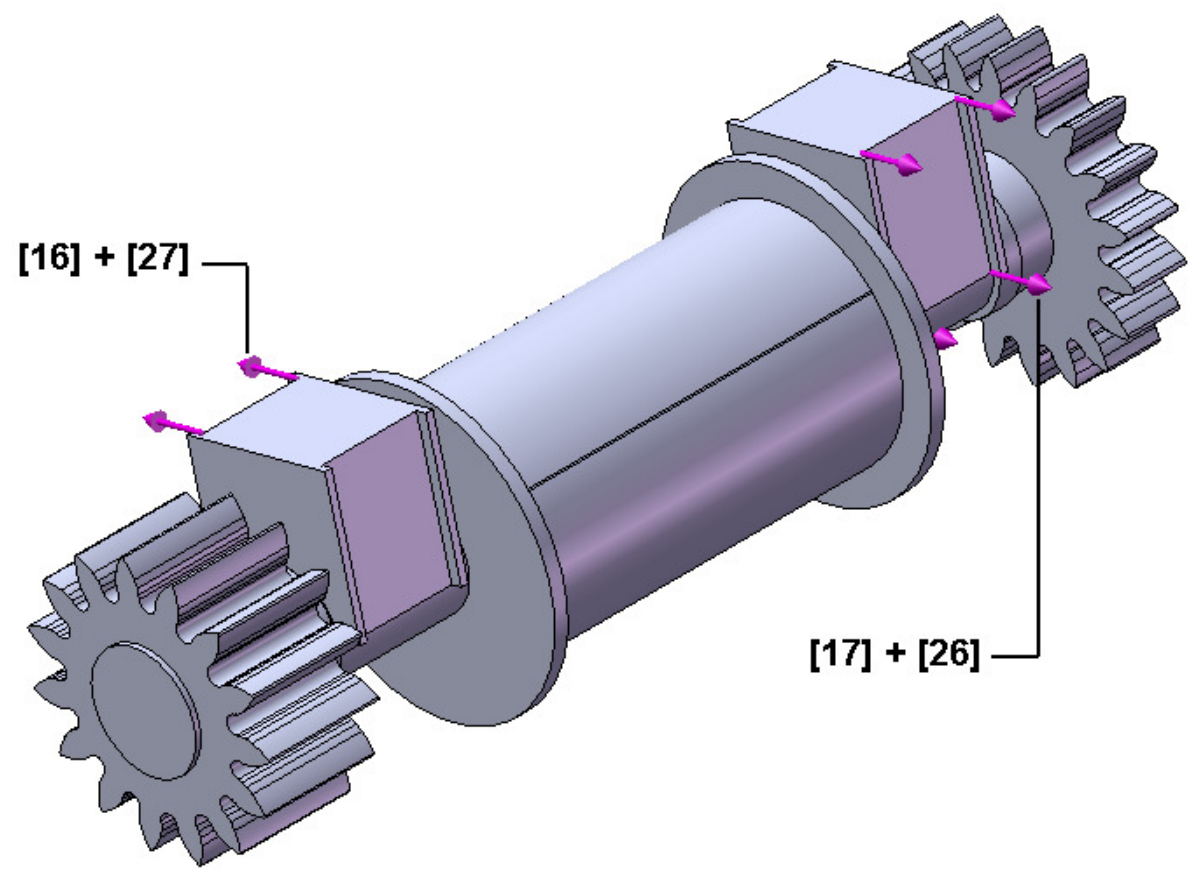

Figura 99: Faces inclinada a $15^{\circ}$ das caixas dos mancais do rolo superior com suas respectivas forças e direções a serem aplicadas.

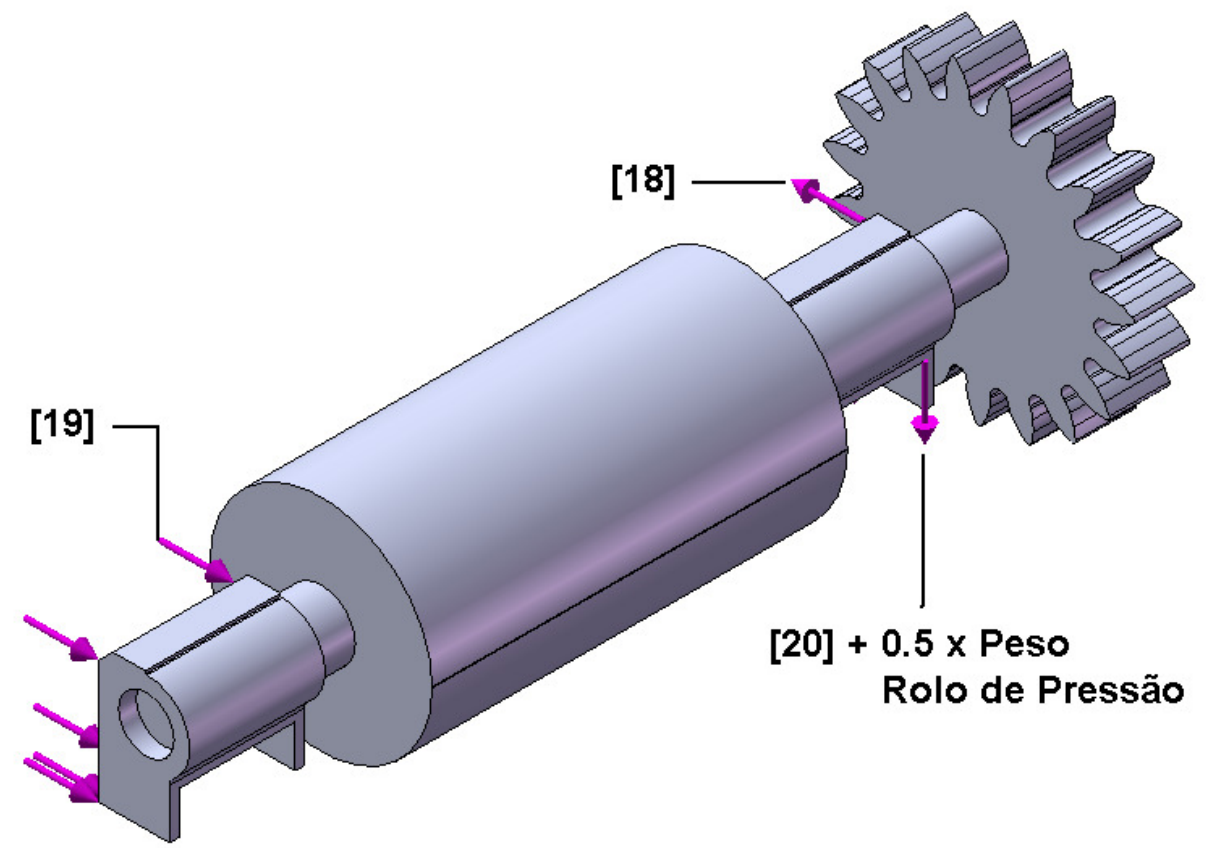

Figura 100: Faces horizontais e verticais das caixas dos mancais do rolo de pressão com suas respectivas forças e direções a serem aplicadas.

xii. Aplicar load $=$ force e no campo type marcar a opção apply normal force. No campo normal force/torque (per entity) entrar com o valor de $9000 \mathrm{Kg}$, dado do projeto conforme seção 8.1. No campo faces for normal force selecionar as duas faces superiores dos “banquinhos” dos castelos conforme Figura 101. O sentido 
das forças será de cima para baixa simulando o peso próprio do sistema de regulagem da bagaceira;

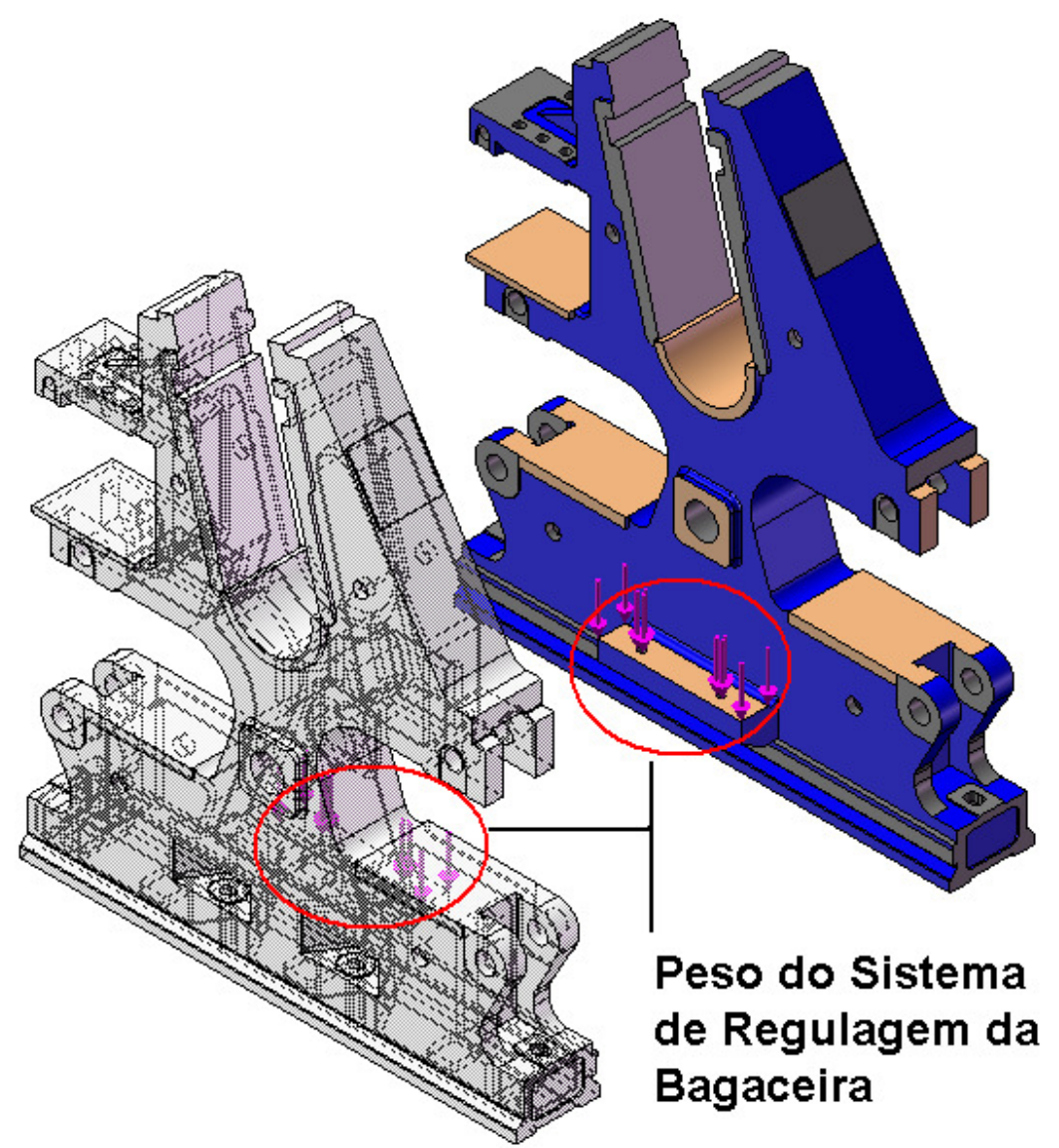

Figura 101: Faces (circuladas em vermelho) onde serão aplicadas as forças correspondentes ao peso do sistema de regulagem da bagaceira assim como sua direção.

xiii. Em set global contact, no campo touching faces, marcar a opção bonded e no campo option marcar compatible mesh;

xiv. Em define contact set, campo source, selecionar as faces de um castelo que estão em contato com o cabeçote hidráulico (faces do encaixe) conforme Figura 102. No campo target, selecionar as faces dos cabeçotes hidráulicos que estão em contato com as dos castelo, conforme Figura 102. Em options marcar node to node; 


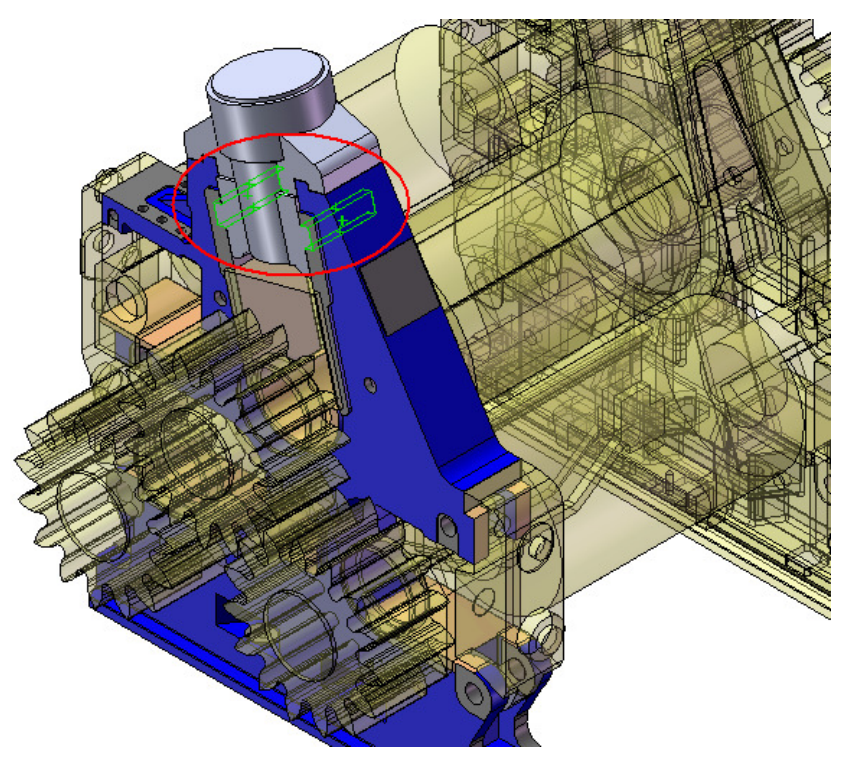

Figura 102: Faces (em verde) do castelo e do cabeçote hidráulico que se tocam.

xv. Idem para o outro castelo com o cabeçote hidráulico;

xvi. Em define contact set, campo source, selecionar as faces de um castelo que estão em contato com o pino excêntrico conforme Figura 103. No campo target, selecionar a face do pino excêntrico que está em contato com a do castelo, conforme Figura 103. Em options marcar node to node;

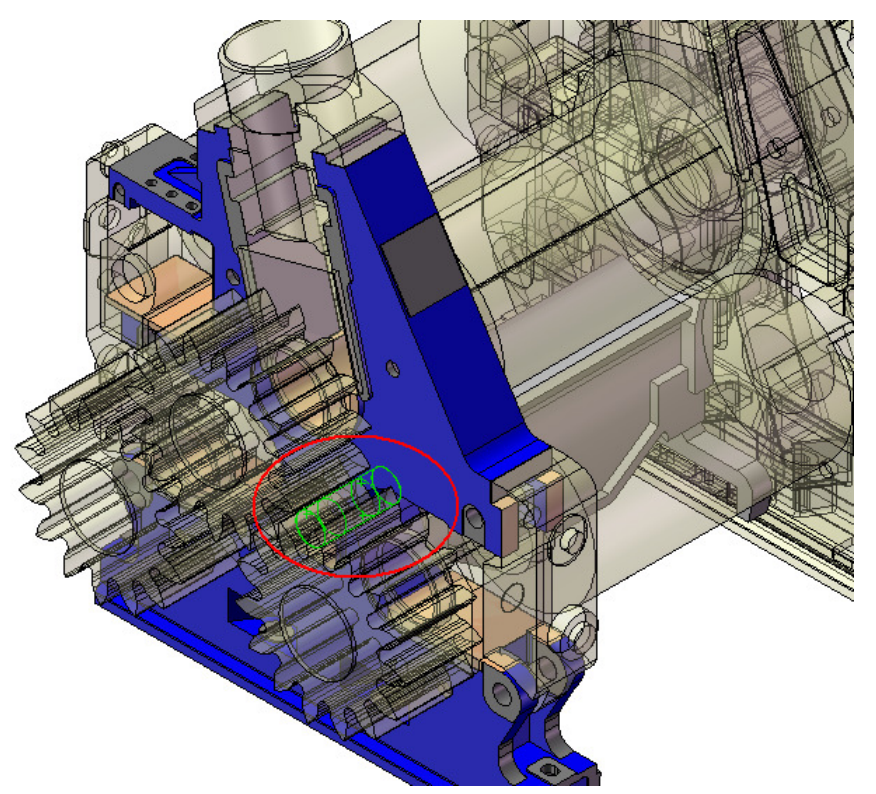

Figura 103: Faces (em verde) do castelo e do pino excêntrico que se tocam.

xvii. Idem para o outro castelo com o pino excêntrico; 
xviii. Em define contact set, campo source, selecionar a face de um castelo que está em contato com o suporte da balança conforme Figura 104. No campo target, selecionar a face do suporte da balança que está em contato com a do castelo, conforme Figura 104. Em options marcar node to node;

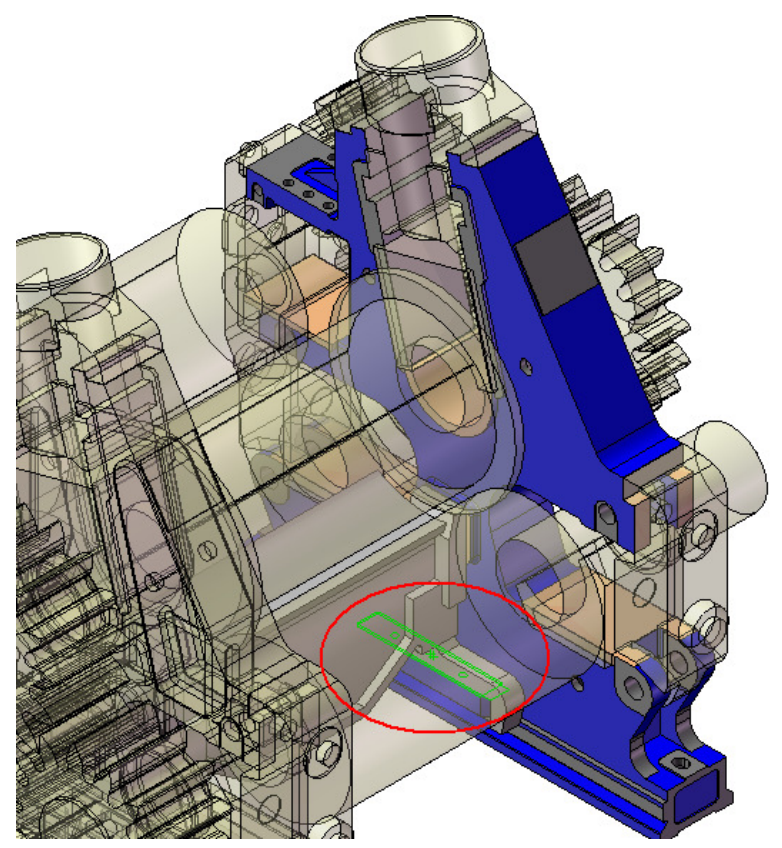

Figura 104: Faces (em verde) do castelo e do suporte da balança que se tocam.

xix. Idem para o outro castelo com o suporte da balança;

xx. Em define contact set, campo source, selecionar as faces de um castelo que estão em contato com o cabeçote lateral de saída conforme Figura 105. No campo target, selecionar as faces do cabeçote lateral de saída que estão em contato com as do castelo, conforme Figura 105. Em options marcar surface to surface; 


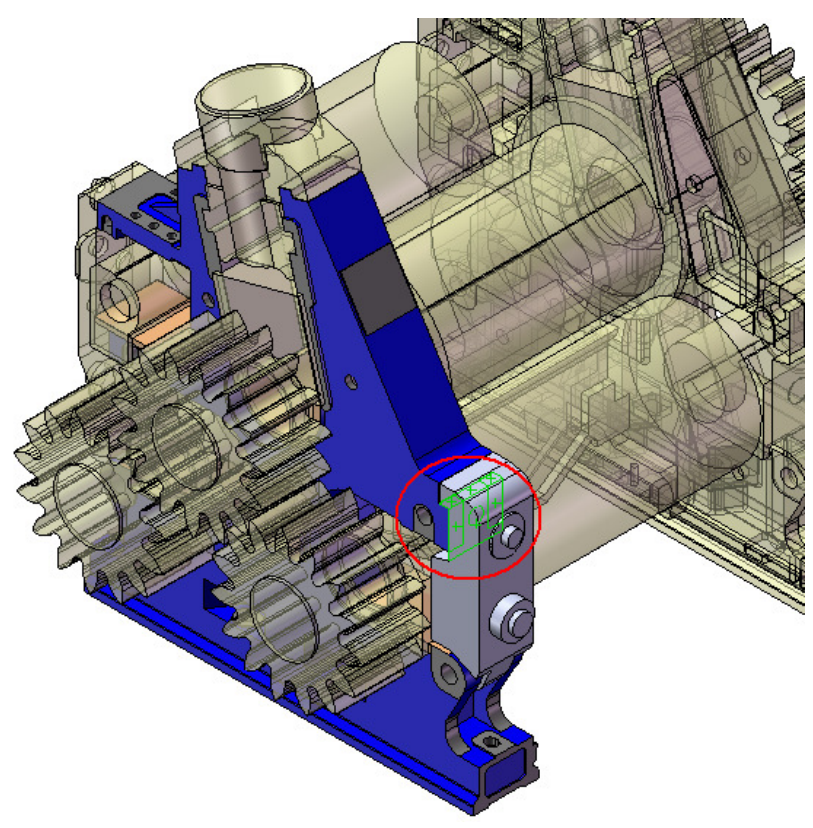

Figura 105: Faces (em verde) do castelo e do cabeçote lateral de saída que se tocam.

xxi. Idem para o outro castelo com o cabeçote lateral de saída;

xxii. Em define contact set, campo source, selecionar as faces de um castelo que estão em contato com o cabeçote lateral de entrada conforme Figura 106. No campo target, selecionar as faces do cabeçote lateral de entrada que estão em contato com as do castelo, conforme Figura 106. Em options marcar surface to surface;

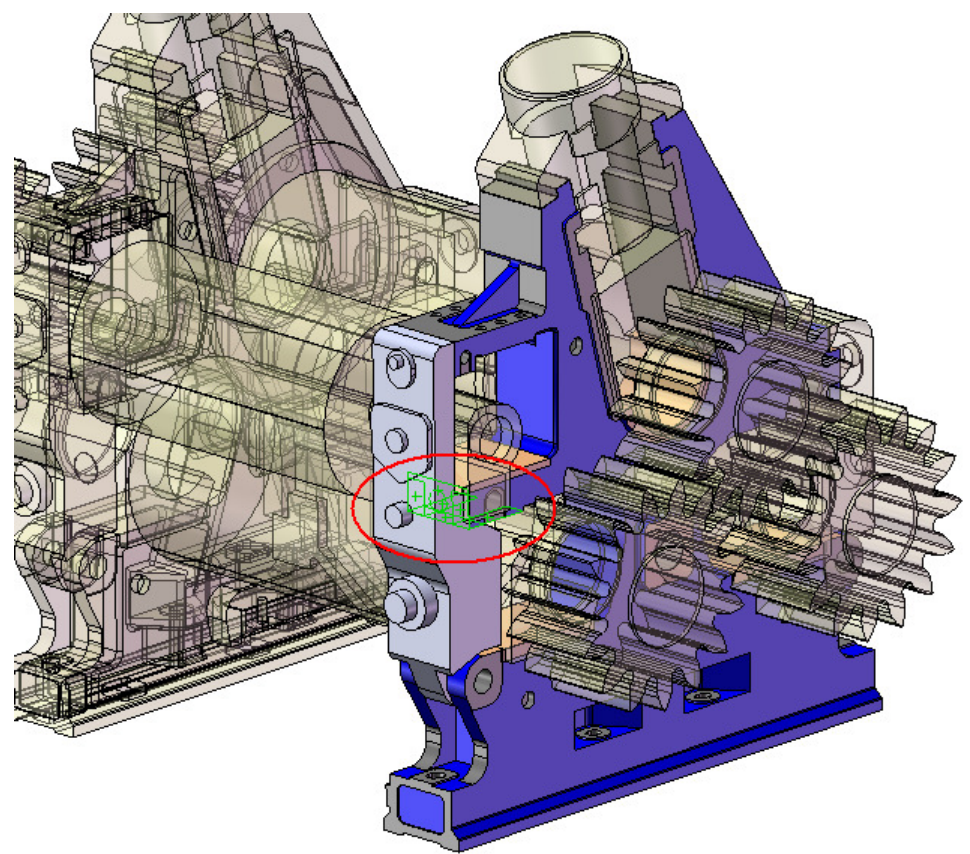

Figura 106: Faces (em verde) do castelo e do cabeçote lateral de entrada que se tocam.

xxiii. Idem para o outro castelo com o cabeçote lateral de entrada; 
xxiv. Em define contact set, campo source, selecionar a face de um castelo que está em contato com o mancal do rolo de pressão conforme Figura 107. No campo target, selecionar a face do mancal do rolo de pressão que está em contato com a do castelo, conforme Figura 107. Em options marcar node to node;

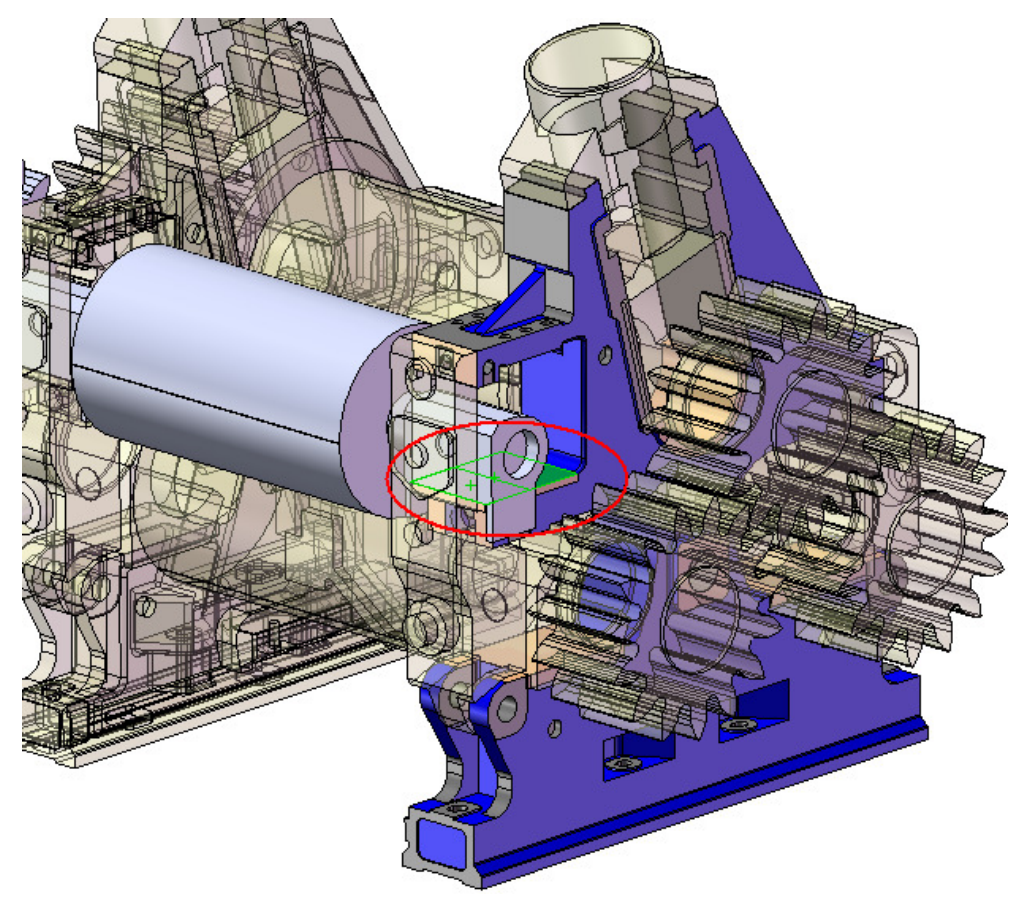

Figura 107: Faces (em verde) do castelo e do mancal do rolo de pressão que se tocam.

XXv. Idem para o outro castelo com o mancal do rolo de pressão;

xxvi. Em define contact set, campo source, selecionar a face do mancal do rolo de pressão que está em contato com o cabeçote lateral de entrada conforme Figura 108. No campo target, selecionar a face do cabeçote lateral de entrada que está em contato com a do mancal do rolo de pressão, conforme Figura 108. Em options marcar node to node; 


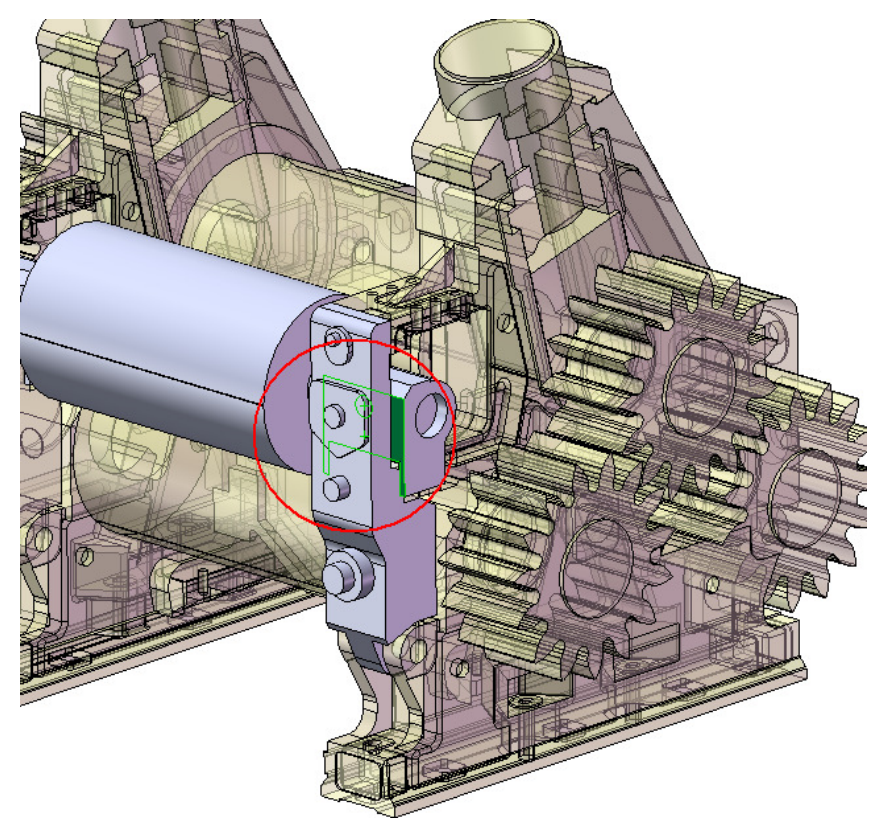

Figura 108: Faces (em verde) do cabeçote lateral de entrada e do mancal do rolo de pressão que se tocam.

xxvii. Idem para o outro cabeçote lateral de entrada e o mancal do rolo de pressão;

xxviii. Em define contact set, campo source, selecionar a face do castelo que está em contato com a face do mancal do rolo inferior de entrada conforme Figura 109. No campo target, selecionar a face do mancal do rolo inferior de entrada que está em contato com a do castelo, conforme Figura 109. Em options marcar node to node;

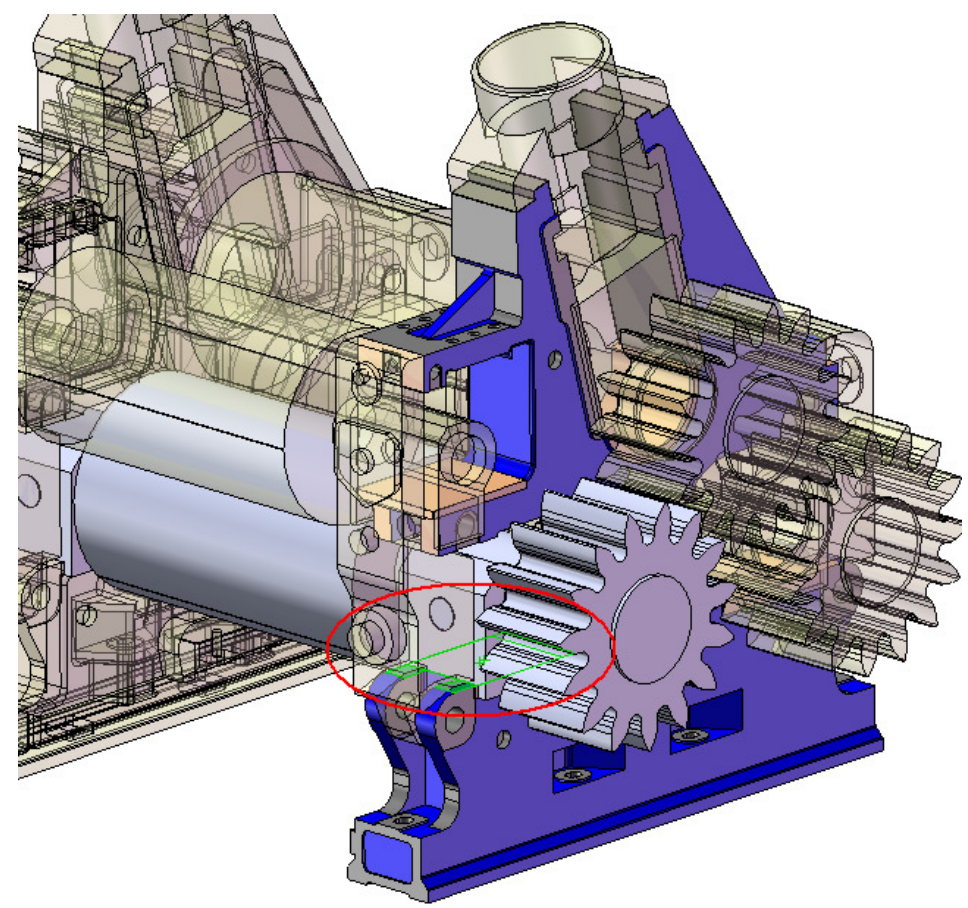

Figura 109: Faces (em verde) do mancal do rolo inferior de entrada e do castelo que se tocam. 
xxix. Idem para o outro castelo e a face do mancal do rolo inferior de entrada;

xxx. Em define contact set, campo source, selecionar a face do cabeçote lateral de entrada que está em contato com a face do mancal do rolo inferior de entrada conforme Figura 110. No campo target, selecionar a face do mancal do rolo inferior de entrada que está em contato com a do cabeçote lateral de entrada, conforme Figura 110. Em options marcar node to node;

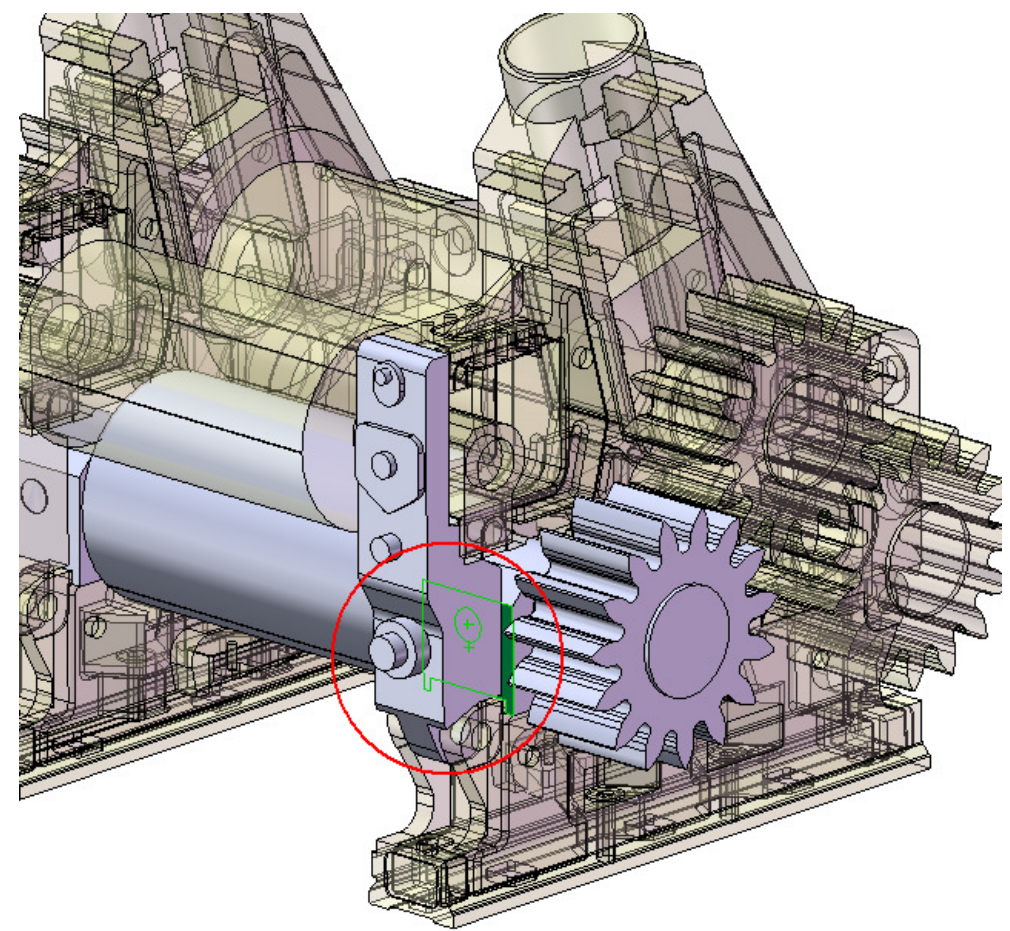

Figura 110: Faces (em verde) do mancal do rolo inferior de entrada e do cabeçote lateral de entrada que se tocam.

xxxi. Idem para o outro cabeçote lateral de entrada e a face do mancal do rolo inferior de entrada;

xxxii. Em define contact set, campo source, selecionar a face do castelo que está em contato com a face do mancal do rolo inferior de saída conforme Figura 111. No campo target, selecionar a face do mancal do rolo inferior de saída que está em contato com a do castelo, conforme Figura 111. Em options marcar node to node; 


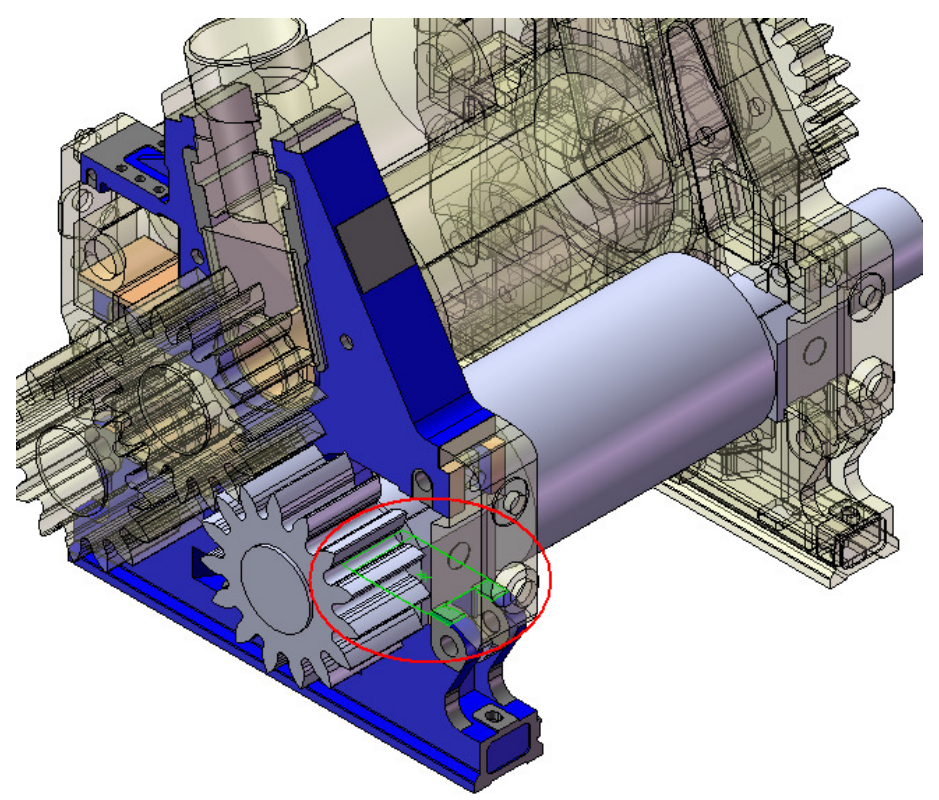

Figura 111: Faces (em verde) do mancal do rolo inferior de entrada e do castelo que se tocam.

xxxiii. Idem para o outro castelo e a face do mancal do rolo inferior de saída;

xxxiv. Em define contact set, campo source, selecionar a face do cabeçote lateral de saída que está em contato com a face do mancal do rolo inferior de saída conforme Figura 112. No campo target, selecionar a face do mancal do rolo inferior de saída que está em contato com a do cabeçote lateral de saída, conforme Figura 112. Em options marcar node to node;

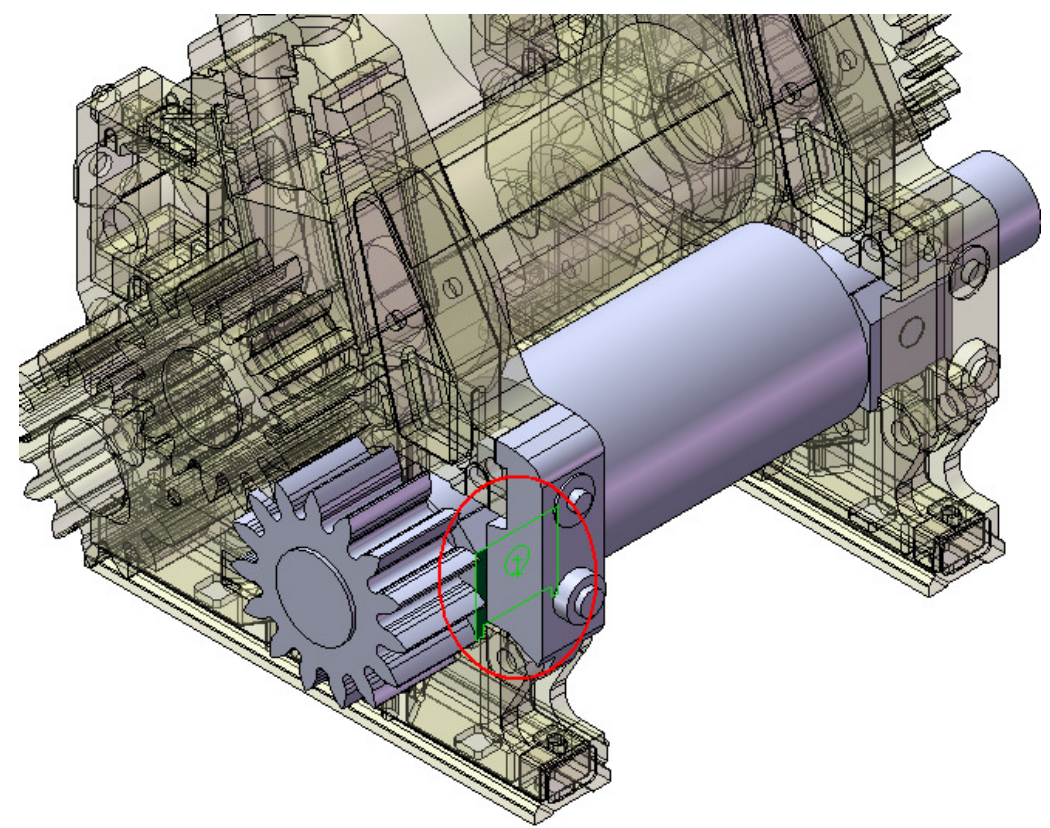

Figura 112: Faces (em verde) do mancal do rolo inferior de saída e do cabeçote lateral de saída que se tocam. 
xxxv. Idem para o outro cabeçote lateral de saída e a face do mancal do rolo inferior de saída;

xxxvi. Em define contact set, campo source, selecionar a face do "garfo" do castelo que está em contato com a face do mancal do rolo superior conforme a Figura 113. No campo target, selecionar a face do mancal do rolo superior que está em contato com o "garfo" do castelo conforme Figura 113. Em options marcar node to node;

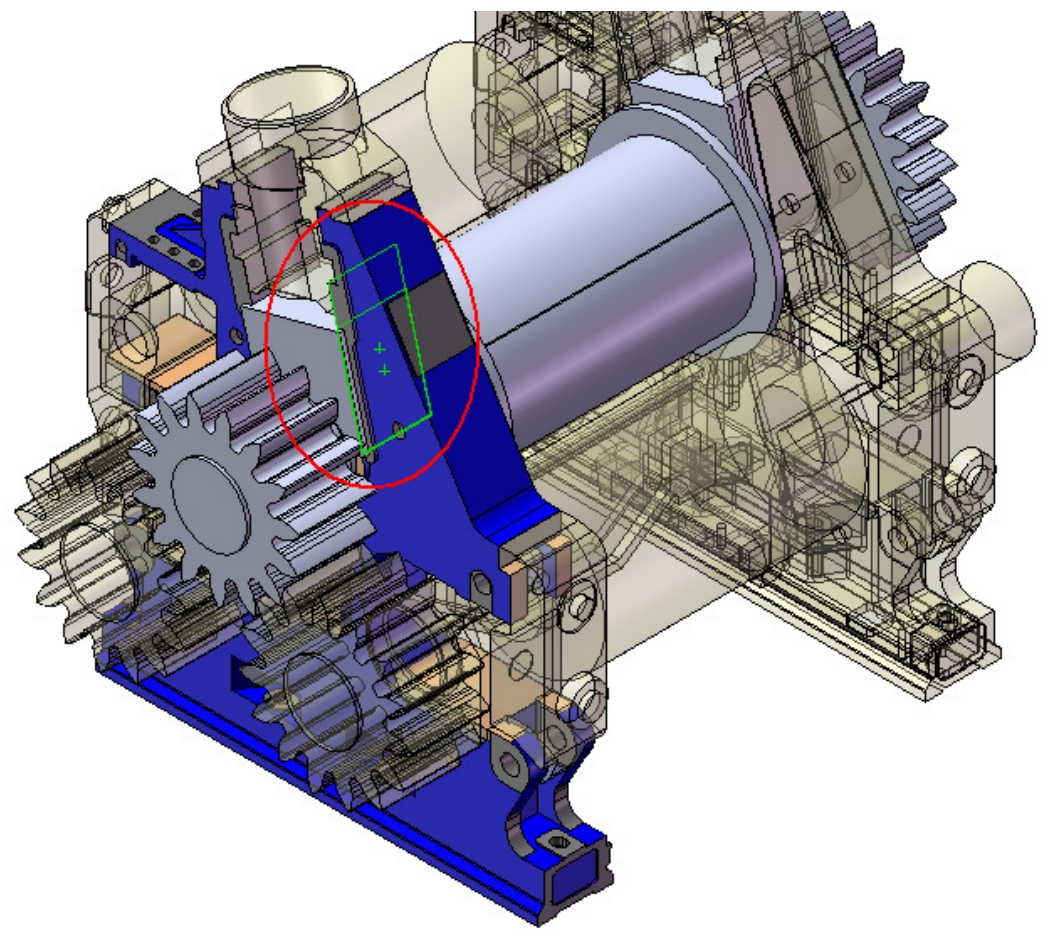

Figura 113: Faces (em verde) do "garfo" do castelo e do mancal do rolo superior que se tocam.

xxxvii. Idem para a outra face do "garfo" do castelo que está em contato com a face do mancal superior e as outras duas do lado oposto ao da Figura 113;

xxxviii. Em define contact set, campo source, selecionar a face do castelo que está em contato com o cabeçote hidráulico (encaixe superior) conforme a Figura 114. No campo target, selecionar a face do do cabeçote hidráulico que está em contato com o castelo conforme amostra a Figura 114. Em options marcar node to node; 


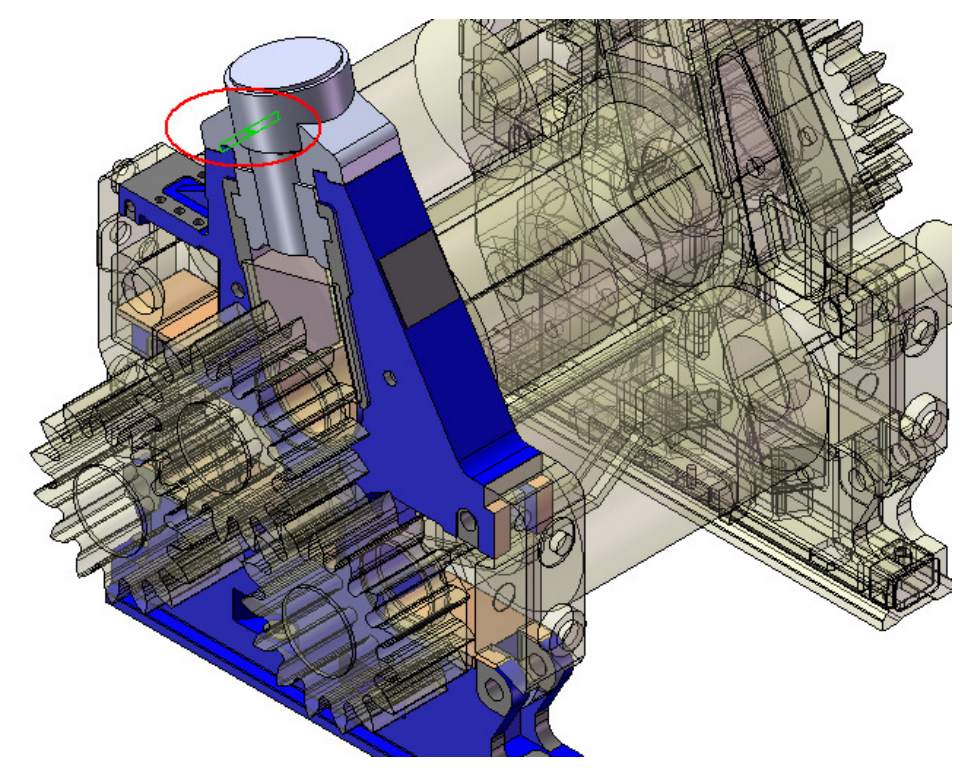

Figura 114: Faces (em verde) do cabeçote hidráulico (encaixe superior) e do castelo que se tocam.

xxxix. Idem para a outra face do cabeçote hidráulico (encaixe superior) que está em contato com o castelo e as outras duas do lado oposto ao da Figura 114;

xl. Em mesh control, no campo components for mrsh control selecionar os dois castelo e atribuir no campo element size um valor de 100;

xli. Em mesh, no campo global size atribuir um valor de 130. Em options, configurar conforme mostra a Figura 115;

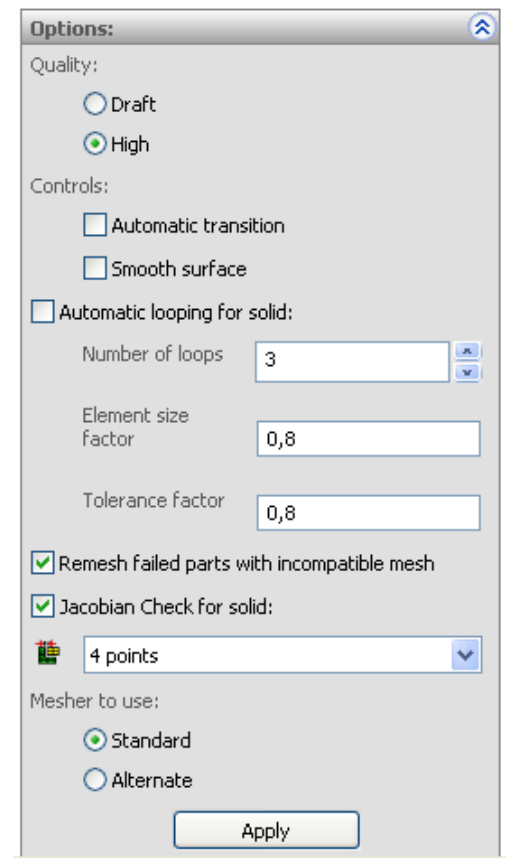

Figura 115: Configuração das opções para a execução da malha. 
xlii. Após as configurações executadas e a confirmação o programa responderá conforme Figura 116;

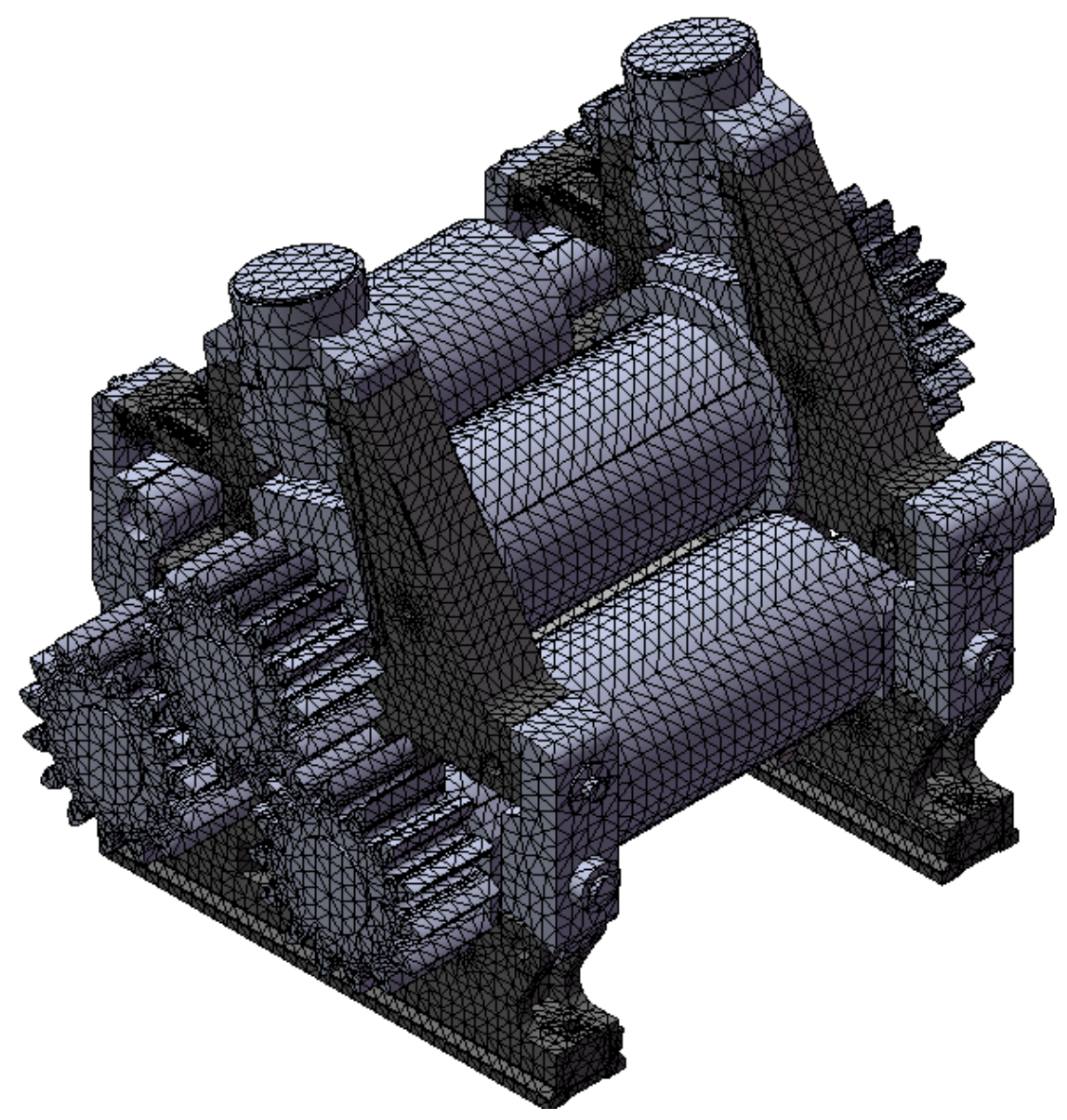

Figura 116: Terno de moenda após a execução da malha.

xliii. Com o BDM em cima do nome do estudo criado, escolher properties... e configurar a caixa de dialogo static como mostra a Figura 117, 


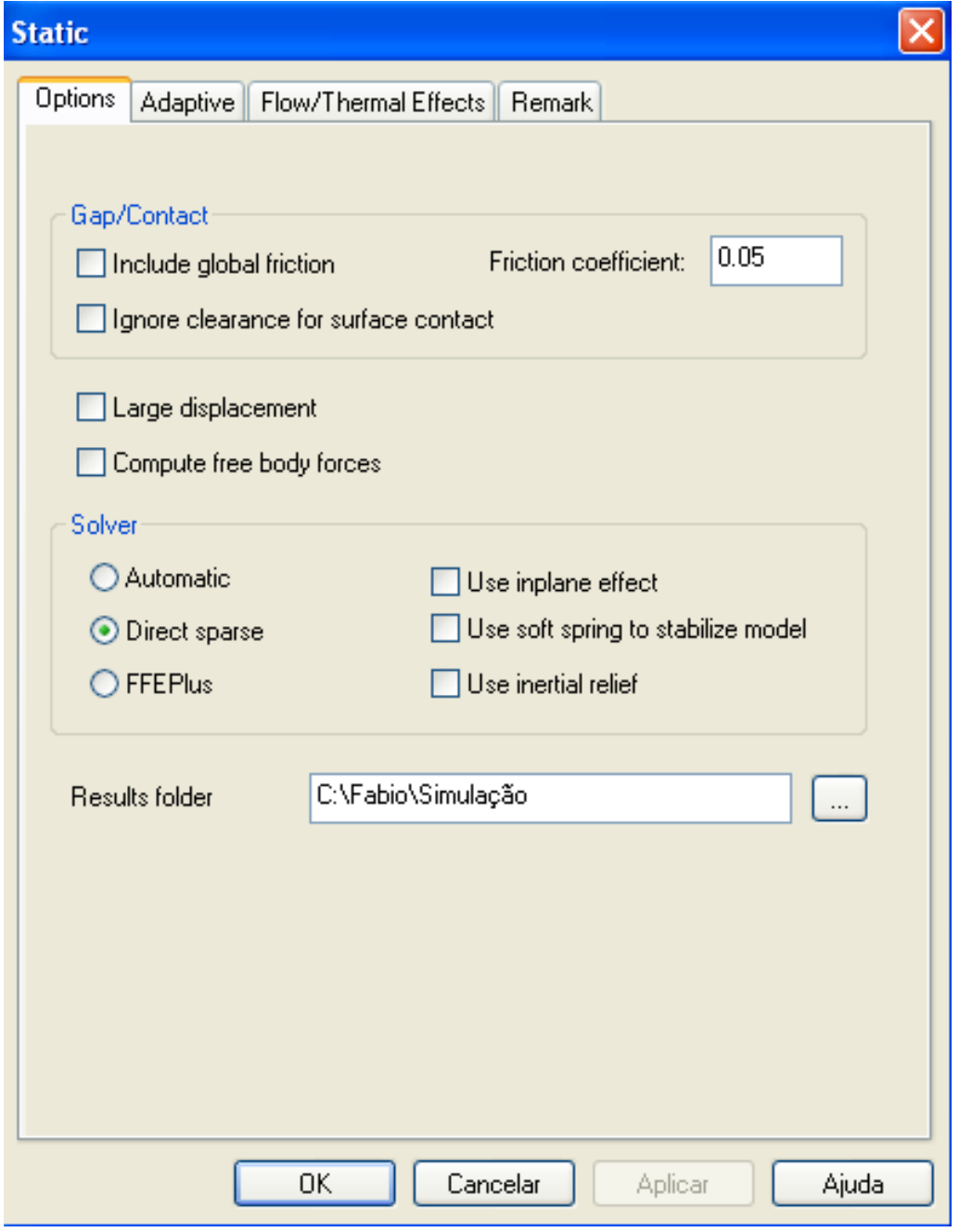

Figura 117: Configuração das opções para a "rodar" o programa.

xliv. Assim feito o programa está pronto para acionar o solver (run); 


\section{Resultados e Discussões}

A seguir serão apresentados os resultados das tensões e deslocamentos do conjunto do terno de moenda e do castelo isoladamente por ser o objeto deste estudo. $\mathrm{O}$ castelo do lado do acionamento apresentou os maiores valores de tensões e deformações comparados com o castelo do lado oposto ao do acionamento. Assim, apenas serão ilustrados os resultados do castelo do lado do acionamento.

Primeiramente, nas Figuras 118 e 119 são ilustrados o terno de moenda com os carregamentos externos já inclusos, sendo que, na Figura 118 são ilustrados as tensões atuantes, em MPa, limitados a 70 Mpa para uma melhor visualização e na Figura 119 são ilustrados os deslocamentos decorrentes dos esforços externos, limitados a $1 \mathrm{~mm}$, também para uma melhor visualização.

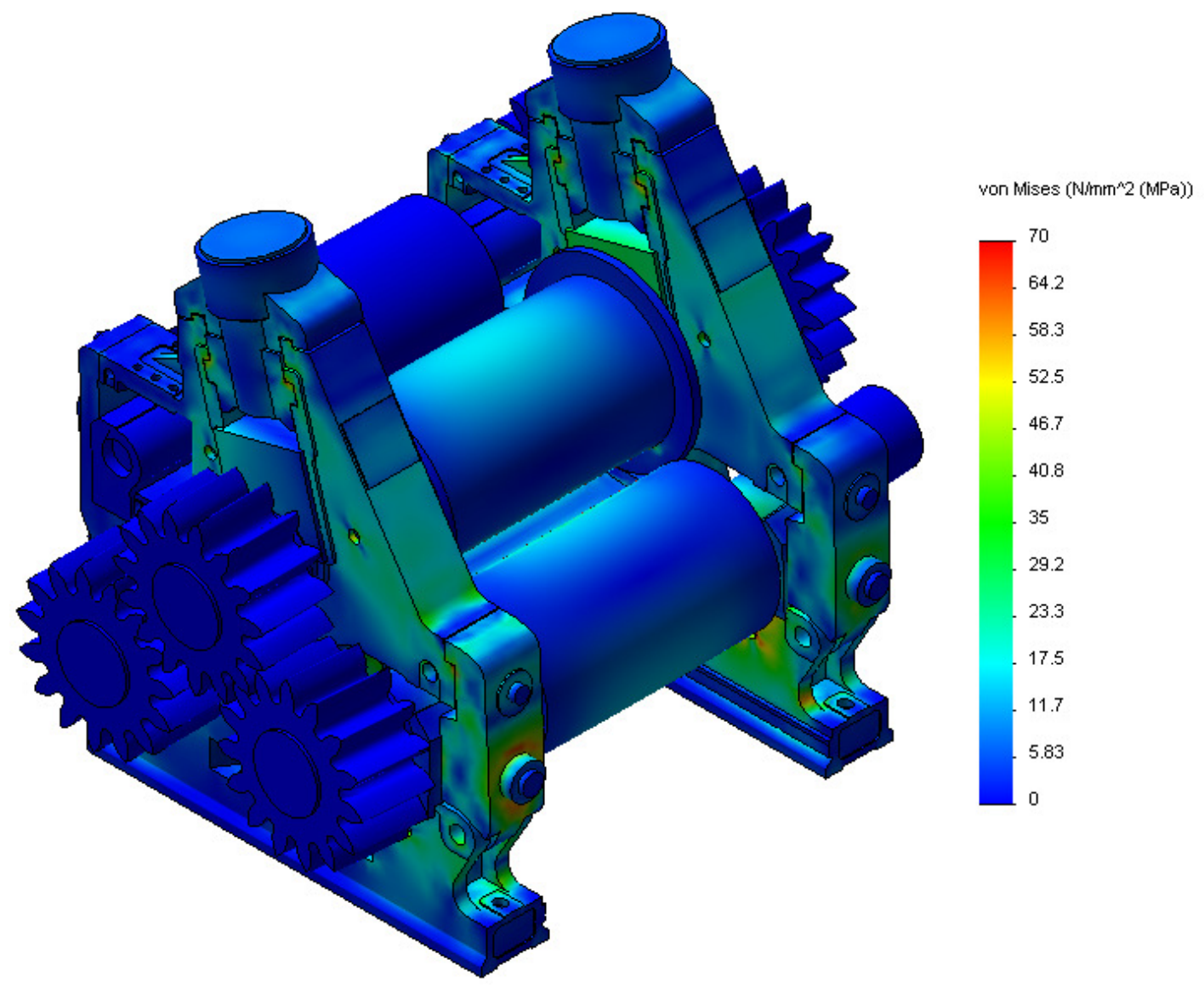

Figura 118: Tensões de Von Misses (MPa) no terno de moenda limitadas a $70 \mathrm{MPa}$. 


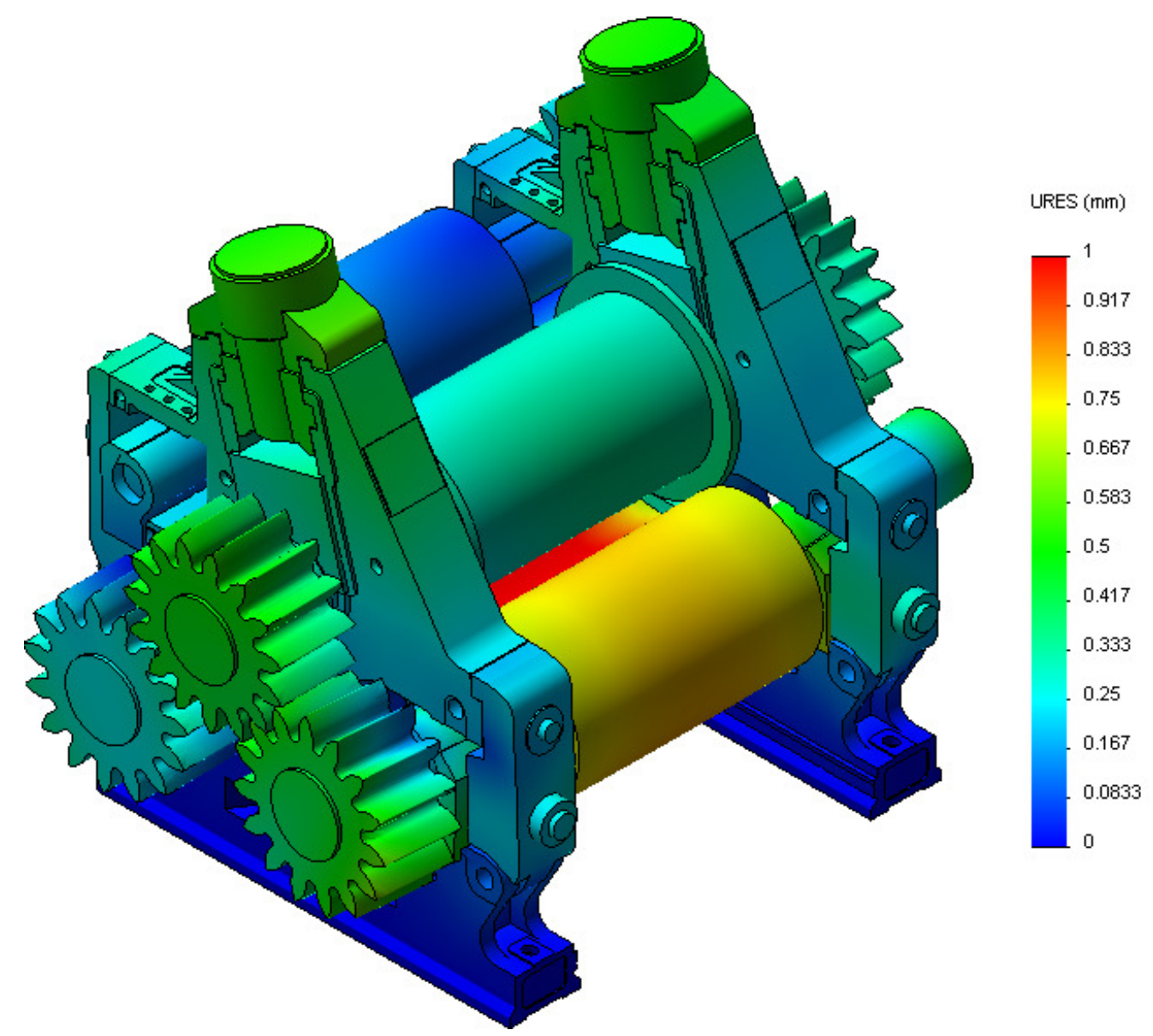

Figura 119: Deslocamentos (mm) no terno de moenda limitado a $1 \mathrm{~mm}$.

A Figura 120 mostra o lado externo do castelo do lado do acionamento com as tensões provenientes dos esforços externos. Nota-se uma maior tensão no encaixe do cabeçote hidráulico (1), pelo fato deste suportar a carga hidráulica total, no encaixe do cabeçote lateral de saída (2), Esta tensão é decorrente das reações de engrenamento dos rodetes atuantes no mancal do rolo superior e também da pressão do bagaço entre os rolos, na região (4), também resultado da posição deformada que o castelo assume depois da aplicação dos esforços externos.

O lado interno do castelo de acionamento é ilustrado na Figura 121, onde se podem observar maiores tensões da região do encaixe do cabeçote hidráulico (5) como já ilustrado na Figura 120, em um dos furos utilizado para içamento do castelo (6), no encaixe do cabeçote lateral de saída (7) e final do "garfo" do castelo (8) como já mencionados. Por fim, observa-se a região (9) onde é montado o pino excêntrico, componente do sistema de regulagem da bagaceira, a tensão é decorrente da reação da passagem do bagaço da entrada para a saída. 


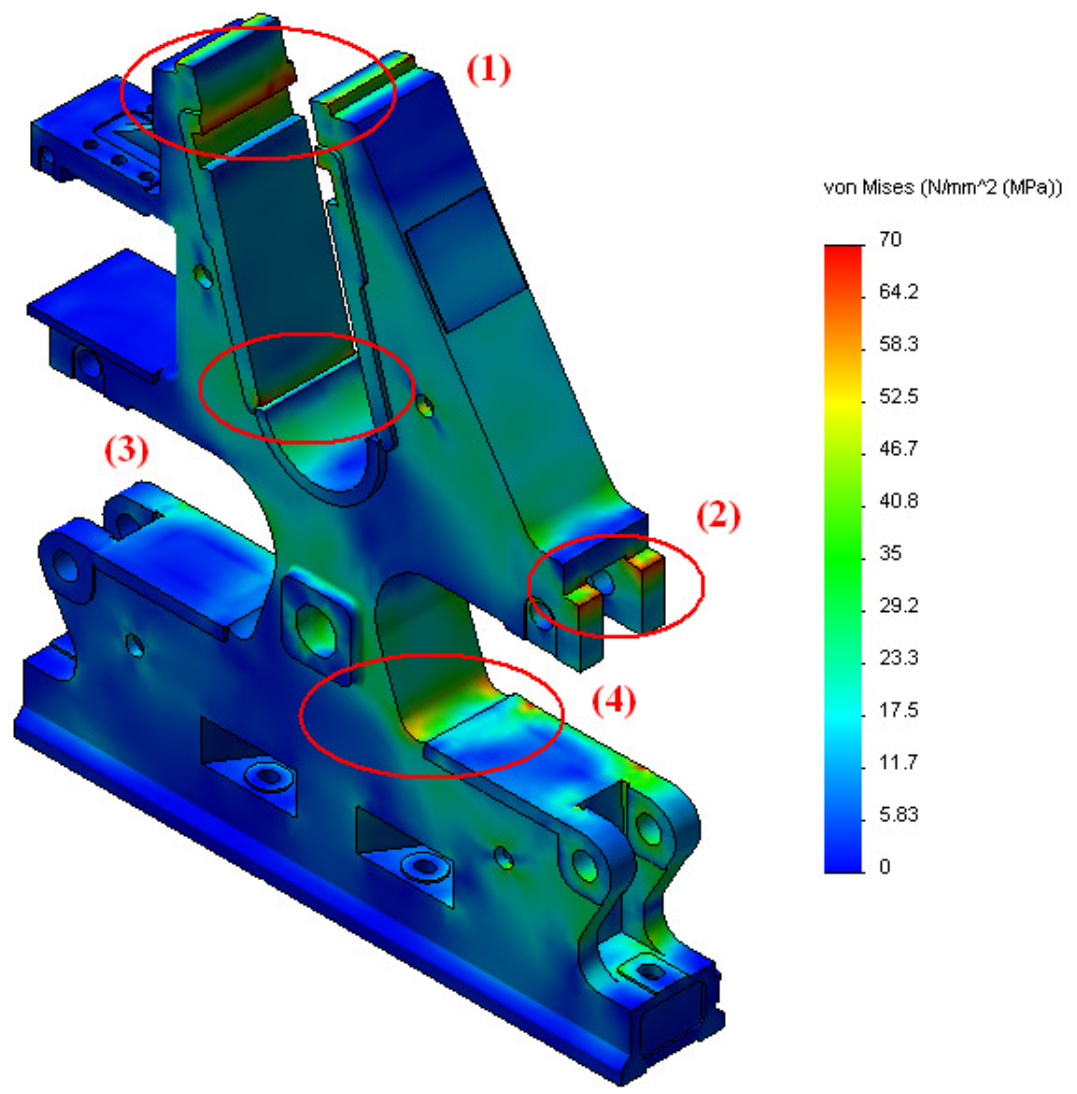

Figura 120: Tensões de Von Misses (MPa) no castelo do lado do acionamento limitadas a $70 \mathrm{MPa}$.

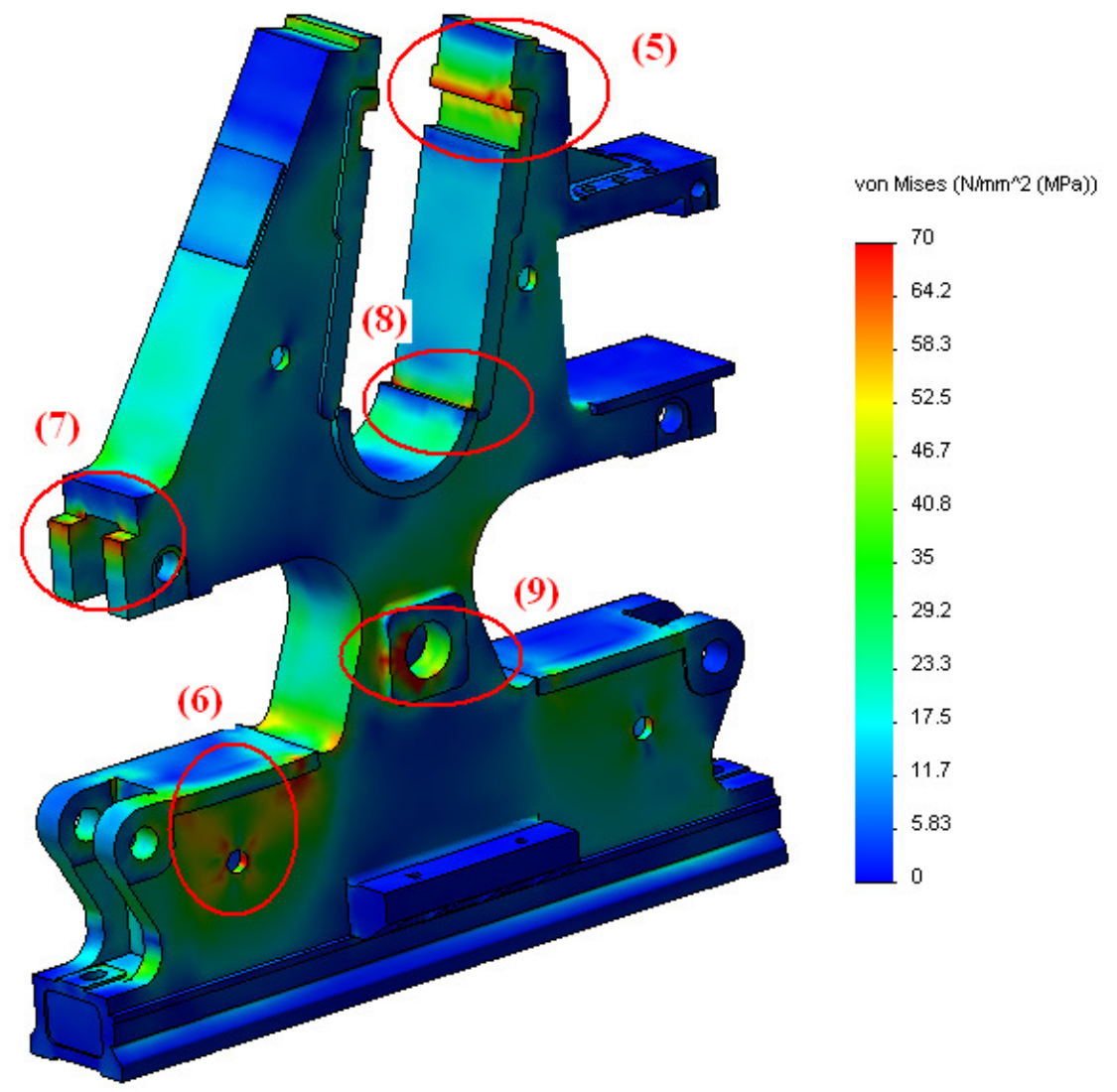

Figura 121: Tensões de Von Misses (MPa) no castelo do lado do acionamento limitadas a 70 MPa. 
Na Figura 122 pode-se observar o castelo do lado do acionamento em corte, ilustrando também as tensões atuantes nas paredes e nervuras internas do castelo. Como pode ser observado não há nenhuma região que mereça atenção especial, além daquelas já mencionadas.

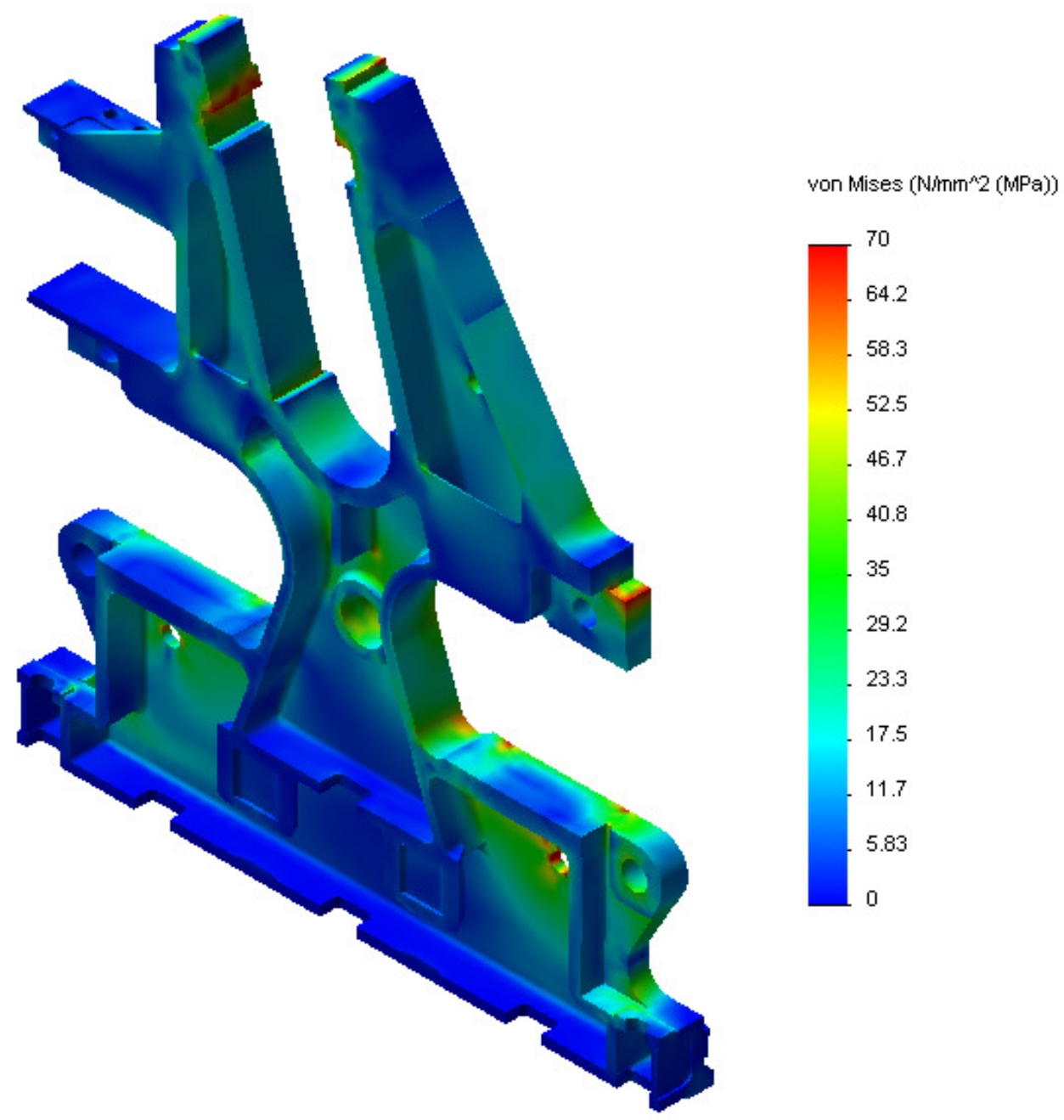

Figura 122: Tensões de Von Misses (MPa) no castelo em corte do lado do acionamento limitadas a 70 $\mathrm{MPa}$.

A Figura 123 ilustra o castelo do lado do acionamento sem sofrer deformações decorrentes dos esforços externos (parte cinza) e outro depois de esforços externos serem aplicados numa escala de 500 vezes maior, para uma melhor visualização. Notase uma maior deformação no topo do castelo trazendo para o lado esquerdo. Como a parte superior do castelo em sua grande maioria tende a se deformar para o lado esquerdo, surgem as tensões já citadas nas regiões (2) e (4) da Figura 120. 


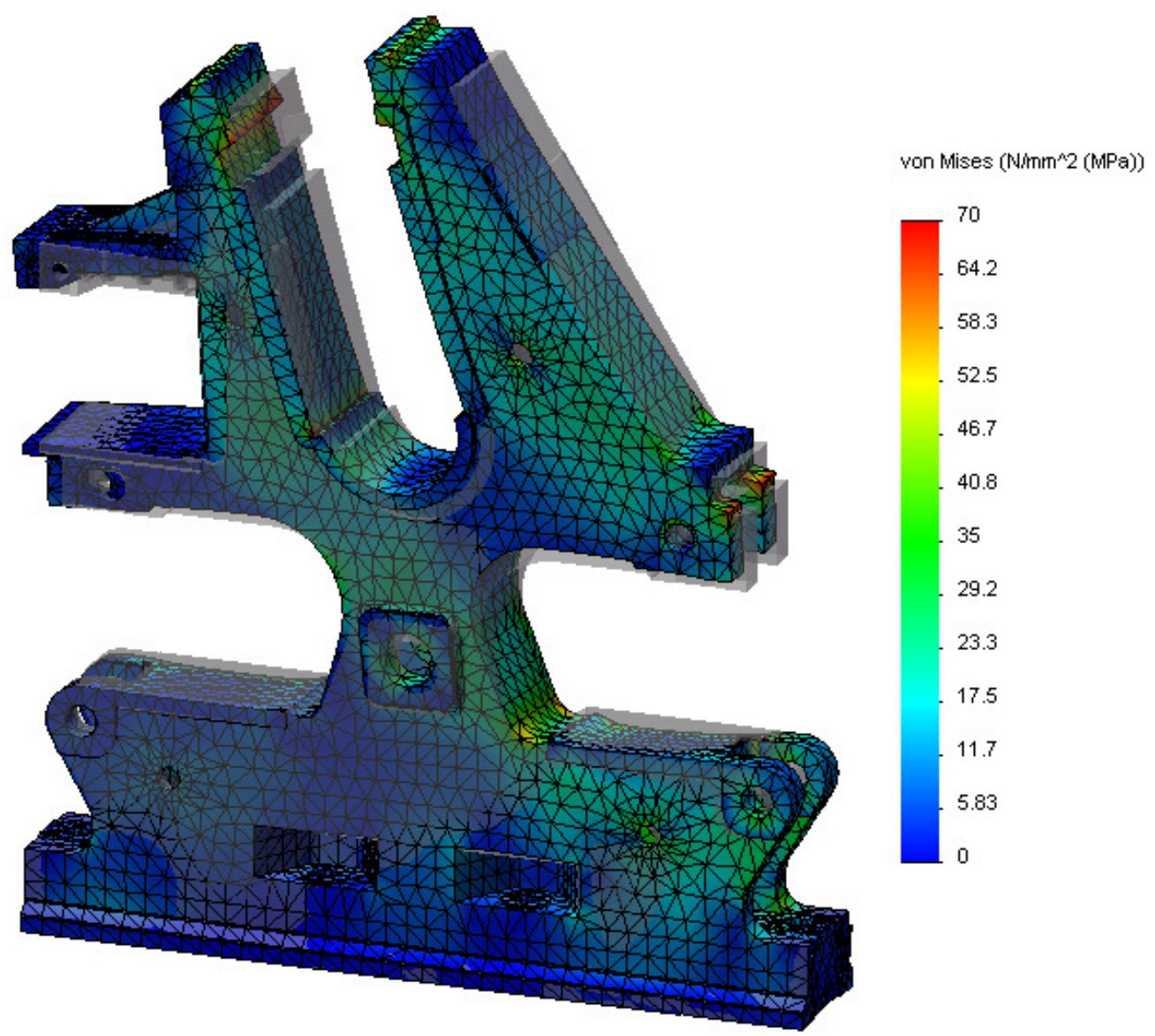

Figura 123: Efeito das tensões no castelo. A parte cinza corresponde ao castelo sem deformação enquanto o modelo está deformado com uma escala de 500 vezes.

$\mathrm{Na}$ Figura 124 é apresentado o deslocamento (em $\mathrm{mm}$ ) que o castelo sofre depois da aplicação dos esforços externos. Pode-se observar um deslocamento da ordem de $0,6 \mathrm{~mm}$ na parte superior do castelo devido à carga hidráulica total atuante no cabeçote hidráulico que conseqüentemente é transferida para o castelo. A deformação do castelo é apenas para ilustração e não tem importância direta para a análise das tensões atuantes no castelo. 


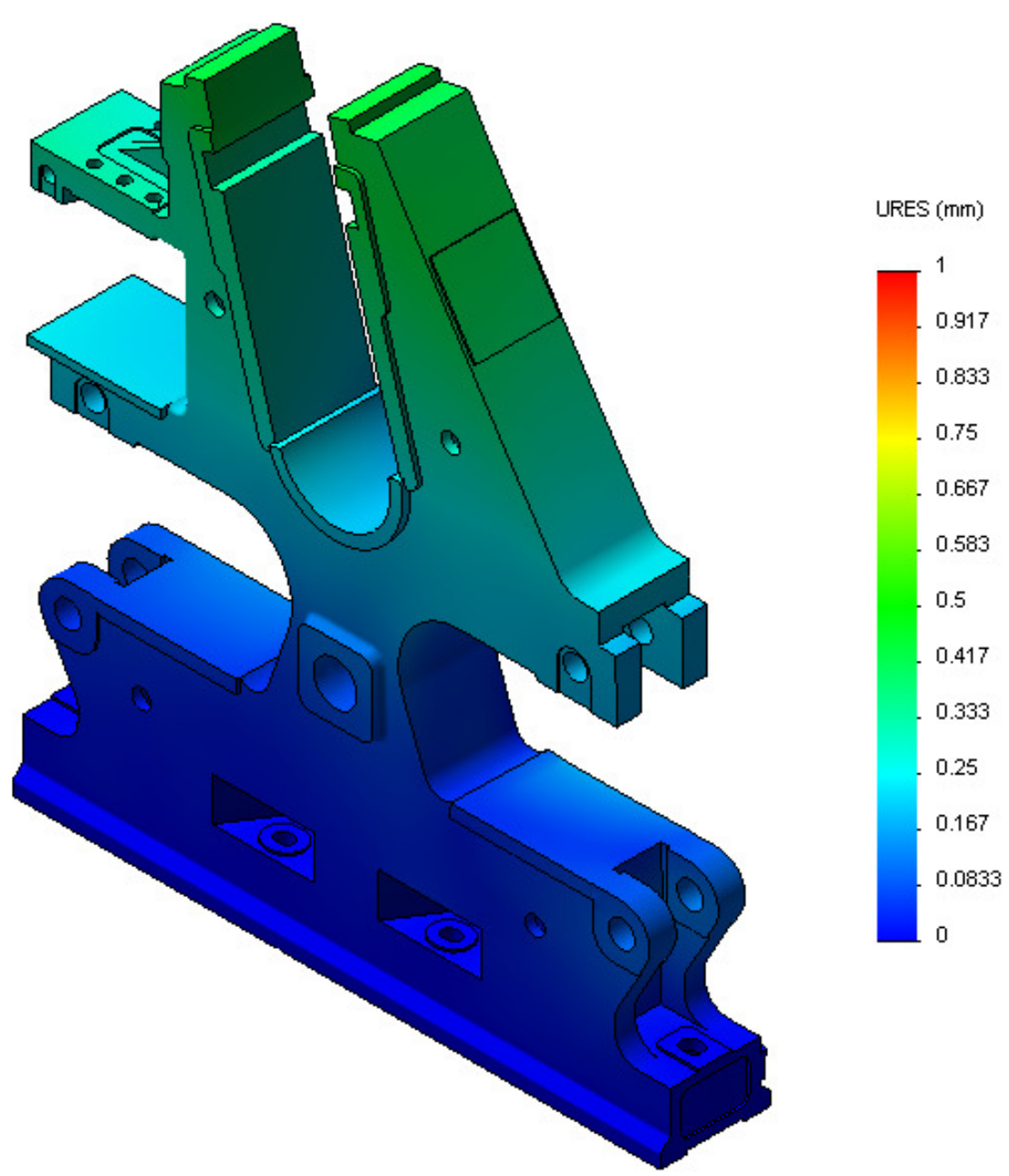

Figura 124: Deslocamentos (mm) no castelo do lado do acionamento limitado a $1 \mathrm{~mm}$.

As Figuras 125, 126 e 127 mostram as magnitudes das tensões nas regiões citadas anteriormente e em outras regiões de menor expressão.

Observa-se que em nenhum ponto é excedido o escoamento do material que é de $255 \mathrm{MPa}$ e, trabalhando com $60 \%$ do limite de escoamento do material, valor normalmente utilizado em projetos, ainda assim o castelo não excede o valor que corresponderia a $153 \mathrm{MPa}$ contra o máximo valor encontrado no castelo que é da ordem de $146 \mathrm{MPa}$. 


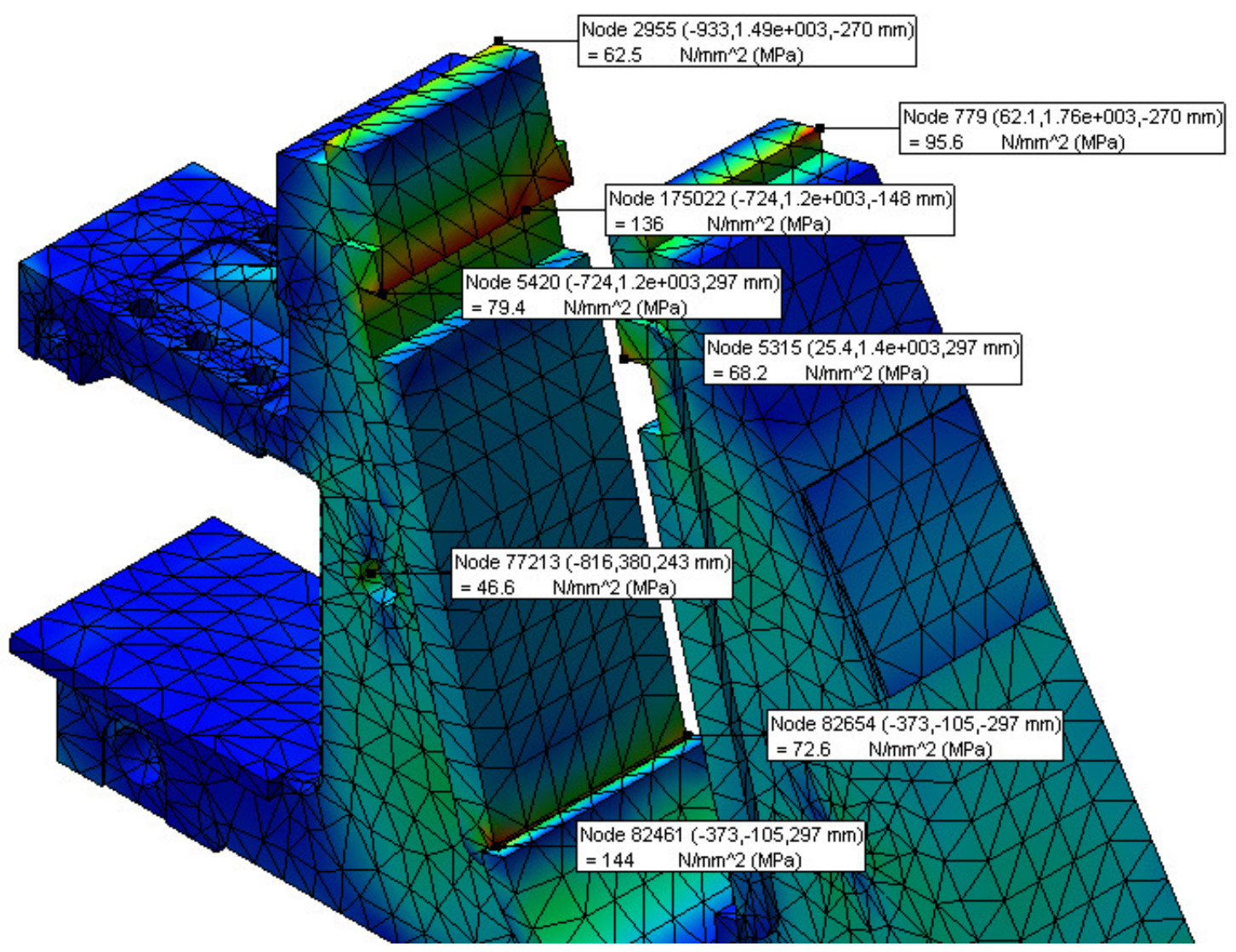

Figura 125: Tensões (MPa) em alguns pontos de maior solicitação.

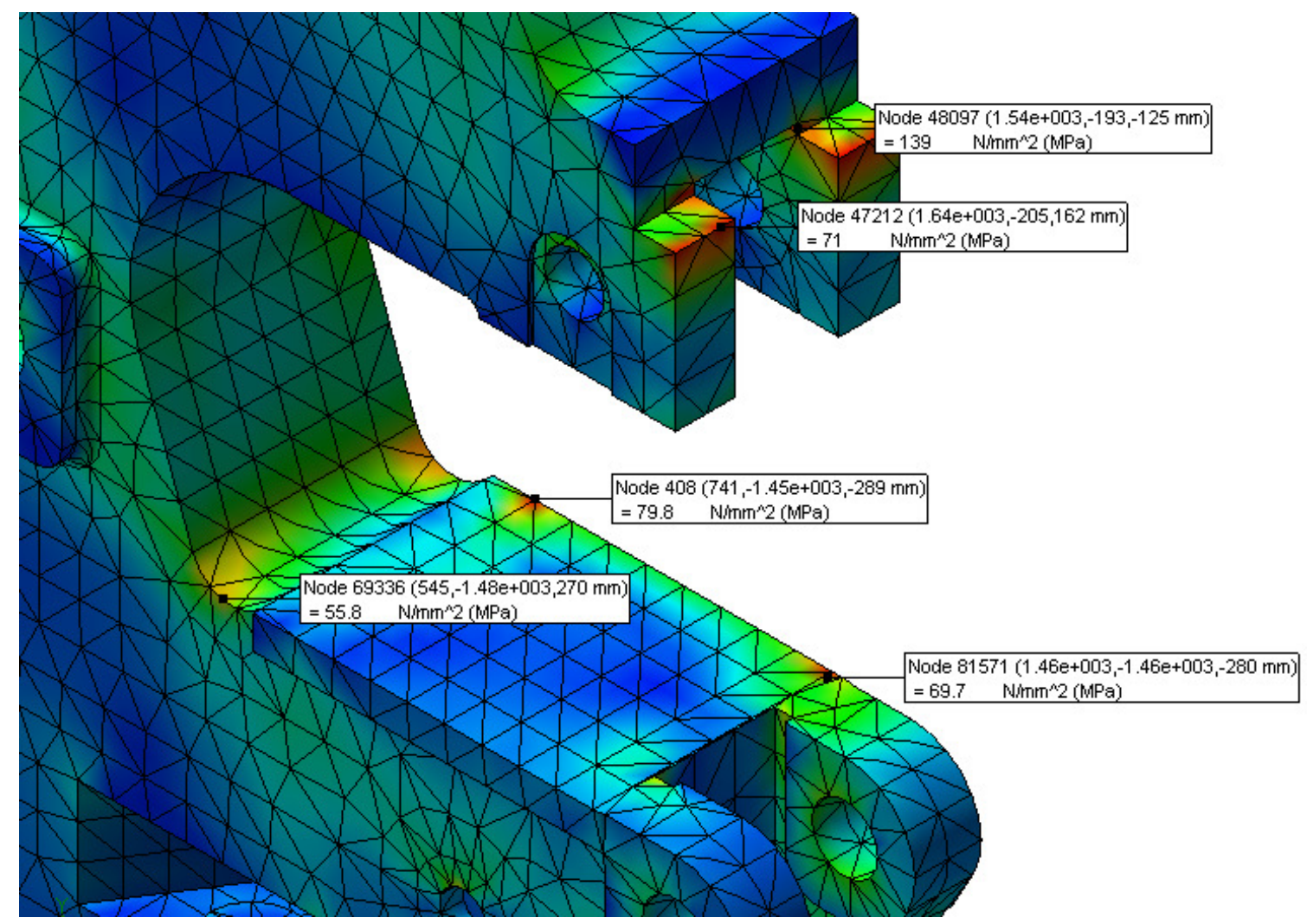

Figura 126: Tensões (MPa) em alguns pontos de maior solicitação. 


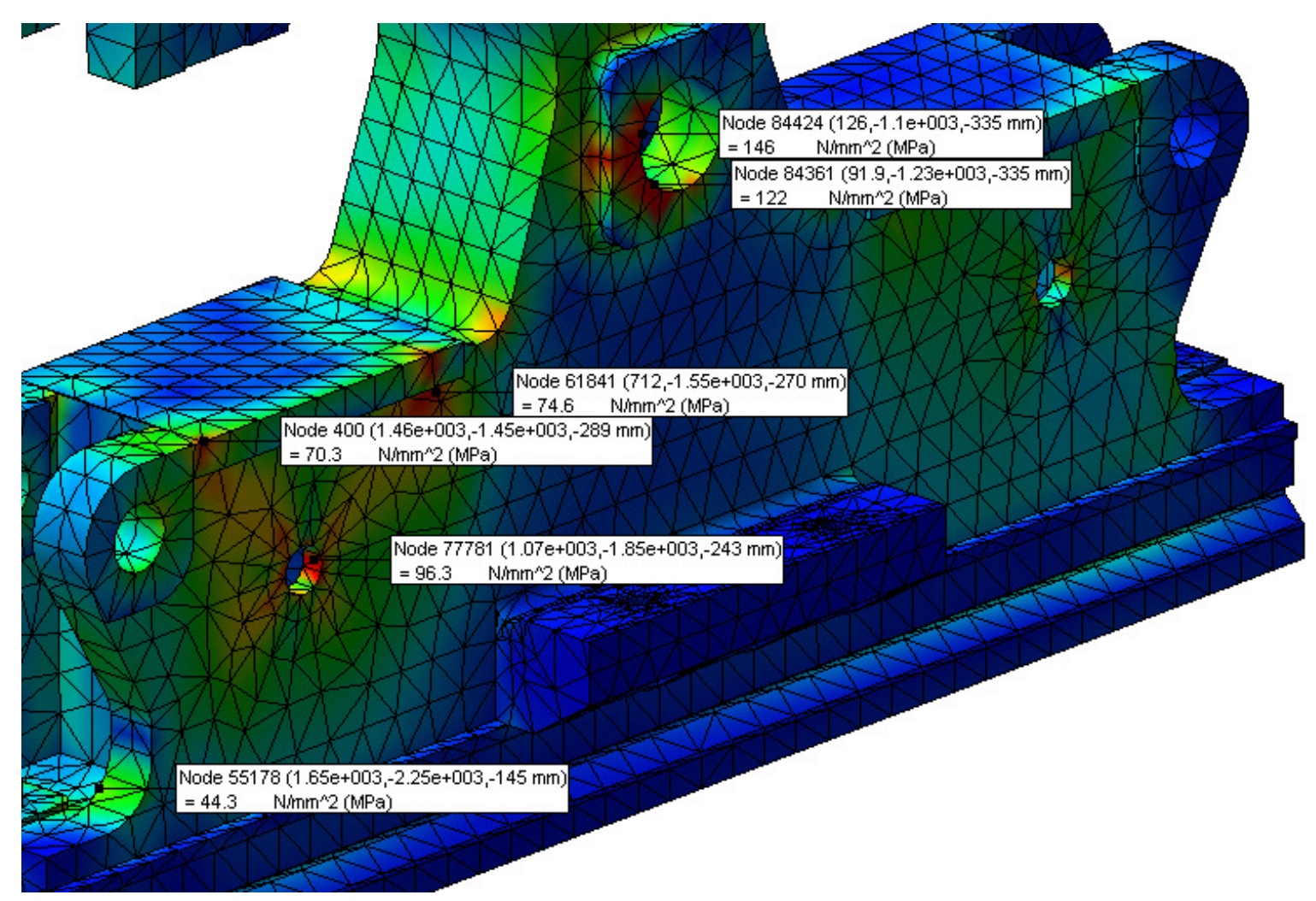

Figura 127: Tensões (MPa) em alguns pontos de maior solicitação.

Por fim, na Figura 128 pode-se observar a distribuição no castelo do lado do acionamento do fator de segurança em relação ao escoamento do material limitado a um valor de 20 para uma melhor visualização. Observa-se também, que em alguns pontos isolados há um coeficiente de segurança satisfatório, da ordem de 2 a 3 mas, na maioria das regiões do castelo há um coeficiente de segurança muito elevado, chegando a ultrapassar o valor de limite estabelecido pelo software, que é 20, em grande parte do mesmo. Assim, nestas regiões há a possibilidade de otimização. 


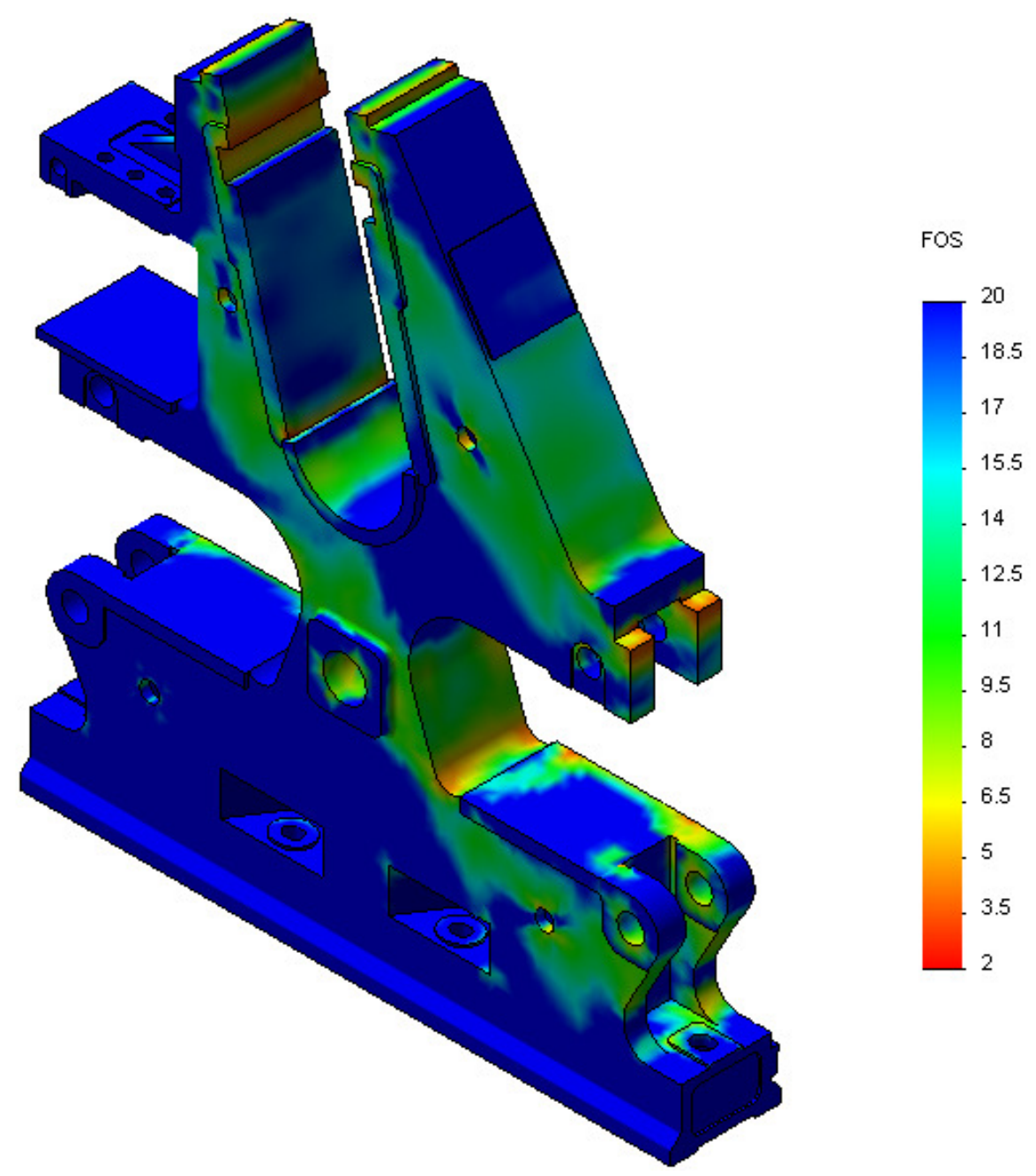

Figura 128: Distribuição do fator de segurança no castelo do lado do acionamento limitado a $20 \mathrm{MPa}$.

\subsection{Proposta de Melhoria para o Castelo de Moenda}

O castelo é uma peça do tipo "gargalo" tanto na fundição como na usinagem por requerer máquinas de grande porte e também por possuir um grande tempo de preparo e usinagem. É também uma peça difícil para o transporte. O castelo, em análise no presente trabalho, de bitola 53" x 90" possui um peso, após usinado, de aproximadamente 19 Ton, sendo necessário em torno de 27 Ton de material líquido para sua fabricação.

Como se observa nos resultados apresentados em relação às tensões atuantes no castelo, verifica-se que na sua grande maioria o mesmo possui elevado coeficiente de segurança, assim, baseando-se nos resultados obtidos, pode-se otimizar o castelo. 
Uma proposta plausível seria a diminuição da espessura das paredes do castelo, diminuindo assim o material para a sua fabricação e conseqüentemente seu peso final. Outra proposta seria, além da diminuição da espessura das paredes do castelo, nos pontos onde o fator de segurança é baixo (entre 2 e 4) aumentar o mesmo substituindo o material do castelo (ADZ-25), que possui um limite de escoamento da ordem de 255 $\mathrm{MPa}$, pelo material do rodete (ADZ-40), que possui um limite de escoamento da ordem de $410 \mathrm{MPa}$, porém, um custo final aproximadamente $15 \%$ maior.

A Figura 129 ilustra o castelo em corte com sua geometria original, enquanto a Figura 130 mostra as modificações realizadas para a otimização das espessuras das paredes do castelo baseadas nos resultados obtidos das tensões atuantes no mesmo.

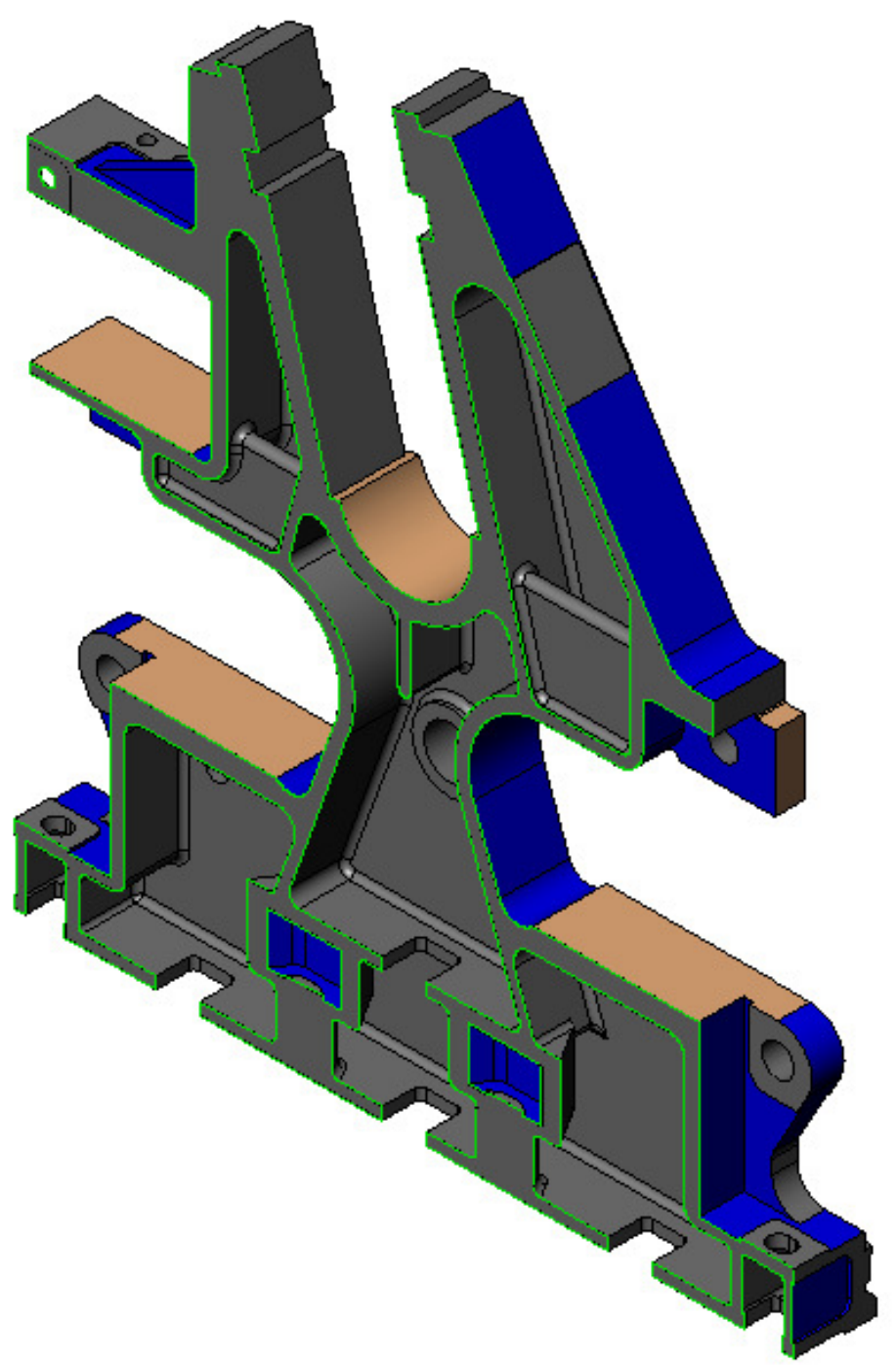

Figura 129: Castelo em corte com sua geometria original. 


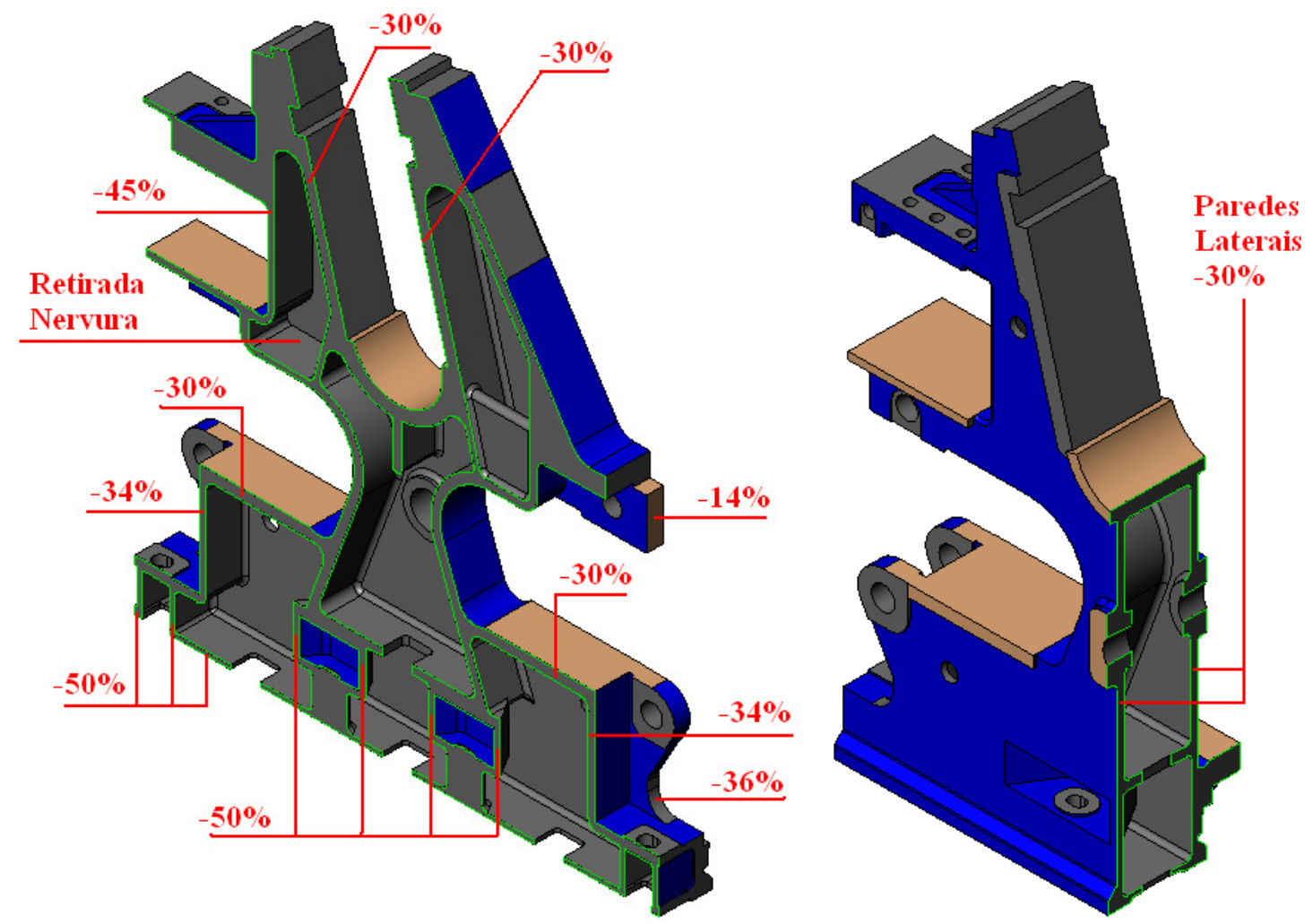

Figura 130: Castelo em corte com sua geometria modificada.

Após as modificações propostas e a mudança do material para o ADZ-40 e, realizando uma nova análise em elementos finitos com os mesmos parâmetros já descritos observa-se que, mesmo com a redução da espessura das paredes do castelo, houve uma melhora do fator de segurança distribuído pelo castelo conforme Figura 131 e, os pontos de maior concentração de tensão não foram prejudicados e sim, em alguns pontos, o fator de segurança aumentou devido a substituição do material original ADZ25 pelo material ADZ-40, ambos de fabricação própria da Dedini Indústrias de base.

Com as modificações realizadas obteve-se uma redução do peso final do castelo em torno de $15 \%$.

Na figura 132 são ilustrados os dois castelo para uma melhor visualização da distribuição do fator de segurança no castelo original e no castelo com as modificações propostas. 


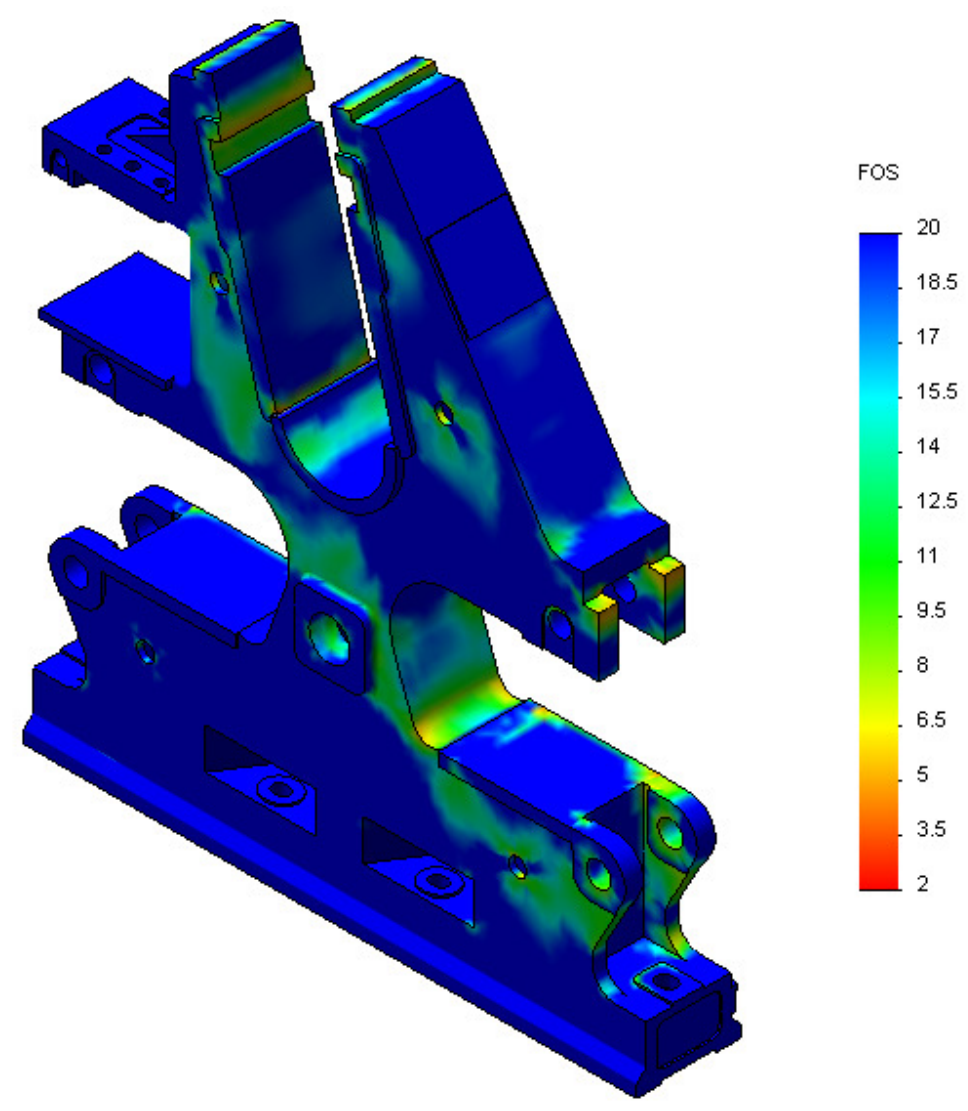

Figura 131: Distribuição do fator de segurança no castelo do lado do acionamento limitado a $20 \mathrm{MPa}$ depois das modificações propostas.
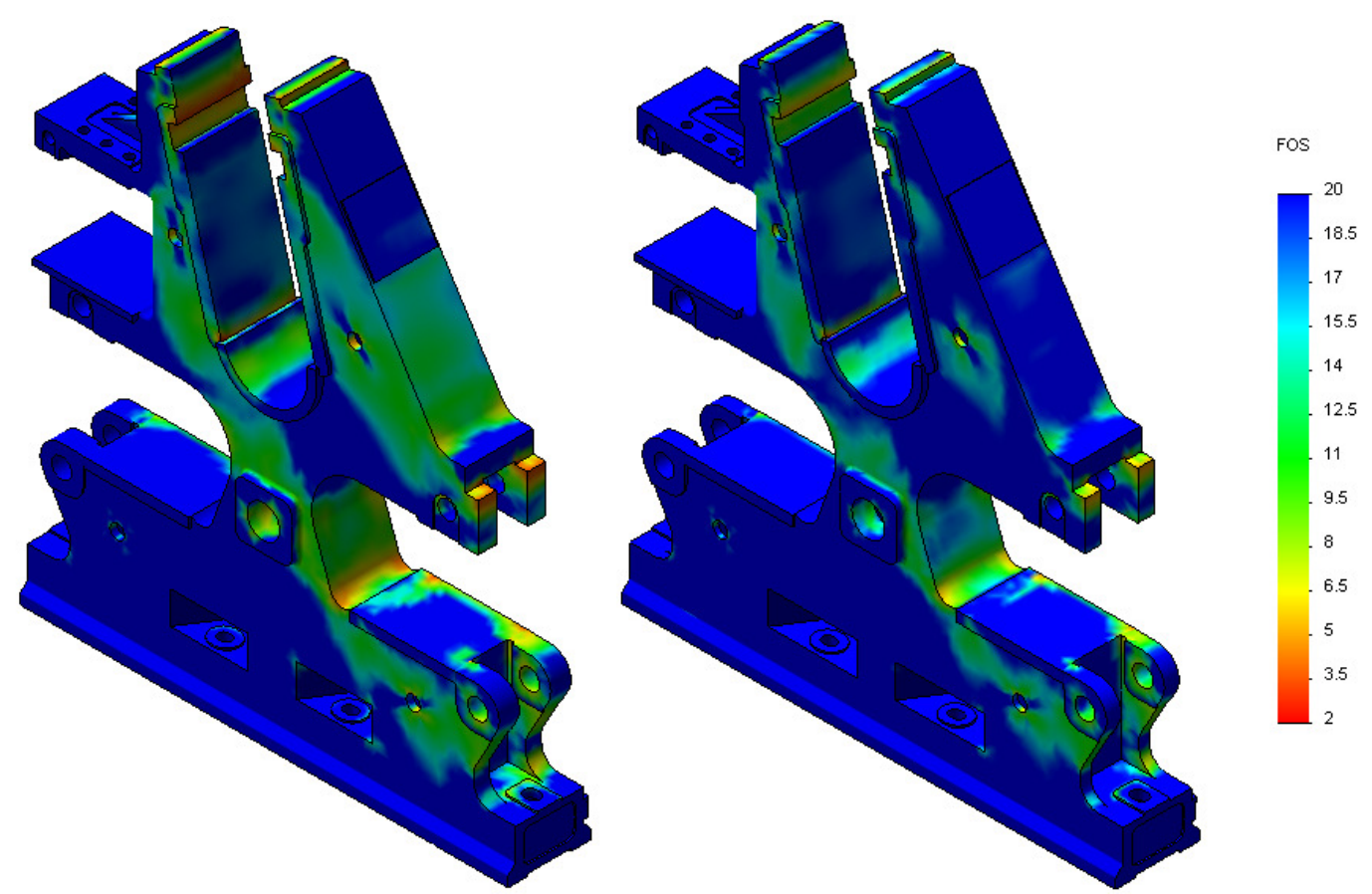

Figura 132: Distribuição do fator de segurança no castelo original (a esquerda) e no castelo com as modificações propostas (a direita). 


\section{Conclusões e Sugestões para Futuros Trabalhos}

Com a finalização do trabalho juntamente com os resultados obtidos pela análise em elementos finitos do terno de moenda, em particular o castelo de moenda, objeto de estudo, pode-se concluir que:

Da revisão bibliográfica:

- A cana-de-açúcar deixou de ser um produto agrícola qualquer para ser um dos mais importantes senão o mais importante hoje no Brasil, gerando milhares de emprego diretos e indiretos.

- Pode-se observar o crescimento do mercado sucroalcooleiro brasileiro no período da realização deste trabalho e, as expectativas para o contínuo crescimento deste mercado proporcionando vários investimentos junto com estudos para este setor.

- A fabricação álcool no Brasil é realizado nas chamadas usinas e a matéria prima para tal é a cana-de-açúcar.

- Há muito que se explorar em equipamentos voltados para a produção de açúcar e álcool no Brasil, pois muitos destes surgiram de projetos antigos e ainda hoje estão atuando no mercado sem nenhuma ou na maioria das vezes com poucas melhorias.

- Um dos equipamentos de maior importância, tanto na produção do açúcar como no álcool, é denominado terno de moenda, um equipamento que extrai o caldo contido na cana e, chamado por muitos o coração de uma usina.

- Dentre os vários componentes do terno de moenda, o castelo de moenda recebe grande atenção por ser uma peça "gargalo", tanto na sua fabricação, por meio de fundição, como na sua usinagem. 
- Num projeto mecânico onde são utilizados materiais dúcteis e, onde a tensão limite é correspondente a tensão de escoamento do mesmo, o critério de resistência de Von Mises obtêm ótimas aproximações.

- O método dos elementos finitos é utilizado em diversas aplicações na engenharia como, por exemplo, transferência de calor, mecânica dos fluídos, acústica, eletromagnetismo, entre outros.

- Com a utilização de softwares CAE, baseados no método dos elementos finitos, pode-se calcular, por exemplo, tensões e deformações em componentes com as mais variadas formas geométricas o que, manualmente não seria possível.

Dos resultados obtidos:

- Foram observados diferentes valores de tensões no castelo do lado do acionamento com o castelo do lado oposto do acionamento, devido às reações ocorridas na transmissão de torque pelos rodetes, não despertando tanto interesse, pois os valores são de pequena magnitude.

- A região do encaixe do cabeçote hidráulico, acima do garfo do castelo, apresenta concentração de tensão devido ao grande esforço, proveniente da carga hidráulica, a qual é submetida.

- Outra região que apresenta concentração de tensão está localizada no contato com o pino excêntrico (componentes do sistema de regulagem da bagaceira) devido ao arraste do bagaço entre o rolo de entrada e saída.

- Devido á deformação do castelo em função dos esforços externos, o encaixe do cabeçote lateral de saída também possui concentração de tensão.

- Também devido á deformação do castelo, em função dos esforços externos, a região central do corpo do castelo (raios longos inferiores) possui concentração de tensões. 
- Com os esforços atuando no castelo e, conseqüentemente em seu estado deformado, observa-se que as principais deformações possuem uma direção da esquerda para a direita, com uma leve inclinação para baixo.

- A maior tensão encontrada no castelo, com valor de $146 \mathrm{MPa}$, não ultrapassa o valor de escoamento do material que é $255 \mathrm{MPa}$, obtendo assim um coeficiente de segurança de 1,7 .

- Furos executados nos componentes concentram tensões como se pode observar nos furos para içamento do castelo, principalmente na sua face interna.

- O castelo possui uma grande variação na distribuição do fator de segurança em suas áreas, valores que possui um mínimo de 1,7 e ultrapassa os 20 com facilidade em algumas regiões.

Da proposta de melhoria:

- Com os resultados apresentados, pôde-se propor uma alternativa para o projeto do castelo, onde foi otimizada as paredes dos mesmos, reduzindo assim em 15\% seu peso, correspondendo para o castelo em estudo aproximadamente $3.000 \mathrm{Kg}$ sem que se comprometesse a resistência mecânica do mesmo.

- Com a substituição do material do castelo, o ADZ-25 pelo ADZ-40, obteve-se uma melhor distribuição de seu fator de segurança.

- Apesar de não ser o objetivo deste trabalho, mas por possuir grande importância na realização da proposta sugerida neste trabalho, fica registrado que não houve ganho em custos, pois a diminuição do material do castelo em aproximadamente $15 \%$ vem defronte ao custo mais elevado do material ADZ-40 em relação ao ADZ-25 que é aproximadamente $17 \%$. 
Como sugestões de futuros trabalhos, sugerem-se:

- Verificar as tensões atuantes em outros componentes do terno de moenda através do método dos elementos finitos, a fim de verificar e otimizar tais componentes.

- Verificar se os deslocamentos do castelo provenientes dos esforços externos estão de acordo com os previstos em projeto.

- Analisar o deslocamento resultante dos esforços externos em outros componentes do terno de moenda através do método dos elementos finitos.

- Realizar análise com diferentes materiais para que se possa otimizar o castelo e obter ganho nos custos da fabricação do mesmo. A substituição do material do castelo, o ADZ-25, pelo ADZ-30 Mn que, possui tensão de escoamento de 345 MPa e custo equivalente ao FDZ-25, seria uma alternativa aplausível. 


\section{Referências Bibliográficas}

AGROBYTE (2007). A cana de açúcar. Disponível em: $<$ http://www.agrobyte.com.br/cana.htm >. Acesso em: 06 Set. 2007.

ALVES FILHO, A. (2006). Elementos finitos - a base da tecnologia CAE. $4^{\text {a }}$ Edição, São Paulo: Editora Érica, 294 p.

ASHBY, M. F. (1999). Materials selection in mechanical design. 2and Edition., Oxiford: B. Heinemann, pp. 20-31.

ASSAN, A. E. (2003). Método dos elementos finitos - primeiros passos. $2^{\text {a }}$ Edição, Campinas: Editora Unicamp, pp. $57-87$.

BRUNELli, S.; TERAMOTO, J.[199-]. Estudo da ruptura de eixos de moenda. [Piracicaba], [s.n.], pp. 117 - 144.

BRUNELLI, S,; MIAYESI, M. [199-]. Projeto de pinhões para acionamento dos rolos de moenda. [Piracicaba], [s.n], pp. 145 - 169.

CALLISTER, W. D. Jr. (1991). Materials science and engineering - an introduction. New York: J. Wiley \& Sons, 408 p.

CHEREMISINOFF, N. P. (1996). Materials Selection Deskbook. New Jersey: N. Publication, 145 p.

CHIAVERINI, V. (1986). Tecnologia mecânica - materiais de construção mecânica. 2 Edição, V. III, Rio de Janeiro: McGRAW-Hill, pp. 115 - 212.

CHRISTOPHER, J. M. (2000). Machinery's handbook. $26^{\text {th }}$ edition, New York: Indrustrial Press Inc., pp. 195-215. 
CHUNG, D. L. D. (2001). Applied materials science. Applications of engineering materials in structural, electronics, thermal and other industries. Boca Raton: CRC Press LLC, pp. 11-22.

CLARKE, C. (2003). Cosmoswork 2003 provides the model for easier design analysis. Engineer, v. 292, n. 7629 , pp. $49-50$.

COMPANHIA NACIONAL DE ABASTECIMENTO - CONAB (2007). Acompanhamento da safra brasileira. Cana de açúcar, $1^{\circ}$ Levantamento. [S.L.: s.n.], 15 p.

COPERSUCAR (1988). Fundamentos dos processos de fabricação de açúcar e álcool. Caderno Copersucar, Piracicaba, SP: Centro de Tecnologia Copersucar, Série Industrial $\mathrm{n}^{\mathrm{o}} 20,12 \mathrm{p}$.

COSAN (2002). Unidade Costa Pinto. Produção de açúcar e álcool. Piracicaba, SP, [s.n.], 08 p.

COSMOSWORKS (2005). CosmosWorks Designer 2005 training manual. [S.L.: s.n.], $196 \mathrm{p}$.

CUNHA, L. S. (2002). Manual prático do mecânico. Nova Edição, Curitiba-PR: Hemus, Capítulo 1, pp.13-33.

D’AVILA, A. C. (2003). Processos de recepção, preparo e moagem da matéria prima. [S.L.: s.n.], 224 p.

FAIRES, M. V. (1974). Elementos orgânicos de máquinas. Tradução: Humberto César Tavares Gonçalves. Rio de Janeiro: Ao livro técnico S. A.,V. 1, Capítulo 2, pp. $59-93$.

FINZI, D. (1963). Engrenagens. $1^{a}$ Edição, Rio de Janeiro: Ao Livro Técnico S.A., pp. $01-117$.

GARCIA, A.; SPIM, J. A.; SANTOS, C. A. (2000). Ensaios dos materiais. Rio de Janeiro: LTC, 247 p. 
HARPER, C. A. (2001). Handbook of materials for product design. 3and Edition, New York: McGRAW-Hill, pp. 01-91.

HEARN, E. J. (1997). Mechanics of materials - an introduction to the mechanics of elastic and plastic deformation of solids and structural materials. 3and Edition, Oxford: B. Heinemann, V 1, pp. 01-28.

HOLAND, I.; BELL, K. (1970). Finite element method - in stress analysis. [S.L.]: Tapir Forlag, pp. $01-42$.

HUGOT, E. (1969). Manual da engenharia açucareira. Tradução: Irmtrud Miocque. São Paulo: M. Jou, V 1, p. 544.

HUGOT, E. (1950). La sucrerie de Cannes. Paris: Dunod, 811 p.

JACQUES, K.; LYONS, T.P.; KELSALL, D.R. (1999). The alcohol textbook. 3rd Edition, [S.L.], Nottingham university press, 347 p.

JÚNIOR, J. F. S. (1962). Resistência dos materiais. Rio de Janeiro: Ao Livro Técnico, pp. $268-283$.

JUVINALL, R. C.; MARSHEK, K. M. (1991). Fundamentals of machine component design. 2 Edition, New York: John Wiley \& Sons, 795 p.

KNIGHT, C. E. (1993). The finite element method in mechanical design. Boston: PWS-KENT Publishing Company, pp. $01-38$.

KRUTZ, G. W.; SCHUELlER, J. K.; CLAAR, P. W. (1994). Machine design - for mobile and industrial applications. [S.L.], Society of Automotive Engineers, 538 p.

LAIER, J. E. (2003). Critérios de resistência: resistência, plasticidade, fratura, fadiga. São Carlos, [s.n.], 44 p.

LIMA, U. A.; AQUARONE, E.; BORZANI, W. (1986). Biotecnologia - Tecnologia das fermentações. 3. Edição, São Paulo: E. Blucher, V 1, pp. 48-68.

LOPES, C. H. (1986). Glossário de termos técnicos para a indústria sucroalcooleira. Planalsugar, Piracicaba, 32 p. 
LUCA, R. N. de (2006). Viabilidade dos processos de fabricação e recondicionamento de flanges de moenda: um estudo comparativo. Monografia Escola de Engenharia de Piracicaba, Piracicaba, 48 p.

MEGSON, T. H. G. (1996). Structural and stress analysis. Oxfod: B. Heinemann, pp. 181-200.

MELCONIAN, S. (2006). Mecânica técnica e resistência dos materiais. 17 Edição, Tatuapé-SP: Editora Érica, 360 p.

NORTON, L. R. (2004). Projeto de máquinas - uma abordagem integrada. Tradução parte I: Maik Briscese Muller, Tradução parte II: João Batista de Aguiar. 2 Edição, São Paulo: Bookman, 931 p.

NORTON, L. R. (2004). Design of machinery - an introductions to the synthesis and analysis of mechanisms and machines. 3and Edition, Boston: McGRAW-Hill, $858 \mathrm{p}$.

OLIVEIRA, N. C. G (1980). Engrenagens. $2^{a}$ Edição, São Paulo: Grêmio Politécnico, $208 \mathrm{p}$.

OWEN, D. R. J. et al. (1997). Finite element simulation of the rolling and extrusion multi-phase materials-application to the rolling of prepared sugar cane. Computer methods In agpllrd mechanlos and englneerlng. NH Elsevier.

PROENÇA, S. P. B. (2007). Curso de resistência dos materiais - notas de aula. Volume II, São Carlos, [s.n.], pp. 235 - 436.

RAIN, P. (2007). Cane sugar engineering. Bartens, Berlin, 750 p.

ROWE, J. (2003) Cosmosworks 2003 professional - finite element analysis. Cadalyst, v. 20 , n. 7 , pp. $35-36$.

SAVASSI, W. (1996). Introdução ao método dos elementos finitos - em análise linear de estruturas. São Carlos: EESC, 260 p.

SHIGLEY, J. E.; MISCHKE, C. R.; BUDYNAS, R. G. (2004). Mechanical engineering design. 7 Edition, Boston: McGRAW-Hill, pp. $02-185$. 
SHINTAKU , A. (2005). Processos da fabricação do açúcar. [S.L.: s.n.], 152 p. SHREVE, R. N,; BRINK, J. A. J. (1997). Indústrias de processos químicos. Tradução: Horacio Macedo. 4. Edição, Rio de Janeiro: Guanabara, pp. 452-486.

SMITH, W. F. (1998). Princípios de ciência e engenharia dos materiais. Tradução: Maria Emília Rosa; Manuel Amaral Fortes;Luis Guerra-Rosa; Maria de Fátima Vaz. Lisboa: McGRAW-Hill, pp. 01-18.

STEMMER, C. E. (1979). Projeto e construção de máquinas - regras gerais de projeto, elementos de máquinas. 2 Edição, Porto Alegre: Editora Globo, pp. 278 293.

TAUPIER, L. O. G. (Coord.) (1990). Manual de los derivados de la cana de azucar. 2da. Edición, Mexico: Geplacea, PP. 31-38.

ZILLO LORENZETTI (2002). Fabricação do álcool. Treinamento industrial - curso básico. [S.L.: s.n.], 245 p.

ZILLO LORENZETTI (2002). Moendas. Treinamento industrial - atualização técnica. [S.L.: s.n.], 80 p. 